UNIVERSIDADE DE SÃO PAULO

ESCOLA DE ENGENHARIA DE SÃO CARLOS

CINTIA ISABEL DE CAMPOS

INVESTIGAÇÃO DE RELAÇÕES ENTRE DADOS INDIVIDUAIS, DO LOCAL DE RESIDÊNCIA, AMBIENTE VIÁRIO E COMPORTAMENTOS DE RISCO DE CONDUTORES DO BRASIL E PORTUGAL 



\title{
INVESTIGAÇÃO DE RELAÇÕES ENTRE DADOS INDIVIDUAIS, DO LOCAL DE RESIDÊNCIA, AMBIENTE VIÁRIO E COMPORTAMENTOS DE RISCO DE CONDUTORES DO BRASIL E PORTUGAL
}

\author{
Tese de doutorado apresentada à Escola de \\ Engenharia de São Carlos da Universidade de São \\ Paulo, como requisito para obtenção do título de \\ Doutora em Ciências - Programa de Pós-graduação \\ em Engenharia de Transportes. \\ Área de concentração: Planejamento e Operações \\ de Sistema de Transportes. \\ Orientadora: Profa. Dra. Cira Souza Pitombo \\ Co-orientadora: Profa. Dra. Patricia Delhomme
}

\section{São Carlos}

2019

EXEMPLAR DEFINITIVO (CORRIGIDO). O EXEMPLAR ORIGINAL ESTÁ DISPONÍVEL NA CPG DA EESC-USP. 
AUTORIZO A REPRODUÇÃO TOTAL OU PARCIAL DESTE TRABALHO, POR QUALQUER MEIO CONVENCIONAL OU ELETRÔNICO, PARA FINS DE ESTUDO E PESQUISA, DESDE QUE CITADA A FONTE.

Ficha catalográfica elaborada pela Biblioteca Prof. Dr. Sérgio Rodrigues Fontes da EESC/USP com os dados inseridos pelo(a) autor(a).

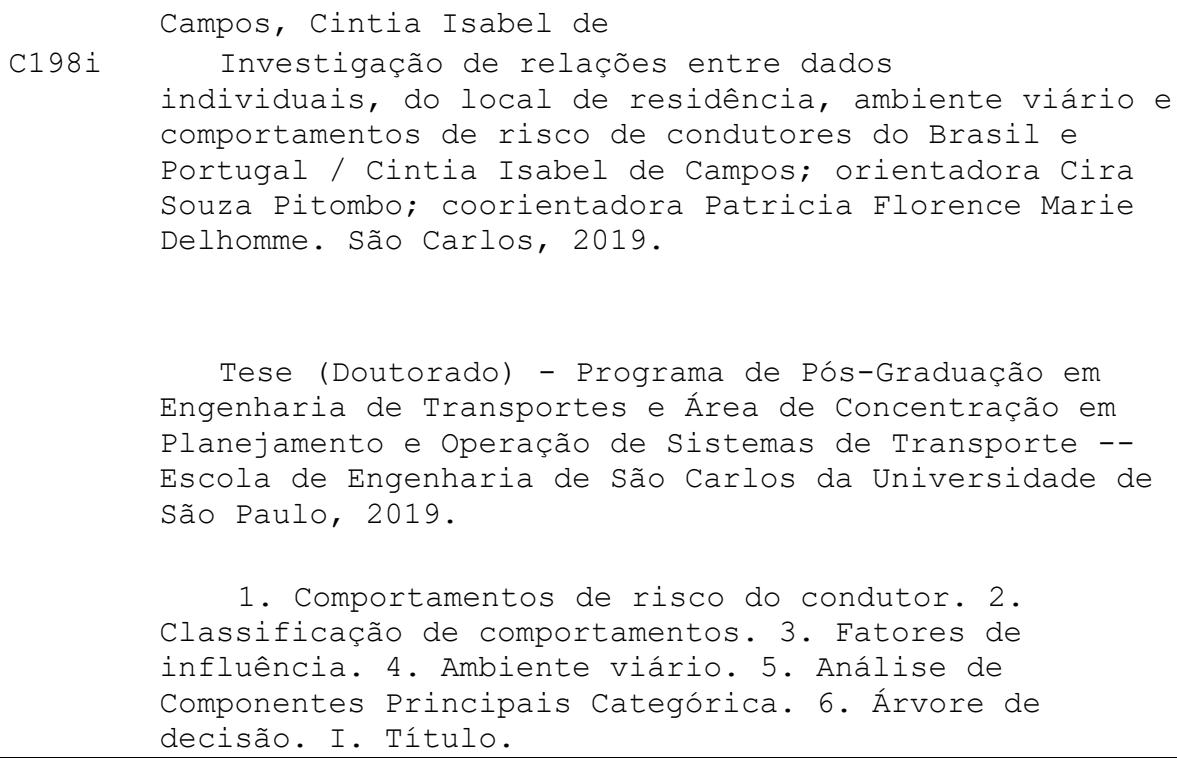

Tese (Doutorado) - Programa de Pós-Graduação em Engenharia de Transportes e Área de Concentração em Planejamento e Operação de Sistemas de Transporte - Escola de Engenharia de São Carlos da Universidade de São Paulo, 2019.

1. Comportamentos de risco do condutor. 2. Classificação de comportamentos. 3. Fatores de influência. 4. Ambiente viário. 5. Análise de Componentes Principais Categórica. 6. Árvore de decisão. I. Título.

Eduardo Graziosi Silva - CRB - 8/8907 


\section{FOLHA DE JULGAMENTO}

Candidata: Tecnóloga CINTIA ISABEL DE CAMPOS.

Título da tese: "Investigaçāo de relaçōes entre dados individuais, do local de residência, ambiente viário e comportamentos de risco de condutores do Brasil e Portugal",

Data da defesa: 04/12/2019.

\section{Comissão Julgadora:}

Resultado:

Profa. Associada Cira Souza Pitombo

(Orientadora)

(Escola de Engenharia de São Carlos/EESC)

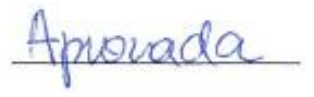

Prof. Dr. Fernando Hideki Hirosue

ATROVADA

[Universidade Federal de São Carlos/UFSCar]

Prof. Associado Jose Alberto Quintanilha

(Escola Politécnica/EP-USP)

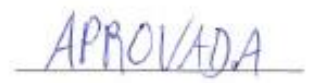

Profa. Dra. Magaly Natalia Pazzian Vasconcellois Romão Aprov ad a (FATEC/Jaú)

Profa. Dra. Sara Maria Pinho Ferreira

(Universidade do Porto/Portugal)

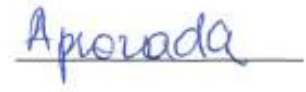

Coordenadora do Programa de Pós-Graduaçāo em Engenharia de Transportes:

Profa. Associada Ana Paula Camargo Larocca

Presidente da Comissão de Pós-Graduação:

Prof. Titular Murilo Araujo Romero 

Primeiramente, agradeço a Deus pelo cumprimento das promessas em minha vida. À minha família, em especial aos meus pais, Elizia e Marcos, por todo incentivo, apoio e paciência. Ao João Vitor, por todo companheirismo, paciência e apoio emocional que foram essenciais para chegar ao fim dessa caminhada.

À minha orientadora Cira Souza Pitombo, pelas valiosas orientações, por compartilhar seu conhecimento, e contribuir para meu amadurecimento pessoal e como pesquisadora. À minha co-orientadora, Patricia Delhomme, pelas orientações e importantes contribuições para este trabalho.

À professora Magaly N. P. V. Romão e ao professor Archimedes A. Raia Junior, por contribuírem e fazerem a diferença no início da minha formação acadêmica. À professora Sara M. P. Ferreira pelo acompanhamento no período de doutorado sanduíche na Universidade do Porto e pelas contribuições dadas a este trabalho. Ao professor José Alberto Quintanilha pelas importantes contribuições neste trabalho.

Agradeço à banca examinadora, professores Fernando Hideki Hirosue, José Alberto Quintanilha, Magaly N. P. V. Romão e Sara M. P. Ferreira por aceitarem avaliar este trabalho de doutorado e pelas contribuições apresentadas.

Às professoras Magaly N. P. V. Romão e Anabela Simões pelo incentivo e apoio para o ingresso no doutorado. À professora Elisabete Freitas, pelo acompanhamento no período sanduíche na Universidade do Minho.

Aos meus amigos de jornada, em especial a Aurenice Figueira e ao Lucas Assirati, pelas contribuições para o desenvolvimento deste trabalho e amizade. Ao Augusto Pinha, Beatriz Albuquerque, Beatriz Segadilha, Felipe Lobo, Fernando Piva, Juliana Cardoso, Leandro Marcomini, Marina Ronchesel, Mariane Bobermin, Murilo Castanho, Natalia Panice, Philippe Barbosa, Samille Rocha, Samuel Marques e Sérgio Oliveira, pela amizade, aflições e risadas compartilhadas. Aos colegas, professores e demais funcionários do STT e do LAT, e a todos os demais colegas que não mencionei, mas que de alguma forma estiveram presentes nessa jornada.

A todos os participantes da pesquisa que possibilitaram a realização deste trabalho.

O presente trabalho foi realizado com apoio da Coordenação de Aperfeiçoamento de Pessoal de Nível Superior - Brasil (CAPES) - Código de Financiamento 001. 

CAMPOS, Cintia Isabel de. Investigação de relações entre dados individuais, do local de residência, ambiente viário e comportamentos de risco de condutores do Brasil e Portugal. 2019. 222 f. Tese (Doutorado) - Escola de Engenharia de São Carlos, Universidade de São Paulo, São Carlos.

As causas dos acidentes de trânsito estão associadas a fatores humanos, veículo e via. Devido à forte influência do fator humano, é fundamental compreender o comportamento do condutor no trânsito e, mais especificamente, comportamentos de risco. Diversos estudos, com questionários, contemplam a análise das relações entre comportamentos de risco e dados socioeconômicos, experiência de condução, traços de personalidade, e envolvimento em acidentes de trânsito, entretanto, são limitados em relação à representação do ambiente viário. Assim, o objetivo geral deste trabalho é investigar relações entre variáveis individuais dos condutores, local de residência, ambiente viário e comportamentos de risco de condutores de Brasil e Portugal. Os objetivos específicos são i) definir variáveis latentes considerando características e restrições da escala Likert usando a Análise de Componentes Principais Categórica; ii) classificar comportamentos de risco dos condutores de acordo com variáveis latentes e o envolvimento em acidentes de trânsito no passado; e iii) avaliar diferenças nos comportamentos de risco entre Brasil e Portugal. Para isso, um método sequencial com uso de técnicas de Análise Multivariada de dados é proposto. Os dados foram obtidos por meio de um questionário online, elaborado para condutores do Brasil e de Portugal, e complementados com base de dados públicos. Sete comportamentos de risco foram identificados e classificados com o uso sequencial das técnicas de Análise em Componentes Principais Categórica e Árvore de Decisão, sendo eles: erros, excesso de velocidade, conduzir sob efeito de álcool, não usar do cinto de segurança, uso do celular no modo viva voz, cansaço e sonolência e expressão de raiva do condutor. Assim, foram definidos dois grupos de condutores, para cada comportamento, baseados na frequência de determinado comportamento e envolvimento em acidentes de trânsito, que foram utilizados como variáveis dependentes em diferentes modelos Logit Binomiais para análise dos fatores que influenciam os comportamentos. Os modelos revelaram uma diferença significativa entre os comportamentos de excesso de velocidade e não usar o cinto de segurança entre os condutores de Brasil e Portugal. Outras diferenças também foram observadas para os demais comportamentos, no âmbito regional e estadual do local de residência, bem como para as configurações do ambiente viário. Verifica-se que, a partir do método proposto, foi possível identificar as características dos locais e dos condutores que contribuem para maior ou menor frequência em adotar os comportamentos de risco e, consequente, envolvimento em acidentes.

Palavras-chave: Comportamentos de risco do condutor. Classificação de comportamentos. Fatores de influência. Ambiente viário. Análise de Componentes Principais Categórica. Árvore de decisão. 

CAMPOS, Cintia Isabel de. Investigation of relationships between individual data, place of residence, road environment and risk behaviors of drivers from Brazil and Portugal. 2019. 222 f. Tese (Doutorado) - Escola de Engenharia de São Carlos, Universidade de São Paulo, São Carlos, 2019.

The causes of traffic accidents are associated with human factors, vehicle and road. Due to the strong influence of the human factor, it is essential to understand driver behavior in traffic and, more specifically, risk behaviors. Several studies, with questionnaires, include the analysis of the relationship between risk behaviors and socioeconomic data, driving experience, personality traits, and involvement in traffic accidents. However, they are limited in relation to the representation of the road environment. Thus, the general objective of this study is to investigate relationships between individual driver variables, place of residence, road environment and the risk behavior of drivers from Brazil and Portugal. The specific objectives are i) to define latent variables considering Likert scale characteristics and it constraints, using Categorical Principal Component Analysis; ii) to classify drivers' risk behaviors according to latent variables and past road traffic involvement; and iii) to evaluate differences in risk behaviors between Brazil and Portugal. For this, we proposed a sequential method using multivariate data analysis techniques. We obtained data through an online questionnaire, designed for drivers from Brazil and Portugal, and complemented with a public database. Through the sequential use of the Categorical Principal Component Analysis and Decision Tree techniques, seven behaviors were identified and classified: errors, speeding, driving under the influence of alcohol, not wearing a seat belt, using the phone in the speakerphone mode, tiredness and drowsiness and driver's expression of anger. Thus, two groups of drivers, for each risk behavior, were defined, based on the frequency of behavior and involvement in traffic accidents, which were used as dependent variables in different Logit Binomial models to analyze the factors that influence behaviors. The models revealed a significant difference between the parameters of drivers from Brazil and Portugal for speeding behaviors and not wearing seat belts. Other differences were also observed for the other behaviors, at the regional and state level of the place of residence, as well as for the road environment characteristics. From the proposed method, it was possible to identify the characteristics of the places and drivers that contribute to take risks frequencies and consequent involvement in accidents.

Keywords: Driver risk behaviors. Behaviors classification. Factors of Influence. Road environment. Categorical Principal Component Analysis. Decision Tree 



\section{LISTA DE FIGURAS}

Figura 3.1 - Distribuição da amostra no Brasil e Portugal................................................ 62

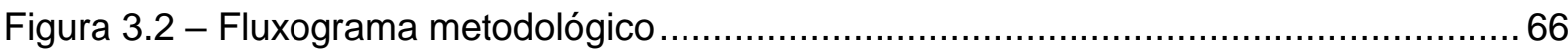

Figura 3.3 - Exemplo do diagrama da árvore de decisão ........................................... 72

Figura 4.1 - Frequência das respostas dos itens sobre habilidades de condução ............... 87

Figura 4.2 - Frequência das respostas dos itens sobre escala de raiva do condutor...........87

Figura 4.3 - Frequência das respostas dos itens sobre busca de sensações ..................... 88

Figura 4.4 - Frequência das respostas dos itens sobre ambiente viário urbano .................. 89

Figura 4.5 - Frequência das respostas dos itens sobre ambiente rodoviário ...................... 89

Figura 4.6 - Frequência das respostas dos itens sobre a percepção de risco ..................... 90

Figura 4.7 - Frequência das respostas dos itens de comportamentos específicos .............. 91

Figura 4.8 - Frequência de respostas dos itens do Driver Behavior Questionnaire ............. 92

Figura 5.1 - Gráfico de declividade das dimensões de habilidades de condução .................96

Figura 5.2 - Gráfico de declividade das dimensões da escala de raiva do condutor............98

Figura 5.3 - Gráfico de declividade da dimensão busca de sensações ............................ 100

Figura 5.4 - Gráfico de declividade das dimensões de percepção de risco ...................... 101

Figura 5.5 - Gráfico de declividade das dimensões de caracterização do ambiente viário 104

Figura 5.6 - Gráfico de declividade das dimensões de comportamento ............................. 106

Figura 6.1- Diagrama de caixa das pontuações normalizadas das observações para cada comportamento .................................................................................... 114

Figura 6.2 - Mapa da árvore de decisão: Erros ...................................................... 117

Figura 6.3 - Mapa da árvore de decisão: Excesso de velocidade ................................... 119

Figura 6.4 - Mapa da árvore de decisão: Conduzir sob efeito de álcool ......................... 120

Figura 6.5 - Mapa de árvore de decisão: Não usar cinto de segurança ............................. 122

Figura 6.6 - Frequência de respostas para cada nó das variáveis que representam o comportamento do não uso de cinto de segurança ....................................... 123

Figura 6.7 - Mapa de árvore de decisão: Uso do celular no modo viva voz...................... 125

Figura 6.8 - Mapa de árvore de decisão: Sonolência e cansaço ..................................... 126

Figura 6.9 - Mapa de árvore de decisão: Expressão de raiva ao conduzir ....................... 128

Figura 7.1 - Relação entre os nós terminais e as funções utilidade ................................... 132

Figura 7.2 - Variáveis independentes utilizadas na calibração dos modelos ..................... 134

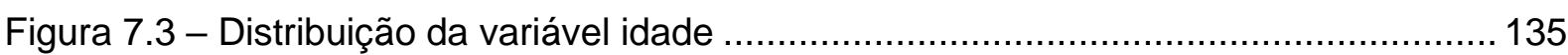

Figura 7.4 - Distribuição das variáveis tempo de habilitação e distância percorrida .......... 135

Figura 7.5 - Distribuição das variáveis agregadas .................................................... 137

Figura 7.6 - Distribuição das variáveis de caracterização do ambiente ............................ 138

Figura 7.7 - Distribuição das variáveis de construto psicológico...................................... 139 
Figura 7.8 - Variáveis independentes dos modelos "A" 140

Figura 7.9 - Variáveis independentes dos modelos "B" .

Figura 7.10 - Variáveis independentes dos modelos " $C$ " 142

Figura 7.11 - Variáveis independentes do modelo "D" 142 


\section{LISTA DE TABELAS}

Tabela 2.1 - Principais causas dos acidentes de trânsito 31

Tabela 3.1 - Locais selecionados e proporção amostral do Brasil ......................................59

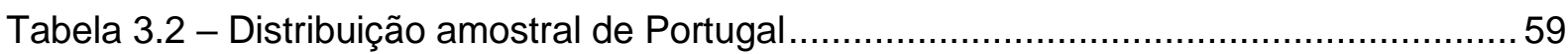

Tabela 3.3 - Medidas de caracterização da amostra ...................................................... 60

Tabela 3.4 - Medidas de caracterização de experiência de condução ................................61

Tabela 4.1 - Alfa de Cronbach do primeiro teste piloto ................................................... 81

Tabela 4.2 - Alfa de Cronbach dos testes piloto 1 e 2 ...................................................... 85

Tabela 5.1 - Valores métricos atribuídos às categorias da escala Likert de Habilidades de

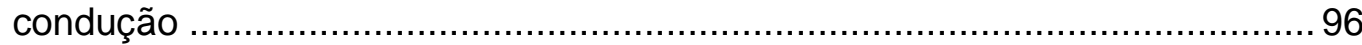

Tabela 5.2 - Cargas fatoriais das dimensões da avaliação das habilidades de condução ...97

Tabela 5.3 - Resultados para validação do construto Habilidades de condução ................. 97

Tabela 5.4 - Valores métricos atribuídos às categorias da escala Likert da escala de raiva do

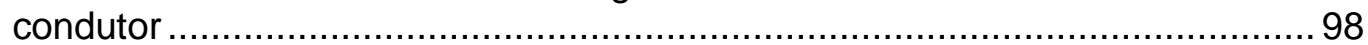

Tabela 5.5 - Cargas fatoriais das dimensões da escala de raiva do condutor .................... 99

Tabela 5.6 - Resultados para validação da "Escala de raiva do condutor" ......................... 99

Tabela 5.7 - Valores métricos atribuídos às categorias da escala Likert de busca de sensações ..................................................................................... 100

Tabela 5.8 - Cargas fatoriais das dimensões de busca de sensações .............................. 101

Tabela 5.9 - Resultados para validação do construto "Busca de sensações" .................... 101

Tabela 5.10 - Valores métricos atribuídos às categorias da escala Likert da percepção de risco ...................................................................................... 102

Tabela 5.11 - Cargas fatoriais das dimensões de percepção do risco de comportamentos 103

Tabela 5.12 - Resultados para validação do construto de "Percepção do risco" ................ 103

Tabela 5.13 - Valores métricos atribuídos às categorias da escala Likert do ambiente viário

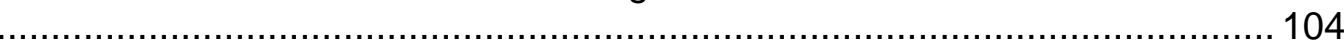

Tabela 5.14 - Cargas fatoriais das dimensões de caracterização do ambiente viário......... 105

Tabela 5.15 - Resultados para validação da caracterização do ambiente urbano e rodoviário 105

Tabela 5.16 - Valores métricos atribuídos às categorias da escala Likert dos comportamentos

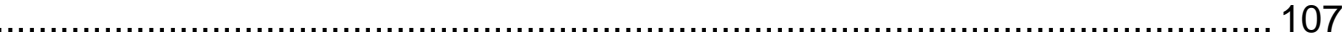

Tabela 5.17 - Cargas fatoriais das dimensões de comportamentos de condutor............... 108

Tabela 5.18 - Resultados para validação do comportamento do condutor .......................... 109

Tabela 7.1 - Medidas de estimação dos modelos, relativos ao comportamento "Erros" .... 143

Tabela 7.2 - Parâmetros estimados para o modelo D, associado ao comportamento "Erros" 144

Tabela 7.3 - Medidas de estimação dos modelos associados ao comportamento "Excesso de velocidade" 
Tabela 7.4 - Parâmetros estimados para o modelo C3, associado ao comportamento "excesso de velocidade"

Tabela 7.5 - Medidas de estimação dos modelos associados ao comportamento "conduzir sob influência de álcool" 148

Tabela 7.6 - Parâmetros estimados para o modelo D, relativo ao comportamento "conduzir sob efeito de álcool" 148

Tabela 7.7 - Medidas de estimação dos modelos associados ao comportamento "não usar cinto de segurança" 150

Tabela 7.8 - Parâmetros estimados para os modelos C3, associados ao comportamento "não usar o cinto de segurança" 150

Tabela 7.9 - Medidas de estimação dos modelos associados ao comportamento "usar o celular no modo viva voz ao conduzir".

Tabela 7.10 - Parâmetros estimados para o modelo C4, relativo ao comportamento "uso do celular no modo viva voz ao conduzir". 153

Tabela 7.11 - Medidas de estimação dos modelos associados ao comportamento "Cansaço e sonolência". 155

Tabela 7.12 - Parâmetros estimados, relativos ao modelo D para o comportamento "Cansaço e Sonolência" 155

Tabela 7.13 - Medidas de estimação dos modelos do comportamento expressão de raiva do condutor

Tabela 7.14 - Parâmetros estimados para o modelo C6, relativo ao comportamento "Expressão de raiva do condutor" 157

Tabela 7.15 - Relação entre os parâmetros significativos dos modelos 162 


\section{LISTA DE QUADROS}

Quadro 2.1 - Síntese de temas e trabalhos abordados neste estudo ................................50

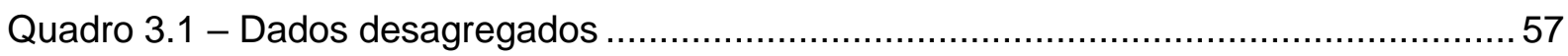

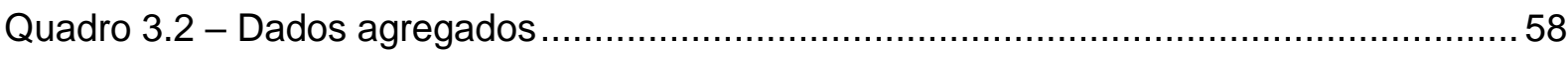

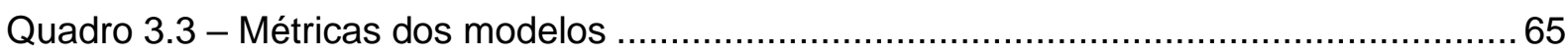

Quadro 3.4 - Quadro resumo dos instrumentos validados usados .................................67

Quadro 3.5 - Grupos de variáveis consideradas nos modelos ...................................... 74

Quadro 4.1 - Perguntas e objetivos da entrevista..................................................... 75

Quadro 4.3 - Comentários dos participantes sobre o primeiro estudo piloto....................... 83

Quadro 4.4 - Mudanças na primeira versão do questionário ............................................ 83

Quadro 5.1 - Sumarização das variáveis latentes obtidas com a CATPCA ...................... 111

Quadro 6.1 - Resumo dos limites e caracterizações dos nós terminais............................. 129

Quadro 7.1 - Ordem e combinações dos modelos avaliados ........................................ 131

Quadro 7.2 - Resumo das relações significativas identificadas ....................................... 164 



\section{SUMÁRIO}

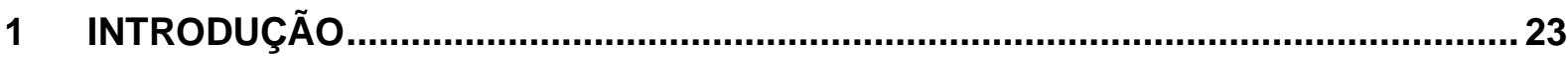

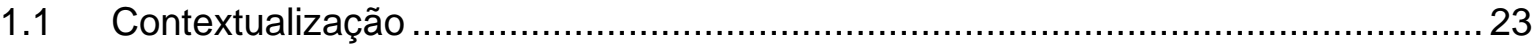

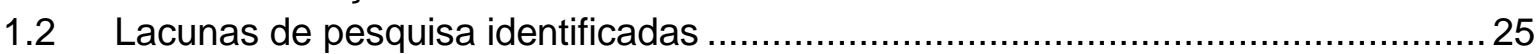

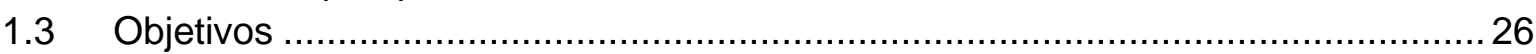

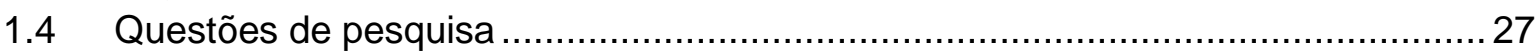

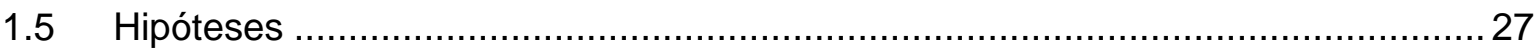

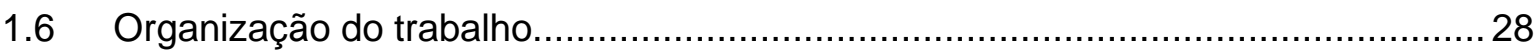

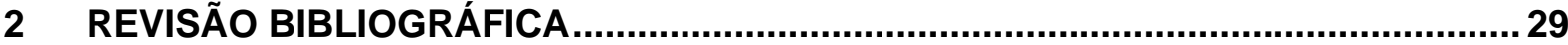

2.1 Considerações iniciais acerca da acidentalidade viária ......................................29

2.1.1 Fatores de risco associados aos acidentes de trânsito .................................29

2.1.2 Investigação do comportamento de risco dos condutores .............................. 32

2.2 Questionários como ferramentas de investigação............................................... 33

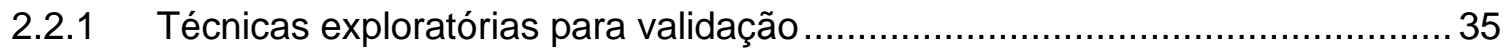

2.3 Influências do comportamento de risco do condutor .......................................... 36

2.4 Fatores de influência do comportamento do condutor ........................................ 43

2.4.1 Características socioeconômicas, experiência de condução e traços de personalidade como fatores de influência ................................................................ 43

2.4.2 Características do ambiente viário e agregadas do local de residência como fatores de influência ............................................................................................ 47

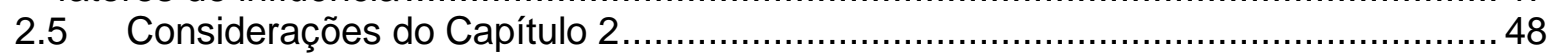

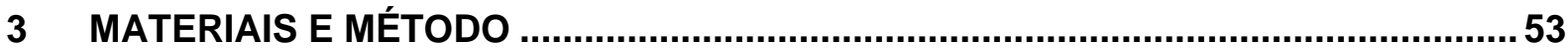

3.1 Síntese das etapas metodológicas ................................................................. 53

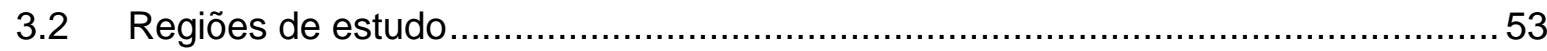

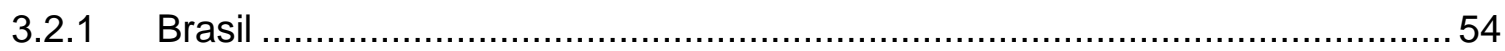

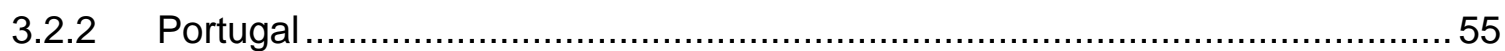

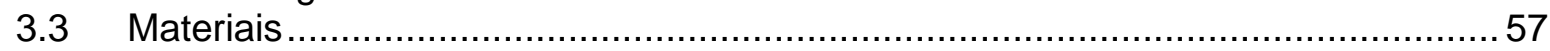

3.3.1 Banco de dados: dados desagregados e agregados .................................. 57

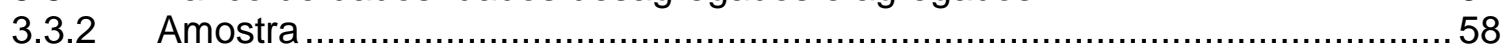

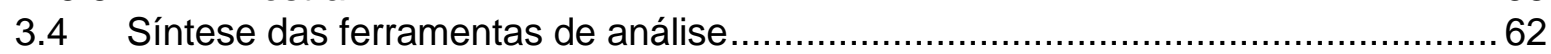

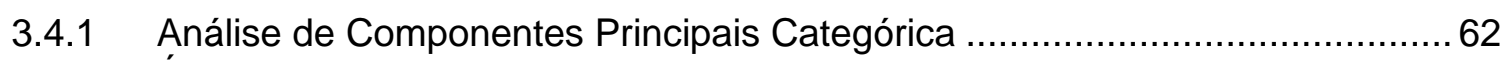

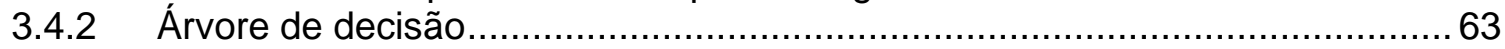

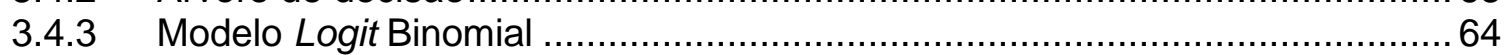

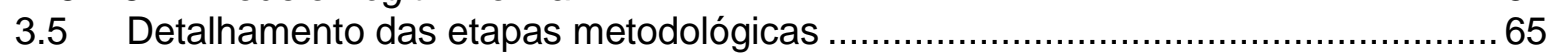

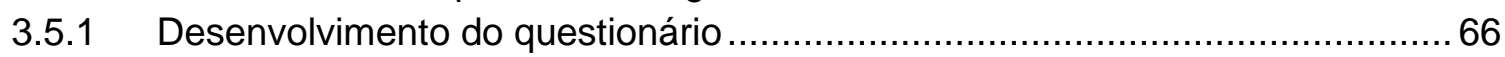

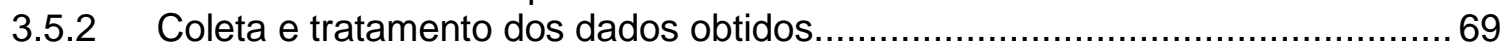

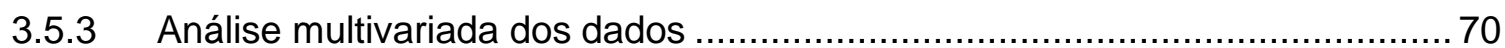

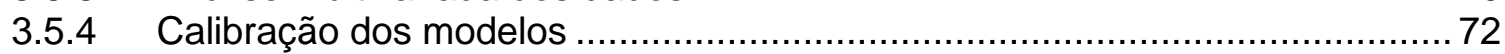

4 QUESTIONÁRIO: DESENVOLVIMENTO E APLICAÇÃO .........................................75

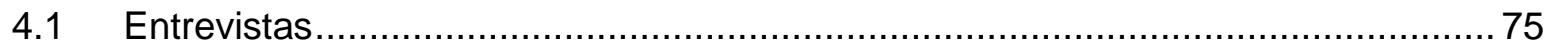

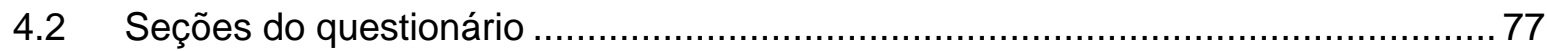

4.2.1 Seção 1: Dados socioeconômicos e histórico como condutor..........................77

4.2.2 Seção 2: Nível de familiaridade com o ambiente da estrada como motorista.. 77

4.2.3 Seção 3: Você mesmo como condutor ...................................................... 78

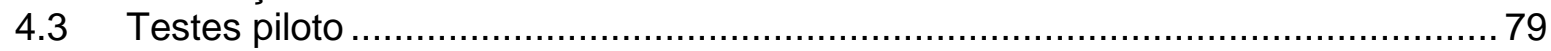

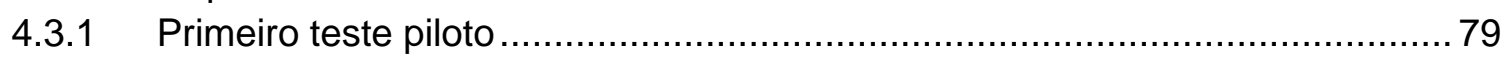

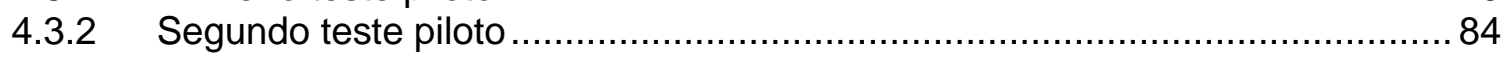


4.4 Versão final: testes da versão online e divulgação............................................. 86

4.5 Distribuição de frequências dos dados em escala Likert da amostra final..............86

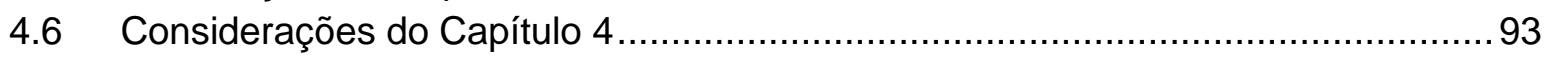

5 VARIÁVEIS LATENTES E VALIDAÇÃO DO QUESTIONÁRIO ...............................95

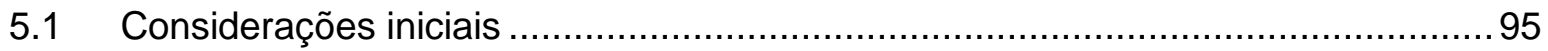

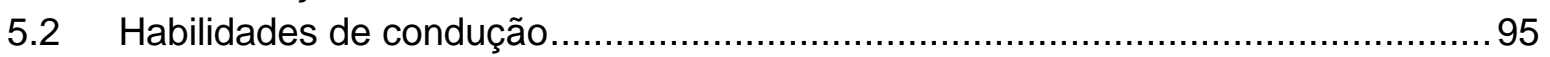

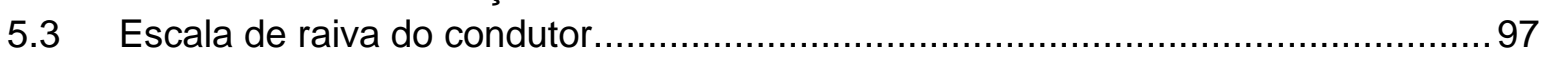

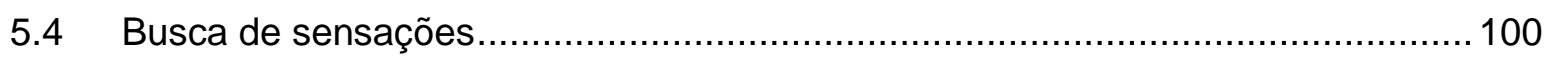

5.5 Percepção do risco de comportamentos .......................................................... 101

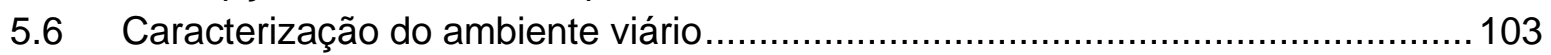

5.7 Comportamentos do condutor auto relatados ............................................... 105

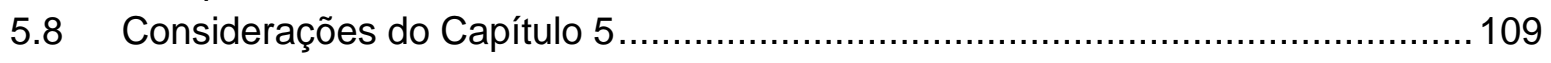

6 CLASSIFICAÇÃO DE COMPORTAMENTOS DE RISCO .......................................113

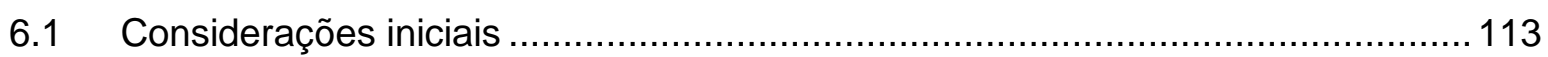

6.2 Distribuição dos escores individuais ....................................................... 113

6.3 Limites de risco e características dos nós terminais........................................... 114

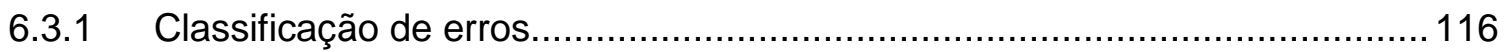

6.3.2 Classificação de excesso de velocidade ..................................................118

6.3.3 Classificação de conduzir sob efeito de álcool ............................................ 120

6.3.4 Classificação do não uso do cinto de segurança ........................................ 121

6.3.5 Classificação do uso do celular no modo viva voz ao conduzir ......................124

6.3.6 Classificação de sonolência e cansaço........................................................ 126

6.3.7 Classificação da expressão de raiva ao conduzir........................................ 127

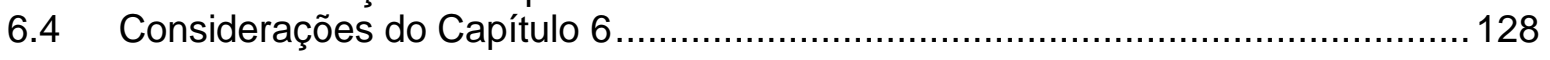

7 MODELOS PARAMÉTRICOS: CALIBRAÇÃO E ANÁLISE.....................................131

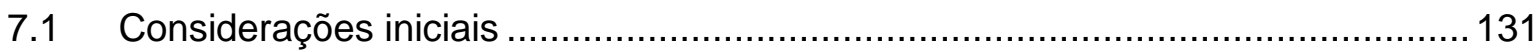

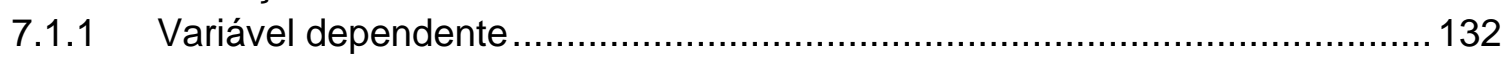

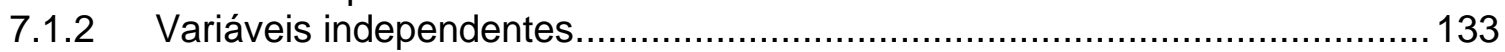

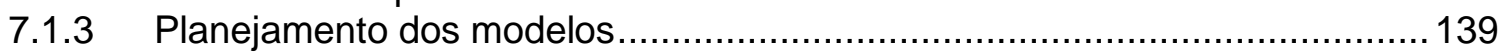

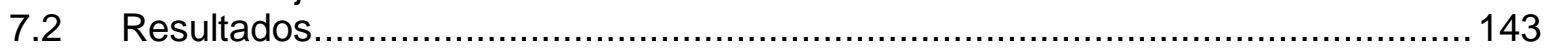

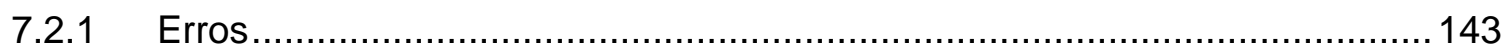

7.2.2 Excesso de velocidade

7.2.3 Conduzir sob efeito de álcool ............................................................... 148

7.2.4 Não usar cinto de segurança ao conduzir .................................................. 150

7.2.5 Usar o celular no modo viva voz enquanto conduz ..................................... 152

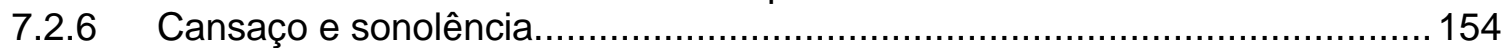

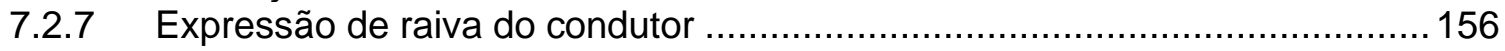

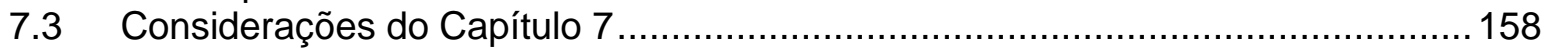

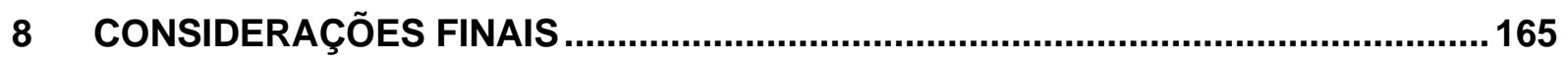

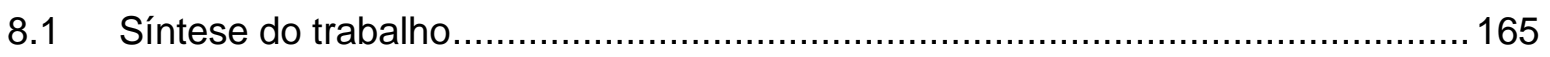

8.2 Respostas às questões de pesquisa e análise das hipóteses ............................. 167

8.3 Conclusões e propostas de intervenções mitigadoras .......................................170

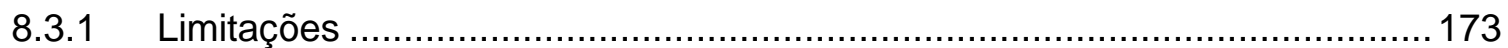

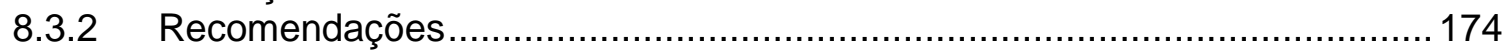

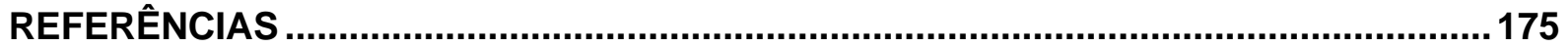

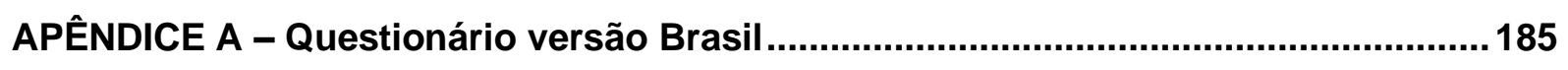

APÊNDICE B - Questionário versão Portugal ......................................................... 195 
APÊNDICE C - Resultados dos testes pilotos......................................................... 205

APÊNDICE D - Distribuição dos escores individuais da CATPCA ..............................209

APÊNDICE E - Testes de hipótese e medidas de caracterização dos nós terminais da

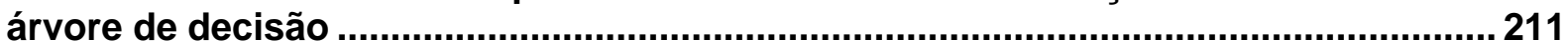

APÊNDICE F - Parâmetros estimados .................................................................. 216 



\section{INTRODUÇÃO}

Neste capítulo introdutório é apresentada uma contextualização, baseada nos temas relacionados a este trabalho. Além disso, são descritos os objetivos, as questões de pesquisa e hipóteses que nortearam esta tese de doutorado.

\subsection{Contextualização}

A ocorrência dos acidentes de trânsito está relacionada a fatores específicos e aleatórios (HIGHWAY SAFETY MANUAL - HSM, 2010). Compreender os fatores específicos, que influenciam a ocorrência de acidentes de trânsito, é essencial para garantir medidas que levem à sua redução, de forma a mitigar os impactos sociais e econômicos para a sociedade.

Em 1962, já se discutia que grupos de população não são afetados da mesma forma pelos acidentes de trânsito, e que as causas desses acidentes estão associadas a diferentes fatores, classificados como: humano, via e veículo (DELHOMME et al., 2009; DOWNING; BAGULEY; HILLS, 1991; NORMAN, 1962).

O ambiente rodoviário é resultado de diferentes interações entre esses fatores, e conduzir corresponde ao constante processo de adaptação a essas interações, que podem ser externas (leis, infraestrutura) ou internas (motivos que levam às ações dos usuários). Quando a adaptação não acontece, podem ocorrer acidentes de trânsito (DELHOMME et al., 2009).

Dessa forma, a ocorrência do acidente pode estar relacionada à idade e gênero do usuário, consumo de álcool e drogas, excesso de velocidade, não usar equipamentos de proteção, comportamentos inseguros, falta de atenção, distração com uso de celular, densidade do tráfego, infraestrutura mal dimensionada, condições do clima e luminosidade, tipo do veículo, entre outros fatores (ELVIK et al., 2009; WORLD HEALTH ORGANIZATION - WHO, 2015).

Diversos estudos são realizados para investigar e compreender esses elementos. No que diz respeito aos fatores humanos, presentes como causa em até $96 \%$ dos acidentes, existem esforços para compreender o comportamento do condutor e como mensurá-lo com diferentes abordagens como o uso de questionários, simuladores de 
direção e estudos naturalísticos (CAMPBELL, 2012; IVERSEN, 2004; RUDINBROWN; EDQUIST; LENNÉ, 2014).

Os questionários, utilizados como ferramentas para obtenção de dados de condutores, apresentam vantagens como baixo custo, fácil aplicação, e acesso a informações em diferentes contextos (LAJUNEN; ÖZKAN, 2011; MARÔCO, 2014; STEVENS et al., 2018). Além disso, devido ao seu amplo alcance e versatilidade para adaptações, permitem estudos comparativos entre diferentes grupos ou países. A seguir, são apresentados alguns aspectos relacionados aos estudos sobre 0 comportamento do condutor com questionários.

- Comportamento do condutor e questionários

A mensuração dos comportamentos de risco, a partir da aplicação de questionários, incide do auto relato da frequência de práticas de atos inseguros no trânsito. A frequência é obtida por meio de escala Likert, que é uma medida categórica ordinal, amplamente utilizada em estudos do comportamento do condutor. Entretanto, o uso de questionários implica em algumas restrições relacionadas a dados auto relatados, fazendo-se necessário a análise de validação e consistência interna do instrumento, para certificar a qualidade dos dados.

As técnicas para determinação de variáveis latentes e validação dos questionários mais utilizadas baseiam-se em medidas numéricas que não atendem às características de dados categóricos. Com a existência de uma técnica adequada a esses tipos de dados, faz-se necessário avaliar sua adequação para análise exploratória e validação dos questionários em estudos acerca do comportamento de condutores.

- Diferenças no comportamento do condutor

Adotar um comportamento de risco é considerado como um fator de influência para ocorrência dos acidentes de trânsito (JONAH, 1986), de modo que o condutor pode assumir o risco devido à falta de consciência da situação (JONAH, 1986), a circunstâncias específicas do trânsito (IVERSEN; RUNDMO, 2004) ou a sua própria natureza (WILDE, 2013).

Sabendo-se da relação entre o comportamento de risco e o envolvimento em acidentes de trânsito e que distinguir grupos de condutores possibilita aumentar o efeito das diferenças individuais nas pesquisas de segurança viária (DORN; AF 
WÅHLBERG, 2019), classificar a frequência dos comportamentos considerando o envolvimento em acidentes no passado possibilita diferenciar os condutores em relação ao nível de risco do comportamento. Dessa forma, torna-se possível identificar o efeito de fatores de influência para comportamentos de risco mais frequentes. Estudos para identificação de fatores de risco são necessários para promoção de interverções para redução da acidentalidade (MOHAN et al., 2006)

- Fatores que influenciam o comportamento de risco do condutor

Os estudos que investigam o comportamento do condutor, com uso de questionários, têm como escopo principal, características individuais do condutor, traços de personalidade e frequência de comportamento de risco auto relatado. Considerando que o local de residência interfere no comportamento do condutor, devido às influências do desenvolvimento econômico, ambiente viário e cultural, estes aspectos devem ser contemplados em estudos com questionários e investigados para fundamentar ações mitigadoras de acordo com as particularidades locais.

Com isso, faz-se necessário a representação das particularidades do local de residência e caracterização do ambiente viário em estudos do comportamento do condutor com questionários para análise de fatores de influência locais.

Examinar os fatores subjacentes ao comportamento humano, bem como suas origens, é fundamental para promoção de políticas de segurança viária que, de algum modo, minimizem os acidentes causados por fatores humanos (DELHOMME et al., 2009).

\subsection{Lacunas de pesquisa identificadas}

Com base no tema sucintamente descrito anteriormente, identificam-se algumas lacunas de pesquisa, que motivaram a realização desta Tese de doutorado:

- Considerando que todos condutores estão sujeitos a adotar algum comportamento de risco, a classificação da frequência dos comportamentos de risco dos condutores contemplando o envolvimento em acidentes de trânsito, torna-se uma contribuição substancial para diferenciação dos condutores e, consequentemente, para análise dos fatores que influenciam a adoção mais frequente do comportamento de risco no trânsito. Dessa forma, para preencher a primeira lacuna desta tese de doutorado, propõe-se a classificação de 
comportamentos de risco a partir de variáveis latentes e envolvimento em acidentes de trânsito no passado;

- Partindo-se do pressuposto de que, em geral, os estudos do comportamento do condutor, com questionários, são baseados em dados auto relatados por meio de respostas em escala Likert, a análise para validação do questionário deve ser baseada em uma técnica adequada para dados qualitativos ordinais. Assim, a segunda lacuna a ser preenchida por esta tese de doutorado será a aplicação de uma técnica associada a dados qualitativos para identificação de variáveis latentes e validação de questionários relacionados à investigação do comportamento do condutor; e

- Visto que os estudos acerca dos fatores que influenciam o comportamento de risco do condutor exploram, em sua maioria, a relação entre dados socioeconômicos, experiência de condução e traços de personalidade, a terceira lacuna de pesquisa desta tese de doutorado consiste na inclusão de variáveis de caracterização do ambiente viário e local de residência para análise das relações com comportamento de risco do condutor. Uma comparação entre países e regiões também é proposta.

Dessa forma, esta Tese de doutorado traz sua contribuição por meio da proposta de um método sequencial, com técnicas de análise multivariada de dados, para investigar as relações entre dados individuais, do local de residência e ambiente viário, em relação aos comportamentos de risco de condutores de Brasil e Portugal.

Além disso, considera, em seu método, as restrições acerca do uso da escala Likert nos questionários e propõe uma abordagem para classificação do comportamento de risco e avaliação das diferenças entre países e regiões.

\subsection{Objetivos}

O objetivo geral desta tese de doutorado é investigar relações entre dados individuais, do local de residência e ambiente viário e comportamentos de risco de condutores de Brasil e Portugal.

A partir do objetivo geral, os seguintes objetivos específicos são apresentados: 
I. Definir variáveis latentes, considerando as características e restrições da escala Likert, usando a Análise de Componentes Principais Categórica;

II. Classificar comportamentos de risco dos condutores de acordo com variáveis latentes e o envolvimento em acidentes de trânsito no passado; e

III. Avaliar diferenças nos comportamentos de risco entre Brasil e Portugal.

\subsection{Questões de pesquisa}

Esta tese de doutorado é norteada pela seguinte questão de pesquisa: "Quais variáveis relativas ao condutor, local de residência e ambiente viário influenciam comportamentos de risco de condutores de Brasil e Portugal? "

Além da pergunta principal, questões secundárias também são apresentadas:

I. A aplicação da Análise de Componentes Principais Categórica corrobora a determinação de variáveis latentes e validação de questionários para investigação de comportamento do condutor?

II. A classificação do comportamento do condutor de acordo com variáveis latentes e a frequência de envolvimento em acidentes de trânsito permite identificar padrões de risco?

III. Os parâmetros estimados indicam diferenças significativas entre Brasil e Portugal para os comportamentos de risco?

\subsection{Hipóteses}

Considerando as questões de pesquisa que norteiam este trabalho, a hipótese básica desta pesquisa é "Além dos dados inerentes ao condutor, os dados relacionados ao local de residência e a caracterização do ambiente viário contribuem para explicar os comportamentos de risco dos condutores do Brasil e de Portugal”.

As hipóteses secundárias são:

I. O uso da técnica de Análise de Componentes Principais Categórica corrobora a definição das variáveis latentes e validade do questionário para investigação dos comportamentos de risco dos condutores; 
II. Os comportamentos de risco do condutor podem ser classificados em níveis de risco de acordo com as variáveis latentes e a frequência de envolvimento em acidentes de trânsito relatado; e

III. Os parâmetros estimados indicam diferenças significativas entre Brasil e Portugal para os comportamentos de risco.

\subsection{Organização do trabalho}

Além deste capítulo introdutório, este trabalho está dividido em sete capítulos. A fundamentação teórica do trabalho é apresentada no Capítulo 2, onde foram reunidos dados acerca dos fatores humanos e estudos de comportamentos de risco do condutor.

No Capítulo 3 são apresentados os países de estudo, os materiais e ferramentas utilizadas, e as etapas metodológicas desenvolvidas para atingir os objetivos propostos e investigar as hipóteses apresentadas no Capítulo 1.

O processo de desenvolvimento do questionário, utilizado como instrumento de coleta de dados da pesquisa, é apresentado no Capítulo 4. No Capítulo 5 são apresentados os resultados da etapa de validação das variáveis latentes com o uso da Análise de Componentes Principais Categórica.

Na sequência, no Capítulo 6, são apresentados os resultados da classificação dos comportamentos de risco, realizada com a aplicação do algoritmo Classification And Regression Tree (CART) da Árvore de Decisão.

No Capítulo 7, são apresentados os resultados da calibração de modelos Logit e a análise dos fatores de influência dos comportamentos. Finalmente, no Capítulo 8, são apresentadas a síntese do trabalho, conclusões e recomendações para trabalhos futuros.

$\mathrm{Na}$ sequência, são apresentadas as Referências citadas neste trabalho e os Apêndices com as versões do questionário e dados complementares dos resultados. 


\section{REVISÃO BIBLIOGRÁFICA}

Este capítulo apresenta uma breve contextualização dos fatores de risco associados aos acidentes de trânsito e a descrição de trabalhos relacionados à investigação do fator humano, em específico, estudos do comportamento de risco do condutor por meio da aplicação de questionários.

\subsection{Considerações iniciais acerca da acidentalidade viária}

Os acidentes de trânsito foram responsáveis por mais de 1,35 milhão de mortes em 2016, tornando-se a principal causa de morte entre crianças e jovens na faixa etária de 5 a 29 anos de idade, e a oitava causa entre toda a população. Mais de $90 \%$ das mortes ocorrem em países de baixa e média renda, que registram taxas de mortalidade até três vezes maiores que os países de alta renda (WHO, 2018).

A relação entre maior segurança viária e o desenvolvimento dos países é explicada por aspectos culturais referentes à segurança no trânsito, existência de legislações e punições severas, conhecimento e respeito às leis por parte da população, oferta de melhor treinamento a condutores e pedestres e acesso às estatísticas sobre acidentes de trânsito (FERRAZ et al., 2012).

Entretanto, as diferenças no cenário da acidentalidade viária não se restringem aos países e podem ocorrer dentro de um mesmo país, estado, região ou cidade. A existência de problemas mais graves e escassez de recursos em locais de baixo desenvolvimento resultam em menos investimentos na segurança viária devido ao atendimento de necessidades mais básicas (FERRAZ et al., 2012). Mesmo nos países de maior desenvolvimento, pessoas com menor nível socioeconômico têm maior probabilidade de se envolver em acidentes de trânsito (WHO, 2018).

\subsubsection{Fatores de risco associados aos acidentes de trânsito}

Os acidentes de trânsito são eventos raros e aleatórios caracterizados pela ocorrência de uma colisão, com pelo menos um veículo motorizado envolvido, que pode, ou não, resultar em ferimentos ou danos materiais (DELHOMME et al., 2009; HSM, 2010).

São denominados como eventos raros, pois correspondem a somente uma pequena proporção do número total de eventos relacionados ao sistema de transportes; E 
aleatórios, pois a ocorrência do acidente é determinada pela combinação de fatores que podem ser controlados (determinísticos) e aleatórios e imprevisíveis (estocásticos), de forma que mesmo em situações semelhantes, o acidente de trânsito poderá, ou não, ocorrer (HSM, 2010).

Os fatores de risco, associados aos acidentes de trânsito, podem ser divididos de acordo com aqueles que influenciam na exposição ao risco, na ocorrência do acidente, na severidade e no resultado da lesão pós acidente (PEDEN et al., 2004; MOHAN et al., 2006; HSM, 2010). Dentre os fatores que influenciam a exposição ao risco, são apresentados os fatores econômicos, como o nível de desenvolvimento social e econômico, características demográficas, uso e ocupação do solo, usuários vulneráveis em ambientes compartilhados e falha na concepção de interação entre limite de velocidade e desenho e projeto da via (MOHAN et al., 2006).

Influenciam no envolvimento em acidentes: comportamentos de excesso de velocidade, conduzir sob efeito de álcool, droga ou medicamentos, fadiga, sexo e idade do condutor, jovens conduzindo no mesmo veículo, a vulnerabilidade do usuário, pouca luminosidade, fatores de manutenção do veículo e fatores ambientais. Já a severidade é influenciada por excesso de velocidade, não uso de capacete, cinto de segurança ou dispositivo de retenção infantil, presença de álcool e drogas, aspectos biológicos do ser humano, entre outros (MOHAN et al., 2006).

Ainda que seja comum atribuir uma única causa ao acidente de trânsito, a maioria dos acidentes ocorre devido a uma série de eventos relacionados a diferentes causas que podem ser classificadas de acordo com os fatores: humano (idade, comportamento, habilidade, humor, pressão do tempo, distração, fadiga, álcool ou abuso de drogas), veículo (falhas técnicas) e via ou ambiente (condições da estrada, do trânsito e do clima) (DELHOMME et al., 2009; HSM, 2010; FERRAZ et al., 2012).

Ao analisar as principais causas dos acidentes, se destacam as causas relacionadas ao fator humano que, além de representarem o maior percentual como fator único, também estão presentes como causa em conjunto com os demais fatores (Tabela 2.1). 
Tabela 2.1 - Principais causas dos acidentes de trânsito

\begin{tabular}{lrrr}
\hline \multicolumn{1}{c}{ Causa } & Treat (1979) & $\begin{array}{c}\text { Wierwille et al. } \\
(2002)^{2}\end{array}$ & Scaringella (Brasil) $)^{3}$ \\
\hline Humano & $57 \%$ & $65 \%$ & $44 \%$ \\
Humano + via & $27 \%$ & $25 \%$ & $29 \%$ \\
Humano + veículo & $6 \%$ & $5 \%$ & $19 \%$ \\
Via & $3 \%$ & $2 \%$ & $0 \%$ \\
Veículo & $3 \%$ & $2 \%$ & $0 \%$ \\
Via + veículo & $1 \%$ & $1 \%$ & $8 \%$ \\
Humano + via + veículo & $3 \%$ & $100 \%$ & $100 \%$ \\
\hline Total & $100 \%$ & & \\
\hline \multicolumn{2}{c}{ Fonte: Adaptado de Delhomme et al. (2009), Ferraz et al. (2012) e HSM (2010) }
\end{tabular}

O fator humano é o mais flexível do trio homem-veículo-via. É o fator que se adapta ao ambiente, tem capacidade de lidar com restrições, tomar decisões, aprender e adquirir novas habilidades, mas também o mais vulnerável; Vulnerabilidade essa decorrente da instabilidade humana (envelhecimento, saúde, estresse, humor, fadiga, etc.), e seus comportamentos (excesso de velocidade, dirigir sob influência de álcool ou drogas, etc.) que, associados a fatores externos e determinadas restrições, influenciam o modo de dirigir. Além disso, também há os aspectos cognitivosmotivacionais, que estão relacionados à percepção de si próprio e dos outros usuários, tendência em assumir ou evitar riscos e o desejo de imitar o comportamento de outros usuários da estrada (DELHOMME et al., 2009).

Muitos estudos, na área da psicologia e ergonomia, têm sido desenvolvidos a fim de se compreender como essas características influenciam o comportamento mais arriscado dos condutores e a relação com a ocorrência de acidentes de trânsito (IVERSEN; RUNDMO, 2002; RUDIN-BROWN; EDQUIST; LENNÉ, 2014; SHINAR, 2017; YANG et al., 2013). De modo geral, esses estudos são realizados com a aplicação de questionários, utilizados como único instrumento de investigação ou, mais recentemente, em conjunto com experimentos em simuladores de direção ou estudos naturalísticos (CAMPBELL, 2012; IVERSEN, 2004; RUDIN-BROWN; EDQUIST; LENNÉ, 2014; VELLOSO; JACQUES; TORRES, 2016).

\footnotetext{
1 TREAT, J.R.; TUMBAS, N.S.; MCDONALD, S.T.; SHINAR, D.; HUME, R.D.; MAYER, R.E.; STANISFER, R.L.; CASTELLAN, N.J. Tri-Level Study of the Causes of Traffic Accidents. Washington, DC: National Highway Traffi C Safety Administration. 1979.

2 WIERWILLE, W. W.; HANOWSKI, R. J.; HANKEY, J. M.; KIELISZEWSKI, C. A.; LEE, S. E.; MEDINA, A.; KEISLER, A. S.; DINGUS, T. A. Identification of driver errors: Overview and recommendations (Report No. FHWARD-02-003).McLean, VA: Federal Highway Administration, 2002.

${ }^{3}$ SCARINGELLA Trânsito. Investigação de Causas de Acidentes de Trânsito - Estudo de Amostra de Acidentes. $<$ http://www.scaringella-transito.com.br/scaringella.html>.
} 


\subsubsection{Investigação do comportamento de risco dos condutores}

Adotar um comportamento de risco não está necessariamente relacionado a um ato volitivo, ou seja, à escolha de se comportar de forma arriscada. "Podem ser tomados riscos ao dirigir com ou sem consciência do que está fazendo" (JONAH, 1986, p. 258, tradução nossa), de modo que o condutor pode não reconhecer o perigo pertinente à sua ação (JONAH, 1986). Dessa forma, uma alternativa para identificar a prática de comportamentos de risco é por meio de perguntas acerca da frequência em que situações específicas no trânsito foram adotadas pelo condutor.

Reason et al. (1990) desenvolveram o Questionário de Comportamento do Condutor (DBQ - do inglês Driver Behaviour Questionnaire), considerado o principal instrumento para medir comportamentos do condutor (LAJUNEN; ÖZKAN, 2011) e prever acidentes (AF WÅHLBERG; BARRACLOUGH; FREEMAN, 2015; DE WINTER; DODOU, 2010).

A versão original do questionário contempla 50 itens, mensurados em uma escala Likert de 6 pontos, relacionados a três níveis de risco (A - baixo, $\mathrm{B}$ - médio e $\mathrm{C}$ - alto). O condutor relata a frequência de comportamentos relacionados a situações de excesso de velocidade, falta de atenção, ultrapassagem perigosa, cansaço, desrespeito à sinalização de trânsito e leis, entre outras. Com auxílio da Análise de Componentes Principais, os itens foram agrupados em três fatores denominados "erros" ", "lapsos" e "violações".

O primeiro fator envolveu violações deliberadas com alto nível de risco para outros usuários da estrada, o segundo fator representou erros perigosos e o terceiro e último fator caracterizou erros "tolos", os lapsos. Os itens foram divididos de acordo com as duas classificações consideradas (comportamento e risco), de modo que os fatores um e dois concentraram comportamentos potencialmente perigosos (REASON et al., 1990).

Posteriormente, uma série histórica de estudos foi realizada com diferentes versões do DBQ para validar os resultados iniciais e identificar as relações com acidentes de trânsito (LAWTON et al., 1997; PARKER; LAJUNEN; STRADLING, 1998; PARKER et al., 1995a, 1995b). Desde então, as versões original e curta foram utilizadas em

\footnotetext{
${ }^{4}$ Erros correspondem a falhas nas ações planejadas para alcançar o objetivo e pode ser classificado de três formas: "erro" quando há deficiência na decisão quanto ao objetivo e meios de alcança-los, "falhas" a falta de atenção e "lapsos" os esquecimentos (REASON et al., 1990; ROMÃO, 2015).
} 
diferentes estudos, replicando a estrutura inicialmente identificada (AF WÅHLBERG; BARRACLOUGH; FREEMAN, 2015; BIANCHI; SUMMALLA, 2002; DE WINTER; DODOU, 2010; MEHDIZADEH; SHARIAT-MOHAYMANY; NORDFJAERN, 2018; ÖZKAN et al., 2006; STANOJEVIĆ et al., 2018; VAHEDI et al., 2018).

Além disso, este instrumento se mostrou consistente para analisar e compreender o comportamento do condutor em diferentes países (BIANCH; SUMMALLA, 2002; DOURADO et al., 2017a, 2017b; ÖZKAN et al., 2006; PARKER; LAJUNEN; STRADLING, 1998; PINATTI, 2007; POÇAS CORREIA; CUNHA HORTA, 2014; ROMÃO, 2015), e continua a ser aplicado mesmo após quase 30 anos do seu desenvolvimento (CHU et al., 2019; KOPPEL et al., 2019; STANOJEVIĆ et al., 2018; ZHANG et al., 2018).

Devido à relevância do $\mathrm{DBQ}$ e o potencial para explorar diferenças de comportamentos entre países, neste trabalho de doutorado, a versão de Özkan et al. (2006) foi utilizada para auxiliar na identificação de comportamentos de risco. Essa versão é composta por 20 itens, classificados em três fatores denominados como: violações comuns, violações agressivas e erros. Erros e violações mostraram-se bastante consistentes para prever acidentes de trânsito de forma prospectiva e retrospectiva, conforme justificado por Özkan et al. (2006) e confirmado por De Winter e Dodou (2010), corroborando o risco associado a esses comportamentos.

Além disso, conforme recomendado por Lajunen, Parker e Summala (2004), neste trabalho, os comportamentos de risco também são representados por itens elaborados para representação de situações condizentes com a realidade dos locais estudados.

\subsection{Questionários como ferramentas de investigação}

O uso de questionários na coleta de dados implica em vantagens e desvantagens. Em respeito aos estudos de comportamento dos condutores, comparado aos simuladores de direção e estudos naturalísticos, por exemplo, os questionários são de fácil aplicação, demandam menos recursos financeiros e físicos, e têm capacidade de obter dados de grandes amostras nas mesmas condições (LAJUNEN; ÖZKAN, 2011; STEVENS et al., 2018). Dessa forma, possibilitam estudos com participantes de diferentes locais e características distintas, promovendo uma análise diversificada. 
Assim como outras abordagens, o uso de questionário também implica em algumas desvantagens, como a possibilidade de respostas enviesadas, ou até mesmo a lacuna entre o que ocorre na realidade e o que é reportado, que podem comprometer a qualidade dos dados. Entretanto, algumas medidas podem ser adotadas para avaliação do instrumento e redução das incertezas, como a análise de validade do construto $^{5}$ e consistência interna (LAJUNEN; ÖZKAN, 2011; SHINAR, 2017; STEVENS et al., 2018).

Por meio da validade do construto é possível verificar se o instrumento avalia aquilo que era pretendido. Esta análise contempla a validade estrutural ou fatorial, comumente obtida a partir da análise fatorial confirmatória ou modelos de equações estruturais e análise fatorial exploratória (SOUZA; ALEXANDRE; GUIRARDELLO, 2017).

Em estudos que investigaram a validade do DBQ em diferentes populações, realizados principalmente em países da Europa e América do Norte, alguns autores utilizaram a Análise Fatorial Confirmatória (AFC), ou modelo de equações estruturais, para testar estruturas fatoriais com 2, 3 ou 4 fatores preliminarmente identificados (MATTSON et al., 2015; ÖZKAN et al., 2006; SÂRBESCU; STANOJEVIĆ; JOVANOVIĆ, 2014; STANOJEVIĆ et al., 2018; STEPHENS; FITZHARRS, 2016). Em busca de identificar o número de fatores aproximadamente correto ao invés do mais replicável, Mattsson et al. (2015) identificaram incoerências com os resultados da AFC e descreveram que novas abordagens metodológicas determinam estruturas fatoriais diferentes, ao menos para as versões de 27 e 28 itens do DBQ.

Outros estudos optaram por avaliar a estrutura fatorial entre diferentes países utilizando somente a análise fatorial exploratória e adotaram, como critérios para determinar o número de fatores, o valor próprio superior a um, gráfico de declividade (scree plot) e interpretação dos fatores. As amostras de cada país eram tratadas individualmente, ou em um único conjunto de dados (AL REESI et al., 2013, 2018; BENER; ÖZKAN; LAJUNEN, 2008; CORDAZZO et al. 2014; DE WINTER; DODOU, 2016; GUÉHO; GRANIÉ; ABRIC, 2014; LAJUNEN; PARKER; SUMMALA; 2004; MARTINUSSEN et al., 2013; ŞIMŞEKOĞLU et al., 2013; WARNER et al., 2011).

\footnotetext{
${ }^{5}$ Construto, ou variável latente, é o termo definido para representar uma variável que não pode ser mensurada ou observada diretamente, mas que pode ser aferida a partir do conjunto de outras variáveis (itens) (HILL, M.; HILL, A., 2008).
} 
Para validação dos instrumentos, aplicados nesta tese de doutorado, optou-se por utilizar a análise fatorial exploratória em um banco de dados único para os dois países estudados.

\subsubsection{Técnicas exploratórias para validação}

Para análises exploratórias, são utilizadas a análise fatorial com extração pelo eixo principal, denominada como Análise Fatorial, e a análise fatorial com extração pela Componente Principal, denominada de Análise de Componentes Principais. Ambas as técnicas retêm informações em um número de variáveis menor que o banco de dados original e resultam em soluções semelhantes (FIELD, 2009; MARÔCO, 2014).

Essas técnicas exploratórias são amplamente utilizadas nas ciências sociais e humanas, especialmente na psicologia (LINTING, 2007; MARÔCO, 2014), e também nos estudos de segurança viária para explorar e validar questionários com dados em escala Likert (CHU et al., 2019; MASLAĆ et al., 2018; MEHDIZADEH; SHARIATMOHAYMANY; NORDFJAERN, 2018; MOHAMADI HEZAVEH et al., 2018; STANOJEVIĆ et al., 2018; VAHEDI et al., 2018; ZHANG et al., 2018).

A Escala Likert é utilizada, nos questionários, para auxiliar na identificação de características que não são diretamente observáveis e podem ser obtidas a partir de variáveis latentes, como traços de personalidade e comportamentos. Por se tratar de um dado categórico ordinal, permite conhecer a ordem das categorias, mas não a distância entre elas (FIELD, 2009; LINTING, 2007). Portanto, medidas descritivas não devem ser utilizadas por se tratar de um dado não métrico (LINTING, 2007; MADSEN, 2016).

Visto que as técnicas de Análise Fatorial e Análise de Componentes Principais são baseadas em medidas métricas, este trabalho de doutorado propõe o uso da Análise de Componentes Principais Categórica (CATPCA) para análise exploratória e validação dos questionários de investigação dos comportamentos do condutor com questões em escala Likert.

Essa técnica é indicada para dados ordinais ou nominais (LINTING, 2007; LINTING; VAN DER KOOIJ, 2012; LINTING et al., 2007; MEULMAN; VAN DER KOOIJ; HEISER, 2004), entretanto, até este momento, não foi aplicada em estudos de comportamento de risco do condutor com uso de questionários, ainda que tenha sido aplicada em 
estudos recentes na área de planejamento de transportes (CHICA-OLMO; GACHSSÁNCHEZ; LIZARRAGA, 2018; CHUNG; SONG, 2018; MANZI; SAIBENE, 2018).

Além disso, ao se considerar os pesos das cargas fatoriais para análise da validade fatorial, observa-se que, em diferentes estudos, há a ocorrência de cargas cruzadas, ou seja, itens que pontuaram com valor alto e semelhante em mais de um fator. Nos estudos de Al Reesi et al. (2013) e Stanojević et al. (2018), os autores não excluíram os itens com cargas cruzadas. Para Al Reesi et al. (2013), as cargas cruzadas podem ser justificáveis considerando circunstâncias específicas. Em um estudo mais recente, entretanto, Al Reesi et al. (2018) descrevem a exclusão dos itens com cargas cruzadas seguida de uma nova análise fatorial exploratória. Mattsson et al. (2015) não excluíram itens com cargas cruzadas, justificando que podem existir inúmeras causas para qualquer tipo de comportamento no trânsito. Dessa forma, entende-se que a exclusão ou não do item dependerá do tipo de análise e objetivos pretendidos. Para determinação das variáveis latentes deste trabalho de doutorado, optou-se pela exclusão dos itens com cargas cruzadas para evitar ambiguidades ou dúvidas de interpretação.

Corroborando a validade estrutural, realizada com auxílio da técnica exploratória, o questionário deve apresentar consistência interna. Neste estudo a confiabilidade do construto foi avaliada por meio do coeficiente de Alfa de Cronbach. Esse índice é o mais utilizado e indica se todas as dimensões do questionário medem a mesma característica por meio da análise de covariância dos itens, de forma que medidas de consistência interna baixa indicam que as respostas são inconsistentes ou medem construtos diferentes (FIELD, 2009; HAIR et al., 2009; LAJUNEN; ÖZKAN, 2011; MARÔCO, 2014; SOUZA; ALEXANDRE; GUIRARDELLO, 2017).

\subsection{Influências do comportamento de risco do condutor}

Diferentes estudos foram realizados com auxílio do $D B Q$, ou outros questionários, a fim de se avaliar os fatores que influenciam os comportamentos de risco, a ocorrência dos acidentes de trânsito (AT) e a relação entre ambos, considerando apenas o uso de questionários como ferramenta de investigação.

Deffenbacher et al. (2001) avaliaram, por meio de análise de correlação, a relação entre o traço de personalidade raiva e comportamentos agressivos, comportamentos 
arriscados, intensidade da raiva no trânsito, e situações específicas de acidentes. No primeiro estudo ( $n=274)$, com dados auto relatados por meio de questionário, o traço de raiva foi relacionado com o comportamento agressivo e o comportamento de risco sendo associado ao uso menos frequente do cinto de segurança, beber e conduzir e condução imprudente. $O$ traço de raiva demonstrou tendência a ser relacionado com diferentes tipos de comportamentos de risco e esteve correlacionado à condição de quase acidentes, e acidentes devido à perda de concentração e perda de controle do veículo. No segundo estudo $(n=179)$, com dados relatados em um diário de trânsito de três dias, a frequência da intensidade de raiva e os comportamentos agressivos e de risco foram altamente correlacionados.

Iversen e Rundmo (2002) avaliaram a relação entre traços de personalidade do condutor, direção arriscada e o envolvimento em AT. O comportamento de risco foi avaliado por cinco itens com situações relacionadas ao limite de velocidade, ultrapassagem e ignorar leis de trânsito em uma amostra de 2.605 condutores. A Análise de Componentes Principais revelou um único fator denominado comportamento de risco e estruturas coerentes relacionados aos traços de personalidade estudados. As relações entre os fatores investigados foram avaliadas com modelo de equações estruturais. Os traços de personalidade explicaram $20 \%$ da variância dos acidentes e 39\% da variância do comportamento de risco, sendo busca de sensações o preditor mais forte. O comportamento de risco apresentou uma relação direta, forte e significativa com o envolvimento em acidentes de trânsito. Os resultados do estudo indicaram que os traços de personalidade influenciam a ocorrência do acidente, entretanto, o comportamento de risco apresentou a relação direta mais importante para o envolvimento no acidente.

Ulleberg e Rundmo (2003) procuraram compreender a importância de traços de personalidade e variáveis cognitivas sociais em relação à adoção de comportamento de risco de jovens condutores $(n=1.932)$. O comportamento de risco foi mensurado com auxílio de 15 itens que representavam três fatores denominados excesso de velocidade, violação de regras e autoafirmação (ações influenciadas pelo julgamento de outros condutores). A relação entre os traços de personalidade, atitudes, percepção de risco e o comportamento foram avaliados com uso do modelo de equações estruturais e o resultado sugeriu que escores individuais altos de busca de 
sensação, falta de norma e agressividade foram associados a atitudes e comportamentos de risco no trânsito.

Iversen e Rundmo (2004) avaliaram a relação entre atitudes, comportamentos de risco e o envolvimento em acidentes. O questionário continha 16 itens sobre atitudes de violação de regras e velocidade, falta de cuidado quanto à condução do outro, e beber e dirigir. O comportamento de risco foi mensurado por meio de 24 itens e a Análise de Componentes Principais revelou uma estrutura de sete componentes, denominadas: violação de regras de tráfego e velocidade, imprudência e diversão, não uso de cinto de segurança, condução cautelosa, beber e dirigir, atenção às crianças no trânsito e dirigir abaixo do limite de velocidade, indicando que adotar comportamentos de risco no trânsito é um aspecto multidimensional. Posteriormente, o modelo de equação estrutural foi utilizado para análise confirmatória e para explorar a relação entre atitudes, comportamentos e "envolvimento" e "quase envolvimento" em acidentes de trânsito. O comportamento de risco demonstrou um efeito direto capaz de explicar $21 \%$ da variância total dos "acidentes" ou "quase acidentes" reportados.

Para representar as distribuições das frequências dos comportamentos de risco, Iversen e Rundmo (2004) classificaram as respostas em escala Likert em três grupos, como "ideal" para as respostas 1 e 2, "não ideal" para as respostas 4 e 5 , e a resposta 3 foi considerada como uma categoria intermediária entre as duas primeiras, buscando associar um grau de risco à frequência reportada que, segundo os autores, pode ser justificada por situações específicas no trânsito.

Em outro estudo, Iversen (2004) investigou se as atitudes poderiam indicar um comportamento de condução de risco no futuro em uma amostra de 1.604 condutores. As mesmas dimensões, definidas em Iversen e Rundmo (2004), foram obtidas neste estudo para as atitudes e comportamentos de risco. O modelo de equação estrutural indicou que as três dimensões de atitude no trânsito explicaram $52 \%$ do comportamento de risco, sendo "violação de regras" e "excesso de velocidade" as variáveis latentes de atitudes mais fortes para explicar os comportamentos de risco.

Ainda no estudo de Iversen (2004), a relação entre os comportamentos de risco e os acidentes de trânsito foi avaliada com o teste não paramétrico Kruskal-Wallis. Os escores dos comportamentos foram avaliados se eram diferentes entre os grupos de condutores que reportaram terem se envolvido em acidentes de trânsito no último ano, os que não se envolveram em acidentes no último ano e os que nunca se envolveram 
em acidentes. Os resultados indicaram diferenças para cinco dos sete comportamentos: "violação de regras de tráfego" e "velocidade", "imprudência e diversão", "não uso de cinto de segurança", "beber e dirigir" e, "atenção às crianças no trânsito". O teste de Bonferroni revelou que as diferenças eram entre aqueles que nunca se envolveram em acidentes e os que se envolveram em acidentes no último ano, de forma que os condutores que estiveram envolvidos em acidentes de trânsito adotaram, mais frequentemente, comportamentos de risco.

Dahlen et al. (2005) investigaram a relação entre traços de personalidade e comportamentos agressivos (gritar com outro condutor, quebrar parte do veículo por raiva, entre outros), comportamentos de risco (não usar cinto de segurança, beber e conduzir, desrespeitar leis, imprudência, entre outros) e diferentes condições de acidentes de trânsito em uma amostra composta por 224 estudantes de diferentes nacionalidades da Universidade de Mississipi. Os autores não deixam claro no texto, entretanto, se os dados indicam que os escores das dimensões foram obtidos por meio da soma dos itens. Uma análise de regressão múltipla foi realizada para identificar o melhor conjunto de variáveis explicativas para os comportamentos e para diferentes condições de acidentes de trânsito. O comportamento de risco foi predito pela idade (relação positiva) e escalas de raiva, impulsividade e busca de sensações. A maioria das condições de acidentes de trânsito avaliadas foram preditas por diferentes traços de personalidade e pelo sexo do condutor.

No estudo de Özkan et al. (2006), a relação entre os comportamentos mensurados, com auxílio de 19 itens do DBQ para os seis países do estudo, e os acidentes de trânsito, foi avaliada com Análise de Regressão Binomial Negativa. Diferentes modelos foram calibrados, sendo o número de acidentes de trânsito a variável dependente, e as variáveis independentes eram os países, os comportamentos, e os dois juntos. No modelo de país, apenas os escores da Turquia não foram significantes. No modelo de comportamentos, erros, violações agressivas e violações ordinárias foram significativos com parâmetros positivos. Ao adicionar os países e um dos comportamentos, em todos os modelos os países foram significativos. As relações de idade foram positivas para o número de acidentes nas amostras relativas a Grécia e Irã, e negativas nas amostras associadas a Grã-Bretanha e Finlândia. Os autores concluíram que o tipo de relação entre os comportamentos e o número de acidentes muda para cada país. 
Rhodes e Pivik (2011) desenvolveram um estudo nos Estados Unidos com 504 participantes para avaliar as diferenças do comportamento de risco segundo a idade e sexo do condutor. $O$ resultado da regressão linear múltipla indicou que $O$ comportamento no trânsito de motoristas jovens e do sexo masculino é influenciado pelo prazer que sentem em dirigir.

Antonopoulos et al. (2011) investigaram o impacto da tomada de risco no envolvimento em acidentes de trânsito. A amostra foi composta por 978 estudantes universitários da Grécia e Itália. Os comportamentos de risco avaliados, relacionados ao trânsito, foram: não usar cinto de segurança, não usar capacete, usar o celular, beber e dirigir, gostar de exceder a velocidade, beber muito e fumar. As variáveis receberam valor 0 para não e 1 para sim. Estudantes, que não se expunham a algum risco, foram classificados como seguros (categoria 0 ). Um escore geral de comportamento também foi obtido por meio de soma, sendo 0 o mais seguro e 8 o mais arriscado. Os dados foram analisados com regressão logística múltipla. Entre os resultados, foram observados que beber e dirigir, pegar carona com alguém bêbado e fumar aumenta significativamente o risco, e que o aumento de um ponto no comportamento de risco aumenta em $35 \%$ o risco de envolvimento em acidentes de trânsito. O comportamento de risco foi considerado um importante preditor do envolvimento em acidentes de trânsito.

Yang et al. (2013) investigaram o poder de previsão de traços de personalidade em relação ao comportamento de risco, aferidos pelo DBQ. O total de 224 motoristas chineses responderam ao questionário que investigava raiva, busca de sensações, gentileza e falta de regras. A partir da análise de regressão de mínimos quadrados ordinários, todos os traços de personalidade foram significativos para violações agressivas e violações comuns, quando tratados individualmente. Em conjunto, todos os traços de personalidade predisseram violações agressivas.

Scott-Parker et al. (2013) analisaram a relação entre sexo do condutor, ansiedade, depressão, sensibilidade de recompensa, busca de sensações e comportamento de risco, entre 390 condutores jovens. O modelo de equação estrutural revelou ansiedade, sensibilidade de recompensa e busca de sensações como variáveis propensas a prever a condução de risco.

Cordazzo et al. (2014) avaliaram os fatores que influenciam o comportamento de risco e a relação com acidentes de trânsito, com itens de diferentes versões do DBQ, além 
de outros adaptados ou elaborados para o estudo. A amostra foi composta por 2.839 condutores de uma associação de automóveis e 456 universitários. A análise de regressão dos escores de erros e violações de Reason et al. (1990) revelou uma relação de sexo e distância percorrida com os comportamentos. O modelo de regressão logística indicou os escores de erros e violações de Reason et al. (1990) positivamente relacionados com o envolvimento em acidentes de trânsito.

No Brasil, Romão (2015) desenvolveu um estudo em que um dos objetivos era identificar fatores comportamentais para auxiliar a elaboração e implementação de campanhas de segurança viária. O comportamento foi mensurado pelo DBQ e a análise contou com a aplicação de Análise de Componentes Principais e Regressão Linear Múltipla em uma amostra de 598 condutores. Como resultados, foram identificados como fatores de risco: baixo nível de aptidão, infração, distração/falta de atenção, condução agressiva, baixa consciência da situação, estresse e adaptação comportamental.

Cordazzo, Scialfa e Ross (2016) avaliaram a relação de multas e acidentes de trânsito e o comportamento de risco avaliado por meio de 65 itens e quatro fatores denominados i) erros por falta de atenção, ii) problemas relacionados a idade, iii) distração e pressa e iv) violações agressivas. Por meio da análise de Regressão Linear verificou-se a relação da "idade" dos condutores com todos os comportamentos, o "sexo" dos condutores com os fatores ii, iii e iv, e a distância percorrida com os fatores iii e iv. Os escores dos fatores i, iii e iv foram significativos em diferentes modelos para prever o envolvimento em acidentes de trânsito.

Um estudo realizado por Komba (2016), na Tanzânia, levou em consideração a percepção de risco, atitude de risco, disposição de risco e comportamento de risco por área geográfica (urbana, semiurbana e rural). O estudo foi realizado com a aplicação de questionários e os resultados indicaram um efeito significativo entre as áreas geográficas e as demais variáveis estudadas, em que 36,8\% do comportamento de risco foi explicado por atitudes, crenças religiosas, disposição ao risco e as áreas geográficas.

Um estudo realizado com 511 motoristas chineses buscou explorar os traços de personalidade e experiência de condução como preditivos de comportamento de risco mensurados com auxílio do DBQ. O resultado do modelo de equações estruturais indicou que os traços de personalidade têm efeito direto no comportamento de risco, 
e juntamente com experiência de condução, predizem o risco de envolvimento em acidentes de trânsito. Os números de acidentes de trânsito relatados foram significativamente relacionados ao número de multas reportadas. Os autores coletaram a informação sobre o tipo de área que os condutores mais comumente conduzem (92\% em áreas urbanas), entretanto, não avaliaram diferenças relacionadas ao ambiente (TAO; ZANG; QU, 2017).

Mekkonnen et al. (2019) avaliaram os fatores associados com os comportamentos de risco e acidentes de trânsito de condutores profissionais na Etiópia $(n=376)$. Os condutores que responderam adotar os comportamentos de risco com alguma frequência foram classificados como 1, e os condutores que reportaram nunca adotar o comportamento de risco foram classificados como zero. Os resultados da Regressão Logística Binária revelaram que idade, salário, experiência de condução, horas dirigidas semanalmente, distância percorrida anualmente e envolvimento em acidentes de trânsito, no passado, são fatores significativos para explicar comportamentos de risco, contemplando excesso de velocidade, sonolência, conduzir sob efeito de álcool e violações do código de trânsito.

Os diferentes trabalhos, aqui apresentados, buscaram verificar fatores que influenciam o comportamento de risco e suas relações com os acidentes de trânsito por meio de diferentes abordagens, como análise de correlação (CHU et al., 2019; DEFFENBACHER et al., 2001), testes estatísticos (IVERSEN, 2004), modelos de equações estruturais (CHU et al., 2019; IVERSEN, 2004; IVERSEN; RUNDMO, 2002, 2004; SCOTT-PARKER et al. 2013; TAO; ZANG; QU, 2017; ULLEBERG; RUNDMO 2003) e, análises de regressão (ANTONOPOULOS et al., 2011; DAHLEN et al., 2005; MEKKONNEN et al., 2019; ÖZKAN et al., 2006; RHODES; PIVIK; 2011; ROMÃO, 2015; YANG et al., 2013).

Para as análises, verifica-se a representação do comportamento de risco mais comumente por meio dos escores fatoriais. De acordo com Dorn e AF Wahlberf (2019), que recentemente propuseram uma classificação dos condutores de acordo com a culpa pelo acidente, a distinção dos condutores possibilita aumentar o efeito das diferenças individuais nas pesquisas de segurança viária.

Nota-se que Antonopoulos et al. (2011) e, mais recentemente, Mekkonnen et al. (2019) buscaram classificar os condutores, qualificando-os como seguros aqueles que nunca adotam o comportamento de risco no trânsito. Entretanto, considerando que os 
condutores estão sujeitos a adotarem comportamentos de risco, seja pela falta de consciência de seus atos (JONAH, 1986), pelas próprias condições do trânsito (IVERSEN, RUNDMO, 2004) ou pela sua própria natureza (WILDE, 2013), classificar os comportamentos de risco, de acordo com a frequência que são adotados, além do envolvimento em acidentes de trânsito, torna-se uma contribuição substancial.

Dessa forma, este trabalho de doutorado propõe avaliar os fatores que influenciam o comportamento de risco por meio de um método sequencial com técnicas de análise multivariada de dados. Especificamente, propõe-se identificar comportamentos de risco com Análise de Componentes Principais Categórica e classificá-los, posteriormente, de acordo com a frequência de envolvimento em acidentes de trânsito reportado, além de variáveis latentes obtidas preliminarmente. A técnica utilizada nesta etapa foi a Árvore de Decisão, para identificação dos condutores com maior e menor envolvimento em acidentes de trânsito, em relação à frequência que adotam o comportamento de risco.

\subsection{Fatores de influência do comportamento do condutor}

As relações entre diferentes fatores de influência e o comportamento do condutor, identificadas em estudos anteriores, são apresentadas nas seções seguintes.

2.4.1 Características socioeconômicas, experiência de condução e traços de personalidade como fatores de influência

Como resultado dos estudos que investigam o fator humano, especificamente o comportamento de risco do condutor, é verificado que o mesmo pode estar relacionado à idade, sexo, experiência, atitudes, traços de personalidade, e fatores transitórios como fadiga, sonolência, falta de atenção enquanto dirige, humor, condições de saúde, consumo de álcool e drogas (DELHOMME et al., 2009; FERRAZ et al., 2012; WHO, 2015).

Ao se considerar as características socioeconômicas e o comportamento de risco no trânsito, alguns resultados indicaram que condutores do sexo masculino reportam uma frequência mais elevada de comportamento de risco (OLTEDAL; RUNDMO, 2006; RHODES; PIVIK, 2011), como maior intenção em exceder a velocidade 
(CESTAC; PARAN; DELHOMME, 2011; DELHOMME; CHAURAND; PARAN, 2012), maior propensão em violar regras e obtenção de um maior número de multas (CONSTANTINOU et al., 2011; GONZÁLEZ-IGLESIAS; GÓMEZ-FRAGUELA; LUENGO-MARTÍN, 2012; LONCZAK; NEIGHBORS; DONOVAN, 2007; POÇAS CORREIA; CUNHA HORTA, 2014). Também foi verificada uma relação positiva entre o comportamento de risco de condutores jovens do sexo masculino e o prazer que sentem em dirigir (RHODES; PIVIK, 2011).

Além do sexo, a idade, experiência de condução e exposição do motorista também têm sido relacionadas ao comportamento de risco. A experiência pode tornar o motorista mais hábil. No entanto, também pode levar à prática de mais violações (DELHOMME et al., 2009). No estudo de Constantinou et al. (2011), condutores jovens reportaram comportamentos mais perigosos. Cestac, Paran e Delhomme (2011) e Delhomme, Chaurand e Paran (2012) identificaram que condutores mais experientes tinham mais intenção em exceder a velocidade e no estudo de Tao, Zhang e Qu (2017), a experiência do condutor explicou 15\% da variância do risco de acidente.

Rhodes e Pivik (2011) encontraram uma relação negativa significativa entre o risco percebido pelo condutor e o comportamento de risco no trânsito, ou seja, condutores que se arriscam mais no trânsito apresentaram uma menor percepção do risco associado a determinados comportamentos. Constantinou et al. (2011) confirmaram esse resultado e identificaram ser mais predominante entre homens com maior propensão à busca de sensações e menor sensibilidade para punição.

Beber por compulsão ou usar drogas foram associados ao aumento de comportamento de risco dos motoristas (WICKENS et al., 2012). Romão (2015) identificou sono, bebidas, drogas e uso do celular para enviar mensagens de texto como comportamentos de risco dos usuários do sistema de trânsito.

Iversen e Rundmo (2002) confirmaram que alguns traços de personalidade poderiam ser usados como variáveis preditoras de uma tendência a dirigir de forma mais arriscada. Em relação às características cognitivas e afetivas estudadas, pode-se citar: raiva e agressividade, busca de sensações, depressão, ansiedade, impulsividade, entre outros (SCHWEBEL et al., 2006; SCOTT-PARKER et al., 2013; WICKENS et al., 2012; YANG et al., 2013; ZHANG; CHAN; ZHANG, 2015). 
Os traços de personalidade, considerados neste trabalho de doutorado, são raiva e busca de sensações. Ambos apresentam um aumento no comportamento de risco dos motoristas, de forma que aqueles que apresentam altas pontuações em busca de sensações e raiva são expostos a um elevado comportamento de risco (SCHWEBEL et al., 2006; YANG et al., 2013). Ambos também demostraram maior poder de previsão de comportamento de risco (DAHLEN et al., 2005).

Existem alguns instrumentos, já validados, que permitem investigar esses traços de personalidade. A Escala de Raiva do Motorista (do inglês Driver Anger Scale-DAS), foi desenvolvida por Deffenbacher, Oetting e Lynch (1994) para avaliar a propensão dos motoristas tornarem-se irritados ou agressivos no trânsito e tem sido amplamente utilizado (DEFFENBACHER; STEPHENS; SULLMAN, 2016). Existem duas versões do questionário DAS. A primeira com 14 itens, curta, e a segunda, com 33 itens divididos em seis subescalas: descortesia, condução ilegal, gestos hostis, condução lenta, obstrução do tráfego e presença da polícia (DEFFENBACHER; OETTING; LYNCH, 1994).

Iversen e Rundmo (2002) usaram a versão curta do DAS e encontraram 3 componentes a partir da ACP que chamaram de: descortesia, presença policial e obstrução de tráfego e gestos hostis. Essa variável se mostrou preditora do comportamento de risco medido, de forma que os motoristas que relataram sentir mais raiva se envolveram mais em comportamento de risco e AT.

Nos estudos, desenvolvidos por Berdoulat, Vavassori e Sastre (2013) e Zhang, Chan e Zhang (2015), os fatores relacionados à raiva, investigados com o DAS, predisseram as violações, lapsos e erros mensurados pelo $D B Q$, de forma que estavam positivamente correlacionados. Assim, quanto maior a pontuação para raiva, as pessoas relataram ter cometido atos inseguros com mais frequência. Wickens et al. (2012) identificaram que a condução mais agressiva estava relacionada a pessoas de maior renda e maior escolaridade. Motoristas mais jovens reportaram mais raiva no estudo de Lonkzak, Neighbors e Donovan (2007). Delhomme, Chaurand e Paran (2012) não conseguiram encontrar diferenças entre os gêneros em relação aos níveis de raiva.

Em um estudo recente e com uma ampla revisão dos trabalhos utilizando o DAS, o mesmo foi considerado um construto consistente que indica que motoristas com alto 
nível de raiva se envolvem em mais comportamentos de risco quando dirigem (DEFFENBACHER; STEPHENS; SULLMAN, 2016).

O outro traço de personalidade, tratado neste trabalho, é a busca de sensações, que foi definida por como "uma característica caracterizada pela busca de sensações e experiências variadas, novas, complexas e intensas, e a vontade de assumir riscos físicos, sociais, legais e financeiros por causa dessa experiência" (ZUCKERMAN", 1994 apud DELHOMME et al., 2009, p. 41, tradução nossa). Taubman, Mikulincer e

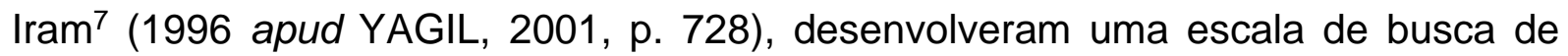
sensações, composta por 7 itens. Mesmo não sendo a escala mais popular para medir esse construto, ela tem vantagens por ser composta por itens pertinentes ao trânsito e não ser longa.

Alguns dos resultados dos estudos que incluíram busca de sensações indicam que: índices elevados de busca de sensações estavam associados a atitudes e comportamento de risco (ULLEBERG; RUNDMO, 2003) e maior envolvimento em comportamentos de risco como excesso de velocidade e violações (IVERSEN, RUNDMO, 2002); o gênero diferencia o traço de busca de sensações e sua associação aos comportamentos de risco durante a condução (DELHOMME; CHAURAND; PARAN, 2012; POÇAS CORREIA; CUNHA HORTA, 2014); e é mais significativo para homens (RUDIN-BROWN; EDQUIST; LENNÉ, 2014). As violações também foram previstas por busca de sensações em uma amostra composta por motoristas mais velhos (LUCIDI et al., 2014).

Neste trabalho de doutorado, além de dados para caracterização socioeconômica e experiência de condução, são utilizados os instrumentos validados para investigação dos traços de personalidade de Escala de Raiva do Motorista (Driver Anger Scale DAS) e Busca de Sensações, que demonstraram forte relação com os comportamentos de risco.

\footnotetext{
6 ZUCKERMAN, M. Behavioural expressions and biosocial bases of sensation seeking. 1994. New York: Cambridge University Press.

7 TAUBMAN, O.; MIKULINCER, M.; HAM, A. The cognitive, motivational and emotional system of driving. Research report, Department of Casualties and Road Safety of the Israeli Army, Israel, 1996.
} 
2.4.2 Características do ambiente viário e agregadas do local de residência como fatores de influência

A relação entre a configuração do ambiente rodoviário e a ocorrência dos acidentes de trânsito é extensamente explorada e confirmada na literatura (ELVIK et al, 2009; PEDEN et al., 2004; WHO, 2018). Alguns trabalhos indicam que o ambiente em que se conduz ou vive também pode influenciar o modo de conduzir e o comportamento do condutor (KOMBA, 2016; RUDIN-BROWN; EDQUIST; LENNÉ, 2014; WICKENS et al., 2012).

A exposição a estradas movimentadas e experiências estressantes na direção foram positivamente relacionados ao comportamento agressivo auto relatado dos condutores (WICKENS et al., 2012), que por sua vez tem se mostrado relacionado ao comportamento de risco e envolvimento em acidentes de trânsito.

Komba (2016) identificou que percepção, atitudes e disposição ao risco, bem como o comportamento de risco, de modo geral, se diferenciavam entre os condutores de áreas rurais e os de áreas urbanas e semiurbanas.

No estudo desenvolvido por Romão (2015), os condutores apontaram más condições da infraestrutura da via, más condições de sinalização, más condições dos veículos que trafegam pelas vias e interação, principalmente com pedestres, como fatores de risco associados à via.

Considerando estudos com abordagens que vão além do uso do questionários e dados auto relatados, Rudin-Brown, Edquist e Lenné (2014) desenvolveram um estudo utilizando questionários e simulador de direção com 29 participantes universitários da Austrália. O estudo buscou avaliar a contribuição da experiência de condução e busca de sensações no desempenho na direção em ambientes rodoviários mais complexos. Para isso, três cenários foram simulados: a) rua sem vagas para estacionamento e com prédios afastados, b) rua com comércios sem áreas para estacionamento, onde as lojas ficam bem próximas, e c) rua com comércios e com áreas para estacionamento. Os resultados apontaram que, conforme a complexidade do meio rodoviário aumentava, os motoristas diminuíam a velocidade de forma gradual, se mantinham mais no centro da pista e desviavam menos, acompanhado do aumento da carga de trabalho mental. 
Em uma análise agregada, Üzümcüoğlu, Özkan e Lajunen (2018) avaliaram a relação entre variáveis culturais, aplicação de leis de trânsito e comportamentos de risco (violações relacionadas a excesso de velocidade e violações não relacionadas a excesso de velocidade) entre 37 países. A análise de regressão hierárquica identificou uma relação significativa e negativa entre o PIB per capita e os comportamentos de violações não relacionadas à excesso de velocidade. Entre os países com mais orientações a longo prazo, há menos violações não relacionadas à velocidade e, consequentemente, menores taxas de acidentes.

De acordo com Üzümcüoğlu, Özkan e Lajunen (2018), embora haja inúmeros trabalhos acerca das diferenças regionais dos comportamentos do condutor e as taxas de mortalidade no trânsito, os estudos com foco nas possíveis causas subjacentes para essas diferenças são limitados.

Iversen e Rundmo (2002, p. 1261, tradução nossa) também destacaram a importância em se considerar outras variáveis no estudo do comportamento de risco do motorista.

Os aspectos situacionais e os fatores ambientais também são de grande interesse ao relacionar comportamentos de risco e características de personalidade. Esses fatores são mais transitórios e temporários e podem representar os estímulos para desencadear reações que resultam de fatores mais temperamentais ou de personalidade.

A partir dos dados apresentados, nota-se que o comportamento do condutor também pode ser afetado pelo ambiente viário em que está inserido. Entretanto, ao se avaliar os estudos realizados com questionários, estes são direcionados a análises das influências de fatores relacionados ao próprio condutor para explicar a adoção dos comportamentos de risco. Dessa forma, esta tese de doutorado propõe avaliar os fatores que influenciam o comportamento do condutor, contemplando em sua análise a representação do ambiente viário de acordo com a percepção do condutor, e do local onde o condutor vive, para identificação dos fatores externos que influenciam os comportamentos de risco do condutor.

\subsection{Considerações do Capítulo 2}

A partir do material apresentado, foi possível identificar variáveis que comumente explicam o comportamento de risco do condutor e as abordagens metodológicas 
utilizadas nos estudos com questionários, que contribuíram para fundamentar e planejar o desenvolvimento desta tese de doutorado. Resumindo, nota-se que:

- Entre os comportamentos de risco considerados nos diferentes estudos, podese citar como mais frequentes, além de erros, lapsos e violações, os comportamentos de excesso de velocidade, não uso do cinto de segurança, conduzir sob efeito de álcool ou usar drogas, conduzir com cansaço, sonolência ou fadiga, ignorar leis de trânsito, violar regras e ações imprudentes.

- Os comportamentos são comumente mensurados por meio de questionários em que o condutor reporta a frequência de situações no trânsito no passado, por meio de escala Likert. O baixo custo e a facilidade de aplicação desse instrumento permitem contemplar condutores de diferentes localizações para análises comparativas. Entretanto, por tratar-se de um dado auto relato, acarretam na necessidade de validação estrutural dos dados e análise da consistência interna. A validação estrutural dos dados reportados neste trabalho de doutorado é realizada com auxílio da Análise de Componentes Principais Categórica que atende aos pressupostos dos dados ordinais, como a escala Likert, transformando-os em um dado métrico, sendo esta uma das lacunas trabalhadas (Lacuna I).

- Diferentes abordagens confirmaram a relação entre os comportamentos de risco e a ocorrência dos acidentes de trânsito, corroborando o risco associado a eles. Entretanto, visto que os condutores estão sujeitos a adotar os comportamentos de risco de forma esporádica, classificar os condutores de acordo com a frequência que adotam os comportamentos de risco e o histórico de envolvimento em acidentes de trânsito permite a avaliação de fatores que estão relacionados à adoção, mais frequente, dos comportamentos de risco e o envolvimento, mais frequente, em acidentes de trânsito. Dessa forma, esse trabalho de doutorado propõe classificar os comportamentos e, assim, distinguir os condutores de acordo com a frequência do comportamento de risco e a frequência de envolvimento em acidentes, possibilitando a identificação dos fatores que contribuem para adoção, mais frequente, dos comportamentos de risco por parte dos condutores, sendo esta outra lacuna explorada (Lacuna II). 
- Os estudos utilizando apenas aplicação de questionários, realizados a título de compreensão dos fatores mais significativos para que o condutor se arrisque no trânsito, exploraram e confirmaram a relação entre características socioeconômicas, experiência de condução e traços de personalidade como variáveis explicativas do comportamento de risco. Entretanto, o uso de dados agregados do local onde conduzem com mais frequência, ou ainda outras variáveis que caracterizem o ambiente viário, não são exploradas nos estudos de comportamento individual, sendo esta uma das principais lacunas a serem investigadas neste trabalho de doutorado, por meio da inclusão de variáveis agregadas do local e da caracterização do ambiente viário (Lacuna III).

O Quadro 2.1 sintetiza alguns estudos apresentados neste capítulo relacionados aos temas abordados nesta pesquisa.

Quadro 2.1 - Síntese de temas e trabalhos abordados neste estudo

\begin{tabular}{|c|c|c|c|c|}
\hline Tema & Trabalhos & Problemas & Soluções propostas & $\begin{array}{l}\text { Justificativa da } \\
\text { solução }\end{array}$ \\
\hline $\begin{array}{c}\text { Questionários e } \\
\text { comportamento } \\
\text { de risco }\end{array}$ & $\begin{array}{l}\text { Lajunen, Parker e Summala (2004); } \\
\text { Warner et al. (2011); Martinussen et } \\
\text { al. (2013); Al Reesi et al. (2013); } \\
\text { Simsekoglu et al. (2013); Cordazzo } \\
\text { et al. (2014); Guého, Granié e Abric } \\
\text { (2014); De Winter e Dodou (2016); } \\
\text { Al Reesi et al. (2018) }\end{array}$ & $\begin{array}{l}\text { Uso de técnicas } \\
\text { inadequadas para } \\
\text { validação de questionário } \\
\text { com dados em escala } \\
\text { Likert (dado ordinal) }\end{array}$ & $\begin{array}{c}\text { Lacuna I } \\
\text { Aplicação de uma } \\
\text { técnica associada a } \\
\text { dados qualitativos para } \\
\text { identificação de variáveis } \\
\text { latentes e validação de } \\
\text { questionários } \\
\text { relacionados à } \\
\text { investigação do } \\
\text { comportamento do } \\
\text { condutor }\end{array}$ & $\begin{array}{l}\text { Meulman, Van } \\
\text { Der Kooij e } \\
\text { Heiser (2004); } \\
\text { Linting et al. } \\
\text { (2007); Linting e } \\
\text { Van Der Kooij } \\
\text { (2012) }\end{array}$ \\
\hline \multirow{3}{*}{$\begin{array}{l}\text { Análise de } \\
\text { Influências do } \\
\text { comportamento } \\
\text { de risco do } \\
\text { condutor com } \\
\text { questionários }\end{array}$} & $\begin{array}{l}\text { Ulleberg e Rundmo (2003); Dahlen } \\
\text { et al. (2005); Özkan et al. (2006); } \\
\text { Scott-Parker et al. (2013); Tao, } \\
\text { Zhang e Qu (2017); CHU et al. } \\
\text { (2019) }\end{array}$ & $\begin{array}{l}\text { Análise da relação entre o } \\
\text { comportamento de risco e } \\
\text { acidentes de trânsito sem } \\
\text { distinção da frequência } \\
\text { dos comportamentos }\end{array}$ & \multirow{2}{*}{$\begin{array}{c}\text { Lacuna II } \\
\text { Classificação de } \\
\text { comportamentos de risco } \\
\text { a partir de variáveis } \\
\text { latentes e envolvimento } \\
\text { em acidentes de trânsito } \\
\text { no passado usando } \\
\text { algoritmo de } \\
\text { classificação }\end{array}$} & \multirow{2}{*}{$\begin{array}{c}\text { Dorn e AF } \\
\text { Wahlberf (2019) }\end{array}$} \\
\hline & $\begin{array}{l}\text { Antonopoulos et al. (2011); } \\
\text { Mekkonner et al. (2019) }\end{array}$ & $\begin{array}{l}\text { Análise da relação entre o } \\
\text { comportamento de risco e } \\
\text { acidentes de trânsito com } \\
\text { distinção dos condutores } \\
\text { atribuídas pelos autores }\end{array}$ & & \\
\hline & $\begin{array}{l}\text { Schwebel et al. (2006); Lonkzak } \\
\text { Neighbors e Donovan (2007); } \\
\text { Constantinou et al. (2011); Cestac, } \\
\text { Paran e Delhomme (2011); Rhodes } \\
\text { e Pivik (2011); Delhomme, Charan e } \\
\text { Paran (2012); González-Iglesias, } \\
\text { Gómez-Fraguela; Luengo-Martín } \\
\text { (2012); Wickens et al. (2012); Scott- } \\
\text { Parker et al. (2013); Yang et al. } \\
\text { (2013); Poças Correia e Cunha } \\
\text { Horta (2014); Zhang, Chan e Zhang } \\
\text { (2015) }\end{array}$ & $\begin{array}{l}\text { Foco em análise de } \\
\text { relações do } \\
\text { comportamento do } \\
\text { condutor e variáveis } \\
\text { socioeconômicas, traços } \\
\text { de personalidade e } \\
\text { experiência de condução }\end{array}$ & $\begin{array}{c}\text { Lacuna III } \\
\text { Inclusão de variáveis de } \\
\text { caracterização do } \\
\text { ambiente viário e local } \\
\text { de residência para } \\
\text { análise das relações com } \\
\text { comportamento de risco } \\
\text { do condutor em } \\
\text { investigações com } \\
\text { questionário e } \\
\text { comparação entre países } \\
\text { e regiões }\end{array}$ & $\begin{array}{l}\text { Elvik et al. } \\
\text { (2009); Peden et } \\
\text { al. (2004) WHO } \\
\text { (2018); } \\
\text { Wickens et al. } \\
\text { (2012); Rudin- } \\
\text { Brown, Edquist e } \\
\text { Lenné (2014); } \\
\text { Komba (2016); } \\
\text { Üzümcüoğlu et } \\
\text { al. (2018) }\end{array}$ \\
\hline
\end{tabular}


Assim, este trabalho visa identificar fatores externos e internos que influenciam o condutor a, mais frequentemente, adotar um comportamento de risco e traz sua contribuição, à medida que propõe um método sequencial com técnicas de análise multivariada de dados para classificar os comportamentos de risco e avaliar os fatores de influência de condutores de Brasil e Portugal, incluindo dados agregados do local e a caracterização do ambiente viário, conforme apresentado nos capítulos seguintes. 



\section{MATERIAIS E MÉTODO}

Neste capítulo são apresentadas as regiões de estudo, o banco de dados, as técnicas estatísticas utilizadas e as etapas metodológicas referentes ao desenvolvimento da pesquisa.

\subsection{Síntese das etapas metodológicas}

Para atingir os objetivos desse trabalho, foi necessário elaborar um questionário e coletar dados dos condutores de Brasil e Portugal. O banco de dados é composto por dados provenientes dessa coleta, acrescido de dados obtidos em bases de dados públicas. A análise dos dados contemplou a aplicação de Análise de Componentes Principais Categórica (CATPCA) para definição das variáveis latentes de atributos psicológicos, caracterização do ambiente viário e comportamento do condutor.

Para investigação dos fatores que influenciam o comportamento de risco do condutor, foram calibrados diferentes modelos Logit Binomiais. As variáveis latentes referentes ao comportamento foram classificadas em níveis de risco, com aplicação do algoritmo Classification And Regression Tree (CART), constituindo as variáveis dependentes do modelo. As variáveis independentes correspondem aos dados socioeconômicos, experiência de condução, traços de personalidade e percepção de risco dos condutores, bem como a caracterização do ambiente segundo o condutor e variáveis agregadas, que foram tratadas de acordo com os propósitos do modelo e da análise.

Esta pesquisa foi aprovada pelo Comitê de Ética da Faculdade de Zootecnia e Engenharia de Alimentos (FZEA-USP), de acordo com os requisitos da Resolução CNS 466/12, conforme parecer número 2.393.454.

\subsection{Regiões de estudo}

Este estudo foi realizado baseado em dados auto relatados de condutores do Brasil e de Portugal, bem como dos locais em que vivem. Os dois países são historicamente relacionados devido à colonização do Brasil por Portugal. Atualmente, ambos mantêm uma relação diplomática e apresentam diferentes acordos de cooperação e investimento em áreas relacionadas ao comércio, educação, ciência e tecnologia (MINISTÉRIO DAS RELAÇÕES EXTERIORES, 2019). Entretanto, são distintos no 
que diz respeito à dimensão territorial, contexto socioeconômico e acidentalidade viária.

Apesar de ambos terem leis de trânsito nacionais sobre fatores de risco, como excesso de velocidade, dirigir sob o efeito do álcool e o uso de cinto de segurança e telefones celulares, os índices de vítimas do trânsito são muito diferentes, tendo o Brasil uma taxa de 19,7 e Portugal 7,4 mortes por 100.000 habitantes (WHO, 2018).

A relação de proximidade entre os países e a diferença no cenário da segurança viária motivaram a escolha de ambos para o presente estudo. Uma breve caracterização dos dois países é apresentada na sequência. Vale ressaltar que este trabalho de doutorado contempla também período de estágio no exterior na Universidade do Minho (Guimarães, Portugal) e na Faculdade de Engenharia da Universidade do Porto (Porto, Portugal).

\subsubsection{Brasil}

O Brasil é o quinto maior país do mundo em dimensão territorial, com uma área superior a 8 milhões de $\mathrm{km}^{2}$ distribuída entre 5.565 municípios e 27 unidades federativas. Tem uma população com mais de 208 milhões de habitantes, PIB per capita de 7.660 dólares e frota veicular superior a 99 milhões de veículos (DEPARTAMENTO NACIONAL DE TRÂNSITO - DENATRAN, 2017; INSTITUTO BRASILEIRO DE GEOGRAFIA E ESTATÍSTICA - IBGE, 2019).

Em relação ao cenário da acidentalidade viária, o número de mortes segue em crescimento no país desde os anos 2000, após um breve efeito positivo de redução, devido à implementação do novo Código de Trânsito Brasileiro em 1998 (WAISELFISZ, 2013). Entre 2004 e 2014, o número de acidentes ocorridos em rodovias brasileiras e mortes no local aumentou em $50,3 \%$ e $34,5 \%$, respectivamente. Somente em 2014, os custos dos acidentes ocorridos nas rodovias, que equivale a $20 \%$ do total das mortes devido ao acidente, foi de $\mathrm{R} \$ 12,3$ bilhões (INSTITUTO DE PESQUISA ECONÔMICA E APLICADA - IPEA, 2015).

Considerando a categoria de usuários, a situação mais crítica está relacionada a motociclistas, cujo número de mortes aumentou em mais de 930\% de 1996 para 2011 (WAISELFZ, 2013), o que também pode ser reflexo da mudança na distribuição da frota. Em 2000, a frota de motocicletas representava $11,9 \%$ da frota nacional e os 
carros 67,2\%. Em 2014, ambas as frotas aumentaram 442,03\% e 140,06\%, respectivamente, aumentando a participação de motocicletas $(22,2 \%)$ e reduzindo a de carros $(55,3 \%)$ (DENATRAN, 2016).

No que diz respeito à infraestrutura, o Brasil tem mais de $1.720 .700 \mathrm{~km}$ de rodovias, mas somente 12,4\% são pavimentadas, $6.932 \mathrm{~km}$ duplicadas (10,6\%) e $1.163 \mathrm{~km}$ (1,8\%) em duplicação. Em 108.863 km avaliados, 52,4\% apresentaram deficiências no pavimento, 48,1\% na sinalização e 76,3\% na geometria (CONFEDERAÇÃO NACIONAL DO TRANSPORTE - CNT, 2019). Em 2019, a qualidade das rodovias brasileiras foi classificada como 3,0 em uma escala entre 1 e 7 pontos, conferindo a posição de 116 no ranking global (SCHWAB, 2019).

Algumas ações para reduzir as fatalidades e promover um trânsito mais seguro acontecem vagarosamente. Em 2008, por exemplo, foi criada a Lei 11.705/08 que estabelece alcoolemia zero e dispõe sobre penalidades para condutores que dirigirem sob a influência do álcool (BRASIL, 2008). O uso de álcool é um fator de risco que contribui para ocorrência e gravidade dos acidentes de trânsito (WHO, 2018).

\subsubsection{Portugal}

Comparado ao Brasil, Portugal é menor em extensão territorial e população. O país tem uma área geográfica de 92.225 km², com 308 municípios, 10.269 .622 habitantes e uma frota veicular de 7,3 milhões de veículos. Contudo, seu PIB per capita equivale a USD 20.187 (AUTORIDADE DE SUPERVISÃO DE SEGUROS E FUNDOS DE PENSÕES - ASF, 2017; INSTITUTO NACIONAL DE ESTATÍSTICA - INE, 2019; PORDATA, 2019).

No ano de 2016, foram registradas 445 mortes e cerca de 41.000 feridos no país em consequência dos mais de 32.200 acidentes de trânsito ocorridos. Com relação à natureza dos acidentes de trânsito, a maior ocorrência é devido à colisão, seguido de saída de pista e atropelamento. O maior número de vítimas fatais ocorre em AT de saída de pista, cuja gravidade pode estar associada ao excesso de velocidade, característico desse tipo de acidente (AUTORIDADE NACIONAL DE SEGURANÇA RODOVIÁRIA - ANSR, 2017).

Entre 1997 e 2008, Portugal registrou uma queda de 147\% no número de mortes no trânsito, variação muito superior a outros países europeus, como França, Itália e 
Grécia. Em 2008, conseguiu aproximar-se das menores taxas dos países da União Europeia (DONÁRIO; SANTOS, 2012), o que pode ser interpretado como reflexo da qualidade de suas estradas. Com 6,0 pontos, Portugal ocupa a oitava posição no ranking global de qualidade de estradas (SCHWAB, 2019).

De acordo com Organization for Economic Co-operation and Development / International Transport Forum - OECD/ITF (2015), entre as medidas que contribuíram para redução no número de acidentes de trânsito em Portugal estão: implementação de medidas de moderação de tráfego, construção de novas estradas (mais de 3.000 $\mathrm{km}$ de autoestradas), mudanças no código de trânsito, campanhas de conscientização, aumento da fiscalização em relação ao excesso de velocidade, a dirigir sob efeito de álcool, ao uso do cinto de segurança e aos sistemas de retenção infantil.

Contudo, tal redução deve ser avaliada com cautela devido ao contexto econômico do país. A partir de 2010, houve uma redução no PIB e consumo de combustíveis, além do aumento da taxa de desempregos, reflexo da crise econômica vivenciada pelo país. A relação entre a variação da atividade econômica e os AT já se mostrou estatisticamente significativa em diferentes estudos, devendo ser levada em consideração (ANSR, 2013; DONÁRIO; SANTOS, 2012; OECD/ITF, 2015). Uma das explicações para esse fato pode ser a redução de deslocamentos, devido ao desaquecimento da economia, resultando em uma menor exposição dos usuários.

Entre 2010 e 2013, os AT representaram um impacto negativo no PIB de Portugal em 5,4 mil milhões de euros, o que corresponde a cerca de 1,0\% do seu valor total (ANSR, 2013).

No que diz respeito à categoria de usuários e local de ocorrência dos acidentes, em 2013, mais da metade das vítimas eram condutores (61\%), sendo que destes, $65 \%$ eram condutores de veículos leves e $27 \%$ motociclistas. As maiores taxas de mortalidade foram registradas em rodovias com estado regular de conservação, após um aumento no número de acidentes nessas estradas, observado entre os anos de 2010 e 2013 (ANSR, 2013). 


\subsection{Materiais}

O banco de dados utilizado nesta pesquisa é composto por variáveis desagregadas e agregadas. Os dados desagregados foram obtidos por meio da aplicação de questionário e correspondem aos dados reportados pelos condutores participantes da pesquisa. O questionário é apresentado nos Apêndices A e B. Os dados agregados correspondem aos dados relacionados com o local de residência desses condutores, e foram obtidos em bases de dados públicas. A elaboração do questionário, e o tratamento realizado com as variáveis deste banco de dados, serão detalhados no método deste trabalho (Item 3.5).

\subsubsection{Banco de dados: dados desagregados e agregados}

Os dados desagregados, que compõem o banco de dados, correspondem ao perfil socioeconômico do condutor, experiência de condução, traços de personalidade, a percepção sobre a forma de conduzir e do risco de determinados comportamentos, bem como a frequência de comportamentos arriscados.

O questionário contemplou 24 questões e 110 itens afirmativos (Quadro 3.1), que correspondem a afirmações respondidas em Escala Likert de 5 pontos, de acordo com o enunciado de cada questão. Dessas questões, 4 delas são questionários já validados, conforme referenciados no quadro, e as demais foram criadas para essa pesquisa. As questões com itens em escala Likert foram analisadas e tratadas para serem utilizadas neste trabalho como variáveis latentes.

\begin{tabular}{cllc}
\multicolumn{4}{c}{ Quadro 3.1 - Dados desagregados } \\
\hline \multicolumn{1}{c}{ Grupo de questões } & \multicolumn{1}{c}{ Questões } & Tipo da variável & Itens $^{1}$ na questão \\
\hline & Sexo & Categórica nominal & - \\
& Idade & Numérica & - \\
& Renda & Categórica ordinal & - \\
\multirow{5}{*}{ Perfil socioeconômico } & Escolaridade & Categórica ordinal & - \\
& Estado Civil & Categórica nominal & - \\
& Número de filhos & Numérica & - \\
& Idade dos filhos & Numérica & - \\
\hline \multirow{5}{*}{ Experiência de condução } & Há quanto tempo conduz (por tipo de veículo) & Numérica & - \\
& Distância que conduz semanalmente & Numérica & - \\
& Acidentes de trânsito nos últimos 3 anos & Numérica & - \\
& Severidade do(s) acidente(s) & Categórica nominal & \\
& Histórico de multas & Categórica nominal & - \\
& Frequência que dirige em rodovia & Categórica ordinal & \\
& & & Continua \\
\hline
\end{tabular}




\begin{tabular}{|c|c|c|c|c|}
\hline \multicolumn{5}{|c|}{ Continuação } \\
\hline Grupo d & questões & Questões & Tipo da variável & Itens ${ }^{1}$ na questão \\
\hline \multirow{5}{*}{$\begin{array}{l}\text { Percepção } \\
\text { do } \\
\text { ambiente }\end{array}$} & \multirow{2}{*}{ urbano } & Densidade & Categórica ordinal* & 4 \\
\hline & & Sinalização e dispositivos & Categórica ordinal* & 8 \\
\hline & \multirow{3}{*}{ rodoviário } & Nível de serviço & Categórica ordinal* & 3 \\
\hline & & Estado de conservação do pavimento & Categórica ordinal* & 5 \\
\hline & & Traçado & Categórica ordinal* & 3 \\
\hline \multicolumn{2}{|c|}{ Habilidades do condutor } & Delhomme (1991) & Categórica ordinal* & 6 \\
\hline \multicolumn{2}{|c|}{ Raiva } & Deffenbacher, Oetting e Lynch (1994) & Categórica ordinal* & 14 \\
\hline \multicolumn{2}{|c|}{ Busca de sensações } & Yagil (2001) & Categórica ordinal* & 7 \\
\hline \multicolumn{2}{|c|}{ Percepção de risco } & Itens específicos & Categórica ordinal* & 20 \\
\hline \multirow{2}{*}{\multicolumn{2}{|c|}{ Comportamento }} & Reason et al. (1990) & Categórica ordinal* & 20 \\
\hline & & Itens específicos & Categórica ordinal* & 20 \\
\hline
\end{tabular}

Nota: * Escala Likert de 5 pontos;

1- Considere como "item" cada afirmação utilizada na pergunta referente a variável latente estudada

Os dados agregados, utilizados nesta pesquisa, são aqueles que podem caracterizar a região que o participante vive e aparecem, na literatura, como fatores também relacionados à ocorrência do AT (Quadro 3.2).

Quadro 3.2 - Dados agregados

\begin{tabular}{|c|c|c|}
\hline Variável & Brasil & Portugal \\
\hline População residente & Instituto Brasileiro de Geografia e Estatística (IBGE) & Base de dados Portugal Contemporâneo (PORDATA) \\
\hline Frota veicular & Departamento Nacional de Trânsito (DENATRAN) & Instituto da Mobilidade e dos Transportes (IMT) \\
\hline Produto Interno Bruto ${ }^{1}$ & Instituto Brasileiro de Geografia e Estatística (IBGE) & Instituto Nacional de Estatística (INE) \\
\hline Área ${ }^{2}$ & Instituto Brasileiro de Geografia e Estatística (IBGE) & Instituto Nacional de Estatística (INE) \\
\hline Índice de motorização & \multicolumn{2}{|c|}{$I M=$ Frota veicular $/$ População residente } \\
\hline $\begin{array}{l}\text { Densidade } \\
\text { populacional }\end{array}$ & \multicolumn{2}{|c|}{$D P=$ População residente /Área } \\
\hline
\end{tabular}

\subsubsection{Amostra}

Os critérios para definição dos locais amostrados, proporção amostral e caracterização da amostra são apresentados nesta subseção.

\subsubsection{Seleção dos locais amostrados}

Devido às dimensões do Brasil, optou-se por limitar os estados participantes deste estudo. Assim, os estados foram selecionados de acordo com dois critérios: maior população e/ou maior taxa de mortalidade (Tabela 3.1), dentro do limite de até dois estados, por critério, para cada região. O Distrito Federal também foi incluído na análise. Durante a coleta de dados, buscou-se respeitar a proporção populacional dos estados participantes. 
Tabela 3.1 - Locais selecionados e proporção amostral do Brasil

\begin{tabular}{|c|c|c|c|c|c|c|}
\hline Região & Estado & $\begin{array}{c}\text { Taxa de } \\
\text { Mortalidade }^{1}\end{array}$ & População² & $\begin{array}{l}\text { Proporção } \\
\text { da } \\
\text { população }\end{array}$ & $\begin{array}{l}\text { Tamanho } \\
\text { da amostra } \\
\text { coletada }\end{array}$ & $\begin{array}{l}\text { Proporção } \\
\text { da amostra }\end{array}$ \\
\hline \multirow{4}{*}{ Norte } & Amazonas & 11,2 & 3.938 .325 & $2,51 \%$ & 10 & $0,74 \%$ \\
\hline & Pará & 21,2 & 8.175 .156 & $5,20 \%$ & 33 & $2,44 \%$ \\
\hline & Roraima & 31,4 & 505.674 & $0,32 \%$ & 7 & $0,52 \%$ \\
\hline & Tocantins & 35,9 & 1.515 .134 & $0,96 \%$ & 21 & $1,55 \%$ \\
\hline \multirow{4}{*}{ Nordeste } & Pernambuco & 20,4 & 9.345 .638 & $5,95 \%$ & 45 & $3,32 \%$ \\
\hline & Bahia & 15,8 & 15.203 .851 & $9,68 \%$ & 56 & $4,14 \%$ \\
\hline & Piauí & 35,2 & 3.203 .248 & $2,04 \%$ & 13 & $0,96 \%$ \\
\hline & Paraíba & 25,7 & 3.972 .175 & $2,53 \%$ & 18 & $1,33 \%$ \\
\hline \multirow{3}{*}{ Sudeste } & Minas Gerais & 18,8 & 20.869 .033 & $13,29 \%$ & 118 & $8,71 \%$ \\
\hline & São Paulo & 14,1 & 44.396 .460 & $28,26 \%$ & 574 & $42,39 \%$ \\
\hline & Espírito Santo & 21,6 & 3.929 .925 & $2,50 \%$ & 23 & $1,70 \%$ \\
\hline \multirow{3}{*}{ Sul } & Paraná & 24,4 & 11.163 .023 & $7,11 \%$ & 110 & $8,12 \%$ \\
\hline & Rio Grande do Sul & 16,2 & 11.247 .923 & $7,16 \%$ & 122 & $9,01 \%$ \\
\hline & Santa Catarina & 23,3 & 6.819 .124 & $4,34 \%$ & 63 & $4,65 \%$ \\
\hline \multirow{4}{*}{ Centro-Oeste } & Mato Grosso & 32,6 & 3.265 .468 & $2,08 \%$ & 24 & $1,77 \%$ \\
\hline & Goiás & 28,4 & 6.610 .683 & $4,21 \%$ & 47 & $3,47 \%$ \\
\hline & Distrito Federal & 15,9 & 2.914 .830 & $1,86 \%$ & 70 & $5,17 \%$ \\
\hline & & Total & 154.160 .840 & $100,00 \%$ & 1354 & $100,00 \%$ \\
\hline
\end{tabular}

Em virtude de Portugal ser menor que o Brasil, tanto em dimensão territorial, como em população, optou-se por não limitar os distritos participantes do estudo, buscando respeitar a proporção populacional das regiões do país na coleta de dados (Tabela 3.2).

Tabela 3.2 - Distribuição amostral de Portugal

\begin{tabular}{lrrrr}
\hline \multicolumn{1}{c}{ Região } & População & Distribuição da população & Tamanho da amostra & Distribuição da amostra \\
\hline Alentejo & 715.019 & $7,3 \%$ & 11 & $3,2 \%$ \\
Algarve & 440.543 & $4,5 \%$ & 17 & $4,9 \%$ \\
Área Metropolitana de Lisboa & 2.827 .514 & $28,9 \%$ & 71 & $20,4 \%$ \\
Centro & 2.237 .640 & $22,8 \%$ & 85 & $24,4 \%$ \\
Norte & 3.580 .390 & $36,5 \%$ & 164 & $47,1 \%$ \\
Total & 9.801 .106 & $100,00 \%$ & 348 & $100,0 \%$ \\
\hline
\end{tabular}

Nota: ${ }^{1}$ PORDATA (2017)

\subsubsection{Caracterização da amostra}

A amostra deste estudo é composta por 1.702 observações válidas, das quais 79,2\% são de condutores brasileiros. A frequência das categorias que descrevem o perfil socioeconômico dos condutores e experiência de condução tiveram valores semelhantes entre as amostras dos dois países. Assim, o banco de dados deste 
trabalho consiste em ambas as amostras como um conjunto de dados único. Foi adicionada a variável binária, associada ao país de residência do respondente.

A amostra ficou equilibrada em relação à distribuição do sexo dos participantes $(50,5 \%$ feminino e 49,5\% masculino). Em relação à idade, houve uma maior participação de condutores entre 25 e 44 anos, com rendas mais elevadas, e que vivem como um casal $(48,4 \%)$ ou solteiros (46,5\%), conforme apresentado na Tabela 3.3 .

Tabela 3.3 - Medidas de caracterização da amostra

\begin{tabular}{|c|c|c|c|}
\hline Variável & $\begin{array}{l}\text { Brasil } \\
\mathrm{N}=1.354(79,6 \%)\end{array}$ & $\begin{array}{l}\text { Portugal } \\
\mathrm{N}=348(20,4 \%)\end{array}$ & $\begin{array}{l}\text { Total } \\
\mathrm{N}=1.702(100 \%)\end{array}$ \\
\hline Idade & $35,68 \pm 11,14$ & $38,67 \pm 13,32$ & $36,29 \pm 11,67$ \\
\hline 18 a 24 & $195(14,4)$ & $67(19,3)$ & $262(15,4)$ \\
\hline 25 a 34 & $523(38,6)$ & $75(21,6)$ & $598(35,1)$ \\
\hline 35 a 44 & $351(25,9)$ & $94(27,0)$ & $445(26,1)$ \\
\hline 45 a 54 & $186(13,7)$ & $62(17,8)$ & $248(14,6)$ \\
\hline 55 a 64 & $88(6,5)$ & $40(11,5)$ & $128(7,5)$ \\
\hline Maiores de 65 & $11(0,8)$ & $10(2,9)$ & $21(1,2)$ \\
\hline \multicolumn{4}{|l|}{ Sexo } \\
\hline Feminino & $674(49,8)$ & $186(53,4)$ & $860(50,5)$ \\
\hline Masculino & $680(50,2)$ & $162(46,6)$ & $842(49,5)$ \\
\hline \multicolumn{4}{|l|}{ Renda } \\
\hline Nenhuma renda & $145(10,7)$ & $55(15,8)$ & $200(11,8)$ \\
\hline Até 1 Salário Mínimo (S.M.) & $43(3,2)$ & $14(4,0)$ & $57(3,3)$ \\
\hline$>1$ até 2 S.M. & $148(10,9)$ & $97(27,9)$ & $245(14,4)$ \\
\hline$>2$ até 3 S.M. & $168(12,4)$ & $58(16,7)$ & $226(13,3)$ \\
\hline$>3$ até 5 S.M. & $210(15,5)$ & $94(27,0)$ & $304(17,9)$ \\
\hline$>5$ até 10 S.M. & $330(24,4)$ & $25(7,2)$ & $355(20,9)$ \\
\hline$>10$ até 20 S.M. & $249(18,4)$ & $0(0,0)$ & $249(14,6)$ \\
\hline$>20$ S.M. & $61(4,5)$ & $5(1,4)$ & $66(3,9)$ \\
\hline \multicolumn{4}{|l|}{ Estado Civil } \\
\hline Solteiro & $630(46,5)$ & $161(46,3)$ & $791(46,5)$ \\
\hline Vivendo como casal & $653(48,2)$ & $170(48,9)$ & $823(48,4)$ \\
\hline Divorciado & $62(4,6)$ & $16(4,6)$ & $78(4,6)$ \\
\hline Viúvo & $9(0,7)$ & $1(0,3)$ & $10(0,6)$ \\
\hline
\end{tabular}

No que diz respeito à experiência de condução (Tabela 3.4), a maior parcela de participantes reportou ter entre 5 e 15 anos de experiência e conduzem, em média, $226 \mathrm{~km}$ semanais. Os dois países foram semelhantes quanto à proporção de condutores que nunca se envolveram em acidentes de trânsito. Contudo, Portugal apresenta uma média menor de AT comparado ao Brasil, sendo a média geral do banco de dados de 0,33 acidentes por condutor participante. 
Tabela 3.4 - Medidas de caracterização de experiência de condução

\begin{tabular}{lrrr}
\hline Variável & Brasil & \multicolumn{1}{c}{ Portugal } & \multicolumn{1}{c}{ Total } \\
& $\mathrm{N}=1.354(79,6 \%)$ & $\mathrm{N}=348(20,4 \%)$ & $\mathrm{N}=1.702(100 \%)$ \\
\hline Tempo de habilitação & $14,23 \pm 10,93$ & $17,08 \pm 12,58$ & $14,81 \pm 11,34$ \\
Até 5 anos & $320(23,6)$ & $80(23,0)$ & $400(23,5)$ \\
5 até 15 & $533(39,4)$ & $90(25,9)$ & $623(36,6)$ \\
15 até 30 & $368(27,2)$ & $127(36,5)$ & $495(29,1)$ \\
30 até 45 & $125(9,2)$ & $47(13,5)$ & $172(10,1)$ \\
45 ou mais & $8(0,6)$ & $4(1,1)$ & $12(0,7)$ \\
\hline Quilometragem média semanal & $222,16 \pm 322,63$ & $241,82 \pm 284,0$ & $226,18 \pm 315,14$ \\
$0-40 \mathrm{~km}$ & $236(17,4)$ & $44(12,6)$ & $280(16,5)$ \\
$40-80 \mathrm{~km}$ & $197(14,5)$ & $44(12,6)$ & $241(14,2)$ \\
$80-120 \mathrm{~km}$ & $212(15,7)$ & $45(12,9)$ & $257(15,1)$ \\
$120-200 \mathrm{~km}$ & $288(21,3)$ & $83(23,9)$ & $371(21,8)$ \\
$200-300 \mathrm{~km}$ & $168(12,4)$ & $56(16,1)$ & $224(13,2)$ \\
$300-500 \mathrm{~km}$ & $157(11,6)$ & $50(14,4)$ & $207(12,2)$ \\
$>500 \mathrm{~km}$ & $96(7,1)$ & $26(7,5)$ & $122(7,2)$ \\
\hline Acidentes de trânsito & $0,34 \pm 0,66$ & $0,26 \pm 0,5$ \\
Nenhum acidente & $997(73,6)$ & $267(76,7)$ & $0,33 \pm 0,63$ \\
1 & $272(20,1)$ & $73(21,0)$ & $1264(74,3)$ \\
2 & $67(4,9)$ & $7(2,0)$ & $345(20,3)$ \\
3 & $15(1,1)$ & $1(0,3)$ & $74(4,3)$ \\
4 & $1(0,1)$ & $0(0,0)$ & $16(0,9)$ \\
5 ou mais acidentes & $2(0,1)$ & $0(0,0)$ & $1(0,1)$ \\
& & & $2(0,1)$ \\
\hline
\end{tabular}

A localização espacial da amostra de ambos os países pode ser observada na Figura 3.1. 
Figura 3.1 - Distribuição da amostra no Brasil e Portugal

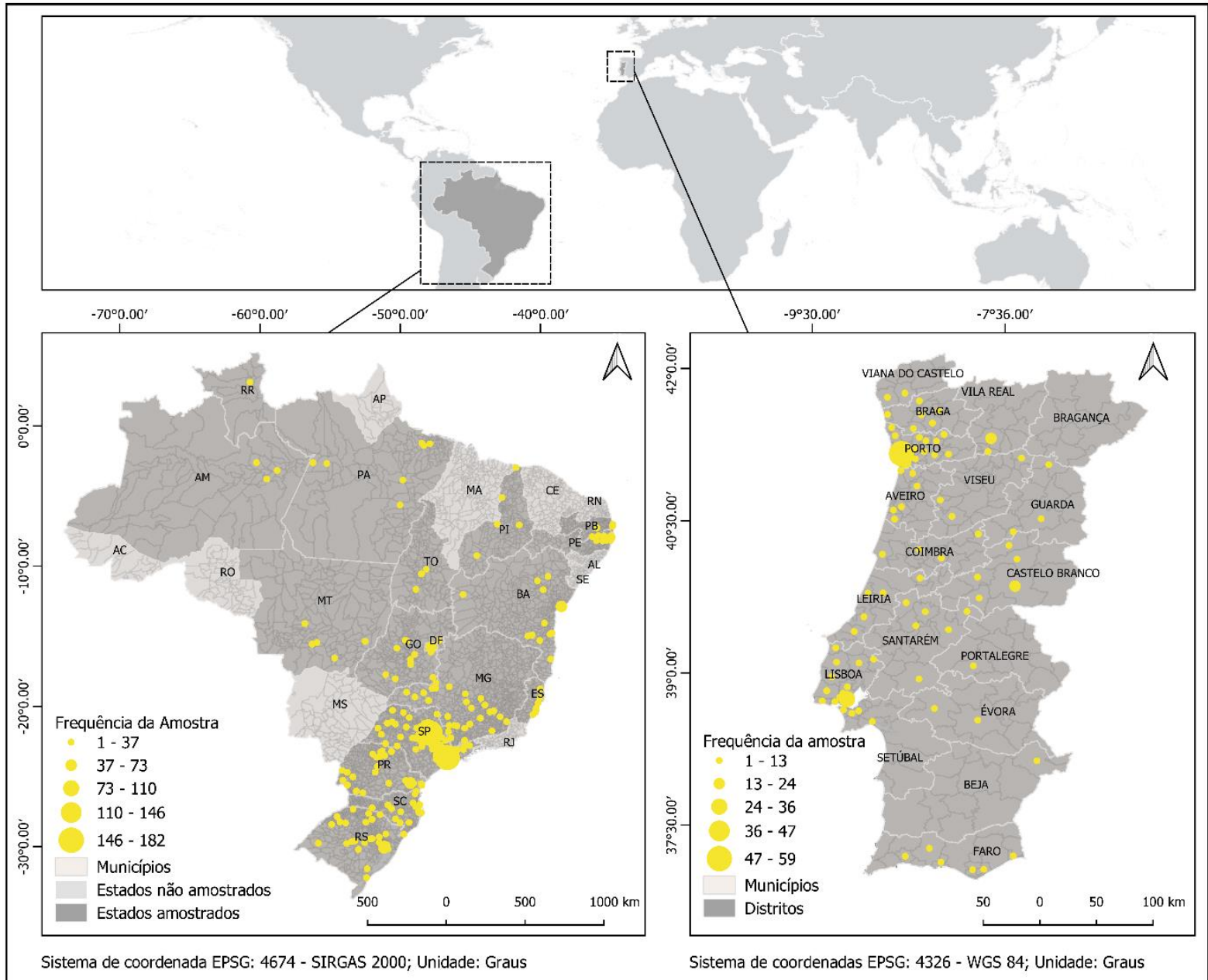

\subsection{Síntese das ferramentas de análise}

Nesta seção são apresentadas as ferramentas de análise utilizadas no desenvolvimento desta tese de doutorado em uma breve descrição.

\subsubsection{Análise de Componentes Principais Categórica}

Para determinar as variáveis latentes, ou construtos, a partir dos dados em Escala Likert, coletados com o questionário, foi utilizada, neste estudo, a Análise de Componentes Principais Não-Linear (NLPCA - do inglês Non-linear Principal Component Analysis).

Essa técnica é uma extensão da Análise de Componentes Principais (PCA - do inglês Principal Component Analysis), aplicada com a mesma finalidade de reduzir $m$ variáveis em $p$ componentes sendo, geralmente, $p<m$. Contudo, diferencia-se por 
ser indicada a variáveis não métricas, com diferentes níveis de medida e relações não lineares. No software IBM SPSS 25 é tratada como Análise de Componentes Principais Categórica (CATPCA - do inglês Categorical Principal Component Analysis). Neste trabalho, a ferramenta será referida como Análise de Componentes Principais Categórica, tal como no pacote estatístico utilizado.

As técnicas tradicionalmente utilizadas nas análises exploratórias e de validação de questionários, análise fatorial e PCA, são baseadas em medidas métricas como variância, covariância e correlação. Contudo, dados categóricos ordinais, como a escala Likert, utilizada neste trabalho, é uma medida não métrica, com a distância entre as categorias diferente de uma unidade.

A CATPCA é indicada para variáveis não métricas, pois transforma essas variáveis em medidas métricas por meio de um procedimento de escalonamento ótimo (Optimal Scaling) obtido por meio do método iterativo mínimos quadrados alternantes (Alternating Least Squares), realizado no IBM SPSS 25 por meio do algoritmo PRINCALS (KURODA et al., 2013; LINTING; VAN DER KOOIJ, 2012; LINTING et al., 2007). Para maiores informações acerca dos algoritmos, recomenda-se a leitura de Kuroda et al. (2013).

Assim, essa técnica foi utilizada, pois se mostra capaz de reduzir os dados considerando as restrições de medida, sendo mais adequada para representar os dados originais, uma vez que atende aos pressupostos de dados numéricos e categóricos com relações lineares e não lineares.

\subsection{2 Árvore de decisão}

Para classificação dos comportamentos de risco do condutor a partir das variáveis latentes e do envolvimento em AT no passado, auto relatado pelo respondente, utilizou-se, neste trabalho, um algoritmo de Árvore de Decisão. Essa técnica consiste em uma ferramenta de mineração de dados, utilizada para classificação ou estimação dos dados (QUINLAN, 1983). É representada por uma estrutura hierárquica dividida em camadas denominadas como nós raiz, nós filho e nós terminais (ROKACH; MAIMON, 2008). Existem diferentes algoritmos para realizar a divisão dos dados. As árvores de classificação são utilizadas para variável dependente categórica e dividem 
dados em um número finito de classes por meio de regras hierárquicas (QUINLAN, 1983).

Neste estudo utilizou-se o algoritmo CART - do inglês Classification and Regression Tree, que atinge resultados satisfatórios para variáveis dependentes numéricas ou categóricas (BREIMAN et al., 1984). Esse algoritmo promove um crescimento com partição binária, com o objetivo de atingir homogeneidade dentro de cada nó (segundo a variável dependente). A homogeneidade pode ser avaliada de acordo com o critério de heterogeneidade, ou impureza, denominado Índice de Gini. Quanto mais próximo do valor zero o índice, maior a pureza ou homogeneidade do nó, de forma que, em cada nova partição, sejam determinados nós mais homogêneos e, consequentemente, menores valores para o índice (BREIMAN et al., 1984).

O índice de Gini é calculado baseado na função de impureza, conforme apresentado na Equação 3.1.

$$
G(t)=1-\sum_{i=1}^{n} p^{2}\left(\frac{i}{t}\right)
$$

Para uma variável dependente categórica x com $n$ categorias $(1,2, i \ldots, n)$, sendo $p(i / t)$ : proporção da categoria i da variável dependente no nó t.

\subsubsection{Modelo Logit Binomial}

O Modelo Logit Binomial (Binário) foi utilizado para análise dos fatores que influenciam comportamentos de risco do condutor. Considerando que as classificações dos comportamentos de risco deste trabalho consistem em variáveis categóricas nominais, os métodos de regressão convencionais são inadequados. Para os casos em que a modelagem será acerca de dado categórico, são utilizados modelos de resposta qualitativa, em que a variável dependente é um indicador de uma categoria (GREENE, 2003; GUJARATI; PORTER, 2011).

No modelo Logit Binomial (Binário), a variável dependente é do tipo binária (dummy) onde estima-se a probabilidade de o indivíduo pertencer a determinada categoria (0 ou 1). O método de Máxima Verossimilhança é utilizado para calibrar modelos a partir de "funções utilidade que consistem em parâmetros de variáveis independentes observáveis e variáveis desconhecidas" (BEN-AKIVA; LEARMAN, 1985, p. 2, tradução nossa). 
A partir da calibração dos parâmetros do modelo, é possível verificar a significância estatística dos parâmetros estimados com base no teste $t$-student, de forma que os parâmetros serão significativos ao nível de confiança superior a 95\%. Assim, pode-se avaliar a relação entre as variáveis explicativas significativas e a variável explicada.

Para avaliar e comparar diferentes modelos de resposta qualitativa, pode-se considerar, entre as métricas disponíveis (BEN-AKIVA; LERMAN, 1985):

- Log de Verossimilhança Final: corresponde à função logarítmica de verossimilhança do modelo com todos os parâmetros estimados e deve ser menor que o inicial, em que se considera apenas a constante (modelo nulo);

- Rho-quadrado-ajustado: é uma medida semelhante ao $\mathrm{R}^{2}$ em termos de escala, desenvolvida para modelos com método de estimação de máxima verossimilhança, em que valores mais próximos de 1 indicam maior qualidade do ajuste e penaliza o número muito elevado de parâmetros; e

- Critério de Informação de Akaike (AIC - Akaike Information Criterion): o AIC avalia a qualidade do ajuste do modelo indicando o quanto de informação foi perdida e o risco de sobreajuste (overfitting), de modo que quanto menor seus valores, melhor o ajuste.

As equações das métricas e parâmetros são apresentadas no Quadro 3.3.

Quadro 3.3 - Métricas dos modelos

\begin{tabular}{lll}
\hline Métrica & Equação & Parâmetros da equação \\
\hline $\begin{array}{l}\text { rho-quadrado } \\
\text { ajustado }\end{array}$ & $\rho^{2}=1-\frac{L^{*}-K}{L_{0}}$ & $\begin{array}{l}L^{*} \text { valor de máximo-verossimilhança obtida quando os parâmetros } \beta \\
\text { correspondem aos valores estimados }\end{array}$ \\
& $\begin{array}{l}L_{0} \text { valor da verossimilhança do modelo apenas com a constante, quando todos } \\
\text { os parâmetros } \beta \text { do modelo são zero } \\
K \text { número de parâmetros estimados }\end{array}$ \\
$\begin{array}{l}\text { Critério de } \\
\text { Informação de } \\
\text { Akaike }\end{array}$ & $A=2 K-2 \ln L^{*}$ & $\begin{array}{l}L^{*} \text { valor de máximo-verossimilhança obtida quando os parâmetros } \beta \\
\text { correspondem aos valores estimados } \\
K \text { número de parâmetros estimados }\end{array}$ \\
\hline
\end{tabular}

Fonte: Adaptado de Bierlaire (2018)

\subsection{Detalhamento das etapas metodológicas}

O método para o desenvolvimento desta tese de doutorado foi dividido em quatro etapas principais, conforme ilustrado na Figura 3.2. 
Figura 3.2 - Fluxograma metodológico

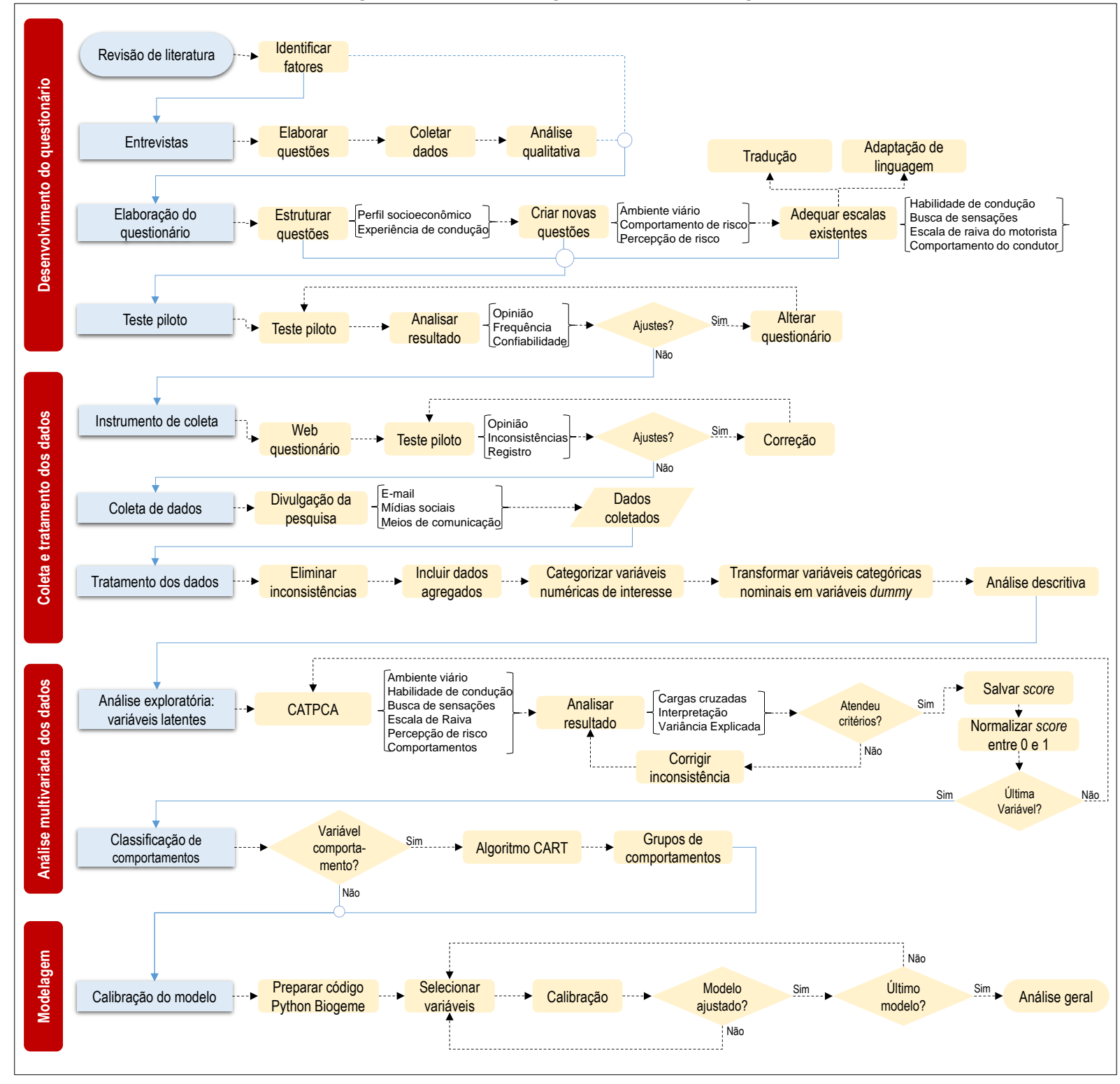

\subsubsection{Desenvolvimento do questionário}

O desenvolvimento do questionário começou com a revisão de literatura sobre tomada de risco de motoristas com a finalidade de identificar características relacionadas a esse comportamento. Na sequência, foram criadas questões abertas relacionadas aos fatores observados na literatura, para entrevistas individuais com condutores e confirmação desses fatores.

Considerando a revisão de literatura e análise qualitativa das entrevistas foi possível delinear a elaboração do questionário, que contemplou: i) a organização de questões para traçar o perfil socioeconômico e a experiência de condução do condutor; ii) a criação de perguntas com a finalidade de caracterizar o ambiente viário que o 
participante conduzia com mais frequência, a frequência em que conduzia conforme situações de risco específicas apresentadas e a percepção de risco desses comportamentos; e iii) o uso de questionários validados relacionados a traços de personalidade (busca de sensações e raiva ao conduzir), habilidades de condução e comportamentos aberrantes.

Os questionários validados, utilizados neste trabalho (Quadro 3.4), passaram por uma etapa de tradução e adequação da língua. Os questionários que possuíam apenas a versão em inglês foram traduzidos para o português. A versão do questionário para Portugal teve todo seu conteúdo revisado e adaptado por portugueses, tanto da área de psicologia, como da engenharia.

\begin{tabular}{|c|c|c|c|c|c|}
\hline Instrumento & Versão usada & Objetivo & Escala Likert original & $\begin{array}{l}\text { Número } \\
\text { de itens }\end{array}$ & Comentário \\
\hline $\begin{array}{l}\text { Habilidades do } \\
\text { Motorista }\end{array}$ & $\begin{array}{l}\text { Adaptada de } \\
\text { Delhomme } \\
\text { (1991) }\end{array}$ & $\begin{array}{l}\text { Participante avaliar a sua } \\
\text { forma de dirigir e a dos } \\
\text { outros condutores }\end{array}$ & $\begin{array}{l}1 \text { = "Discordo plenamente"; } 5 \\
=\text { "Concordo plenamente" }\end{array}$ & $4(2)$ & $\begin{array}{l}2 \text { itens foram } \\
\text { adicionados para esse } \\
\text { trabalho de doutorado }\end{array}$ \\
\hline $\begin{array}{l}\text { Busca de } \\
\text { sensações }^{1}\end{array}$ & Yagil (2001) & $\begin{array}{l}\text { Investigar a busca de } \\
\text { sensações de acordo } \\
\text { com preferências de } \\
\text { condução no trânsito }\end{array}$ & $\begin{array}{l}1=\text { "Não é verdade"; } 7= \\
\text { "Absolutamente verdade" }\end{array}$ & 7 & $\begin{array}{l}\text { Tradução baseada nas } \\
\text { versões em Inglês e } \\
\text { francês de Yagil (2001) } \\
\text { e Delhomme et al } \\
\text { (2009). }\end{array}$ \\
\hline $\begin{array}{l}\text { Escala de raiva } \\
\text { do condutor }{ }^{2}\end{array}$ & $\begin{array}{l}\text { Cantini et al. } \\
(2015)\end{array}$ & $\begin{array}{l}\text { Avaliar a propensão a } \\
\text { tornarem-se irritados ou } \\
\text { agressivos no trânsito }\end{array}$ & 1 = "Nada"; 5 = "Muitíssima". & 14 & Versão em português \\
\hline $\begin{array}{l}\text { Questionário do } \\
\text { comportamento } \\
\text { do condutor }{ }^{3}\end{array}$ & $\begin{array}{l}\text { Özkan et al. } \\
(2006)\end{array}$ & $\begin{array}{l}\text { Investigar } \\
\text { comportamentos } \\
\text { aberrantes relacionados } \\
\text { a erros e violações }\end{array}$ & 1 = "Nada"; 5 = "Muitíssima". & 20 & $\begin{array}{l}\text { Baseado na versão em } \\
\text { português: Bianchi e } \\
\text { Summala (2002) com } \\
\text { algumas adaptações }\end{array}$ \\
\hline
\end{tabular}

As perguntas que foram criadas (ii) e as escalas validadas (iii) constituíram em conjuntos de itens afirmativos para serem avaliados em uma escala Likert de 5 pontos, de acordo com o enunciado da questão. O padrão de cinco alternativas no nível de concordância foi adotado por serem indicadas para medir atitudes (HILL; HILL, 2008). As questões são apresentadas com mais detalhes no Capítulo 4 e a versão final do questionário pode ser consultada nos Apêndices $A$ e $B$ deste trabalho.

Durante todo o processo de criação do questionário foram realizadas discussões e revisões, juntamente com as orientadoras, a fim de se avaliar as questões considerando os objetivos do estudo, bem como a semântica das mesmas. Medidas 
de sensibilidade, confiabilidade e validade das questões foram avaliadas no estudo piloto.

\subsubsection{Testes piloto}

Nesta fase foram realizados dois estudos pilotos para testar a compreensão das perguntas por parte dos respondentes e a confiabilidade das escalas. As amostras foram obtidas por conveniência e contaram com a participação de 12 condutores de cada país, em cada um dos dois testes pilotos realizados. As respostas dos 24 participantes não foram incluídas na amostra final.

Para avaliar a compreensão e adequação das perguntas e itens escritos, os participantes foram convidados a responder o questionário em uma versão impressa e a fazer anotações sobre dúvidas com relação à compreensão, erros ou sugestões sobre as questões. Além dos comentários, foram analisadas as frequências das respostas para verificar se havia perguntas em que as respostas se concentravam em uma única opção. A falta de variabilidade na resposta pode indicar que a pergunta não estava sendo bem interpretada na forma como foi apresentada ou que a escala não estava adequada (ALFERES, 1997).

A análise de consistência interna avalia a confiabilidade do conjunto de itens que representa a variável latente, baseando-se no pressuposto de que itens individuais devem apresentar resultados consistentes com os demais itens do conjunto (FIELD, 2009; HILL; HILL, 2008).

Neste trabalho, a confiabilidade foi avaliada com o Alfa de Cronbach, que é o teste mais indicado (FIELD, 2009; HAIR et al., 2009; HILL; HILL, 2008) e possibilita calcular todas as divisões possíveis para o conjunto de itens computando os coeficientes de correlação entre cada parte (FIELD, 2009; HILL; HILL, 2008). Para definição dos termos utilizados neste texto, considera-se como "item" cada afirmação utilizada na pergunta referente à variável latente estudada. $O$ Alfa de Cronbach pode ser calculado conforme a Equação 3.2 (FIELD, 2009):

$$
\alpha=\frac{N^{2} \overline{\operatorname{Cov}}}{\sum s_{\text {item }}^{2}+\sum \operatorname{Cov}_{\text {item }}}
$$

Onde $N^{2}$ é o número de itens ao quadrado, $\overline{\operatorname{Cov}}$ é a covariância média entre itens, $s^{2}$ é a variância do item e Cov é a covariância entre pares de itens. 
Ao analisar os resultados do primeiro teste piloto, considerando as anotações dos participantes, distribuição das respostas e análise de confiabilidade, alguns problemas foram identificados e, posteriormente, corrigidos, conforme será apresentado no Capítulo 4.

Após as correções, uma nova versão foi aplicada a outros condutores, consistindo no segundo teste piloto. O questionário foi entregue impresso e com as mesmas orientações do primeiro teste. Foram realizadas análises para comparação com o estudo piloto preliminar e avaliação das correções realizadas. A versão final do questionário, obtida após o segundo teste piloto, encontra-se nos Apêndices A e B.

\subsubsection{Coleta e tratamento dos dados obtidos}

\subsubsection{Instrumento de coleta online}

A versão online do questionário foi desenvolvida baseada em uma estrutura préexistente na linguagem HTML, e hospedada no servidor do Departamento de Engenharia de Transportes da Escola de Engenharia de São Carlos da Universidade de São Paulo (BETH, 2019).

A opção de não usar um website de formulários pronto permitiu maior controle na forma como as perguntas foram apresentadas aos participantes. Por se tratar de um questionário com muitas questões, e visando maior taxa de respostas completas, foram criadas regras no código de programação em que perguntas dependentes apareceram em função da resposta anterior. Por exemplo, ao responder o tipo de veículo que dirige, apenas a reposta dada apareceu como opção nas perguntas seguintes relacionadas ao tipo de veículo, ou quando reportado não dirigir em rodovias, as perguntas referentes às rodovias não apareceram, e assim por diante.

O terceiro teste piloto foi realizado para testar o website. Nesta etapa, o link foi distribuído de forma controlada, através de convites por e-mail para participação com feedback de possíveis erros e análise de inconsistências relacionadas à codificação. As respostas dos participantes desta etapa não foram consideradas na amostra final. Após os testes finais, a distribuição do link de acesso ao questionário foi realizada por meio de convites via e-mail, mídias sociais, aplicativos de comunicação e outras mídias de comunicação (jornal, rádio). 


\subsubsection{Tratamento dos dados}

Após a coleta de dados, o banco de dados foi avaliado e participantes com mesma resposta em todas as perguntas ou que não responderam o questionário por completo foram eliminados.

As variáveis agregadas, relacionadas ao local de residência dos participantes, foram incluídas no banco de dados. Para preparação das variáveis para etapa de modelagem, as variáveis numéricas população, densidade populacional, frota veicular, índice de motorização, PIB da região, quilometragem percorrida e tempo de carteira de habilitação foram transformadas em variáveis categóricas, com auxílio dos procedimentos de discretização ideal e categorização visual do Software IBM SPSS 25. Posteriormente, essas e as demais variáveis categóricas do banco de dados foram transformadas em variáveis dummy para inclusão nos modelos.

Foi realizada uma análise descritiva para caracterização do perfil socioeconômico e da experiência de condução da amostra. As demais perguntas, com itens em escala Likert, foram avaliadas quanto à frequência e submetidas, posteriormente, para aplicação das ferramentas de análise multivariada de dados.

\subsubsection{Análise multivariada dos dados}

\subsubsection{Análise e validação de variáveis latentes}

Variável latente (construto) é o termo definido para representar uma variável que não pode ser mensurada ou observada diretamente, mas que pode ser aferida a partir do conjunto de outras variáveis (HILL; HILL, 2008), no caso deste trabalho denominado conjunto de itens.

Ao se criar um questionário com variáveis latentes é necessário verificar sua validade, ou seja, verificar se o questionário mede aquilo que foi proposto durante sua elaboração e se está de acordo com conhecimentos prévios (HILL; HILL, 2008; VIEIRA, 2009). Neste trabalho, as variáveis latentes foram obtidas com a aplicação de Análise de Componentes Principais Categórica (CATPCA).

Para definição e validade das variáveis latentes, foram utilizados como critérios de análise a variância explicada, as cargas fatoriais dos itens nas dimensões e a coerência interpretativa dos itens para cada dimensão da CATPCA. Nos casos em que as cargas fatoriais foram altas para mais de uma dimensão, optou-se pela 
exclusão do item para definir variáveis latentes sem ambiguidades e imprecisões. A consistência interna das dimensões foi avaliada a partir do índice de confiabilidade Alfa de Cronbach e utilizou-se, quando necessário e possível, a análise de correlação de Spearman.

Dessa forma, foi possível verificar itens que deveriam ser excluídos das próximas etapas da pesquisa por não representarem fortemente a variável latente ou construto. Nesta etapa, foram analisados os itens em escala Likert referentes às questões que investigavam os traços de personalidade, busca de sensações e raiva ao conduzir, a percepção de risco dos comportamentos específicos criados para este estudo e comportamento de risco, que foi avaliado com auxílio de duas questões.

Os escores individuais das variáveis latentes de comportamentos foram utilizados para classificação dos comportamentos com auxílio da árvore de decisão. Os escores individuais, das demais variáveis latentes, foram utilizados como variáveis independentes nos modelos Logit.

\subsubsection{Classificação dos comportamentos de risco}

Nessa etapa, as variáveis latentes de comportamento, identificadas com aplicação da CATPCA, foram classificadas de acordo com a frequência de envolvimento em acidentes de trânsito nos últimos 3 anos.

Para tal, utilizou-se o algoritmo CART da árvore de decisão, em que a variável dependente foi a frequência dos acidentes de trânsito, representada pela variável "número de acidentes de trânsito", e as variáveis independentes foram os escores individuais de cada comportamento de risco identificado com a CATPCA. Assim, foi gerada uma árvore de decisão para cada comportamento de risco identificado com a CATPCA.

Como mencionado na Subseção 3.4.2, o algoritmo CART classifica os dados baseando-se em partições binárias, de forma a definir nós cada vez mais homogêneos, segundo variável dependente. Sua aplicação, considerando as variáveis selecionadas, possibilitou classificar os participantes de acordo com a frequência que realizam o comportamento de risco (representado pelos escores individuais das dimensões identificadas na CATPCA) e a frequência de envolvimento em acidentes de trânsito no passado. 
Visto que o objetivo foi diferenciar os participantes que se comportam de forma arriscada no trânsito com menor frequência daqueles que se arriscam com maior frequência, foi atribuído o nível 1 como regra de parada de crescimento da árvore para classificar os comportamentos de risco em dois grupos, de acordo com a frequência do comportamento e a frequência dos acidentes de trânsito.

O resultado se assemelha à estrutura da Figura 3.3, onde são considerados no nó terminal 1 os participantes que relataram menor frequência do comportamento, enquanto no nó terminal 2 são considerados os participantes que reportaram maior frequência do comportamento, cuja divisão foi definida de acordo com a frequência de envolvimento em acidentes de trânsito.

Figura 3.3 - Exemplo do diagrama da árvore de decisão

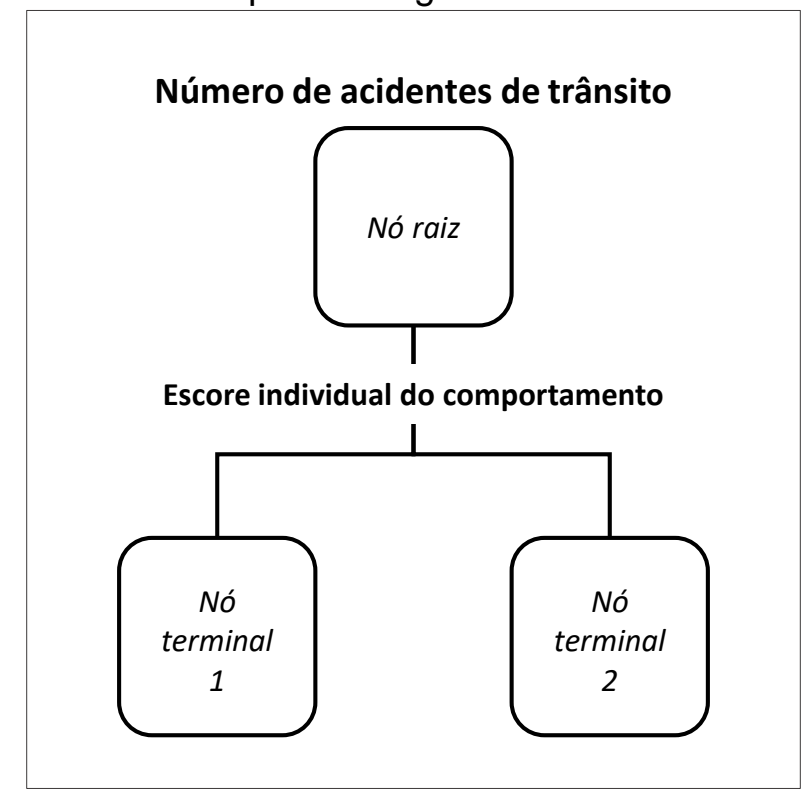

3.5.4 Calibração dos modelos

O modelo paramétrico, utilizado neste trabalho, foi o Logit Binomial, calibrado no Software PandaBiogeme (BIERLAIRE, 2018), por meio do método de Máxima Verossimilhança. As variáveis dependentes dos modelos são os grupos de comportamentos classificados na etapa anterior, usando o algoritmo CART. Dessa forma, para cada modelo calibrado, a variável dependente corresponde aos nós terminais 1 e 2 do comportamento analisado.

Durante o procedimento de calibração, considerou-se a Função Utilidade $0\left(\mathrm{FU}_{0}\right)$, igual a 0 , e a Função Utilidade $1\left(\mathrm{FU}_{1}\right)$, igual aos parâmetros a serem estimados para as variáveis independentes, de modo que a $\mathrm{FU}_{1}$ corresponde ao nó terminal 2. Dessa 
forma, os parâmetros significativos estimados com valores positivos são positivamente relacionados à classe de comportamentos do nó terminal 2, ou seja, àqueles que reportaram maior frequência do comportamento de risco. Consequentemente, os parâmetros negativos influenciam positivamente comportamentos classificados no nó terminal 1, onde foram classificados os condutores que reportaram menor frequência do comportamento.

As variáveis independentes consideradas neste trabalho foram: dados socioeconômicos (idade, sexo, estado civil, escolaridade, renda, filhos), experiência do condutor (tempo de habilitação, quilometragem percorrida semanalmente), multas, construtos dos traços de personalidade (busca de sensações, escala de raiva do condutor), percepção de risco, habilidades de condutor, caracterização do ambiente e os dados agregados (população, densidade populacional, frota veicular do município, índice de motorização e Produto Interno Bruto da região - em US\$). As variáveis categóricas foram incluídas no modelo como variáveis dummy. As variáveis numéricas foram incluídas como numéricas, ou categorizadas e também incluídas como dummy.

A categorização das variáveis numéricas "tempo de habilitação" e "quilometragem percorrida semanalmente" foi realizada com o procedimento de categorização visual do software IBM SPSS 25. Esse procedimento auxilia na determinação de categorias a partir do agrupamento de valores de escala contínuas de uma variável existente (GUIA..., 2016). As variáveis numéricas população, densidade populacional, frota veicular, índice de motorização e Produto Interno Bruto da região foram categorizadas em função da variável Estado, por meio do procedimento de categorização ideal do IBM SPSS 25. Esse procedimento realiza a categorização da variável distribuindo os valores de acordo com outra variável categórica guia (OPTIMAL BINNING, 2019).

Foram calibrados 16 modelos (Quadro 3.5) para cada um dos sete comportamentos identificados com a aplicação da CATPCA. Para cada modelo as variáveis foram introduzidas, sequencialmente, de acordo com os critérios abaixo:
A. Variáveis do mesmo grupo;
B. Variáveis relacionadas ao local de residência;
C. Inclusão de variáveis de diferentes grupos; e
D. Todas as variáveis incluídas juntas. 
Quadro 3.5 - Grupos de variáveis consideradas nos modelos

\begin{tabular}{ll}
\hline Código do modelo & Grupo de variáveis independentes \\
\hline A1 & Socioeconômico \\
A2 & Experiência do condutor \\
A3 & Histórico de multas \\
A4 & Construtos psicológicos \\
A5 & Ambiente Viário \\
B1 & País \\
B2 & Região \\
B3 & Distrito \\
B4 & Variáveis agregadas primárias e secundárias \\
C1 & Socioeconômico + Experiência do Condutor + Multas \\
C2 & Socioeconômico + Experiência do Condutor + Multas + Psicológico + Ambiente Viário \\
C3 & Socioeconômico + Experiência do Condutor + Multas + Psicológico + Ambiente Viário + País \\
C4 & Socioeconômico + Experiência do Condutor + Multas + Psicológico + Ambiente Viário + Região \\
C5 & Socioeconômico + Experiência do Condutor + Multas + Psicológico + Ambiente Viário + Distrito \\
C6 & Socioeconômico + Experiência do Condutor + Multas + Psicológico + Ambiente Viário + Agregado \\
D & Todos os conjuntos de variáveis \\
\hline
\end{tabular}

Os parâmetros dos modelos foram avaliados de acordo com a coerência dos mesmos e a importância relativa. As medidas de ajuste dos modelos foram comparadas considerando-se os valores da verossimilhança final, Rho-quadrado-ajustado e Critério de Informação Akaike.

Vale ressaltar que a avaliação se trata de um procedimento metodológico sequencial, que pode ser sintetizado da seguinte forma:

A) Parte 1: Determinação de construtos através de agrupamentos dos itens (variáveis latentes) - aplicação de CATPCA;

B) Parte 2: Classificação de comportamentos a partir de variáveis latentes, determinadas na Parte 1, além de envolvimento em acidentes de trânsito no passado - aplicação de algoritmo CART;

C) Parte 3: Estudos de fatores de influência de comportamentos. As variáveis dependentes são obtidas na Parte 2 - calibração de modelos Logit Binomial. 


\section{QUESTIONÁRIO: DESENVOLVIMENTO E APLICAÇÃO}

Neste capítulo é apresentado todo o procedimento para elaboração do questionário, incluindo as etapas de entrevistas, desenvolvimento de questões, versões dos testes piloto e os resultados. Ao final, também são apresentadas as frequências das respostas dos itens em escala Likert da amostra válida deste estudo.

\subsection{Entrevistas}

Considerando o fluxograma metodológico, apresentado no Capítulo 3, após a etapa de revisão bibliográfica, algumas perguntas foram formuladas, embasadas no conhecimento teórico obtido. As perguntas foram realizadas, na forma de entrevistas, para confirmar os fatores que influenciam o comportamento mais arriscado do condutor. Tanto a revisão da literatura quanto a realização de entrevistas antecedem e auxiliam na etapa de elaboração do questionário.

A amostra foi constituída por dois homens e uma mulher, entre 30 e 34 anos, com 10 anos de experiência de condução, em média, e condução frequente em rodovias. Os participantes foram escolhidos por conveniência. As entrevistas foram realizadas individualmente. Esta amostra foi limitada a apenas três participantes, pois todos apresentaram respostas semelhantes, sem inclusão de novos fatores.

Dessa forma, as perguntas visavam investigar o comportamento e opinião do condutor em relação aos tópicos: excesso de velocidade, avaliação do ambiente externo, conduzir sob efeito de álcool e drogas, desrespeito às leis de trânsito, sensações ao cometer infrações de trânsito, conduta habitual no trânsito e envolvimento em acidentes de trânsito. As perguntas, objetivos e um resumo das respostas obtidas nas entrevistas são apresentados no Quadro 4.1.

Quadro 4.1 - Perguntas e objetivos da entrevista

\begin{tabular}{|c|c|c|}
\hline Perguntas conduzidas & Objetivo & Resumo das respostas \\
\hline $\begin{array}{l}\text { O que você acha sobre o excesso } \\
\text { de velocidade entre os } \\
\text { motoristas? • Em qual velocidade } \\
\text { você dirige na estrada reta } \\
\text { quando o trânsito é leve? Acha } \\
\text { que isso é um risco? Por quê? } \\
\text { Porque você acha que os } \\
\text { motoristas correm? }\end{array}$ & $\begin{array}{l}\text { Investigar a opinião } \\
\text { e percepção do risco } \\
\text { relacionado ao } \\
\text { excesso de } \\
\text { velocidade e seu } \\
\text { próprio } \\
\text { comportamento }\end{array}$ & $\begin{array}{l}\text { Os entrevistados relataram que costumam dirigir no limite da via, e excedem } \\
\text { a velocidade para realizar ultrapassagens. A presença de caminhões na } \\
\text { rodovia influencia esse comportamento. Contudo, o excesso de velocidade } \\
\text { dos demais condutores causa incomodo e insegurança, principalmente } \\
\text { quando o veículo de trás se encontra muito próximo e fazendo sinais de luz, } \\
\text { mas agem da mesma forma com outros condutores. Relatam um incomodo } \\
\text { ocasionado por motoristas costurando o trânsito devido ao risco de acidentes. } \\
\text { Os motivos para que outros motoristas excedam a velocidade foram o perfil } \\
\text { da pessoa (homens e jovens), ou por estarem com pressa para chegar ao } \\
\text { destino final. }\end{array}$ \\
\hline
\end{tabular}




\begin{tabular}{ll}
\hline Continuação & \\
Perguntas conduzidas & Objetivo \\
& Identificar como o \\
Você se sente seguro nas vias & motorista analisa o \\
em que dirige? Por quê? $\bullet$ Você & ambiente que dirige \\
conhece motoristas que se & e como percebe o \\
arriscam? O que eles fazem? Por & comportamento dos \\
quê? & motoristas ao seu \\
& entorno
\end{tabular}

Você já bebeu e dirigiu alguma vez? $\bullet$ Você acha que beber e dirigir é um risco? • Você já dirigiu sob efeito de drogas? • Você acha que é um risco? Por quê? • As pessoas a sua volta fazem isso? Qual é sua opinião sobre a conduta delas?

\section{Investigar a}

percepção do risco associado à prática de dirigir sob efeito de álcool ou drogas, em contraste ao próprio comportamento

\section{Resumo das respostas}

Sentem-se seguros em estradas com boas condições de pavimento e sinalização, mesmo que elas não sejam duplicadas. Observam diferenças na qualidade de infraestrutura rodoviária de uma região para outra. Quando a via não está em boas condições, precisam tomar mais cuidado, não há avisos sobre os buracos, por exemplo. Sobre o comportamento dos outros motoristas, relataram o excesso de velocidade como um comportamento de risco, contudo, também o fazem por se considerarem bons motoristas sentem-se seguros e não se preocupam com as possíveis consequências.

Todos os participantes relataram beber e dirigir, ainda que menos frequentemente atualmente comparado a quando eram mais jovens. Consideram essa conduta muito arriscada, o que levou a outra pergunta: "Então, porque dirigir após beber? ". Em geral, relataram que se sentem em condições de dirigir após beber, e que a dificuldade maior é a limitação de opções para poder retornar para casa durante a noite, sem opções de transporte público, por exemplo. O álcool faz acreditar que é "capaz de tudo". Não costuma fazer isso em cidades com mais opções para poder retornar (transporte público e Uber), e onde há fiscalização mais rigorosa. As perguntas relacionadas a direção sob efeito de drogas foram encaradas de forma menos natural, comparada a beber e dirigir. $\mathrm{O}$ ato de usar drogas $\mathrm{e}$ conduzir foi considerado mais perigoso, sendo que um deles considera que o perigo também está relacionado com tipo e a quantidade ingerida, e neste caso seria válido não somente para drogas, mas também bebidas.

Todos os participantes já foram autuados por excesso de velocidade em mais de uma vez. Com relação às infrações sem serem autuados, dois disseram ter o costume de passar por semáforos vermelhos, no entanto, apenas no período noturno por questão de segurança. Um deles afirmou não usar cinto de segurança em determinados horários e distâncias.

Identificar práticas recorrentes de violação Nenhum dos participantes discordam da legislação de trânsito atual, e afirmam conhecer, ainda que minimamente, as punições previstas em lei. Com relação a respeitar as regras de trânsito, o fazem e acreditam que isso está mais relacionado com educação do que com risco, e que ajuda no fluxo de trânsito. Desrespeitá-lo prejudicaria mais o sistema, e não necessariamente representaria um risco.

Com relação à sensação em cometer infrações de velocidade, as respostas foram diferentes. Houve a descrição de: preocupação com radares, indiferença e se sentir à vontade, pois quando corre está sob efeito de álcool. Ao se dirigir alcoolizado, a sensação descrita foi de tranquilidade e autoconfiança. Nenhum deles relatou dirigir sob efeito de drogas, e não relataram qualquer tipo de sensação ao infringir leis.

Todos os participantes relataram sentir que mudam o comportamento no trânsito influenciados pelo local onde estão dirigindo e em relação a como as outras pessoas dirigem. Se sentem irritados com a falta de educação dos outros motoristas, ou atos inseguros cometidos.
Você acha que seu comportamento muda no trânsito? Se sim, quais os tipos de mudanças você observa? • 0 que te leva a se alterar?
Identificar fatores externos que influenciam 0 comportamento do motorista motivos

relacionados à emoção associados à violação

Você já sofreu algum tipo de acidente de trânsito?

Se sim, foi grave? • Você teve alguma culpa no acidente? • Você sente que mudou seu comportamento após o acidente?
Obter informação acerca do histórico de acidente
Dois participantes relataram envolvimento com acidentes de trânsito e que tiveram culpa. Um deles foi devido à sonolência, e atualmente procura descansar ao invés de arriscar.

\title{
Os resultados das entrevistas corroboraram os principais fatores identificados na
}

\author{
literatura. Assim, foi possível estruturar o questionário com base nos fatores \\ identificados.
}




\subsection{Seções do questionário}

Desde a elaboração da primeira versão do questionário, muitas alterações foram realizadas tanto no conteúdo do questionário como na forma escrita das perguntas. Entretanto, o conteúdo do questionário foi organizado em três seções principais: Seção 1: Dados socioeconômicos e histórico como condutor, Seção 2: Nível de familiaridade com o ambiente da estrada como condutor, e Seção 3: Você mesmo como condutor.

\subsubsection{Seção 1: Dados socioeconômicos e histórico como condutor}

Esta seção contempla a caracterização da amostra com questões do local onde reside, sexo, idade, escolaridade, renda, bem como estado civil e se tem filho(s), indicando a idade do(s) filho(s), que foram incluídos após o primeiro teste piloto.

A experiência de condução foi caracterizada pelo tempo de carteira de habilitação, os quilômetros percorridos semanalmente, o número de vezes que foi autuado nos últimos três anos e os motivos, o número de vezes que esteve envolvido em acidentes de trânsito nos últimos 3 anos, e a gravidade do(s) acidente(s). As respostas foram organizadas em variáveis categóricas nominais e numéricas.

4.2.2 Seção 2: Nível de familiaridade com o ambiente da estrada como motorista A segunda seção corresponde a questões criadas para caracterizar o ambiente viário de acordo com a visão do condutor. No contexto urbano, a investigação decorreu da análise da interferência da i) densidade urbana e ii) infraestrutura percebida pelo motorista.

A densidade urbana foi avaliada por meio de quatro imagens selecionadas no Google Earth (duas imagens de cada país diferenciando-se quanto a largura das vias e altura das edificações), em que os participantes tinham que indicar a frequência em que conduziam em ruas similares às imagens. A infraestrutura viária urbana foi representada pela indicação da presença de condições físicas e dispositivos viários como rotatórias, semáforos, sinalização vertical, sinalização horizontal, entre outros, em que os participantes indicavam a frequência em que estes itens estavam presentes nos caminhos que percorriam. 
No contexto rodoviário, a investigação contemplou a frequência que o usuário conduz em rodovias e a frequência que dirige em rodovias semelhantes às imagens de acordo com: i) nível de serviço das rodovias que dirige; ii) qualidade do pavimento; e iii) tipo de traçado da via.

Para caracterização do estado de conservação do pavimento das rodovias, foram utilizadas seis imagens com diferentes condições físicas da pista de rolamento, considerando desde uma situação sem pavimento até pavimento sem deformações. O traçado da pista foi representado em três imagens (reto, com curvas ou sinuoso) e outras três imagens caracterizaram o nível de serviço da rodovia de acordo com os níveis de serviço "A", "C" e "E" (HIGHWAY CAPACITY MANUAL - HCM, 2010) de forma a representar a densidade na rodovia.

Todas as respostas foram obtidas em uma escala Likert de cinco níveis onde 1 representava "Nunca" (Eu nunca dirijo em uma rua/rodovia parecida) e 5 a "Muito frequentemente" (Eu muito frequentemente dirijo em uma rua/rodovia parecida).

\subsubsection{Seção 3: Você mesmo como condutor}

Esta seção investiga as habilidades como condutor, traços de personalidade, percepção de comportamentos de risco e a frequência de comportamentos arriscados dos motoristas. Essas medidas consistem em questionários validados e questões elaboradas especialmente para esta tese de doutorado.

Para avaliação da habilidade de dirigir dos condutores, o questionário de Delhomme (1991) foi traduzido e adaptado para uso neste estudo. Originalmente, os participantes tinham que avaliar a própria forma de conduzir e a dos demais condutores por meio de 4 perguntas. Nesse estudo, dois itens foram incluídos, complementando a versão original, onde também foram questionados sobre a cautela e os reflexos dos outros condutores seguindo o mesmo padrão dos demais itens.

Os traços de personalidade busca de sensações e raiva ao conduzir foram investigados com auxílio dos questionários "Sensation Seeking" (SS) de Taubman, Mikulincer e Iram (19965 apud YAGIL, 2001, p. 728) e "Driver Anger Behavior" (DAS) de Deffenbacher, Oetting e Lynch (1994). Como visto na literatura e apresentado na revisão bibliográfica, estes traços de personalidade são positivamente relacionados 
ao comportamento de risco no trânsito, e mensurá-los auxilia na caracterização desse comportamento.

A versão do Driver Behavior Questionnaire (DBQ), utilizada neste trabalho, investigou a frequência de comportamentos inseguros, classificados como: erros, violações agressivas e violações comuns (ÖZKAN et al., 2006). Esses fatores estão associados ao envolvimento de acidentes de trânsito, caracterizando-se, então, como comportamentos de risco.

Para avaliação de comportamentos específicos e a percepção de risco, foram apresentados itens afirmativos com situações de comportamentos inseguros no trânsito em que o condutor tinha que indicar, de acordo com duas questões diferentes, a frequência que se comportava daquela maneira e o nível de risco associado ao comportamento. Um total de 20 itens afirmativos contemplavam situações relacionadas ao uso do celular enquanto dirige; violações como excesso de velocidade, atravessar o semáforo na luz vermelha, não usar o cinto de segurança, dirigir muito próximo ao carro da frente; e cometer atos inseguros como mudança de faixa sem sinalizar, ultrapassagem sem olhar o espelho retrovisor, conduzir muito próximo ao veículo da frente e dirigir cansado.

Os itens afirmativos foram avaliados em uma escala Likert de 5 níveis, conforme o enunciado da questão, e podem ser consultados nos Apêndices A (versão do Brasil) e B (versão de Portugal).

\subsection{Testes piloto}

Dois estudos piloto foram conduzidos para testar as questões e as escalas do questionário. Esta seção apresenta os resultados e alterações realizadas a partir de cada teste.

\subsubsection{Primeiro teste piloto}

O primeiro teste piloto foi realizado entre os dias 22 e 31 de maio de 2017, sendo que nenhum dos participantes desta etapa fez parte da etapa anterior.

A amostra foi composta por 6 brasileiros e 6 portugueses, e foi propositalmente homogênea por sexo (50\% homens, 50\% mulheres). A idade média dos entrevistados 
foi de 31,08 anos ( $D P=5,632$; intervalo $=25$ a 46 ). A experiência como motorista foi medida pelo tempo de carteira de habilitação e os quilômetros percorridos semanalmente. A média do tempo de licença de motorista de carro foi de 10,58 anos $(\mathrm{DP}=5,779$; intervalo $=2$ a 22) e a para motoristas de motocicletas foi de 6,25 anos $(\mathrm{DP}=8,540$, intervalo $=0$ a 22). Não houve participantes das outras categorias de veículos. Os participantes relataram que dirigiam semanalmente uma média de 204,83 quilômetros de carro ( $D P=246,245$, intervalo $=28$ a 800) e 63,08 quilômetros de motocicleta $(\mathrm{DP}=171,989$, intervalo $=0$ a 600$)$.

\subsubsection{Análise de confiabilidade}

Nesta etapa, a avaliação da confiabilidade das escalas foi realizada com auxílio do Alfa de Cronbach (Tabela 4.1).

Os questionários já validados foram analisados baseados na estrutura fatorial das escalas originais. Na avaliação, foram considerados o número de itens da questão e $\alpha \geq 0,60$ para confiabilidade aceitável, conforme recomendado por Kline ${ }^{8}$ (1999, apud FIELD, 2009, p. 594-595).

- Habilidades do motorista apresentou níveis aceitáveis de confiabilidade, uma vez que o Alfa de Cronbach foi superior a 0,60 e as variáveis latentes são compostas por 3 itens apenas, que penalizam o indicador.

- A escala de raiva do condutor apresentou um nível de confiabilidade semelhante à escala original $(0,800)$ de Deffenbacher, Oetting e Lynch (1994).

- Busca de sensações apresentou um índice inferior ao original $(0,84)$ de Yagil (2001), contudo, está dentro de um valor aceitável para construtos psicológicos (acima de 0,60).

Os itens criados para avaliar o comportamento frequente do motorista foram analisados como fator único nesta etapa da pesquisa e se mostraram aceitáveis, uma vez que o alfa foi superior a 0,60. Esses itens foram elaborados para este questionário, por isso não foi possível compará-los a resultados prévios encontrados na literatura. No âmbito da percepção de risco, em que os mesmos itens foram analisados quanto

${ }^{8}$ KLINE, P. The handbook of psychological testing (2nd ed.). London: Routledge, 1999. 
ao nível de risco dos comportamentos, a escala se mostrou confiável em um nível excelente, segundo a classificação de Hill e Hill (2008).

O resultado do questionário de comportamento do motorista (DBQ), que também avalia a frequência dos comportamentos dos condutores, indicou resultados de confiabilidade entre baixo e inaceitável. Os valores estiveram abaixo dos apresentados por Özkan et al. (2006) para violação comum $(0,730-0,850)$ e violação agressiva $(0,590-0,740)$, salvo o construto erros, que apresentou valores semelhantes $(0,620-0,750)$. O item 12 do questionário (Ficar furioso por causa de outro motorista e persegui-lo com a intenção de dizer exatamente o que você pensa dele/dela) foi excluído desta análise por não apresentar variação. Os itens de violação comum apresentaram um valor negativo para o alfa (-0.404), indicando que havia uma covariância média negativa entre os itens. Esses valores eram um indicativo de problema com relação à interpretação dos itens, que pode ser consequência da tradução.

Tabela 4.1 - Alfa de Cronbach do primeiro teste piloto

\begin{tabular}{lccc}
\hline \multicolumn{1}{c}{ Grupo de questões } & Alfa de Cronbach & $\begin{array}{c}\text { Alfa de Cronbach (itens } \\
\text { padronizados) }\end{array}$ & $\begin{array}{c}\mathrm{N} \text { de } \\
\text { itens }\end{array}$ \\
\hline Eu mesmo como motorista & 0,714 & 0,709 & 3 \\
Os outros como motorista & 0,646 & 0,639 & 3 \\
Escala de raiva do condutor & 0,805 & 0,821 & 14 \\
Busca de sensações & 0,697 & 0,752 & 7 \\
Comportamento frequente & 0,797 & 0,811 & 17 \\
Percepção do risco & 0,924 & 0,921 & 16 \\
DBQ (todos os itens) & 0,473 & 0,635 & 19 \\
DBQ - Erro & 0,703 & 0,746 & 8 \\
DBQ - Violação agressiva & 0,474 & 0,501 & 3 \\
DBQ - Violação comum & $-0,404$ & 0,069 & 8 \\
\hline
\end{tabular}

Os itens das perguntas criadas para investigação do ambiente viário não foram avaliados com o Alfa de Cronbach nesta etapa, sendo avaliados na etapa de análise exploratória (Capítulo 5).

\subsubsection{Medidas de localização das respostas}

As perguntas relacionadas à investigação do ambiente e as relacionadas à investigação do comportamento foram avaliadas a partir dos resultados de média, desvio padrão e variância, apresentados no Apêndice C. Calcular medidas como a média para questões com escalas ordinais não é representativo, mas podem ser 
informativas no âmbito de uma medida de localização quando usada com cautela (MADSEN, 2016), o que foi realizado nesta etapa do trabalho.

Dessa forma, foi possível verificar que todos os itens de investigação do ambiente apresentaram variação, ou seja, não se concentraram em uma única opção. O fato dos respondentes selecionarem diferentes opções para as imagens foi interpretado como um indicativo positivo de que as imagens representavam, minimamente, o local que dirigem, ou seja, que as pessoas conseguiram assimilar as características das imagens com as dos locais que dirigem. Caso contrário, as repostas estariam concentradas na opção "Nunca".

Nas perguntas sobre comportamento, os itens: 3.5 e 4.5 (Usar algum tipo de droga ilegal e dirigir), 4.13 (Dirigir após exceder o limite de álcool permitido) e 5.12 (Ficar furioso por causa de outro motorista e o perseguir com a intenção de dizer exatamente o que você pensa dele/dela) não apresentaram variação, isto é, todos os participantes responderam a mesma opção, "nunca", para os itens 3.5 e 5.12, e "muito arriscado" para os itens 4.5 e 4.13 .

Os itens relacionados ao uso de drogas e consumo de álcool podem ser condicionados pela resposta socialmente desejável, como abordado por Özkan et al. (2006). Com relação ao item de investigação do DBQ, perseguir alguém é considerado um comportamento muito ruim e também pode ser uma resposta socialmente condicionada.

\subsubsection{Comentários dos participantes e alterações}

Como mencionado anteriormente, os participantes foram instruídos a fazer anotações sobre qualquer dúvida, sugestão ou comentário que tivessem em relação ao questionário. As indicações mais relevantes são apresentadas no Quadro 4.2. 
Quadro 4.2 - Comentários dos participantes sobre o primeiro estudo piloto

\begin{tabular}{|c|c|}
\hline $\begin{array}{l}\text { Parte do } \\
\text { questionário }\end{array}$ & Anotação \\
\hline Enunciado & $\begin{array}{l}\text { Descrever o número de questões no enunciado do questionário para a pessoa saber quando está próxima de } \\
\text { terminar }\end{array}$ \\
\hline Formatação & Incluir um título para cada divisão de grupos de perguntas para saber o assunto que será abordado \\
\hline Escolaridade & Incluir o nível de pós-graduação \\
\hline Questão 6 & Seis participantes relataram dúvida ao responder a questão 6 , tempo de carteira de habilitação \\
\hline Questão 13b & Duas pessoas afirmaram não existir estradas como as duas primeiras imagens em Portugal \\
\hline Questão 14 & Não entendeu quais características deveriam ser avaliadas \\
\hline Questão 15 & $\begin{array}{l}\text { i) Dúvidas sobre quais ambientes avaliar: rodovias ou urbano?; ii) Incluir exemplos de sinalização horizontal e } \\
\text { vertical; iii) } 0 \text { que seria interseção sinalizada }\end{array}$ \\
\hline Questão 17 & Mudar a escala para "Absolutamente falso" para ficar mais coerente \\
\hline Questão 18 & $\begin{array}{l}\text { Item 12: "Dirigir 20km, em média, sem usar cinto de segurança" - Não entendeu } \\
\text { Item 15: "Ignorar regras para andar mais rápido" - Quais regras? } \\
\text { Item 18: "Usar o celular enquanto dirige em uma rodovia" - Considera modo viva voz? }\end{array}$ \\
\hline Questão 20 & $\begin{array}{l}\text { Item 7: "Parar em uma esquina tão para frente que o motorista com direito de passagem tem que parar e deixar } \\
\text { você passar" Não entendeu }\end{array}$ \\
\hline
\end{tabular}

Todos os participantes afirmaram que o questionário foi rápido e fácil de responder, que os fizeram pensar sobre a forma que dirigem e que está dentro da realidade deles. Após analisar os resultados do Alfa de Cronbach, a distribuição das respostas e os comentários dos participantes, algumas mudanças foram realizadas para o segundo teste piloto, apresentadas no Quadro 4.3.

Quadro 4.3 - Mudanças na primeira versão do questionário

\begin{tabular}{|c|c|}
\hline Alteração & Objetivo \\
\hline Inclusão do número de questões e tempo médio de resposta & Indicar ao participante o tempo necessário para responder \\
\hline Inclusão de barra de progressão & Orientá-lo de quanto ainda falta para terminar \\
\hline Nome indicando cada seção & $\begin{array}{l}\text { Para o participante saber o contexto das questões que irá } \\
\text { responder }\end{array}$ \\
\hline $\begin{array}{l}\text {-Inclusão da pergunta sobre: estado civil, se tem filhos e idade dos } \\
\text { filhos; } \\
\text {-Inclusão do item pós-graduação; } \\
\text {-Exclusão da opção "Outros" e "Não quero declarar" na pergunta } \\
\text { sobre Renda }\end{array}$ & Para caracterizar com mais informações o perfil do motorista \\
\hline $\begin{array}{l}\text { Exclusão da coluna meses na pergunta sobre o tempo de } \\
\text { habilitação, e inclusão de um item "Menos de } 1 \text { ano" nas opções de } \\
\text { resposta }\end{array}$ & Deixar a resposta mais clara \\
\hline Inclusão de exemplos de sinalização horizontal e vertical & Melhorar a compreensão dos termos \\
\hline Mudança na tradução da escala de busca de sensações & $\begin{array}{l}\text { Deixar a tradução da escala indicando opostos: Absolutamente } \\
\text { falso vs absolutamente verdadeiro }\end{array}$ \\
\hline Inclusão de quatro itens sobre celular & $\begin{array}{l}\text { Investigar a frequência e percepção do risco do uso do celular } \\
\text { em área urbana ou rodovias, manuseando com as mãos ou em } \\
\text { modo viva voz }\end{array}$ \\
\hline $\begin{array}{l}\text { Alteração do item: "Dirigir } 20 \mathrm{~km} \text {, em média, sem usar o cinto de } \\
\text { segurança" para "Dirigir uma distância de } 20 \mathrm{~km} \text {, em média, sem usar } \\
\text { o cinto de segurança" }\end{array}$ & Melhorar a compreensão desses itens \\
\hline Avaliação da tradução do DBQ & Melhorar o resultado do Alfa de Cronbach \\
\hline
\end{tabular}

Todos os itens do DBQ passaram por uma etapa de revisão da tradução, onde quatro indivíduos de cada país foram convidados para avaliar a tradução e melhorar a 
semântica dos itens. Dos 20 itens, 13 foram modificados nas versões de Brasil e Portugal.

O item sobre o consumo de álcool, que inicialmente estava expresso por "Dirigir quando você suspeita que você pode estar acima do limite legal de álcool no sangue", foi modificado para "Dirigir após consumir bebida alcoólica", visto que, no Brasil, a Lei Seca 11.705/2008 (BRASIL, 2008), no artigo 165, prevê multa aos motoristas que dirigirem sob influência de álcool, sem especificar um teor mínimo.

As perguntas referentes à avaliação do ambiente foram reescritas com o objetivo de deixá-las mais claras e objetivas para facilitar a interpretação. A primeira imagem da pergunta sobre o contexto urbano foi alterada para se aproximar mais da realidade dos dois países.

\subsubsection{Segundo teste piloto}

Após as alterações mencionadas anteriormente, o segundo teste piloto foi realizado, no período de 07 a 16 de junho de 2017, com outros 12 participantes que receberam as mesmas orientações que foram feitas durante o primeiro teste.

A amostra foi novamente dividida em proporções iguais de nacionalidade ( 6 brasileiros e 6 portugueses) e sexo ( $50 \%$ homens e $50 \%$ mulheres). A média de idade foi de 34,75 anos ( $\mathrm{DP}=8,92$; intervalo $=21$ a 53), com tempo médio de habilitação de carro de 14,25 anos ( $\mathrm{DP}=8,52$; intervalo $=3$ a 33 ) e 1 condutor de motociclos com 3 anos de experiência. Não houve participantes das outras categorias de veículos. Os participantes relataram dirigir em média 160,58 quilômetros de carro (DP $=132,55$, intervalo $=10$ a 450) e 100 quilômetros de motocicleta. De modo geral, observa-se que o segundo teste piloto foi composto por participantes mais velhos, com mais tempo de experiência, porém, que dirigem, em média, menos quilômetros por semana.

\subsubsection{Comparação da análise de confiabilidade}

Com relação à comparação dos resultados de teste de confiabilidade de escala (Tabela 4.2), de modo geral, todos os itens melhoraram, destacando-se o resultado do DBQ que passou por uma reavaliação da tradução e modificações. 
Os itens relacionados à auto avaliação tiveram seu valor reduzido, podendo ser explicado pelo item "Eu sou um ótimo motorista", que apresentou menor variabilidade na resposta. Considerando que os resultados do primeiro teste foram melhores e não foram feitos comentários sobre esses itens por parte dos participantes, foi necessária uma reavaliação após obtenção de maior número de respostas. Na atual versão, esse item foi alterado para "Eu sou um motorista muito bom", seguindo a tradução literal.

Também houve uma redução nos valores de alfa relacionados à busca de sensações. Como inicialmente estes itens apresentaram um valor satisfatório, os resultados podem estar relacionados à caracterização da amostra (idade).

Tabela 4.2 - Alfa de Cronbach dos testes piloto 1 e 2

\begin{tabular}{lcccccc}
\hline \multicolumn{1}{c}{ Item avaliado } & \multicolumn{3}{c}{ Teste Piloto 1 } & \multicolumn{3}{c}{ Teste Piloto 2 } \\
\cline { 2 - 7 } & $\begin{array}{c}\text { Alfa de } \\
\text { Cronbach }\end{array}$ & $\begin{array}{c}\text { Alfa de Cronbach } \\
\text { (itens } \\
\text { padronizados) }\end{array}$ & $\begin{array}{c}\mathrm{N} \text { de } \\
\text { itens }\end{array}$ & $\begin{array}{c}\text { Alfa de } \\
\text { Cronbach }\end{array}$ & $\begin{array}{c}\text { Alfa de Cronbach } \\
\text { (itens } \\
\text { padronizados) }\end{array}$ & $\begin{array}{c}\mathrm{N} \text { de } \\
\text { itens }\end{array}$ \\
\hline Auto avaliação & 0,714 & 0,709 & 3 & 0,386 & 0,232 & 3 \\
Avaliação dos demais & 0,646 & 0,639 & 3 & 0,699 & 0,714 & 3 \\
DAS & 0,805 & 0,821 & 14 & 0,866 & 0,868 & 14 \\
Busca de sensações & 0,697 & 0,752 & 7 & 0,484 & 0,543 & 7 \\
Comportamento frequente & 0,797 & 0,811 & 17 & 0,840 & 0,847 & 19 \\
Percepção de risco & 0,924 & 0,921 & 16 & 0,940 & 0,942 & 20 \\
DBQ (todos os itens) & 0,473 & 0,635 & 19 & 0,845 & 0,846 & 20 \\
DBQ - Erro & 0,703 & 0,746 & 8 & 0,792 & 0,792 & 8 \\
DBQ - Violação agressiva & 0,474 & 0,501 & 3 & 0,778 & 0,788 & 3 \\
DBQ - Violação comum & $-0,404$ & 0,069 & 8 & 0,704 & 0,704 & 8 \\
\hline
\end{tabular}

\subsubsection{Comparação das distribuições das respostas}

No primeiro estudo piloto, os itens relacionados ao álcool e uso de drogas não apresentaram variação na distribuição das respostas. No segundo estudo piloto, apenas o item 3.5 não apresentou variação, onde a pessoa é questionada sobre a frequência em que usou algum tipo de droga e dirigiu. As métricas usadas como medidas de localização das respostas são apresentadas na Tabela C.1 do Apêndice C.

\subsubsection{Comentários e sugestões do segundo teste piloto}

O segundo teste piloto resultou em poucas sugestões para alterações que foram: i) a substituição do termo bluetooth, em inglês, pelos termos "modo viva voz" (Br) e "mãos livres" (Pt), nas sentenças sobre a frequência em que usavam celular enquanto conduziam em área urbana ou rodovias; e ii) enfatizar no enunciado do questionário 
que as respostas serão confidenciais e anônimas para evitar constrangimentos em informar a renda e evitar viés de respostas socialmente desejáveis.

\subsection{Versão final: testes da versão online e divulgação}

Alguns testes com a versão online do questionário foram realizados. O link da pesquisa foi distribuído de forma controlada e os participantes foram instruídos a relatarem qualquer tipo de anormalidade ocorrida durante o preenchimento do questionário. Alguns erros de formato, digitação e sequência de questões foram identificados e corrigidos para divulgação e coleta dos dados.

Finalmente, a versão final foi divulgada por meio de convites individuais enviados por e-mail, além da divulgação da pesquisa em jornais, rádios e mídias sociais.

\subsection{Distribuição de frequências dos dados em escala Likert da amostra final}

Como apresentado no Capítulo 3, Materiais e Método, a pesquisa teve um total de 1702 respostas válidas. Nesta seção são apresentadas as frequências das respostas das perguntas com itens em escala Likert.

Ao se avaliar os itens que mensuravam as habilidades de condução (Figura 4.1), observa-se que poucos participantes se autoavaliaram com poucas habilidades de condução. Em relação à cautela ao dirigir (HabCond03 e HabCond04), de forma geral, os participantes se autoavaliaram como cautelosos ao conduzir, contudo, tendem a ver os demais condutores como menos cautelosos.

Os itens que mensuravam a escala de raiva do condutor (Figura 4.2) apresentaram, de modo geral, respostas bem distribuídas entre as opções da escala Likert, exceto pelo item DAS06 (Um policial manda você encostar). Neste caso, houve uma grande concentração de respostas na opção 1 , indicando que esse tipo de abordagem não causa raiva para maior parte dos participantes. De forma contrária, as situações DAS03 (Alguém dá marcha ré em sua direção sem olhar) e DAS08 (Alguém avança o sinal de trânsito (semáforo/sinaleira) vermelho ou a placa de "pare") causam elevados níveis de raiva na maior parte dos participantes. 
Figura 4.1 - Frequência das respostas dos itens sobre habilidades de condução

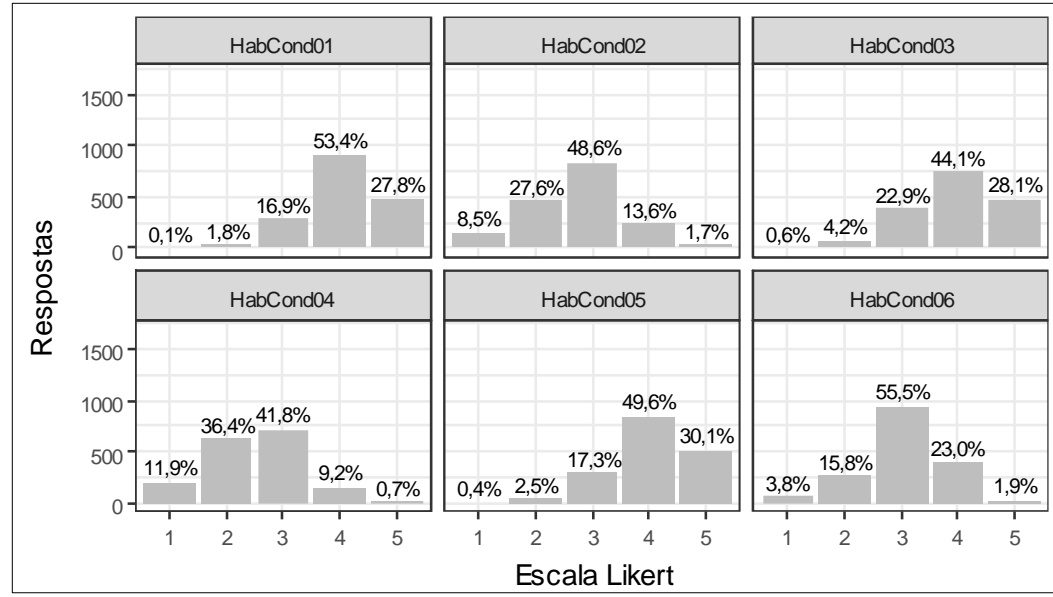

Nota: HabCond01. Eu sou um motorista muito bom; HabCond02. Em geral, outras pessoas são muito boas motoristas: HabCond03. Eu dirijo muito cautelosamente; HabCond04. Em geral, outras pessoas dirigem muito cautelosamente; HabCond05. Meus reflexos enquanto dirijo são muito bons; HabCond06. Em geral, os reflexos das outras pessoas enquanto dirigem são muito bons. Escala Likert: 1. Discordo totalmente, 5. Concordo totalmente.

Figura 4.2 - Frequência das respostas dos itens sobre escala de raiva do condutor

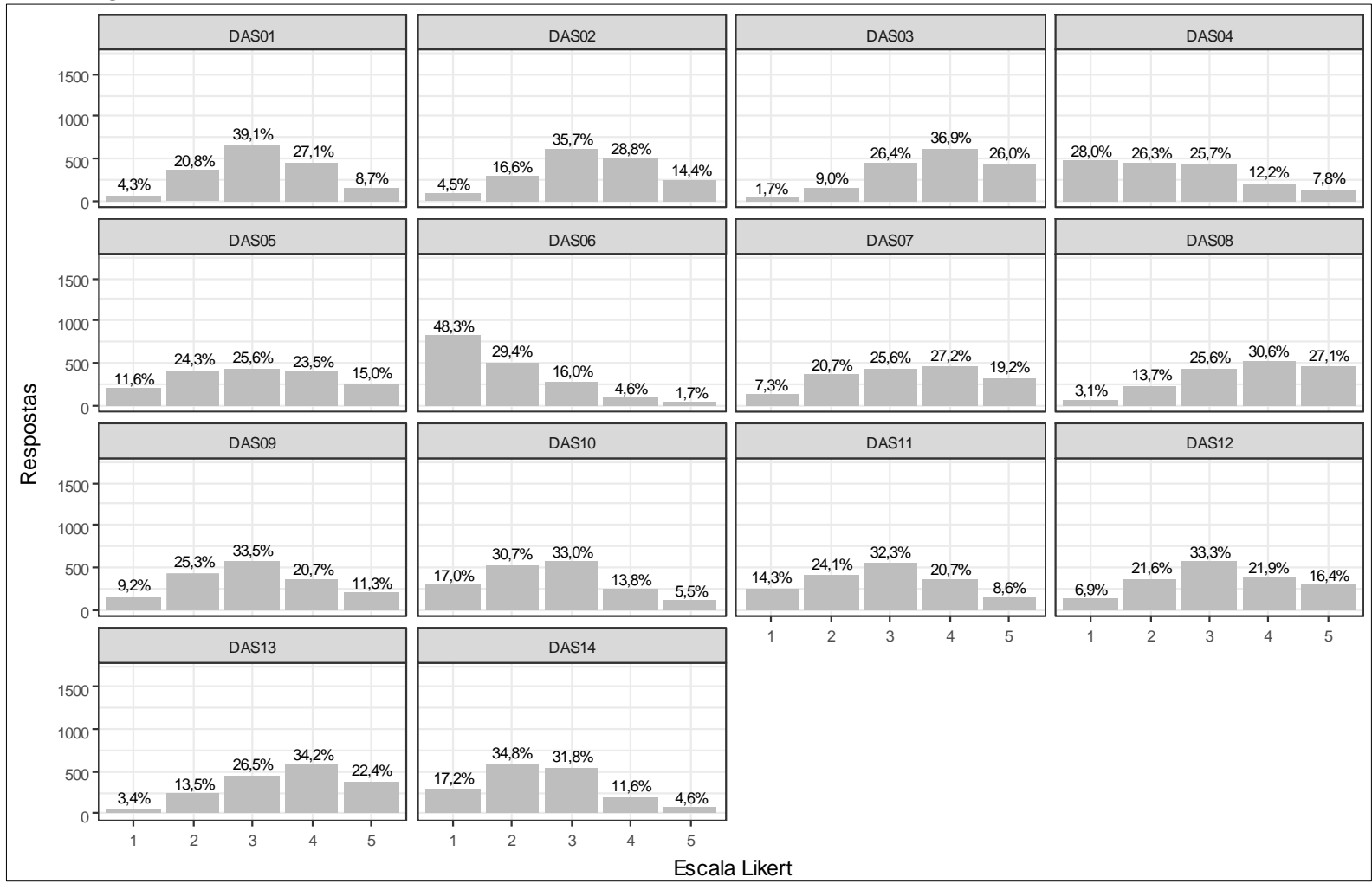

Nota: DAS01. Alguém está "costurando" o trânsito; DAS02. Um veículo lento na subida da serra não oferece passagem para os demais motoristas passarem; DAS03. Alguém dá marcha ré em sua direção sem olhar; DAS04. Você passa por um radar de velocidade; DAS05. Alquém faz um gesto obsceno para você por causa da sua maneira de dirigir: DAS06. Um policial manda você encostar; DAS07. Um caminhão joga areia ou cascalho no carro que você está dirigindo; DAS08. Alguém avança o sinal de trânsito (semáforo/sinaleira) vermelho ou a placa de "pare"; DAS09. Alguém buzina para você por causa da sua maneira de dirigir; DAS10. Você está dirigindo atrás de um caminhão grande e não consegue ver ao redor dele; DAS11. Um ciclista está andando no meio da pista e congestionando o trânsito; DAS12. Você está preso no congestionamento; DAS13. Alguém aumenta a velocidade quando você tenta ultrapassá-lo; DAS14. Alguém demora ao estacionar, atrasando o trânsito. Escala Likert: 1. Nada, 2. Pouco, 3. Razoável, 4. Muita, 5. Muitíssima.

Em relação aos itens de busca de sensações (Figura 4.3), observa-se que o item SS1 (Eu gostaria de dirigir sem uma rota pré-definida e um tempo para chegar), que demonstrava uma situação com menos riscos envolvidos, apresentou os dados mais distribuídos entre as categorias da escala Likert, comparado às demais situações 
apresentadas, em que a maior parcela de participantes relatou não se identificar com aquelas sensações.

Contudo, apesar do item SS3 indicar que 73,6\% dos participantes relatam não gostar de conduzir perigosamente, nos itens SS2, SS5 e SS6, há uma mudança na concentração das frequências, em que um número maior de participantes manifesta concordância com situações de perigo.

Figura 4.3 - Frequência das respostas dos itens sobre busca de sensações

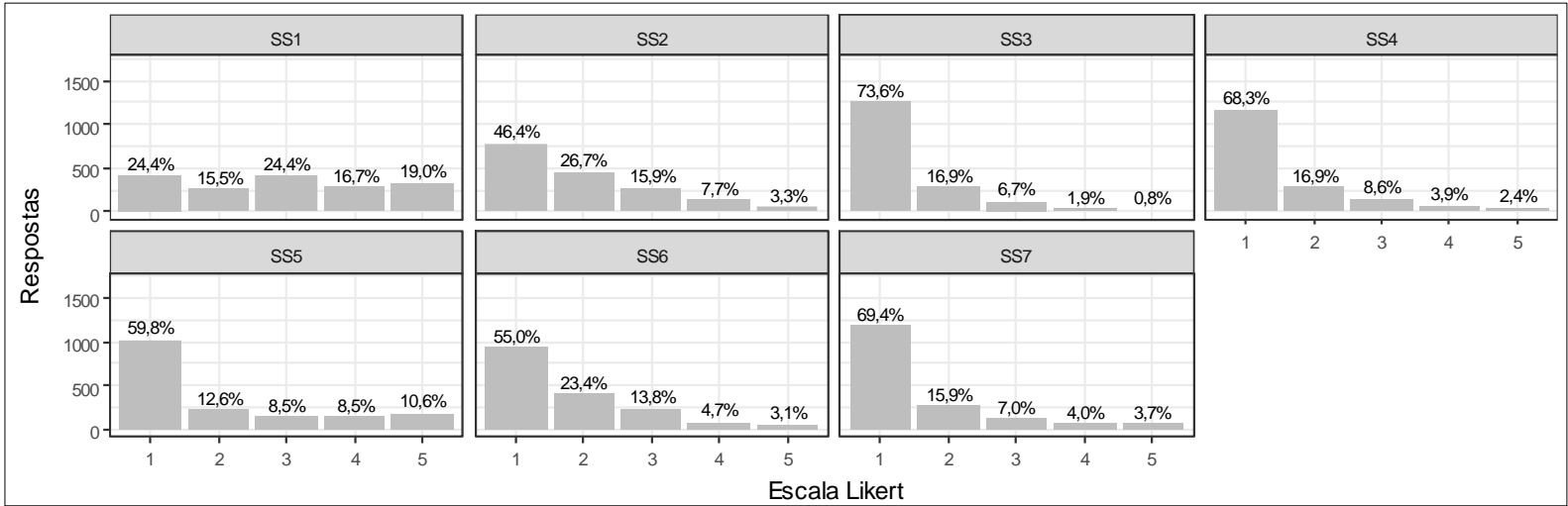

Nota: SS1. Eu gostaria de dirigir sem uma rota pré-definida e um tempo para chegar; SS2. Muitas vezes eu me sinto como um piloto de corrida; SS3. Eu gosto de dirigir perigosamente; SS4. Eu gosto de dirigir em estradas com muitas curvas fechadas; SS5. Eu gostaria de aprender a dirigir carros que podem exceder a velocidade de $300 \mathrm{~km} / \mathrm{h}$; SS6. Eu não tenho paciência para pessoas que dirigem o carro de maneira previsivel e chata; SS7. Eu acho que eu gostaria da experiência de dirigir muito rápido em uma rua íngreme. Escala Likert: 1. "Totalmente falso" a 5. "Totalmente verdadeiro.

Em relação aos itens de caracterização do ambiente urbano (Figura 4.4), observa-se maior variabilidade de respostas entre as questões de imagem que representavam a densidade urbana (Urb01 a Urb04). Este pode ser um indicativo de que as imagens foram capazes de representar a densidade dos diferentes locais amostrados, uma vez que a pergunta pedia que o participante indicasse a frequência que conduzia em locais semelhantes às imagens apresentadas.

A partir do item Urb05 até o item Urb12 é representada a frequência que determinados dispositivos viários estão presentes nos locais em que conduzem. Observa-se que a maior parte dos participantes considerara os dispositivos contemplados nesta pergunta como frequentes nos locais onde conduzem. Contudo, ainda assim há casos em que esses dispositivos são menos frequentes, podendo indicar locais menos desenvolvidos, ou com pouca infraestrutura viária. 
Figura 4.4 - Frequência das respostas dos itens sobre ambiente viário urbano

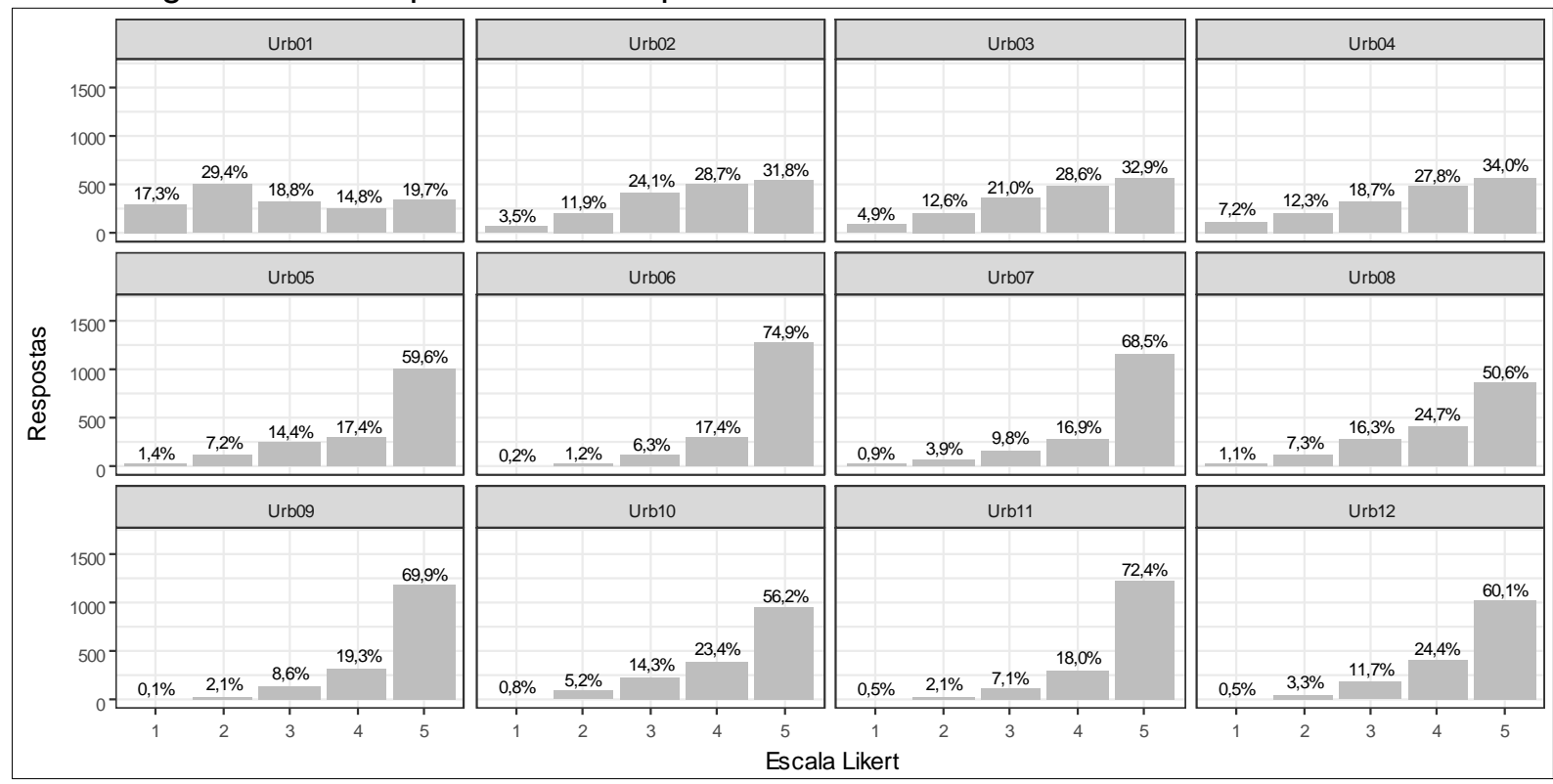

Nota: Urb01. Imagem de rua estreita e edificações baixas; Urb02. Imagem de rua estreita e edificações baixas; Urb03. Imagem de rua estreita e edificações altas; Urb04. Imagem de rua larga e edificações altas; Urb05. Rotatória; Urb06. Faixa de pedestre; Urb07. Semáforo; Urb08. Lombada/Redutor de velocidade; Urb09. Sinalização vertical urbana; Urb10. Sinalização horizontal urbana; Urb11. Ruas pavimentadas; Urb12. Interseção sinalizada. Escala Likert: 1. "Nunca" a 5. "Muito frequentemente".

Os itens de caracterização do ambiente rodoviário (Figura 4.5) indicam que a maior parte dos participantes reportou não conduzir com frequência em vias sem pavimentação (Rodo01 e Rodo02), sendo mais frequente em vias pavimentadas com buracos, e com ou sem a presença de deformações no pavimento.

Figura 4.5 - Frequência das respostas dos itens sobre ambiente rodoviário

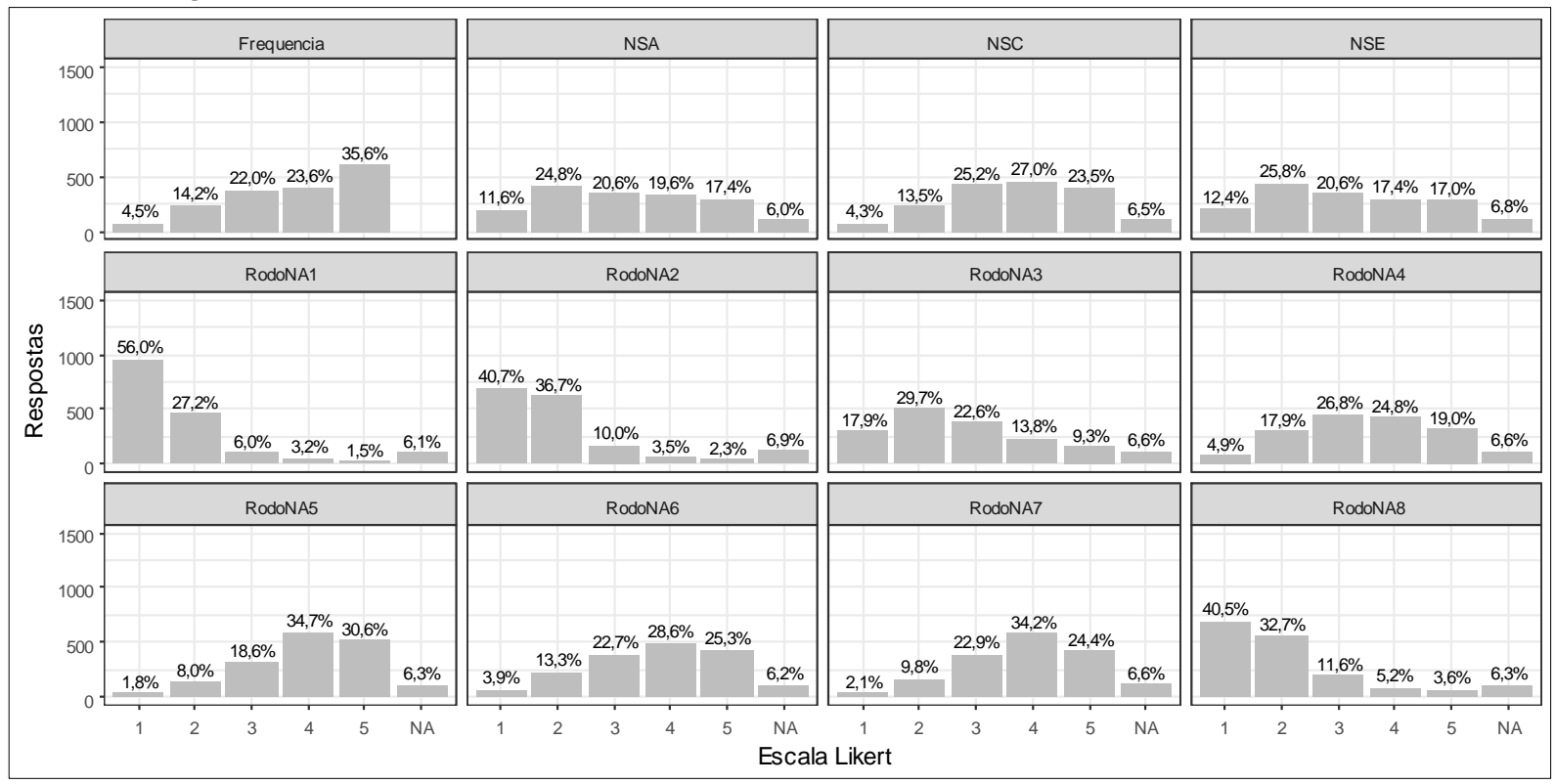

Nota: Frequência. Frequência que dirige em rodovias; NSA. Imagem de rodovia com nivel de serviço A; NSC. Imagem de rodovia com nível de serviço C; NSE. Imagem de rodovia com nível de serviço E; Rodo01. Estradas de terra com deformações; Rodo02. Estradas de terra planas; Rodo03. Pavimento de rod ovia com buracos; Rodo04. Pavimento de rodovia com deformações; Rodo05. Pavimento de rodovia sem deformações; Rodo06. Imagem de traçado reto; Rodo07. Imagem de traçado com curva; Rodo08. Imagem de traçado sinuoso; Escala Likert: 1. Nunca, 5. Muito frequentemente, NA = Não Avaliado.

Observa-se ainda que, em relação à densidade veicular das rodovias, houve uma distribuição semelhante das frequências em relação aos níveis de serviço 
apresentados ("A", "C" e "E”), que representavam o número de veículos nas rodovias. Foram reportadas com mais frequência conduções em vias de traçado retos e com curvas.

Ao avaliar a percepção de risco (Figura 4.6), observa-se que as situações que podem interferir no nível de atenção do condutor foram consideradas como "Muito arriscadas", como sonolência e uso de drogas, ações que possam gerar conflitos e possíveis colisões como não usar o espelho retrovisor, desrespeito às regras de trânsito e sinalizações, e dirigir muito próximo ao veículo da frente. Com relação ao uso de celular, foi considerado como menos perigoso o uso do celular no modo viva voz, comparado ao uso de celular sendo manuseado com as mãos.

Figura 4.6 - Frequência das respostas dos itens sobre a percepção de risco

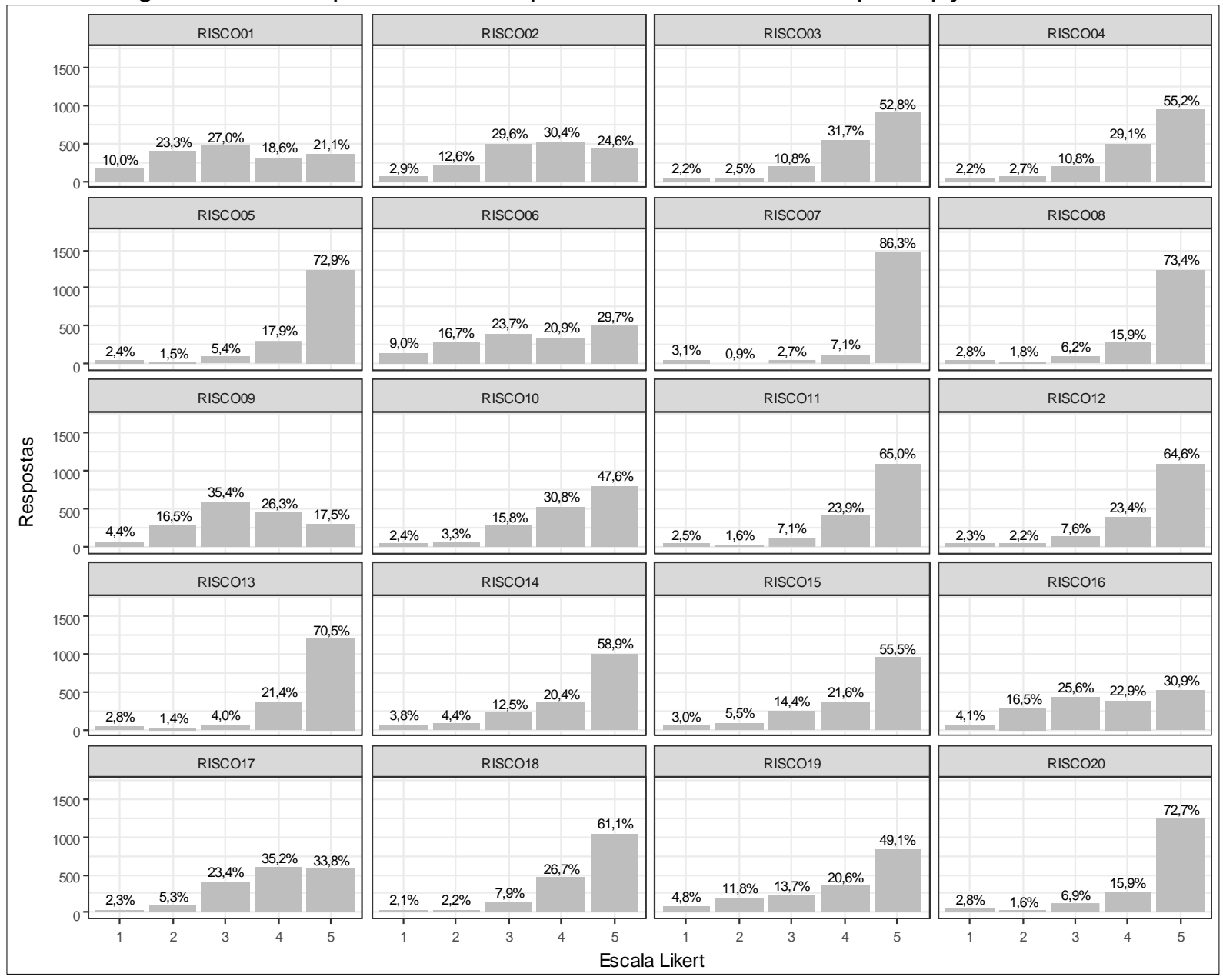

Nota: RISCO01. Usar o celular, no modo viva voz, enquanto dirige em uma área urbana; RISCO02. Exceder o limite de velocidade em pelo menos $20 \mathrm{~km} / \mathrm{h}$ quando você está com pressa; RISCO03. Dirigir muito próximo ao veículo da frente; RISCO04. Mudar de faixa sem fazer sinal; RISCO05. Dirigir com sono; RISCO06. Usar o celular, no modo viva voz, enquanto dirige em uma rodovia; RISCO07. Usar algum tipo de droga ilegal e dirigir; RISCO08. Atravessar o semáforo com o sinal vermelho durante o dia; RISCO09. Exceder a velocidade quando o tráfego está tranquilo; RISCO10. Ignorar placas de sinalização; RISC011. Ultrapassar em local proibido; RISCO12. Usar o celular com as mãos enquanto você dirige em uma área urbana; RISC013. Mudar de faixa sem olhar o espelho; RISC014. Dirigir uma distância de 20km, em média, sem usar o cinto de segurança; RISCO15. Dirigir após beber pelo menos dois copos de bebida alcoólica; RISCO16. Atravessar o semáforo com o sinal vermelho durante a noite; RISCO17. Ignorar limites de velocidade para andar mais rápido; RISC018. Continuar dirigindo quando você está cansado e precisaria de uma pausa; RISCO19. Dirigir pelo menos $2 \mathrm{~km}$ sem usar 0 cinto de segurança; RISCO20. Usar o celular com as mãos enquanto você dirige em uma rodovia. Escala Likert: 1. Não é arriscado, 5. Arriscado. 
$\mathrm{Na}$ Figura 4.7 são apresentadas as frequências dos 20 itens relacionados aos comportamentos específicos, desenvolvidos para esta pesquisa de doutorado. Observa-se que em oito itens, as respostas para opção 1 (Nunca) teve uma frequência superior a 60\%. Esses itens abordavam situações de conduzir sob efeito de drogas ou álcool, não utilizar cinto de segurança, utilizar celular com as mãos em rodovias e condutas que também causavam perigos a terceiros como ultrapassar semáforo durante o dia, ultrapassar em local proibido e mudar de faixa sem olhar no espelho. Entre os comportamentos mais frequentes dos condutores, foram relatos o uso do celular no modo viva voz na área urbana e exceder o limite de velocidade quando está com pressa, para andar mais rápido ou quando há pouco tráfego.

Figura 4.7 - Frequência das respostas dos itens de comportamentos específicos

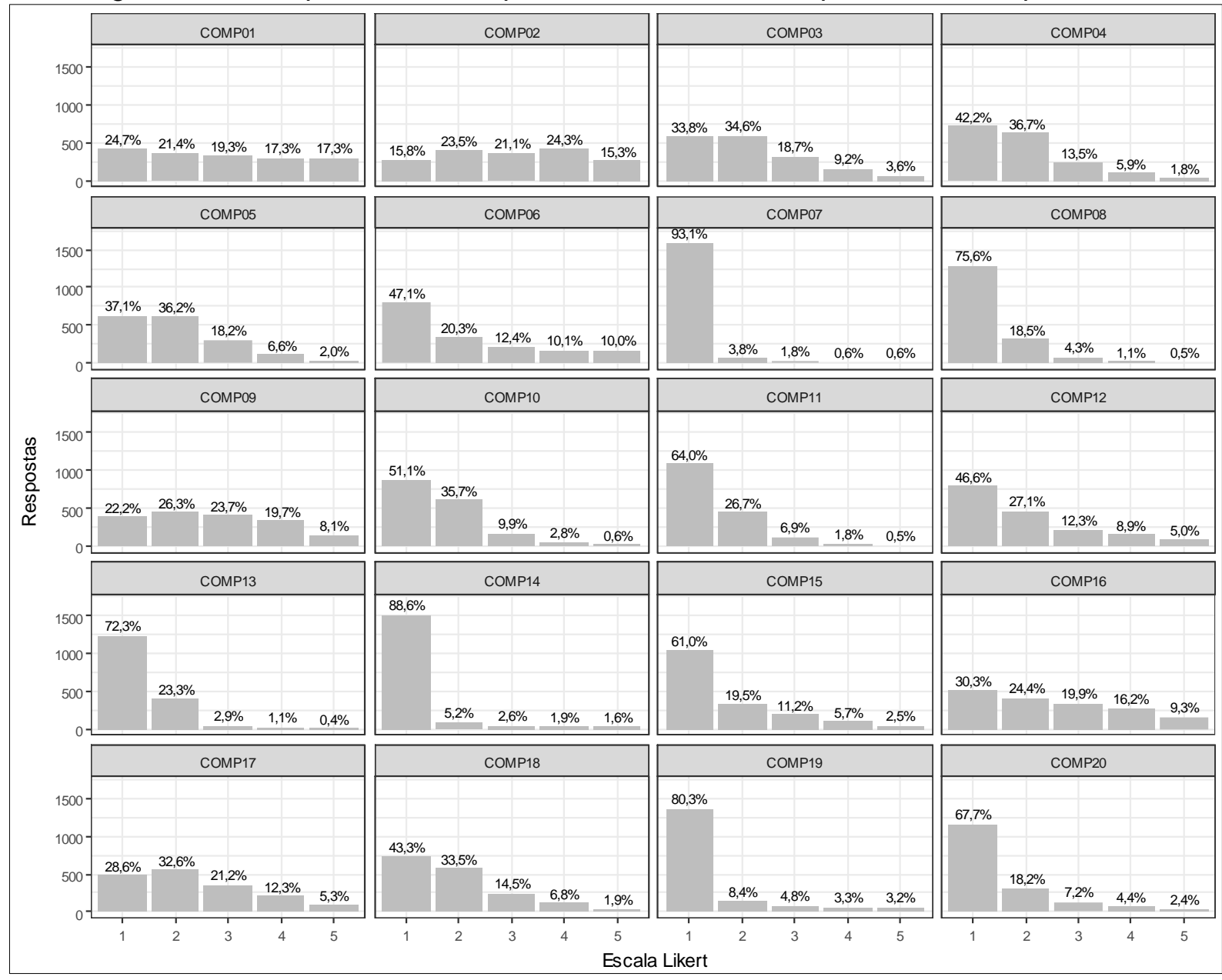

Nota: COMP01. Usar o celular, no modo viva voz, enquanto dirige em uma área urbana; COMP02. Exceder o limite de velocidade em pelo menos $20 \mathrm{~km} / \mathrm{h}$ quando você está com pressa; COMP03. Dirigir muito próximo ao veículo da frente; COMP04. Mudar de faixa sem fazer sinal; COMP05. Dirigir com sono; COMP06. Usar o celular, no modo viva voz, enquanto dirige em uma rodovia; COMP07. Usar algum tipo de droga ilegal e dirigir; COMP08. Atravessar o semáforo com o sinal vermelho durante o dia; COMP09. Exceder a velocidade quando o tráfego está tranquilo; COMP10. Ignorar placas de sinalização; COMP11. Ultrapassar em local proibido; COMP12. Usar o celular com as mãos enquanto você dirige em uma área urbana; COMP13. Mudar de faixa sem olhar o espelho; COMP14. Dirigir uma distância de 20km, em média, sem usar o cinto de segurança; COMP15. Dirigir após beber pelo menos dois copos de bebida alcoólica; COMP16. Atravessar o semáforo com o sinal vermelho durante a noite; COMP17. Ignorar limites de velocidade para andar mais rápido; COMP18. Continuar dirigindo quando você está cansado e precisaria de uma pausa; COMP19. Dirigir pelo menos $2 \mathrm{~km}$ sem usar o cinto de segurança; COMP20. Usar o celular com as mãos enquanto você dirige em uma rodovia. Escala Likert: 1. Nunca, 5. Muito frequentemente. 
Entre os 20 itens relacionados aos comportamentos mensurados pelo DBQ (Figura 4.8), observa-se uma distribuição da frequência mais equilibrada das respostas em escala Likert para sete itens, relacionados a falta de atenção, desrespeito ao limite de velocidade e semáforo e manifestação da raiva perante outro condutor. Entre os itens reportados como menos frequentes pelos participantes estão: intenção de perseguir outro condutor para manifestar a insatisfação, falta de atenção levando a não perceber ciclista e sinais de preferência, e em manobras de ultrapassagens.

Em relação ao Item DBQ01, o resultado deste item corrobora com o item COMP15, em que frequências semelhantes foram relatas referentes ao comportamento de conduzir sob efeito de bebida alcoólica.

Figura 4.8 - Frequência de respostas dos itens do Driver Behavior Questionnaire

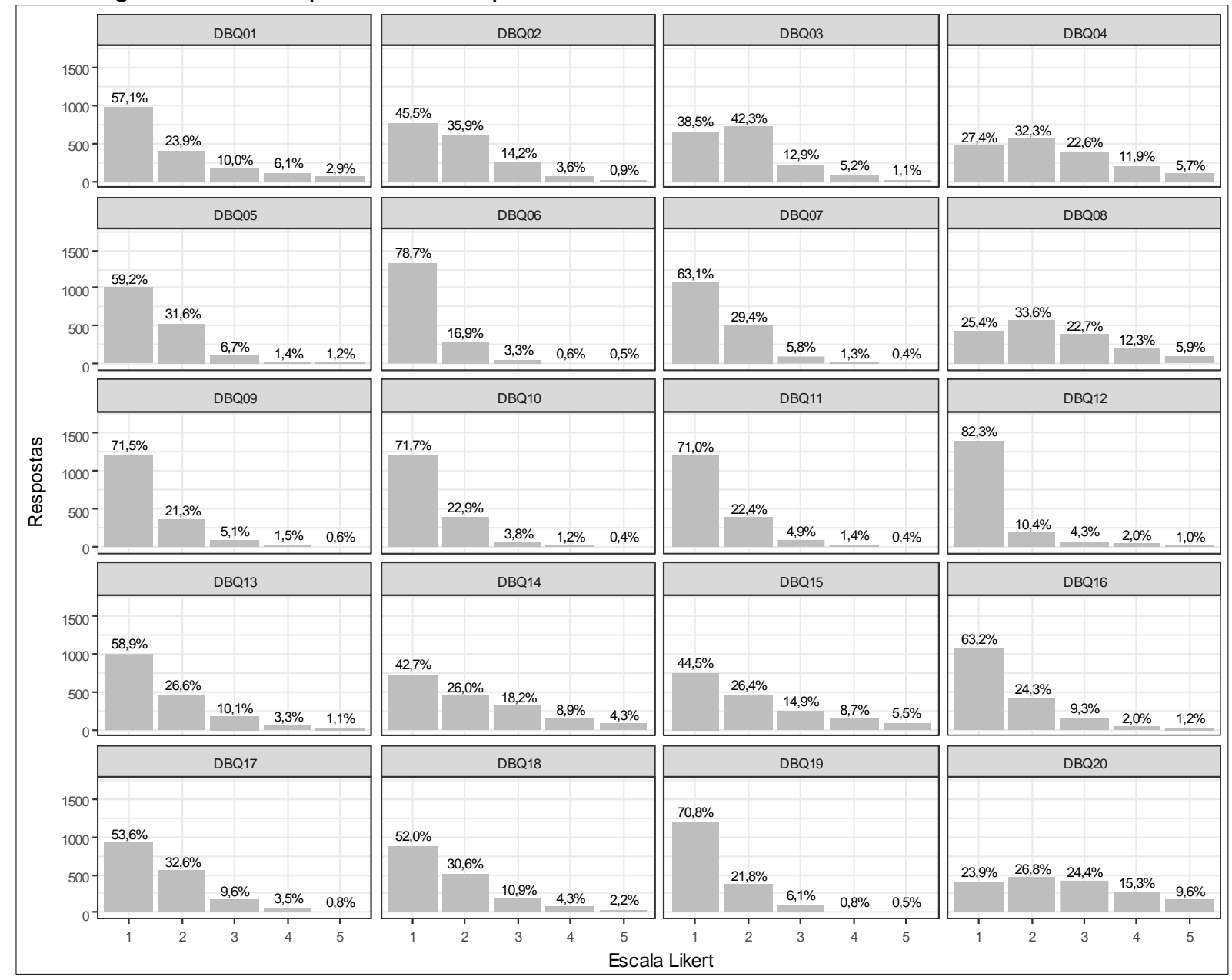

Nota: DBQ01. Dirigir após consumir bebida alcoólica; DBQ02. Estar em uma fila para entrar à direita em uma rua principal e prestar tanta atenção no trânsito dessa rua, que quase bate na traseira do carro à sua frente; DBQ03. Não perceber que pedestres estão atravessando, ao entrar em uma rua lateral, vindo de uma rua principal; DBQ04. Buzinar para indicar sua contrariedade com relação a outro usuário da via; DBQ05. Não verificar seu espelho retrovisor antes de sair com o carro, mudar de faixa etc; DBQ06. Frear muito rápido em uma estrada escorregadia, ou girar o volante para o lado errado em uma derrapagem; DBQ07. Parar em um cruzamento tão para a frente que o motorista que tem preferência precisa parar e deixar você passar; DBQ08. Desrespeitar o limite de velocidade em uma rua de área residencial; DBQ09. Ao virar à direita, quase bater em um ciclista que apareceu do seu lado; DBQ10. Não prestar atenção aos sinais de "Dê a preferência" e evitar, por pouco, colidir com outro veículo que tem a preferência; DBQ11. Tentar ultrapassar alguém que você não viu estar sinalizando para entrar à esquerda; DBQ12. Ficar muito bravo por causa de outro (a) motorista e persegui-lo (a) com a intenção de dizer o que você pensou dele/dela; DBQ13. Ficar em uma faixa da pista, que você sabe que estará interrompida adiante, e forçar sua entrada na outra faixa no último instante; DBQ14. Ultrapassar um motorista lento pelo lado direito; DBQ15. Arrancar nos semáforos com a intenção de ser mais rápido que o motorista ao seu lado; DBQ16. Dirigir tão próximo ao veículo da frente que seria difícil parar em uma situação de emergência; DBQ17. Atravessar o cruzamento sabendo que o semáforo já fechou para você; DBQ18. Ficar muito bravo com um determinado tipo de motorista e indicar sua hostilidade de qualquer maneira; DBQ19. Subestimar a velocidade de um veículo que está vindo no sentido contrário ao iniciar uma ultrapassagem; DBQ20. Desrespeitar o limite de velocidade em uma rodovia. Escala Likert: 1. Nunca, 5. Muito frequentemente. 


\subsection{Considerações do Capítulo 4}

O desenvolvimento e avaliação das perguntas para a aplicação do questionário demandaram, além da análise quantitativa, uma análise qualitativa detalhada e crítica para garantir a qualidade do instrumento de coleta de dados.

Inicialmente, as perguntas selecionadas e desenvolvidas para comporem este trabalho, bem como a forma de obter as respostas, foram cuidadosamente planejadas, de acordo com os objetivos deste estudo. A partir dos comentários dos participantes nos estudos piloto, foi possível identificar problemas de interpretação das perguntas e itens do questionário, bem como a adequação dos itens à realidade dos condutores, que foram corrigidos ou ajustados para a versão final do questionário.

A análise de confiabilidade realizada com o Alfa de Cronbach foi importante nesta etapa para uma avaliação analítica das perguntas, uma vez que foram realizadas alterações nas escalas originais dos questionários validados e perguntas que foram criadas. O resultado do segundo teste piloto demonstrou que o questionário desenvolvido atendeu aos critérios de sensibilidade e confiabilidade e estava pronto para ser aplicado.

Destaca-se que o uso do coeficiente de Alfa de Cronbach nesta etapa da pesquisa auxiliou na identificação dos itens que necessitavam de intervenção. Entretanto, seu uso teve um caráter analítico, visto que é baseado em medidas de variância e covariância e foi aplicado em dados em escala ordinal, não métrico.

A análise da frequência das respostas em escala Likert permitiu avaliar a distribuição das respostas dos participantes, bem como a coerência das respostas para os itens. Estas análises antecederam a aplicação de Análise de Componentes Principais Categórica para validação do questionário por meio da confirmação das dimensões dos construtos e avaliação da consistência interna. 



\section{VARIÁVEIS LATENTES E VALIDAÇÃO DO QUESTIONÁRIO}

Neste capítulo são apresentados os resultados da Análise de Componentes Principais Categórica (CATPCA), aplicada para identificar as variáveis latentes deste estudo e analisar a validade do questionário.

\subsection{Considerações iniciais}

A Análise de Componentes Principais Categórica (CATPCA) foi aplicada nos itens em escala Likert, que mensuravam traços de personalidade, caracterização do ambiente viário, avaliação das habilidades do condutor, percepção de risco e comportamento do condutor.

Destaca-se que, na CATPCA, as variáveis obtidas a partir da redução dos dados são denominadas dimensões, que nominalmente correspondem aos fatores da Análise Fatorial e às componentes da Análise de Componentes Principais.

$\mathrm{Na}$ CATPCA, o algoritmo de quantificação ótima (Optimal Scaling) depende do número de dimensões $p$, não há um critério automatizado para determinar o número de dimensões a serem extraídas. Portanto, foram avaliados diferentes números de dimensões para cada construto analisado, e adotou-se como critério para selecionar o número de dimensões o autovalor superior a 1. Conforme recomendado por Linting et al. (2007), foram avaliadas as dimensões $p, p-1$ e $p+1$ para confirmar a seleção.

\subsection{Habilidades de condução}

As habilidades de condução foram mensuradas, neste estudo, por meio de seis itens adaptados da escala de avaliação das habilidades do condutor desenvolvida por Delhomme (1991). Este construto aborda a forma que o indivíduo conduz, comparativamente a outros condutores.

Considerando o critério adotado, de autovalor superior a 1, duas dimensões foram extraídas para representar as habilidades do condutor (Figura 5.1). 
Figura 5.1 - Gráfico de declividade das dimensões de habilidades de condução

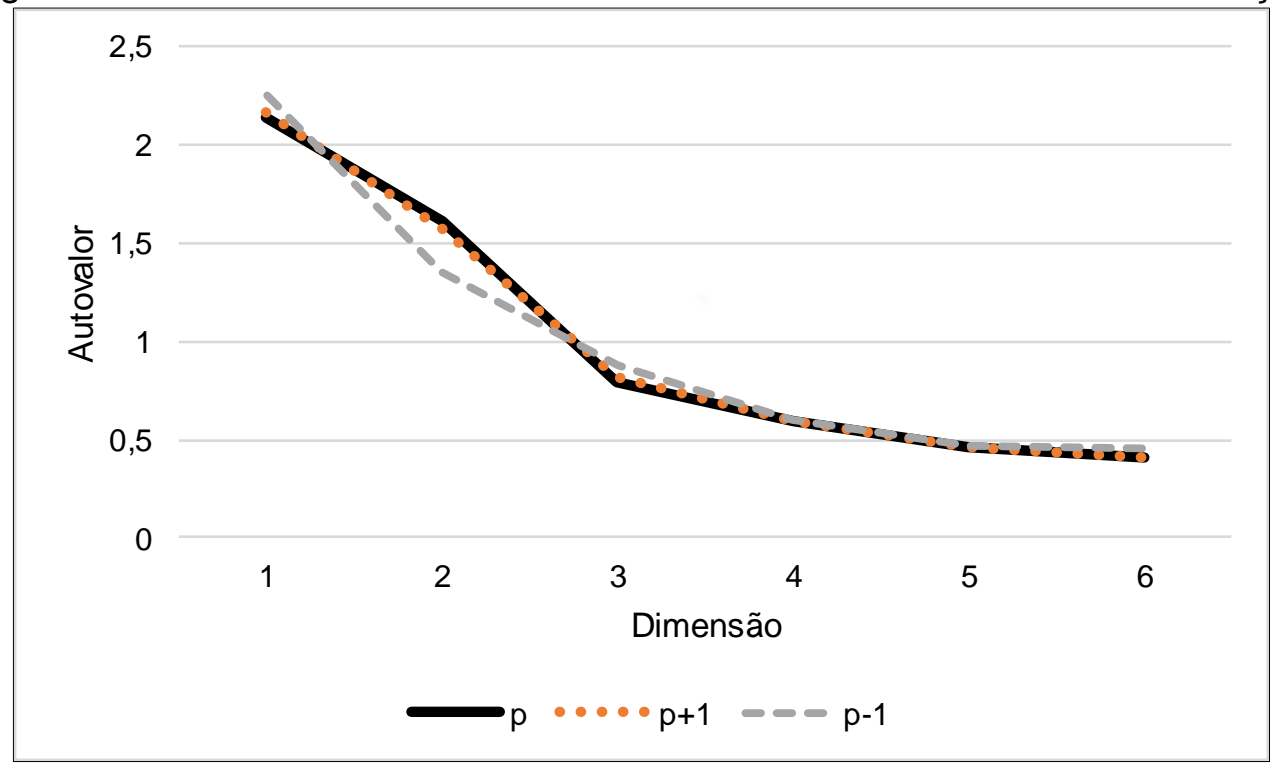

A Tabela 5.1 mostra os novos valores atribuídos para as categorias da escala Likert, que passaram a ter distâncias diferente de 1. Nota-se que foram atribuídos o mesmo valor às categorias 1 e 2 dos itens HabCond1, HabCond3 e HabCond5, onde frequências baixas foram registradas. O mesmo ocorre para as categorias 4 e 5 dos itens HabCond2 e, HabCond4.

Tabela 5.1 - Valores métricos atribuídos às categorias da escala Likert de Habilidades de condução

\begin{tabular}{|c|c|c|c|c|c|c|c|c|c|c|}
\hline \multirow[t]{2}{*}{ Itens } & \multicolumn{3}{|c|}{1} & \multicolumn{2}{|l|}{2} & \multicolumn{2}{|l|}{3} & \multicolumn{2}{|l|}{4} & \multirow{2}{*}{$\begin{array}{c}5 \\
\text { QO }\end{array}$} \\
\hline & $\mathrm{F}$ & QO & $\mathrm{F}$ & QO & $\mathrm{F}$ & QO & $\mathrm{F}$ & QO & $\mathrm{F}$ & \\
\hline HabCond01. Eu sou um motorista muito bom & 2 & $-2,96$ & 30 & $-2,96$ & 288 & $-1,35$ & 909 & $-0,17$ & 473 & 1,35 \\
\hline $\begin{array}{l}\text { HabCond02. Em geral, outras pessoas são muito } \\
\text { boas motoristas }\end{array}$ & 145 & $-2,51$ & 469 & $-0,65$ & 828 & 0,39 & 231 & 1,33 & 29 & 1,33 \\
\hline HabCond03. Eu dirijo muito cautelosamente & 11 & $-1,37$ & 72 & $-1,37$ & 389 & $-1,24$ & 751 & $-0,1$ & 479 & 1,40 \\
\hline $\begin{array}{l}\text { HabCond } 04 \text {. Em geral, outras pessoas dirigem } \\
\text { muito cautelosamente }\end{array}$ & 202 & $-2,18$ & 620 & $-0,39$ & 712 & 0,60 & 156 & 1,53 & 12 & 1,53 \\
\hline $\begin{array}{l}\text { HabCond05. Meus reflexos enquanto dirijo são } \\
\text { muito bons }\end{array}$ & 6 & $-2,59$ & 43 & $-2,59$ & 295 & $-1,32$ & 845 & $-0,16$ & 513 & 1,28 \\
\hline $\begin{array}{l}\text { HabCond06. Em geral, os reflexos das outras } \\
\text { pessoas enquanto dirigem são muito bons }\end{array}$ & 65 & $-3,27$ & 269 & $-1,22$ & 944 & 0,05 & 392 & 1,12 & 32 & 1,83 \\
\hline
\end{tabular}

As cargas fatoriais para os itens de cada dimensão foram altas $(>0,6)$, o que possibilitou distinguir claramente as habilidades dos próprios condutores e dos demais (Tabela 5.2). A partir das cargas fatoriais, foi possível realizar a interpretação das 
dimensões, nomeando-as como "Habilidades dos demais condutores" (Dimensão 1) e "Eu mesmo como condutor" (Dimensão 2).

\begin{tabular}{lcc} 
Tabela 5.2 - Cargas fatoriais das dimensões da avaliação das habilidades de condução \\
\hline Itens & \multicolumn{2}{c}{ Dimensão } \\
\cline { 2 - 3 } & 1 & 2 \\
\hline HabCond04. Em geral, outras pessoas dirigem muito cautelosamente & 0,837 & 0,044 \\
HabCond02. Em geral, outras pessoas são muito boas motoristas & $\mathbf{0 , 8 0 9}$ & 0,063 \\
HabCond06. Em geral, os reflexos das outras pessoas enquanto dirigem são muito bons & $\mathbf{0 , 7 9 8}$ & 0,044 \\
HabCond01. Eu sou um motorista muito bom & 0,035 & $\mathbf{0 , 8 3 7}$ \\
HabCond05. Meus reflexos enquanto dirijo são muito bons & 0,067 & $\mathbf{0 , 8 1 7}$ \\
HabCond03. Eu dirijo muito cautelosamente & 0,038 & $\mathbf{0 , 6 1 3}$ \\
\hline
\end{tabular}

Nota: 1 - Habilidades dos demais condutores; 2 - Eu mesmo como condutor

Com as duas dimensões foi possível explicar $62,51 \%$ da variância total dos dados (Tabela 5.3). A análise de confiabilidade da escala, realizada pelo Alfa de Cronbach, indicou um nível de confiabilidade entre fraco e inaceitável. Contudo, devido a esse indicador ser penalizado pelo número reduzido de itens que representam a variável latente e apresentar maior diversidade nas respostas, por se tratar de um construto psicológico, pode ser considerado como aceitável conforme Cortina (1993) e Kline ${ }^{8}$ (1999, apud FIELD, 2009, p. 675).

Tabela 5.3 - Resultados para validação do construto Habilidades de condução

\begin{tabular}{lrrr}
\hline Dimensão & Alfa de Cronbach & \multicolumn{2}{c}{ Variância contabilizada para } \\
\cline { 3 - 4 } & & Total (Autovalor) & Variância (\%) \\
\hline 1 - Habilidades dos demais condutores & 0,608 & 1,999 & 33,319 \\
2 - Eu mesmo como condutor & 0,526 & 1,751 & 29,191 \\
Total & $0,880^{a}$ & 3,751 & 62,510 \\
\hline
\end{tabular}

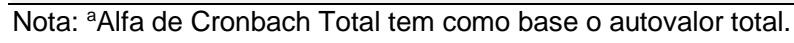

\subsection{Escala de raiva do condutor}

A versão, utilizada neste trabalho, para avaliar o traço de personalidade de raiva ao conduzir é composta por 14 itens (DEFFENBACHER; OETTING; LYNCH, 1994). Contudo, cinco desses itens foram excluídos devido a cargas fatoriais cruzadas, ou seja, itens com valores altos de cargas fatoriais em mais de uma dimensão, e que contribuíam para explicar mais de uma dimensão do traço de personalidade de raiva. Considerando o critério de autovalor superior a 1, três dimensões foram extraídas e representam os nove itens restantes da escala da raiva. 
Figura 5.2 - Gráfico de declividade das dimensões da escala de raiva do condutor

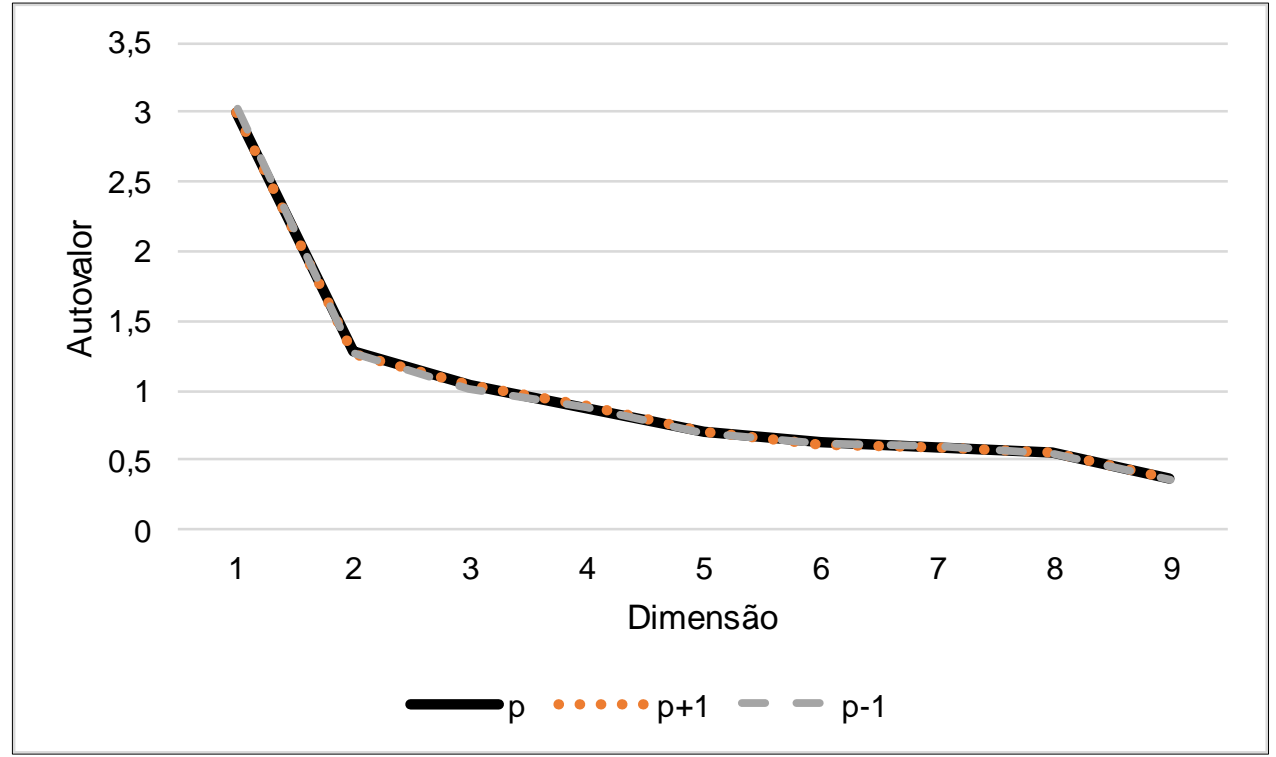

Os valores métricos atribuídos às categorias da escala Likert, obtidos a partir do procedimento de quantificação ótima, são apresentados na Tabela 5.4.

Tabela 5.4 - Valores métricos atribuídos às categorias da escala Likert da escala de raiva do condutor

\begin{tabular}{|c|c|c|c|c|c|c|c|c|c|c|}
\hline \multirow[t]{2}{*}{ Itens } & \multicolumn{3}{|c|}{1} & \multicolumn{2}{|l|}{2} & \multicolumn{2}{|l|}{3} & \multicolumn{2}{|l|}{4} & \multirow{2}{*}{$\begin{array}{c}5 \\
\text { QO }\end{array}$} \\
\hline & $\mathrm{F}$ & QO & $\mathrm{F}$ & QO & $\mathrm{F}$ & QO & $\mathrm{F}$ & QO & $\mathrm{F}$ & \\
\hline DAS01. Alguém está "costurando" o trânsito & 73 & $-2,20$ & 354 & $-1,13$ & 665 & $-0,10$ & 462 & 0,67 & 148 & 2,15 \\
\hline DAS04. Você passa por um radar de velocidade & 476 & $-1,44$ & 447 & $-0,12$ & 438 & 0,84 & 208 & 0,96 & 133 & 1,27 \\
\hline $\begin{array}{l}\text { DAS05. Alguém faz um gesto obsceno para você } \\
\text { por causa da sua maneira de dirigir }\end{array}$ & 198 & $-1,73$ & 413 & $-0,83$ & 436 & $-0,01$ & 400 & 0,76 & 255 & 1,52 \\
\hline DAS06. Um policial manda você encostar & 822 & $-0,99$ & 500 & 0,56 & 273 & 1,35 & 78 & 1,51 & 29 & 1,51 \\
\hline $\begin{array}{l}\text { DAS08. Alguém avança o sinal de trânsito } \\
\text { (semáforo/sinaleira) vermelho ou a placa de } \\
\text { "pare" }\end{array}$ & 52 & $-2,16$ & 233 & $-1,37$ & 435 & $-0,66$ & 520 & 0,20 & 462 & 1,33 \\
\hline $\begin{array}{l}\text { DAS09. Alguém buzina para você por causa da } \\
\text { sua maneira de dirigir }\end{array}$ & 157 & $-1,84$ & 431 & $-0,96$ & 570 & 0,15 & 352 & 0,91 & 192 & 1,56 \\
\hline $\begin{array}{l}\text { DAS10. Você está dirigindo atrás de um } \\
\text { caminhão grande e não consegue ver ao redor } \\
\text { dele }\end{array}$ & 289 & $-1,72$ & 522 & $-0,46$ & 562 & 0,60 & 235 & 0,98 & 94 & 1,80 \\
\hline DAS12. Você está preso no congestionamento & 117 & $-2,65$ & 367 & $-0,92$ & 566 & 0,13 & 373 & 0,62 & 279 & 1,22 \\
\hline $\begin{array}{l}\text { DAS14. Alguém demora ao estacionar, atrasando } \\
\text { o trânsito }\end{array}$ & 292 & $-1,78$ & 593 & $-0,35$ & 541 & 0,76 & 198 & 0,97 & 78 & 1,64 \\
\hline
\end{tabular}

Nota: F - Frequência; QO - Quantificação ótima

A estrutura obtida assemelha-se à obtida no estudo de Iversen e Rundmo (2002). Após análise da distribuição dos valores das cargas fatoriais (Tabela 5.5), foi possível 
nomear as dimensões 1, 2 e 3 como "Raiva devido ao impedimento para prosseguir viagem", "Raiva devido à demonstração direta de hostilidade do outro condutor", e "Raiva devido à imprudência de outros condutores", respectivamente.

Tabela 5.5 - Cargas fatoriais das dimensões da escala de raiva do condutor

\begin{tabular}{lccc}
\hline Itens & \multicolumn{2}{c}{ Dimensão } \\
\cline { 2 - 3 } & 1 & 2 & 3 \\
\hline DAS14. Alguém demora ao estacionar, atrasando o trânsito & $\mathbf{0 , 6 9 8}$ & 0,053 & 0,185 \\
DAS06. Um policial manda você encostar & $\mathbf{0 , 6 7 7}$ & 0,170 & $-0,123$ \\
DAS04. Você passa por um radar de velocidade & $\mathbf{0 , 6 7 6}$ & 0,078 & $-0,069$ \\
DAS10. Você está dirigindo atrás de um caminhão grande e não consegue ver ao redor dele & $\mathbf{0 , 6 7 3}$ & 0,094 & 0,281 \\
DAS12. Você está preso no congestionamento & $\mathbf{0 , 5 7 3}$ & 0,209 & 0,198 \\
DAS05. Alguém faz um gesto obsceno para você por causa da sua maneira de dirigir & 0,141 & $\mathbf{0 , 8 9 3}$ & 0,090 \\
DAS09. Alguém buzina para você por causa da sua maneira de dirigir & 0,213 & $\mathbf{0 , 8 5 0}$ & 0,181 \\
DAS01. Alguém está "costurando" o trânsito & 0,129 & 0,075 & $\mathbf{0 , 7 7 4}$ \\
DAS08. Alguém avança o sinal de trânsito (semáforo/sinaleira) vermelho ou a placa de "pare" & 0,032 & 0,155 & $\mathbf{0 , 7 7 0}$ \\
\hline Nota: 1 - Impedimento para prosseguir viagem; 2 - Demonstração direta de hostilidade do outro condutor; 3 - Imprudência de outros condutores
\end{tabular}

$\mathrm{Na}$ Tabela 5.6 pode-se observar que $59 \%$ da variância dos dados foi explicada. Contudo, o índice de confiabilidade atingiu um valor considerado inaceitável (KLINE ${ }^{8}$, 1999 apud FIELD, 2009) para as dimensões 2 e 3.

Tabela 5.6 - Resultados para validação da "Escala de raiva do condutor"

\begin{tabular}{|c|c|c|c|c|}
\hline \multirow[t]{2}{*}{ Dimensão } & \multirow[t]{2}{*}{ Alfa de Cronbach } & \multicolumn{2}{|c|}{ Variância contabilizada para } & \multirow{2}{*}{$\begin{array}{c}\text { Correlação } \\
\text { de } \\
\text { Spearman }\end{array}$} \\
\hline & & Total (Autovalor) & Variância (\%) & \\
\hline 1 - Impedimento para prosseguir viagem & 0,691 & 2,267 & 25,190 & - \\
\hline 2 - Demonstração direta de hostilidade do outro condutor & 0,584 & 1,639 & 18,214 & $0,629^{* *}$ \\
\hline 3 - Imprudência de outros condutores & 0,471 & 1,405 & 15,614 & $0,308^{* *}$ \\
\hline Total & $0,913^{a}$ & 5,312 & 59,018 & - \\
\hline
\end{tabular}

${ }^{* *}$ A correlação é significativa no nível 0,01 (2 extremidades)

Novamente, o fato de as dimensões serem compostas por poucos itens, e caracterizarem um construto psicológico, explicam os valores baixos obtidos. Entretanto, como as dimensões 2 e 3 são compostas por dois itens cada uma, a análise de correlação de Spearman foi realizada com a finalidade de avaliar o resultado encontrado e validar as dimensões. O resultado indicou uma correlação positiva e significativa, a um nível de $99 \%$ de confiabilidade, entre os itens de cada construto. Com isso, foi possível confirmar a confiabilidade destes a partir desta métrica. 


\subsection{Busca de sensações}

Ao aplicar a CATPCA nos sete itens que compõem o construto "busca de sensações", verificou-se que o item SS1 (Eu gostaria de dirigir sem uma rota pré-definida e um tempo para chegar) apresentava uma carga fatorial inferior às cargas dos demais itens $(0,373)$ e apenas $44 \%$ da variância era explicada.

De acordo com Marôco (2014), ao se utilizar técnicas de redução de dados, como é o caso da CATPCA, recomenda-se a explicação de pelo menos $50 \%$ da variância total dos dados. Após a exclusão do item SS1, novamente uma única dimensão com autovalor maior que 1 foi obtida (Figura 5.3). Os valores métricos atribuídos às categorias da escala Likert são apresentadas na Tabela 5.7.

Figura 5.3 - Gráfico de declividade da dimensão busca de sensações

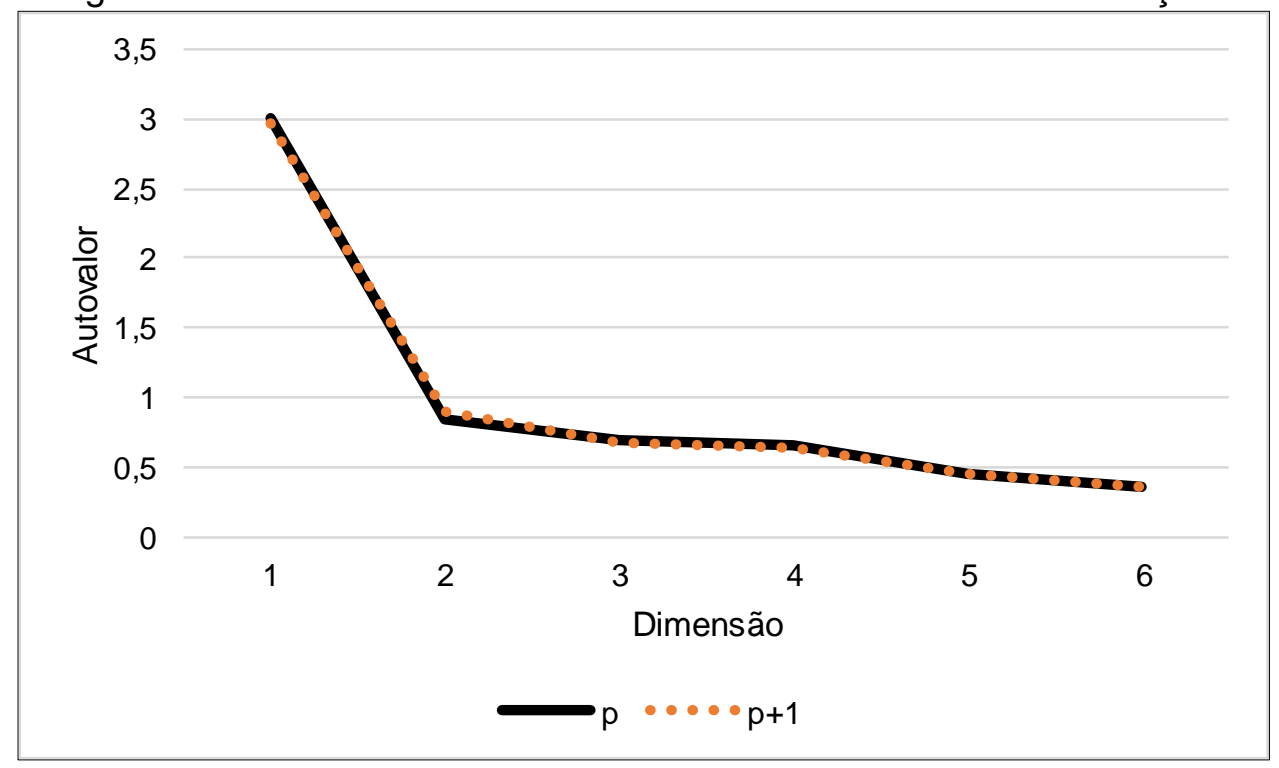

Tabela 5.7 - Valores métricos atribuídos às categorias da escala Likert de busca de sensações

\begin{tabular}{|c|c|c|c|c|c|c|c|c|c|c|}
\hline \multirow[t]{2}{*}{ Itens } & \multicolumn{3}{|c|}{1} & \multicolumn{2}{|l|}{2} & \multicolumn{2}{|l|}{3} & \multicolumn{2}{|l|}{4} & \multirow{2}{*}{$\begin{array}{c}5 \\
\text { QO }\end{array}$} \\
\hline & $\mathrm{F}$ & QO & $\mathrm{F}$ & QO & $\mathrm{F}$ & QO & $\mathrm{F}$ & QO & $\mathrm{F}$ & \\
\hline $\begin{array}{l}\text { SS2. Muitas vezes eu me sinto como um piloto } \\
\text { de corrida }\end{array}$ & 798 & $-0,91$ & 455 & 0,14 & 271 & 1,09 & 131 & 1,63 & 56 & 2,58 \\
\hline SS3. Eu gosto de dirigir perigosamente & 1.253 & -056 & 288 & 1,12 & 114 & 1,95 & 33 & 2,81 & 14 & 4,28 \\
\hline $\begin{array}{l}\text { SS4. Eu gosto de dirigir em estradas com muitas } \\
\text { curvas fechadas }\end{array}$ & 1.162 & $-0,64$ & 287 & 1,04 & 147 & 1,11 & 66 & 2,34 & 40 & 3,06 \\
\hline $\begin{array}{l}\text { SS5. Eu gostaria de aprender a dirigir carros que } \\
\text { podem exceder a velocidade de } 300 \mathrm{~km} / \mathrm{h}\end{array}$ & 1.018 & $-0,77$ & 215 & 0,59 & 144 & 0,77 & 144 & 1,30 & 181 & 1,96 \\
\hline $\begin{array}{l}\text { SS6. Eu não tenho paciência para pessoas que } \\
\text { dirigem o carro de maneira previsível e chata }\end{array}$ & 936 & $-0,85$ & 399 & 0,65 & 235 & 1,21 & 80 & 1,78 & 52 & 2,20 \\
\hline $\begin{array}{l}\text { SS7. Eu acho que eu gostaria da experiência de } \\
\text { dirigir muito rápido em uma rua íngreme }\end{array}$ & 1.182 & $-0,62$ & 270 & 0,89 & 119 & 1,58 & 68 & 2,17 & 63 & 2,56 \\
\hline
\end{tabular}


Composta por seis itens, a dimensão foi nomeada como "busca de sensações" (Tabela 5.8). A variância explicada aumentou para 50,1\% (Tabela 5.9) e a escala se mostrou confiável, resultando, para o Alfa de Cronbach, valor semelhante ao da escala original de Yagil (2001), equivalente a 0,84.

Tabela 5.8 - Cargas fatoriais das dimensões de busca de sensações

\begin{tabular}{lc}
\hline Itens & Dimensão \\
\cline { 2 - 2 } & 1 \\
\hline SS3. Eu gosto de dirigir perigosamente & 0,792 \\
SS2. Muitas vezes eu me sinto como um piloto de corrida & 0,759 \\
SS7. Eu acho que eu gostaria da experiência de dirigir muito rápido em uma rua íngreme & 0,752 \\
SS5. Eu gostaria de aprender a dirigir carros que podem exceder a velocidade de 300km/h & 0,738 \\
SS4. Eu gosto de dirigir em estradas com muitas curvas fechadas & 0,617 \\
SS6. Eu não tenho paciência para pessoas que dirigem o carro de maneira previsível e chata & 0,560 \\
\hline Nota: 1- Busca de sensações &
\end{tabular}

Tabela 5.9 - Resultados para validação do construto "Busca de sensações"

\begin{tabular}{llrrr}
\hline \multirow{2}{*}{ Dimensão } & Alfa de Cronbach & \multicolumn{2}{c}{ Variância contabilizada para } \\
\cline { 3 - 5 } & & Total (Autovalor) & \multicolumn{2}{c}{ Variância (\%) } \\
\hline Busca de sensações & 0,801 & 3,009 & 50,146 \\
\hline
\end{tabular}

\subsection{Percepção do risco de comportamentos}

Neste trabalho, a percepção de risco dos condutores foi avaliada a partir de 20 situações apresentadas em itens afirmativos. A análise, resultante da aplicação da CATPCA, revelou uma estrutura com 3 dimensões com autovalor maior que 1 (Figura $5.4)$.

Figura 5.4 - Gráfico de declividade das dimensões de percepção de risco

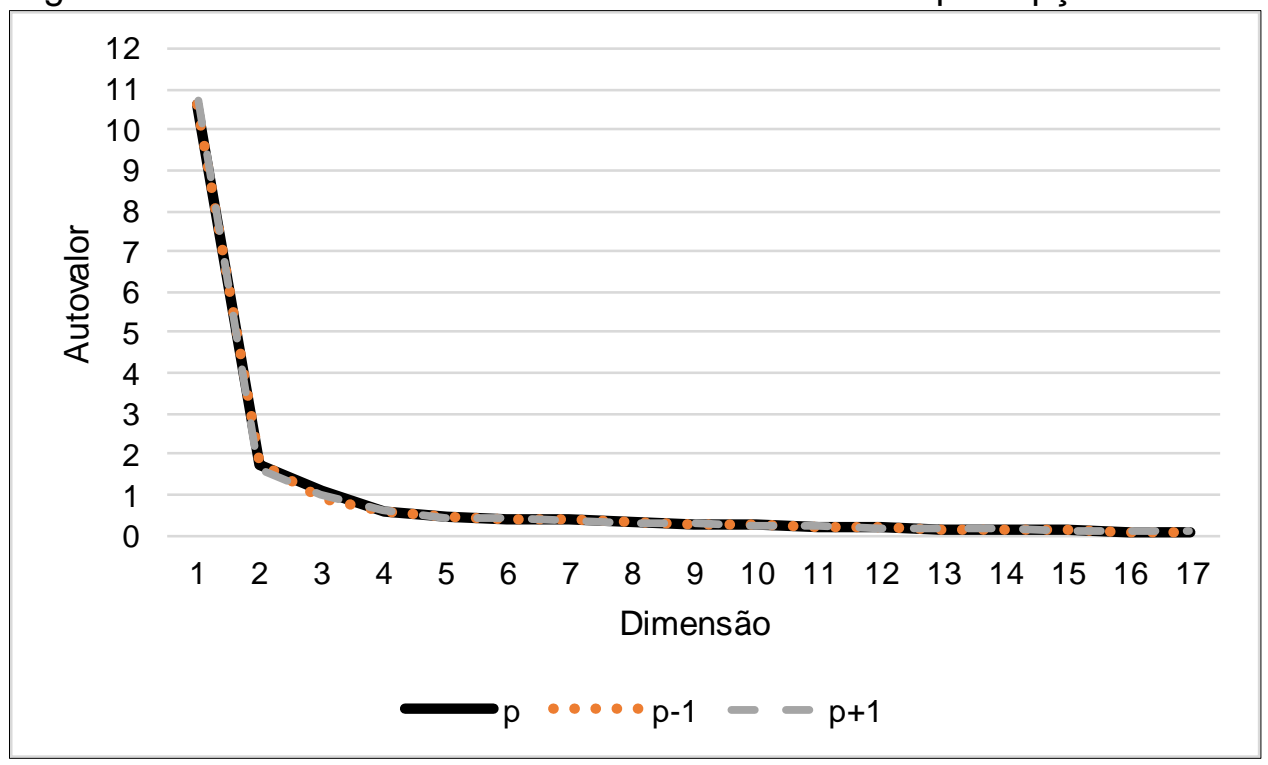


$\mathrm{Na}$ Tabela 5.10, são apresentados os valores atribuídos, pelo algoritmo de quantificação ótima, às categorias da escala Likert, que representavam a intensidade do risco associado às situações apresentadas nas sentenças.

Tabela 5.10 - Valores métricos atribuídos às categorias da escala Likert da percepção de

\begin{tabular}{|c|c|c|c|c|c|c|c|c|c|c|}
\hline \multirow{2}{*}{ Itens } & \multicolumn{3}{|c|}{1} & \multicolumn{2}{|l|}{2} & \multicolumn{2}{|l|}{3} & \multicolumn{2}{|l|}{4} & \multirow{2}{*}{$\begin{array}{c}5 \\
\mathrm{QO}\end{array}$} \\
\hline & $\mathrm{F}$ & QO & $\mathrm{F}$ & QO & $\mathrm{F}$ & QO & $\mathrm{F}$ & QO & $\mathrm{F}$ & \\
\hline $\begin{array}{l}\text { RISCO01. Usar o celular, no modo viva voz, } \\
\text { enquanto dirige em uma área urbana }\end{array}$ & 171 & $-2,52$ & 397 & $-0,53$ & 459 & 0,20 & 316 & 0,55 & 359 & 1,05 \\
\hline $\begin{array}{l}\text { RISCO03. Dirigir muito próximo ao veículo da } \\
\text { frente }\end{array}$ & 38 & $-5,98$ & 43 & $-2,50$ & 183 & 0,06 & 540 & 0,17 & 898 & 0,26 \\
\hline RISCO04. Mudar de faixa sem fazer sinal & 38 & $-6,33$ & 46 & $-1,56$ & 183 & $-0,02$ & 496 & 0,19 & 939 & 0,24 \\
\hline RISCO05. Dirigir com sono & 41 & $-5,85$ & 25 & $-3,01$ & 92 & $-0,16$ & 304 & 0,17 & 1.240 & 0,22 \\
\hline $\begin{array}{l}\text { RISCO06. Usar o celular, no modo viva voz, } \\
\text { enquanto dirige em uma rodovia }\end{array}$ & 153 & $-2,71$ & 284 & $-0,72$ & 403 & 0,11 & 356 & 0,41 & 506 & 0,85 \\
\hline RISCO07. Usar algum tipo de droga ilegal e dirigir & 52 & $-5,51$ & 15 & $-1,99$ & 46 & $-0,04$ & 120 & 0,14 & 1.469 & 0,21 \\
\hline $\begin{array}{l}\text { RISCO08. Atravessar o semáforo com o sinal } \\
\text { vermelho durante o dia }\end{array}$ & 48 & $-5,73$ & 30 & $-1,36$ & 105 & $-0,08$ & 270 & 0,16 & 1.249 & 0,22 \\
\hline $\begin{array}{l}\text { RISCO09. Exceder a velocidade quando tráfego } \\
\text { está tranquilo }\end{array}$ & 75 & $-2,57$ & 280 & $-1,19$ & 603 & $-0,23$ & 447 & 0,49 & 297 & 1,50 \\
\hline RISC010. Ignorar placas de sinalização & 41 & $-6,12$ & 57 & $-1,28$ & 269 & 0,05 & 525 & 0,19 & 810 & 0,26 \\
\hline RISC011. Ultrapassar em local proibido & 43 & $-5,85$ & 27 & $-2,48$ & 120 & 0,05 & 406 & 0,15 & 1.106 & 0,23 \\
\hline $\begin{array}{l}\text { RISCO12. Usar o celular com as mãos enquanto } \\
\text { você dirige em uma área urbana }\end{array}$ & 39 & $-6,16$ & 37 & $-1,97$ & 129 & $-0,16$ & 398 & 0,18 & 1.099 & 0,24 \\
\hline RISC013. Mudar de faixa sem olhar o espelho & 47 & $-5,76$ & 23 & $-1,85$ & 68 & 0,03 & 364 & 0,16 & 1.200 & 0,21 \\
\hline $\begin{array}{l}\text { RISCO14. Dirigir uma distância de } 20 \mathrm{~km} \text {, em } \\
\text { média, sem usar o cinto de segurança }\end{array}$ & 65 & $-4,95$ & 75 & $-0,52$ & 212 & 0,09 & 348 & 0,17 & 1.002 & 0,28 \\
\hline $\begin{array}{l}\text { RISC015. Dirigir após beber pelo menos dois } \\
\text { copos de bebida alcoólica }\end{array}$ & 51 & $-5,49$ & 94 & $-0,81$ & 245 & 0,04 & 368 & 0,12 & 944 & 0,32 \\
\hline $\begin{array}{l}\text { RISCO16. Atravessar o semáforo com o sinal } \\
\text { vermelho durante a noite }\end{array}$ & 70 & $-2,91$ & 281 & $-1,25$ & 435 & $-0,21$ & 390 & 0,15 & 526 & 1,11 \\
\hline $\begin{array}{l}\text { RISCO18. Continuar dirigindo quando você está } \\
\text { cansado e precisaria de uma pausa }\end{array}$ & 35 & $-6,34$ & 37 & $-2,45$ & 135 & $-0,09$ & 455 & 0,17 & 1.040 & 0,24 \\
\hline $\begin{array}{l}\text { RISCO20. Usar o celular com as mãos enquanto } \\
\text { você dirige em uma rodovia }\end{array}$ & 48 & $-5,71$ & 28 & $-1,58$ & 117 & 0,04 & 271 & 0,16 & 1.238 & 0,22 \\
\hline
\end{tabular}

Nota: F - Frequência; QO - Quantificação ótima

Três itens foram excluídos por apresentarem cargas fatoriais elevadas em duas ou mais dimensões, de forma que as três dimensões contemplaram 17 itens. A distribuição das cargas fatoriais (Tabela 5.11) permitiu a interpretação das dimensões e posterior proposta de nomenclatura para as mesmas. As nomenclaturas foram: 1ações que prejudicam a concentração e vigilância ao conduzir, 2- tarefas secundárias ao conduzir e 3-comportamentos perigosos. 
Tabela 5.11 - Cargas fatoriais das dimensões de percepção do risco de comportamentos

\begin{tabular}{|c|c|c|c|}
\hline \multirow[t]{2}{*}{ Itens } & \multicolumn{3}{|c|}{ Dimensão } \\
\hline & 1 & 2 & 3 \\
\hline RISC013. Mudar de faixa sem olhar o espelho & 0,927 & 0,071 & 0,102 \\
\hline RISCO07. Usar algum tipo de droga ilegal e dirigir & 0,924 & 0,092 & 0,105 \\
\hline RISCO20. Usar o celular com as mãos enquanto você dirige em uma rodovia & 0,908 & 0,130 & 0,114 \\
\hline RISC011. Ultrapassar em local proibido & 0,901 & 0,120 & 0,112 \\
\hline RISCO08. Atravessar o semáforo com o sinal vermelho durante o dia & 0,893 & 0,081 & 0,138 \\
\hline RISCO04. Mudar de faixa sem fazer sinal & 0,887 & 0,119 & 0,129 \\
\hline RISC010. Ignorar placas de sinalização & 0,886 & 0,110 & 0,171 \\
\hline RISC012. Usar o celular com as mãos enquanto você dirige em uma área urbana & 0,859 & 0,153 & 0,128 \\
\hline RISCO05. Dirigir com sono & 0,859 & 0,112 & 0,102 \\
\hline RISC018. Continuar dirigindo quando você está cansado e precisaria de uma pausa & 0,846 & 0,107 & 0,146 \\
\hline RISCO03. Dirigir muito próximo ao veículo da frente & 0,813 & 0,096 & 0,149 \\
\hline RISC014. Dirigir uma distância de $20 \mathrm{~km}$, em média, sem usar o cinto de segurança & 0,802 & 0,074 & 0,193 \\
\hline RISC015. Dirigir após beber pelo menos dois copos de bebida alcoólica & 0,751 & 0,174 & 0,219 \\
\hline RISCO01. Usar o celular, no modo viva voz, enquanto dirige em uma área urbana & 0,089 & 0,907 & 0,151 \\
\hline RISCO06. Usar o celular, no modo viva voz, enquanto dirige em uma rodovia & 0,206 & 0,901 & 0,073 \\
\hline RISC016. Atravessar o semáforo com o sinal vermelho durante a noite & 0,201 & $-0,010$ & 0,851 \\
\hline RISCO09. Exceder a velocidade quando tráfego está tranquilo & 0,164 & 0,275 & 0,767 \\
\hline
\end{tabular}

Nota: 1- ações que prejudicam a concentração e vigilância ao conduzir, 2- tarefas secundárias ao conduzir e 3- comportamentos perigosos

O resultado do Alfa de Cronbach indicou que as dimensões são confiáveis $(>0,7)$ e $78,73 \%$ da variância total dos dados foi explicada (Tabela 5.12).

Tabela 5.12 - Resultados para validação do construto de "Percepção do risco"

\begin{tabular}{lrrr}
\hline Dimensão & Alfa de Cronbach & \multicolumn{2}{c}{ Variância contabilizada para } \\
\cline { 3 - 4 } & & Total (Autovalor) & Variância (\%) \\
\hline 1 - Ações que prejudicam a concentração e vigilância ao conduzir & 0,961 & 9,895 & 58,206 \\
2 - Tarefas secundárias ao conduzir & 0,745 & 1,880 & 11,056 \\
3 - Comportamentos perigosos & 0,798 & 1,609 & 9,463 \\
Total & $0,983^{\mathrm{a}}$ & 13,383 & 78,726 \\
\hline Nota: aAlfa de Cronbach Total tem como base o autovalor total. & & &
\end{tabular}

\subsection{Caracterização do ambiente viário}

A caracterização do ambiente viário buscava acessar informações acerca da existência e condições da infraestrutura viária dos locais que os condutores conduziam com mais frequência. Dos 24 itens considerados inicialmente, nove foram excluídos por apresentarem cargas cruzadas entre duas ou mais dimensões. Conforme apresentado na Figura 5.5, quatro dimensões apresentaram autovalor maior que 1. 
Figura 5.5 - Gráfico de declividade das dimensões de caracterização do ambiente viário

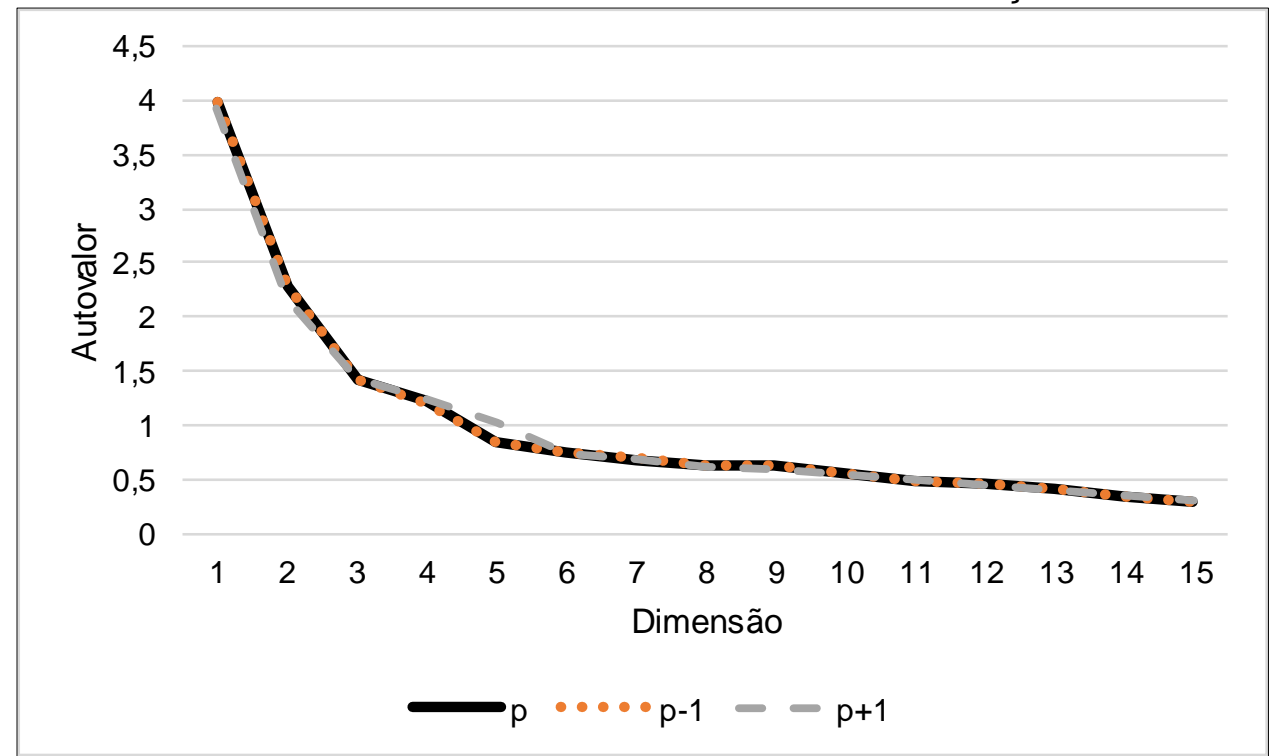

Na Tabela 5.13 estão os valores atribuídos às categorias da escala Likert, em que os condutores indicavam a frequência em que conduziam em locais que contemplassem as características semelhantes às apresentadas no questionário.

Tabela 5.13 - Valores métricos atribuídos às categorias da escala Likert do ambiente viário

\begin{tabular}{|c|c|c|c|c|c|c|c|c|c|c|}
\hline \multirow[t]{2}{*}{ Itens } & \multicolumn{2}{|c|}{1} & \multicolumn{2}{|r|}{2} & \multicolumn{2}{|c|}{3} & \multicolumn{2}{|c|}{4} & \multicolumn{2}{|c|}{5} \\
\hline & $\mathrm{F}$ & QO & $F$ & QO & $\mathrm{F}$ & QO & $\mathrm{F}$ & QO & $\mathrm{F}$ & QO \\
\hline NSA. Rodovias com nível de serviço A & 197 & $-0,69$ & 422 & $-0,69$ & 351 & $-0,36$ & 334 & $-0,01$ & 296 & 2,11 \\
\hline NSC. Rodovias com Nível de serviço C & 74 & $-0,87$ & 230 & $-0,58$ & 429 & $-0,35$ & 459 & 1,78 & 400 & 1,78 \\
\hline $\begin{array}{l}\text { Rodo03. Pavimento da rodovia com } \\
\text { buracos }\end{array}$ & 305 & $-1,10$ & 618 & $-0,61$ & 385 & 0,26 & 235 & 1,06 & 159 & 2,26 \\
\hline $\begin{array}{l}\text { Rodo04. Pavimento da rodovia com } \\
\text { deformações }\end{array}$ & 84 & $-1,44$ & 304 & $-1,07$ & 456 & $-0,50$ & 422 & 0,41 & 324 & 1,73 \\
\hline $\begin{array}{l}\text { Rodo05. Pavimento da rodovia sem } \\
\text { deformações }\end{array}$ & 31 & $-1,18$ & 137 & $-1,18$ & 316 & $-0,94$ & 590 & $-0,37$ & 520 & 1,45 \\
\hline Rodo06. Traçado da rodovia: reto & 66 & $-0,79$ & 227 & $-0,79$ & 387 & $-0,59$ & 487 & $-0,46$ & 430 & 1,71 \\
\hline Rodo07. Traçado da rodovia: curvas suaves & 36 & $-0,91$ & 166 & $-0,91$ & 390 & $-0,58$ & 582 & $-0,45$ & 416 & 1,74 \\
\hline Urb03. Rua estreita e edificações altas & 83 & $-1,46$ & 214 & $-1,04$ & 358 & $-0,78$ & 487 & $-0,28$ & 560 & 1,36 \\
\hline Urb04. Rua larga e edificações altas & 123 & $-1,12$ & 209 & $-1,09$ & 318 & $-0,68$ & 474 & $-0,43$ & 578 & 1,36 \\
\hline Urb06. Faixa de pedestre & 3 & $-2,04$ & 21 & $-2,04$ & 108 & $-2,04$ & 296 & $-1,57$ & 1.274 & $-0,58$ \\
\hline Urb07. Semáforo & 16 & $-2,06$ & 66 & $-2,00$ & 167 & $-1,39$ & 287 & $-1,35$ & 1.166 & 0,67 \\
\hline Urb09. Sinalização vertical urbana & 2 & $-3,33$ & 35 & $-2,31$ & 147 & $-1,74$ & 329 & $-1,29$ & 1.189 & 0,65 \\
\hline Urb10. Sinalização horizontal urbana & 14 & $-1,90$ & 89 & $-1,90$ & 243 & $-1,32$ & 399 & $-0,74$ & 957 & 0,85 \\
\hline Urb11. Ruas pavimentadas & 8 & $-2,54$ & 36 & $-2,54$ & 120 & $-2,04$ & 306 & $-1,25$ & 1.232 & 0,60 \\
\hline Urb12. Interseção sinalizada & 8 & $-1,81$ & 56 & $-1,81$ & 199 & $-1,53$ & 416 & $-0,95$ & 1023 & 0,80 \\
\hline
\end{tabular}

Nota: F - Frequência; QO - Quantificação ótima

As quatro dimensões, da estrutura fatorial, foram denominadas como: 1 - Elementos urbanos (Dimensão 1); Rodovias confortáveis (Dimensão 2); Rodovias com defeitos 
no pavimento (Dimensão 3); e Áreas urbanas com edificações altas (Dimensão 4), conforme as cargas fatoriais altas das dimensões (Tabela 5.14).

Tabela 5.14 - Cargas fatoriais das dimensões de caracterização do ambiente viário

\begin{tabular}{llrrr}
\hline Itens & \multicolumn{4}{c}{ Dimensão } \\
\cline { 2 - 5 } & 1 & 2 & 3 & 4 \\
\hline Urb09. Sinalização vertical urbana & $\mathbf{0 , 8 1 7}$ & 0,084 & $-0,008$ & 0,051 \\
Urb10. Sinalização horizontal urbana & $\mathbf{0 , 7 9 8}$ & 0,085 & $-0,036$ & 0,013 \\
Urb12. Interseção sinalizada & $\mathbf{0 , 7 5 7}$ & 0,146 & $-0,105$ & 0,073 \\
Urb06. Faixa de pedestre & $\mathbf{0 , 7 2 2}$ & 0,045 & 0,051 & 0,186 \\
Urb07. Semáforo & $\mathbf{0 , 6 6 7}$ & $-0,002$ & 0,086 & 0,267 \\
Urb11. Ruas pavimentadas & $\mathbf{0 , 6 2 4}$ & 0,143 & $-0,220$ & $-0,019$ \\
Rodo06. Traçado da rodovia: reto & 0,098 & $\mathbf{0 , 7 0 7}$ & 0,113 & 0,014 \\
Rodo05. Pavimento da rodovia: sem deformações & 0,171 & $\mathbf{0 , 6 8 5}$ & $-0,097$ & $-0,038$ \\
NSA. Rodovias com nível de serviço A & $-0,045$ & $\mathbf{0 , 6 5 4}$ & $-0,005$ & 0,080 \\
Rodo07. Traçado da rodovia: curvas suaves & 0,134 & $\mathbf{0 , 6 5 3}$ & 0,216 & 0,097 \\
NSC. Rodovias com Nível de serviço C & 0,075 & $\mathbf{0 , 6 0 7}$ & 0,057 & 0,222 \\
Rodo03. Pavimento da rodovia com buracos & $-0,096$ & 0,042 & $\mathbf{0 , 8 9 2}$ & 0,046 \\
Rodo04. Pavimento da rodovia com deformações & $-0,047$ & 0,168 & $\mathbf{0 , 8 7 2}$ & $-0,012$ \\
Urb03. Rua estreita e edificações altas & 0,155 & 0,116 & 0,068 & $\mathbf{0 , 8 3 9}$ \\
Urb04. Rua larga e edificações altas & 0,162 & 0,159 & $-0,039$ & $\mathbf{0 , 8 2 0}$ \\
\hline Nonyyyyyy
\end{tabular}

Nota: 1 - Elementos urbanos; 2 - Rodovias confortáveis; 3 - Rodovias com defeitos no pavimento; 4 - Áreas urbanas com edificações altas.

Os índices de confiabilidade das dimensões 3 e 4 ficaram abaixo de 0,6. Por serem compostas por dois itens cada, a confiabilidade foi confirmada com a análise de correlação de Spearman, que apresentou correlações altas e significativas entre os itens, confirmando a consistência interna das dimensões (Tabela 5.15).

Tabela 5.15 - Resultados para validação da caracterização do ambiente urbano e rodoviário

\begin{tabular}{lrrrr}
\hline Dimensão & Alfa de Cronbach & \multicolumn{2}{c}{ Variância contabilizada para } & Correlação de Spearman \\
\cline { 3 - 4 } & & Total (Autovalor) & Variância (\%) & \\
\hline 1 - Elementos urbanos & 0,779 & 3,359 & 22,391 & - \\
2 - Rodovias confortáveis & 0,670 & 2,317 & 15,448 & - \\
3 - Rodovias com defeitos no pavimento & 0,480 & 1,705 & 11,365 & $0,673^{* *}$ \\
4 - Áreas urbanas com edificações altas & 0,542 & 1,560 & 10,400 & $0,491^{* *}$ \\
Total & $0,952 b$ & 8,941 & 59,604 & \\
\hline Nota: ${ }^{* A l f a}$ de Cronbach Total tem como base 0 autovalor total. & & &
\end{tabular}

\subsection{Comportamentos do condutor auto relatados}

O comportamento do condutor foi avaliado com 20 itens do questionário do comportamento do condutor (DBQ) (ÖZKAN et al., 2006), além de outros 20 itens, desenvolvidos especificamente para esta pesquisa, totalizando 40 itens. 
$\mathrm{Na}$ análise inicial, com todos os itens, foi possível determinar 10 dimensões com autovalor acima de 1. Contudo, diferentes itens apresentaram cargas elevadas em duas ou mais dimensões, e foram removidos em um processo iterativo. $O$ item com cargas altas em duas ou mais dimensões era removido primeiro, uma nova análise era realizada, e outro item era removido, de forma sucessiva até atingir uma estrutura interpretável sem a presença de itens com cargas cruzadas. Esse processo foi realizado com a finalidade de determinar comportamentos específicos e evitar dúvidas de interpretação. A estrutura final contemplou 22 itens, organizados em sete dimensões com autovalor maior que 1 (Figura 5.6).

Figura 5.6 - Gráfico de declividade das dimensões de comportamento

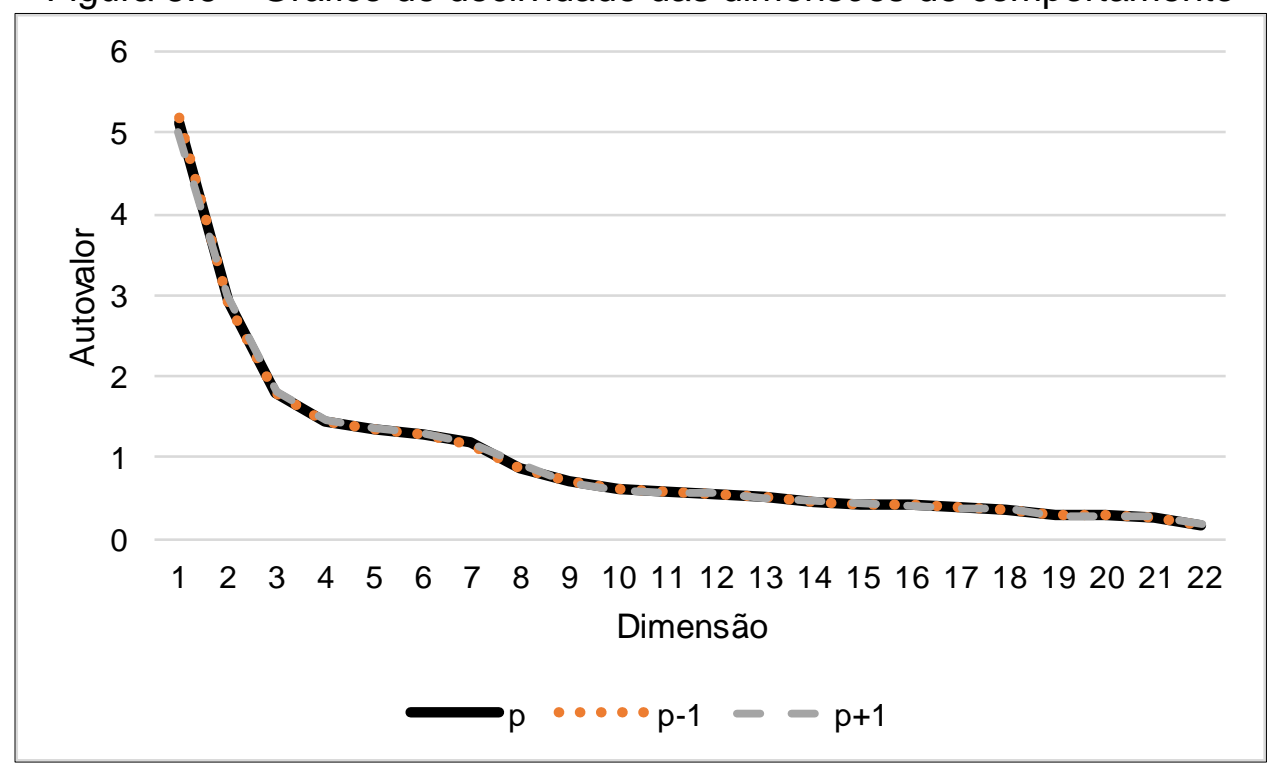

Os novos valores das categorias das escalas Likert, que indicavam a frequência do comportamento, são apresentados na Tabela 5.16. 
Tabela 5.16 - Valores métricos atribuídos às categorias da escala Likert dos comportamentos

\begin{tabular}{|c|c|c|c|c|c|c|c|c|c|c|}
\hline \multirow{2}{*}{ Itens } & \multicolumn{3}{|c|}{1} & \multicolumn{2}{|l|}{2} & \multicolumn{2}{|l|}{3} & \multicolumn{2}{|l|}{4} & \multirow{2}{*}{$\begin{array}{c}5 \\
\text { QO }\end{array}$} \\
\hline & $\mathrm{F}$ & QO & $\mathrm{F}$ & QO & $\mathrm{F}$ & QO & $\mathrm{F}$ & QO & $\mathrm{F}$ & \\
\hline $\begin{array}{l}\text { COMP1. Usar o celular, no modo viva voz, } \\
\text { enquanto dirige em uma área urbana }\end{array}$ & 421 & $-1,06$ & 364 & $-0,53$ & 328 & $-0,19$ & 294 & 0,51 & 295 & 1,84 \\
\hline COMP5. Dirigir com sono & 631 & $-1,06$ & 616 & 0,08 & 309 & 1,00 & 112 & 2,07 & 34 & 2,42 \\
\hline $\begin{array}{l}\text { COMP6. Usar o celular, no modo viva voz, } \\
\text { enquanto dirige em uma rodovia }\end{array}$ & 802 & $-0,78$ & 346 & $-0,08$ & 211 & 0,29 & 172 & 1,07 & 171 & 2,41 \\
\hline $\begin{array}{l}\text { COMP9. Exceder a velocidade quando o } \\
\text { tráfego está tranquilo }\end{array}$ & 378 & $-1,23$ & 447 & $-0,62$ & 404 & 0,28 & 335 & 1,03 & 138 & 2,04 \\
\hline $\begin{array}{l}\text { COMP14. Dirigir uma distância de } 20 \mathrm{~km} \text {, em } \\
\text { média, sem usar o cinto de segurança }\end{array}$ & 1.508 & $-0,33$ & 89 & 1,61 & 44 & 2,30 & 33 & 3,46 & 28 & 4,65 \\
\hline $\begin{array}{l}\text { COMP15. Dirigir após beber pelo menos dois } \\
\text { copos de bebida alcoólica }\end{array}$ & 1.036 & $-0,71$ & 332 & 0,50 & 191 & 1,34 & 97 & 2,10 & 43 & 2,73 \\
\hline $\begin{array}{l}\text { COMP17. Ignorar limites de velocidade para } \\
\text { andar mais rápido }\end{array}$ & 487 & $-1,14$ & 555 & $-0,31$ & 361 & 0,63 & 209 & 1,42 & 90 & 2,24 \\
\hline $\begin{array}{l}\text { COMP18. Continuar dirigindo quando você } \\
\text { está cansado e precisaria de uma pausa }\end{array}$ & 737 & $-0,94$ & 571 & 0,15 & 247 & 1,27 & 115 & 1,73 & 32 & 3,01 \\
\hline $\begin{array}{l}\text { COMP19. Dirigir pelo menos } 2 \mathrm{~km} \text { sem usar o } \\
\text { cinto de segurança }\end{array}$ & 1.367 & 0,41 & 143 & 0,54 & 81 & 1,38 & 56 & 2,56 & 55 & 4,07 \\
\hline DBQ1. Dirigir após consumir bebida alcoólica & 972 & $-0,74$ & 407 & 0,36 & 170 & 1,37 & 104 & 2,02 & 49 & 2,75 \\
\hline $\begin{array}{l}\text { DBQ3. Não perceber que pedestres estão } \\
\text { atravessando, ao entrar em uma rua lateral, } \\
\text { vindo de uma rua principal }\end{array}$ & 655 & 0,57 & 720 & 0,03 & 220 & 0,60 & 89 & 1,31 & 18 & 8,35 \\
\hline $\begin{array}{l}\text { DBQ4. Buzinar para indicar sua contrariedade } \\
\text { com relação a outro usuário da via }\end{array}$ & 467 & $-1,02$ & 550 & $-0,44$ & 385 & 0,47 & 203 & 1,53 & 97 & 2,38 \\
\hline $\begin{array}{l}\text { DBQ5. Não verificar seu espelho retrovisor } \\
\text { antes de sair com o carro, mudar de faixa etc. }\end{array}$ & 1.007 & $-0,41$ & 537 & 0,13 & 114 & 1,10 & 23 & 1,95 & 21 & 7,87 \\
\hline $\begin{array}{l}\text { DBQ6. Frear muito rápido em uma estrada } \\
\text { escorregadia, ou girar o volante para o lado } \\
\text { errado em uma derrapagem }\end{array}$ & 1.340 & $-0,19$ & 288 & 0,27 & 56 & 0,96 & 10 & 1,90 & 8 & 13,89 \\
\hline $\begin{array}{l}\text { DBQ7. Parar em um cruzamento tão para a } \\
\text { frente que o motorista que tem preferência } \\
\text { precisa parar e deixar você passar }\end{array}$ & 1.074 & $-0,42$ & 500 & 0,30 & 99 & 1,13 & 22 & 5,38 & 7 & 10,03 \\
\hline $\begin{array}{l}\text { DBQ8. Desrespeitar o limite de velocidade } \\
\text { em uma rua de área residencial }\end{array}$ & 433 & $-1,17$ & 572 & $-0,40$ & 386 & 0,57 & 210 & 1,40 & 101 & 2,19 \\
\hline $\begin{array}{l}\text { DBQ9. Ao virar à direita, quase bater em um } \\
\text { ciclista que apareceu do seu lado }\end{array}$ & 1.217 & $-0,32$ & 362 & 0,31 & 87 & 1,10 & 26 & 2,44 & 10 & 11,33 \\
\hline $\begin{array}{l}\text { DBQ10. Não prestar atenção aos sinais de } \\
\text { "Dê a preferência" e evitar, por pouco, colidir } \\
\text { com outro veículo que tem a preferência }\end{array}$ & 1.220 & $-0,27$ & 390 & 0,30 & 65 & 0,89 & 20 & 3,03 & 7 & 13,85 \\
\hline $\begin{array}{l}\text { DBQ11. Tentar ultrapassar alguém que você } \\
\text { não viu estar sinalizando para entrar à } \\
\text { esquerda }\end{array}$ & 1.208 & $-0,32$ & 381 & 0,30 & 83 & 1,04 & 23 & 4,16 & 7 & 12,29 \\
\hline $\begin{array}{l}\text { DBQ18. Ficar muito bravo com um } \\
\text { determinado tipo de motorista e indicar sua } \\
\text { hostilidade de qualquer maneira }\end{array}$ & 885 & $-0,78$ & 521 & 0,29 & 185 & 1,32 & 74 & 2,50 & 37 & 3,00 \\
\hline $\begin{array}{l}\text { DBQ19. Subestimar a velocidade de um } \\
\text { veículo que está vindo no sentido contrário ao } \\
\text { iniciar uma ultrapassagem }\end{array}$ & 1.205 & $-0,29$ & 371 & 0,28 & 103 & 1,02 & 14 & 1,71 & 9 & 12,59 \\
\hline $\begin{array}{l}\text { DBQ20. Desrespeitar o limite de velocidade } \\
\text { em uma rodovia }\end{array}$ & 406 & $-1,14$ & 456 & $-0,59$ & 415 & 0,26 & 261 & 1,14 & 164 & 1,99 \\
\hline
\end{tabular}

Nota - F: Frequência; QO: Quantificação ótima

A análise de interpretação de cada dimensão resultou em comportamentos claramente definidos, com valores altos de carregamentos (Tabela 5.17), de modo 
que foi possível rotulá-los como: 1- Erros; 2- Excesso de velocidade; 3- Conduzir sob efeito de álcool; 4- Não usar o cinto de segurança; 5- Usar o celular no modo viva voz; 6- Sonolência e cansaço; 7- Expressão de raiva do condutor.

Tabela 5.17 - Cargas fatoriais das dimensões de comportamentos de condutor

\begin{tabular}{|c|c|c|c|c|c|c|c|}
\hline \multirow{2}{*}{ Itens } & \multicolumn{7}{|c|}{ Dimensão } \\
\hline & 1 & 2 & 3 & 4 & 5 & 6 & 7 \\
\hline $\begin{array}{l}\text { DBQ6. Frear muito rápido em uma estrada escorregadia, ou } \\
\text { girar o volante para o lado errado em uma derrapagem }\end{array}$ & 0,801 & 0,022 & 0,071 & $-0,013$ & 0,015 & $-0,024$ & $-0,024$ \\
\hline $\begin{array}{l}\text { DBQ10. Não prestar atenção aos sinais de "Dê a preferência" e } \\
\text { evitar, por pouco, colidir com outro veículo que tem a preferência }\end{array}$ & 0,776 & 0,009 & 0,067 & 0,042 & $-0,025$ & 0,038 & 0,043 \\
\hline $\begin{array}{l}\text { DBQ19. Subestimar a velocidade de um veículo que está vindo } \\
\text { no sentido contrário ao iniciar uma ultrapassagem }\end{array}$ & 0,736 & 0,064 & 0,105 & 0,033 & 0,006 & 0,086 & 0,096 \\
\hline $\begin{array}{l}\text { DBQ11. Tentar ultrapassar alguém que você não viu estar } \\
\text { sinalizando para entrar à esquerda }\end{array}$ & 0,677 & 0,086 & $-0,024$ & 0,080 & 0,026 & 0,033 & 0,051 \\
\hline $\begin{array}{l}\text { DBQ9. Ao virar à direita, quase bater em um ciclista que } \\
\text { apareceu do seu lado }\end{array}$ & 0,662 & 0,040 & $-0,010$ & 0,016 & $-0,049$ & 0,020 & 0,142 \\
\hline $\begin{array}{l}\text { DBQ5. Não verificar seu espelho retrovisor antes de sair com o } \\
\text { carro, mudar de faixa etc. }\end{array}$ & 0,609 & 0,020 & 0,009 & 0,019 & 0,035 & 0,059 & 0,030 \\
\hline $\begin{array}{l}\text { DBQ7. Parar em um cruzamento tão para a frente que } 0 \\
\text { motorista que tem preferência precisa parar e deixar você } \\
\text { passar }\end{array}$ & 0,607 & 0,152 & 0,059 & 0,010 & 0,142 & 0,011 & $-0,081$ \\
\hline $\begin{array}{l}\text { DBQ3. Não perceber que pedestres estão atravessando, ao } \\
\text { entrar em uma rua lateral, vindo de uma rua principal }\end{array}$ & 0,594 & 0,067 & $-0,015$ & 0,004 & 0,025 & 0,071 & 0,166 \\
\hline COMP17. Ignorar limites de velocidade para andar mais rápido & 0,048 & 0,857 & 0,090 & 0,061 & 0,096 & 0,124 & 0,084 \\
\hline COMP9. Exceder a velocidade quando o tráfego está tranquilo & 0,021 & 0,844 & 0,065 & 0,064 & 0,046 & 0,106 & 0,059 \\
\hline DBQ20. Desrespeitar o limite de velocidade em uma rodovia & 0,131 & 0,796 & 0,101 & 0,002 & 0,159 & 0,109 & 0,005 \\
\hline $\begin{array}{l}\text { DBQ8. Desrespeitar o limite de velocidade em uma rua de área } \\
\text { residencial }\end{array}$ & 0,172 & 0,766 & 0,071 & 0,052 & 0,063 & 0,056 & 0,155 \\
\hline DBQ1. Dirigir após consumir bebida alcoólica & 0,123 & 0,136 & 0,929 & 0,080 & 0,041 & 0,056 & 0,077 \\
\hline $\begin{array}{l}\text { COMP15. Dirigir após beber pelo menos dois copos de bebida } \\
\text { alcoólica }\end{array}$ & 0,043 & 0,155 & 0,926 & 0,129 & 0,061 & 0,091 & 0,024 \\
\hline $\begin{array}{l}\text { COMP14. Dirigir uma distância de } 20 \mathrm{~km} \text {, em média, sem usar o } \\
\text { cinto de segurança }\end{array}$ & 0,068 & 0,038 & 0,090 & 0,917 & 0,040 & 0,022 & 0,009 \\
\hline COMP19. Dirigir pelo menos $2 \mathrm{~km}$ sem usar o cinto de segurança & 0,062 & 0,109 & 0,102 & 0,909 & 0,015 & 0,054 & 0,004 \\
\hline $\begin{array}{l}\text { COMP1. Usar o celular, no modo viva voz, enquanto dirige em } \\
\text { uma área urbana }\end{array}$ & 0,048 & 0,152 & 0,045 & 0,023 & 0,894 & 0,051 & 0,116 \\
\hline $\begin{array}{l}\text { COMP6. Usar o celular, no modo viva voz, enquanto dirige em } \\
\text { uma rodovia }\end{array}$ & 0,052 & 0,153 & 0,052 & 0,034 & 0,885 & 0,156 & 0,003 \\
\hline COMP5. Dirigir com sono & 0,092 & 0,147 & 0,052 & 0,007 & 0,084 & 0,879 & 0,035 \\
\hline $\begin{array}{l}\text { COMP18. Continuar dirigindo quando você está cansado e } \\
\text { precisaria de uma pausa }\end{array}$ & 0,116 & 0,197 & 0,092 & 0,075 & 0,121 & 0,843 & 0,035 \\
\hline $\begin{array}{l}\text { DBQ4. Buzinar para indicar sua contrariedade com relação a } \\
\text { outro usuário da via }\end{array}$ & 0,101 & 0,118 & 0,020 & 0,010 & 0,095 & $-0,020$ & 0,839 \\
\hline $\begin{array}{l}\text { DBQ18. Ficar muito bravo com um determinado tipo de } \\
\text { motorista e indicar sua hostilidade de qualquer maneira }\end{array}$ & 0, & 0,122 & 0,075 & 0,003 & 0,015 & 0,088 & 0,812 \\
\hline
\end{tabular}

Nota: 1- Erros; 2- Excesso de velocidade; 3- Conduzir sob efeito de álcool; 4- Não usar o cinto de segurança; 5- Usar o celular no modo viva voz; 6 - Sonolência e cansaço; 7- Expressão de raiva do condutor

A estrutura de sete dimensões explicou $68,7 \%$ da variância total. A confiabilidade da escala foi avaliada com o Alpha de Cronbach (Tabela 5.18). As duas primeiras dimensões indicaram uma boa confiabilidade (KLINE ${ }^{8}$, 1999, apud FIELD, 2009). 
Contudo, as cinco dimensões restantes apresentaram uma confiabilidade considerada pobre/baixa, novamente devido ao número de variáveis presentes nas respectivas dimensões. Como as dimensões eram constituídas por apenas dois itens, realizou-se uma análise de correlação de Spearman com as variáveis originais de cada dimensão, as quais todas indicaram uma correlação alta e positiva a um nível de significância de 99\%. Dessa forma, a estrutura encontrada pôde ser considerada como confiável.

Tabela 5.18 - Resultados para validação do comportamento do condutor

\begin{tabular}{|c|c|c|c|c|}
\hline \multirow{2}{*}{ Dimensão } & \multirow{2}{*}{ Alfa de Cronbach } & \multicolumn{2}{|c|}{ Variância contabilizada para } & \multirow{2}{*}{ Correlação de Spearman } \\
\hline & & Total (Autovalor) & Variância (\%) & \\
\hline 1- Erros & 0,802 & 3,921 & 17,822 & - \\
\hline 2- Excesso de velocidade & 0,761 & 2,900 & 13,180 & - \\
\hline 3- Conduzir sob efeito de álcool & 0,597 & 1,812 & 8,236 & $0,812^{* *}$ \\
\hline 4- Não usar o cinto de segurança & 0,515 & 1,719 & 7,812 & $0,646^{* *}$ \\
\hline 5- Usar o celular no modo viva voz & 0,564 & 1,688 & 7,671 & $0,653^{* *}$ \\
\hline 6- Sonolência e cansaço & 0,581 & 1,593 & 7,243 & $0,599^{* *}$ \\
\hline 7- Expressão de raiva do condutor & 0,515 & 1,490 & 6,771 & $0,462^{* *}$ \\
\hline Total & & & & \\
\hline
\end{tabular}

\subsection{Considerações do Capítulo 5}

Para esta pesquisa, adotou-se como critério para definição das variáveis latentes, ou construtos, não apenas a interpretação dos mesmos, mas também a presença de cargas (carregamentos) fatoriais cruzadas e variância total explicada. O objetivo foi confirmar traços de personalidade, caracterizar o ambiente e identificar comportamentos sem ambiguidade entre os itens presentes, explicando a maior parcela de variância dos dados de forma clara e precisa.

Os resultados dos questionários relacionados aos traços de personalidade "busca de sensações" e "escala de raiva do condutor" mostraram-se coerentes com as estruturas definidas na literatura (DEFFENBACHER; OETTING; LYNCH, 1994; IVERSEN; RUNDMO, 2002; YAGIL, 2001). O questionário de "habilidades do condutor", mesmo não sendo avaliado quanto a sua estrutura fatorial no estudo original (DELHOMME, 1991) e tendo incluído dois itens especificamente para esse estudo, mostrou-se coerente com os objetivos do estudo original.

Em relação aos itens de "caracterização do ambiente", foram identificadas estruturas que caracterizam o ambiente viário urbano e rodoviário (rural), possibilitando a avaliação quanto à densidade, qualidade de infraestrutura e tipo das vias, conforme planejado durante a elaboração das questões e itens para este estudo. $\mathrm{O}$ ambiente 
viário representado pelo volume de tráfego, o traçado das vias e presença de infraestrutura são associados à exposição e consequente risco de envolvimento em acidentes de trânsito (ELVIK et al., 2009), bem como as áreas urbanas e rurais mostraram-se significativas para explicação da variância do comportamento de risco (KOMBA, 2016).

Na definição dos comportamentos de risco, o uso dos itens DBQ, além daqueles elaborados para este trabalho, permitiu associar a estabilidade do questionário $D B Q$, com as condições locais pertinentes aos condutores de Brasil e Portugal, contempladas nos 20 itens elaborados para esta pesquisa, conforme recomendado por Lajunen, Parker e Summala (2004). A identificação dos comportamentos foi realizada sob os critérios de encontrar comportamentos claramente definidos, ou seja, sem ambiguidades e que permitissem uma análise precisa acerca dos fatores que influenciam os países amostrados neste estudo.

Os comportamentos "Erros" e "Expressão de raiva do condutor" identificados neste trabalho e comumente avaliados com a aplicação do DBQ mostraram-se relacionados ao envolvimento de acidentes de trânsito em diferentes estudos (ÖZKAN et al., 2006). Os demais comportamentos identificados ("excesso de velocidade", "conduzir sob efeito de álcool", "não usar cinto de segurança enquanto conduz", "usar o celular no modo viva voz durante a condução", "sonolência e cansaço") são considerados como fatores de risco para o envolvimento e severidade de acidentes de trânsito (ELVIK et al., 2009; PEDEN et al., 2004; SHINAR, 2017).

O uso da Análise de Componentes Principais Categórica possibilitou confirmar os construtos referentes aos traços de personalidade, corroborando os resultados presentes na literatura. Também foi possível definir as variáveis latentes acerca dos itens elaborados para este estudo, de acordo com o embasamento teórico e investigação exploratória realizada durante a elaboração do questionário. A validade foi alcançada por meio dos pesos das cargas fatoriais elevados, pelo percentual da variância explicada, pelo indicador de confiabilidade de escala Alfa de Cronbach e a correlação de Spearman, que nos casos em que foi avaliado apresentou valores elevados e com níveis de significância de 0,01.

Dessa forma, a técnica se mostrou adequada para análise de validação de construtos e variáveis latentes relacionadas à investigação do comportamento do condutor, respeitando as condições inerentes da escala Likert como um dado ordinal. As 
distribuições dos escores individuais das dimensões são apresentados no Apêndice $\mathrm{D}$ deste trabalho.

O Quadro 5.1 sintetiza as variáveis latentes obtidas a partir da aplicação da CATPCA.

\begin{tabular}{|c|c|c|c|c|}
\hline Conjunto de itens avaliados & $\begin{array}{l}\text { Número de } \\
\text { itens } \\
\text { utilizados }\end{array}$ & $\begin{array}{l}\text { Número de } \\
\text { dimensões } \\
\text { obtidas }\end{array}$ & Nomenclatura das dimensões obtidas & $\begin{array}{l}\text { Variância } \\
\text { Total } \\
\text { explicada } \\
\text { (\%) }\end{array}$ \\
\hline Habilidades de condução & 6 & 2 & $\begin{array}{l}1 \text { - Habilidades dos demais condutores } \\
2 \text { - Eu mesmo como condutor }\end{array}$ & 62,5 \\
\hline Escala de raiva do condutor & 9 & 3 & $\begin{array}{l}1 \text { - Impedimento para prosseguir viagem } \\
2 \text { - Demonstração direta de hostilidade do outro condutor } \\
3 \text { - Imprudência de outros condutores }\end{array}$ & 59,0 \\
\hline Busca de sensações & 6 & 1 & 1 - Busca de sensações & 50,1 \\
\hline Percepção de risco & 17 & 3 & $\begin{array}{l}1 \text { - Ações que prejudicam a concentração e vigilância ao } \\
\text { conduzir } \\
2 \text { - Tarefas secundárias ao conduzir } \\
3 \text { - Comportamentos perigosos }\end{array}$ & 78,7 \\
\hline Ambiente viário & 15 & 4 & $\begin{array}{l}1 \text { - Elementos urbanos } \\
2 \text { - Rodovias confortáveis } \\
3 \text { - Rodovias com defeitos no pavimento } \\
4 \text { - Áreas urbanas com edificações altas }\end{array}$ & 59,6 \\
\hline Comportamento do condutor & 22 & 7 & $\begin{array}{l}1 \text { - Erros } \\
2 \text { - Excesso de velocidade } \\
3 \text { - Conduzir sob efeito de álcool } \\
4 \text { - Não usar o cinto de segurança } \\
5 \text { - Usar o celular no modo viva voz } \\
6 \text { - Sonolência e cansaço } \\
7 \text { - Expressão de raiva do condutor }\end{array}$ & 68,7 \\
\hline
\end{tabular}

Os escores individuais dos comportamentos serão utilizados para classificá-los de acordo com o envolvimento de acidentes de trânsito com auxílio da Árvore de Decisão (próxima etapa metodológica). Os escores individuais das demais dimensões serão utilizados como variáveis independentes dos modelos para análise dos fatores de influência dos comportamentos de risco dos condutores de Brasil e Portugal. 



\section{CLASSIFICAÇÃO DE COMPORTAMENTOS DE RISCO}

Neste capítulo é apresentado o resultado da classificação dos comportamentos de risco que foram identificados a partir da Análise de Componentes Principais Categórica (CATPCA). A classificação foi realizada com a aplicação do algoritmo CART da Árvore de Decisão (AD), contido no software IBM SPSS 25.

\subsection{Considerações iniciais}

Para a geração da Árvore de Decisão (AD), utilizou-se a frequência de acidentes de trânsito que o participante se envolveu nos últimos 3 anos como variável dependente. A variável independente corresponde aos escores individuais de cada um dos sete comportamentos obtidos a partir da Análise de Componentes Principais Categórica (CATPCA). A classificação obtida com os nós terminais da AD caracterizam a variável dependente, a ser utilizada na etapa posterior de modelagem paramétrica.

\subsection{Distribuição dos escores individuais}

Os escores individuais, ou pontuações dos objetos, correspondem às pontuações provenientes da CATPCA, para cada comportamento de risco identificado, atribuídas a cada participante da pesquisa. Para classificação com o algoritmo CART, os valores foram normalizados entre 0 e 1 . Dessa forma, os participantes que reportaram nunca ou pouco frequentemente se comportaram de acordo com os itens que compõem o comportamento de risco e passaram a ter valores de escore próximo a 0 , enquanto os escores mais próximos de 1 representam maior frequência reportada.

As distribuições normalizadas dos escores individuais, para cada comportamento, são apresentadas na Figura 6.1. Vale ressaltar que esta figura representa a distribuição dos resultados obtidos com a CATPCA para 1.702 observações. 
Figura 6.1- Diagrama de caixa das pontuações normalizadas das observações para cada comportamento

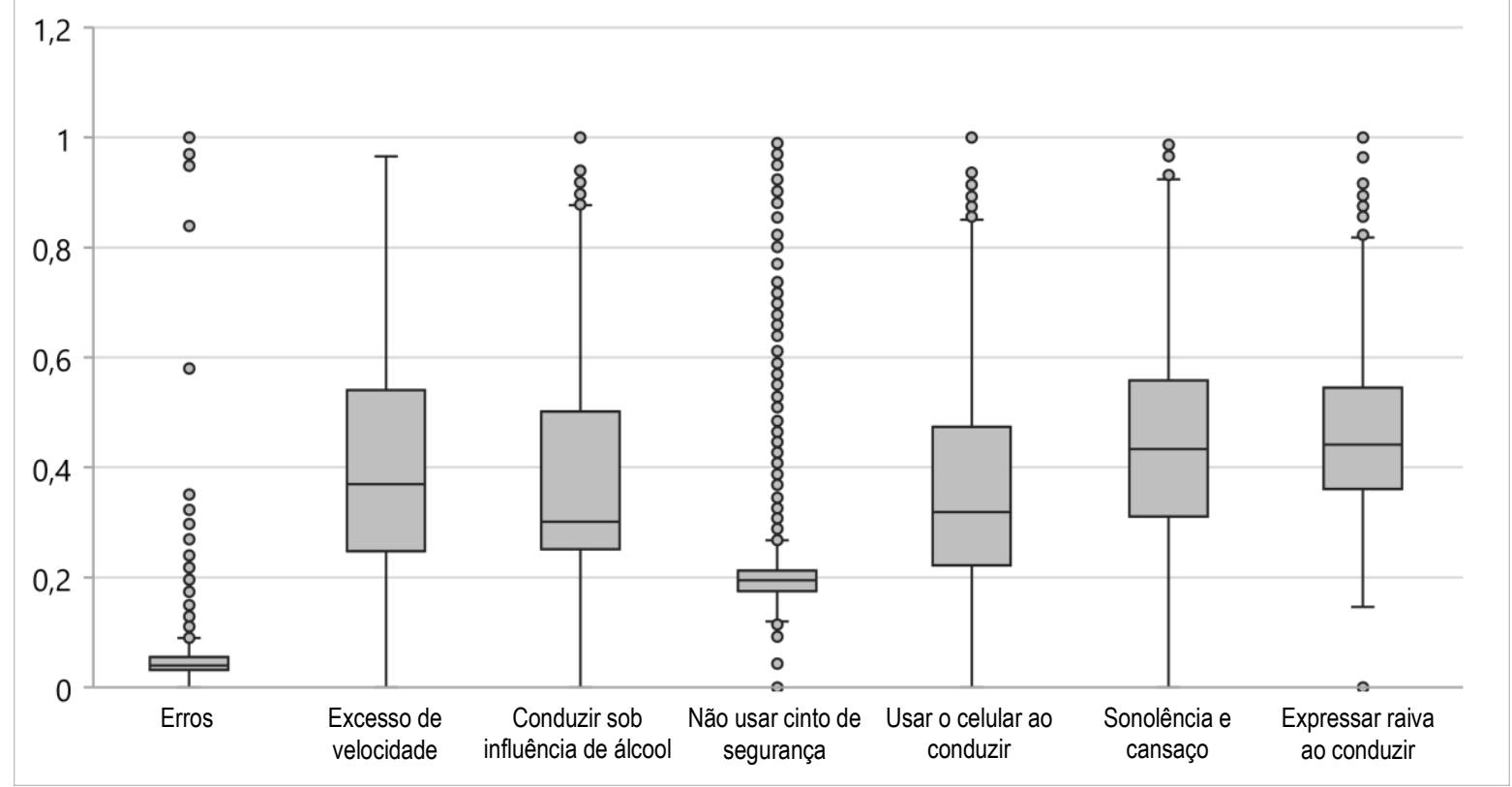

Os escores individuais indicaram que os condutores da amostra se comportam de maneira muito semelhante em relação ao comportamento "Erros" e também ao comportamento "Não usar o cinto de segurança", com maior frequência de valores extremos para ambos os casos.

Os demais comportamentos apresentaram pontuações mais dispersas, indicando maior variação no estilo de condução referente aos comportamentos de risco "excesso de velocidade", "conduzir sob efeito de álcool", "usar o celular enquanto conduz", "sonolência e cansaço" e "expressar raiva ao conduzir".

\subsection{Limites de risco e características dos nós terminais}

Para geração da Árvore de Decisão (AD), a partir do uso do algoritmo CART (Classification And Regression Tree), foi utilizada a variável "frequência de envolvimento em acidentes nos últimos 3 anos" como variável dependente. Os escores individuais normalizados, provenientes da CATPCA, foram as variáveis independentes utilizadas. A classificação dos comportamentos foi determinada pelos nós terminais da $A D$. Vale ressaltar que cada $A D$ caracteriza um comportamento identificado na etapa anterior, com a CATPCA. 
Assim, foram geradas sete árvores: (1) Escores relativos ao comportamento "Erros" $x$ "envolvimento em acidentes nos últimos 3 anos"; (2) Escores relativos ao comportamento "Excesso de velocidade" x "envolvimento em acidentes nos últimos 3 anos"; (3) Escores relativos ao comportamento "Conduzir sob efeito de álcool" $\mathrm{x}$ "envolvimento em acidentes nos últimos 3 anos"; (4) Escores relativos ao comportamento "Não uso do cinto de segurança" x "envolvimento em acidentes nos últimos 3 anos"; (5) Escores relativos ao comportamento "Uso do celular no modo viva voz ao conduzir" x "envolvimento em acidentes nos últimos 3 anos"; (6) Escores relativos ao comportamento "Sonolência e cansaço" $x$ "envolvimento em acidentes nos últimos 3 anos"; e (7) Escores relativos ao comportamento "Expressão de raiva ao conduzir" x "envolvimento em acidentes nos últimos 3 anos".

A partir desta análise, foi possível identificar os padrões e valores limites para frequência de cada comportamento, delimitando os condutores que se envolveram mais e os que se envolveram menos em acidentes. A escolha do valor de corte, no algoritmo CART, para o caso de variáveis independentes numéricas e variável dependente discreta, como no caso do presente trabalho, é dada da seguinte forma (BREIMAN et al., 1984):

- Para $k$ valores possíveis ordenados da variável independente, k-1 divisões são possíveis;

- O algoritmo testa cada uma das "k-1" divisões, calculando o aprimoramento para cada divisão;

- O valor do aprimoramento é dado pela diferença entre o índice Gini para o nó pai e a soma dos valores para os nós filhos, ponderados pela proporção de casos em cada nó filho. Conforme mencionado no Capítulo 3 deste trabalho, o índice Gini é dado pela Equação 3.1

Em seguida, o teste não paramétrico Mann-Whitney foi realizado para comparar e caracterizar os nós terminais em relação às variáveis "número de acidentes", "severidade" (danos materiais, ferimentos leves, ferimentos graves), "multas (excesso de velocidade, álcool, celular, desrespeito a sinais de trânsito, estacionar em local proibido, carteira de habilitação irregular) " e os próprios "comportamentos de risco".

O teste de Mann-Whitney é adequado para comparar funções de distribuição de uma variável, pelo menos ordinal, medida em duas amostras independentes (MARÔCO, 
2014, p. 307). Neste trabalho, tem-se como hipótese nula que a distribuição da variável ' $x$ ' é a mesma entre os nós terminais da árvore de decisão do comportamento ' $z$ '.

Os resultados mais importantes são apresentados ao longo deste capítulo. Todos os resultados são apresentados no Apêndice $E$ deste trabalho, juntamente com as médias de escores individuais, número de acidentes e multas para os nós de cada comportamento.

Na sequência, serão apresentados os valores limites e as caracterizações das classificações obtidas para cada comportamento. Os valores limites são representados pelos valores de corte das variáveis independentes em cada uma das sete árvores obtidas.

\subsubsection{Classificação de erros}

Os escores individuais para o comportamento "Erros" (Figura 6.2) foram segmentados em dois nós terminais de acordo com o valor de corte equivalente a 0,039. O valor próximo a zero é reflexo dos valores e da distribuição dos escores, que demonstrou pouca variação referente a esse comportamento na amostra, conforme apresentado na Figura 6.1.

Os relatos desse comportamento concentram-se, majoritariamente, em categorias que indicam baixa frequência de ocorrência. Pode-se justificar este fato pelas situações descritas nos itens muitas vezes serem realizadas de modo não consciente, levando a uma menor percepção acerca da frequência de situações de erros, uma vez que erros são tratados como ocasiões onde houve alguma falha mental ou física, ou ainda resultados indesejados de ações involuntárias (ÖZKAN et al., 2006; REASON et al., 1990).

Mesmo com a concentração dos dados em baixa frequência de ocorrência, foi possível identificar uma diferença entre os nós obtidos com a $A D$ em relação à frequência de envolvimento em acidentes de trânsito. A proporção de condutores que não se envolveram em acidentes é superior no Nó $1(77,1 \%)$ - menores valores dos escores relativos a "erros" - comparado ao nó $2(71,7 \%)$ - maiores valores dos escores relativos a "erros". Além disso, observou-se que a média de acidentes do Nó 2 é superior em $24,6 \%$. 
Figura 6.2 - Mapa da árvore de decisão: Erros

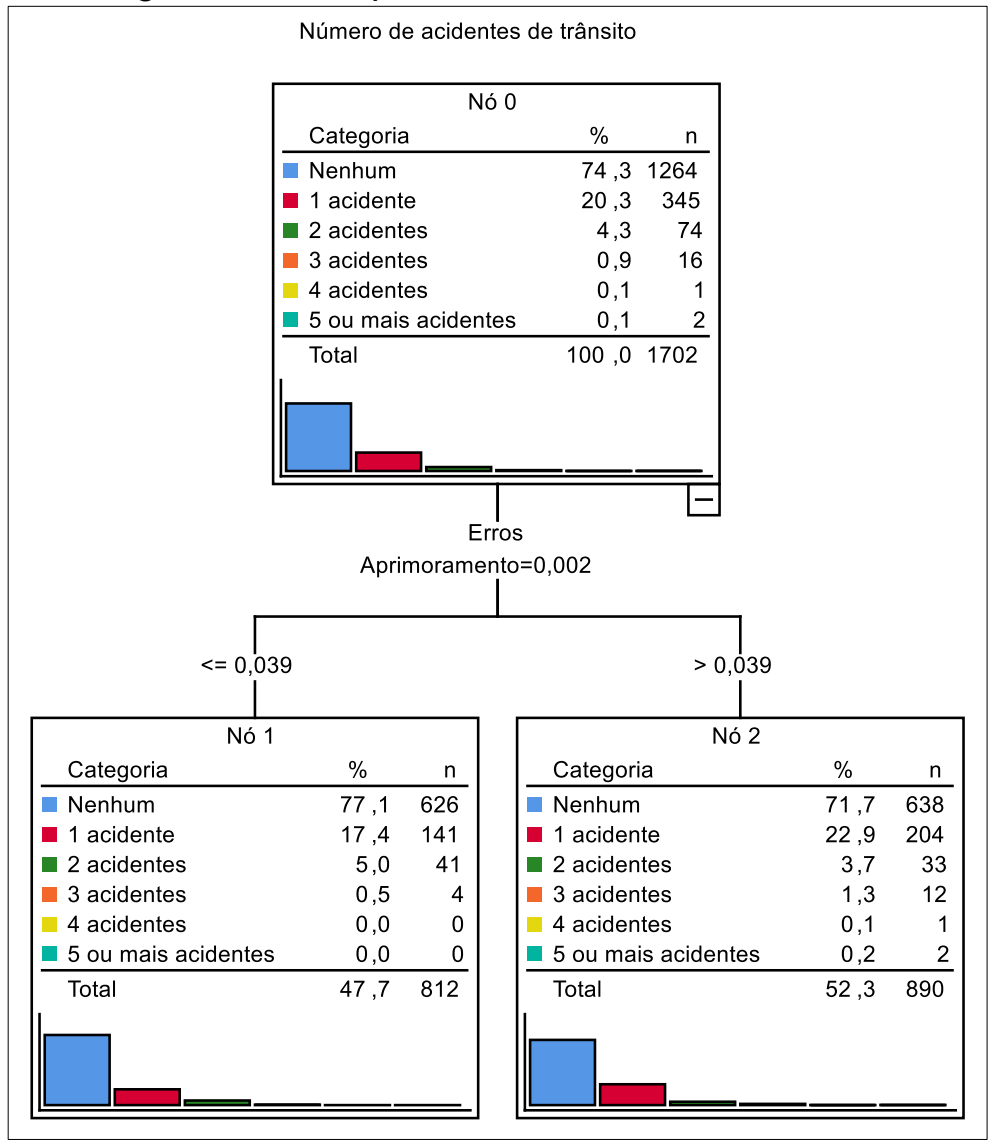

O teste de Mann-Whitney demonstrou que há uma diferença significativa ( $U=379.223$; $p=0,016)$ no número de acidentes entre os nós 1 e 2 . Mesmo com escores individuais semelhantes entre os condutores participantes da amostra, foi possível identificar um padrão de comportamento em que aqueles que pontuaram valores mais altos, ou seja, mais frequentemente cometiam erros no trânsito, estiveram mais envolvidos em acidentes, corroborando com outros estudos (ÖZKAN et al., 2006).

Há uma diferença significativa entre os nós terminais $(U=370.897 ; p=0,019)$ referente ao número de multas devido ao uso do celular, que pode indicar uma relação entre o uso do celular e a frequência de erros com consequente envolvimento em acidentes, visto que a média de multas é maior em $24,6 \%$ no Nó $2(0,080)$, em relação ao nó 1 . O hábito de uso do celular pode acarretar na redução do nível de atenção do condutor, levando-o a cometer mais erros.

Ao analisar a relação do comportamento erros com os demais comportamentos de risco, o teste de Mann-Whitney indicou que a distribuição populacional dos escores foi significativamente diferente entre os nós 1 e 2 para os comportamentos beber e dirigir 
$(U=312.691 ; p<0,001)$ e conduzir com sono ou cansado $(U=403.148 ; p<0,001)$. Este resultado demonstra que condutores que cometem mais erros e se envolvem mais em acidentes também apresentam maior frequência nos comportamentos de conduzir sob efeito de bebida alcoólica e cansado ou sonolento. Esses comportamentos podem interferir na consciência da situação/cognição, tornando o condutor propenso a cometer mais erros. Usar o celular ao conduzir não foi significativamente diferente, contudo, apresentou um valor no limiar para um nível de confiança de $95 \%(p=0,056)$.

\subsubsection{Classificação de excesso de velocidade}

Os escores individuais normalizados relativos ao "excesso de velocidade" foram segmentados, pelo algoritmo CART, de acordo com o valor limite 0,242 (Figura 6.3). O Nó 1 foi composto por apenas $24,1 \%$ da amostra. Neste nó estão contidos os indivíduos que relataram menor frequência em exceder a velocidade, demonstrando que excesso de velocidade é um comportamento relatado como mais frequente pelos condutores.

O Nó 1 é composto por mais participantes que não se envolveram em acidentes nos últimos 3 anos $(81,8 \%)$, comparado ao Nó $2(71,9 \%)$. A principal diferença pertinente àqueles que se envolveram em acidentes está na frequência da categoria '1 acidente', que corresponde a $22,7 \%$ do Nó 2 , e $12,7 \%$ do nó 1 . Essa diferença é refletida na média de acidentes por participante de cada nó, sendo 0,263 para o Nó 1 e 0,346 para o Nó 2.

O teste de Mann-Whitney indicou uma diferença significativa $(U=289.863 ; p<0,001)$ na distribuição populacional da variável frequência de acidentes entre os nós e na severidade em relação aos danos materiais $(U=286.286 ; p=0,001)$ e ferimentos leves $(U=269.323 ; p=0,049)$. A distribuição dos acidentes reportados com severidade de ferimentos graves não foi significativamente diferente, entretanto, dos 3 registros no banco de dados, 2 foram classificados no Nó 2. Dessa forma, verifica-se um padrão em que a maior frequência de comportamentos de excesso de velocidade está relacionada com a maior frequência de envolvimento em acidentes de trânsito $e$ acidentes de maior severidade. A probabilidade de acidentes mais severos aumenta com o aumento da velocidade (ELVIK et al., 2009), corroborando com estudos preliminares (PEDEN et al., 2004; SHINAR, 2017). 
Figura 6.3 - Mapa da árvore de decisão: Excesso de velocidade

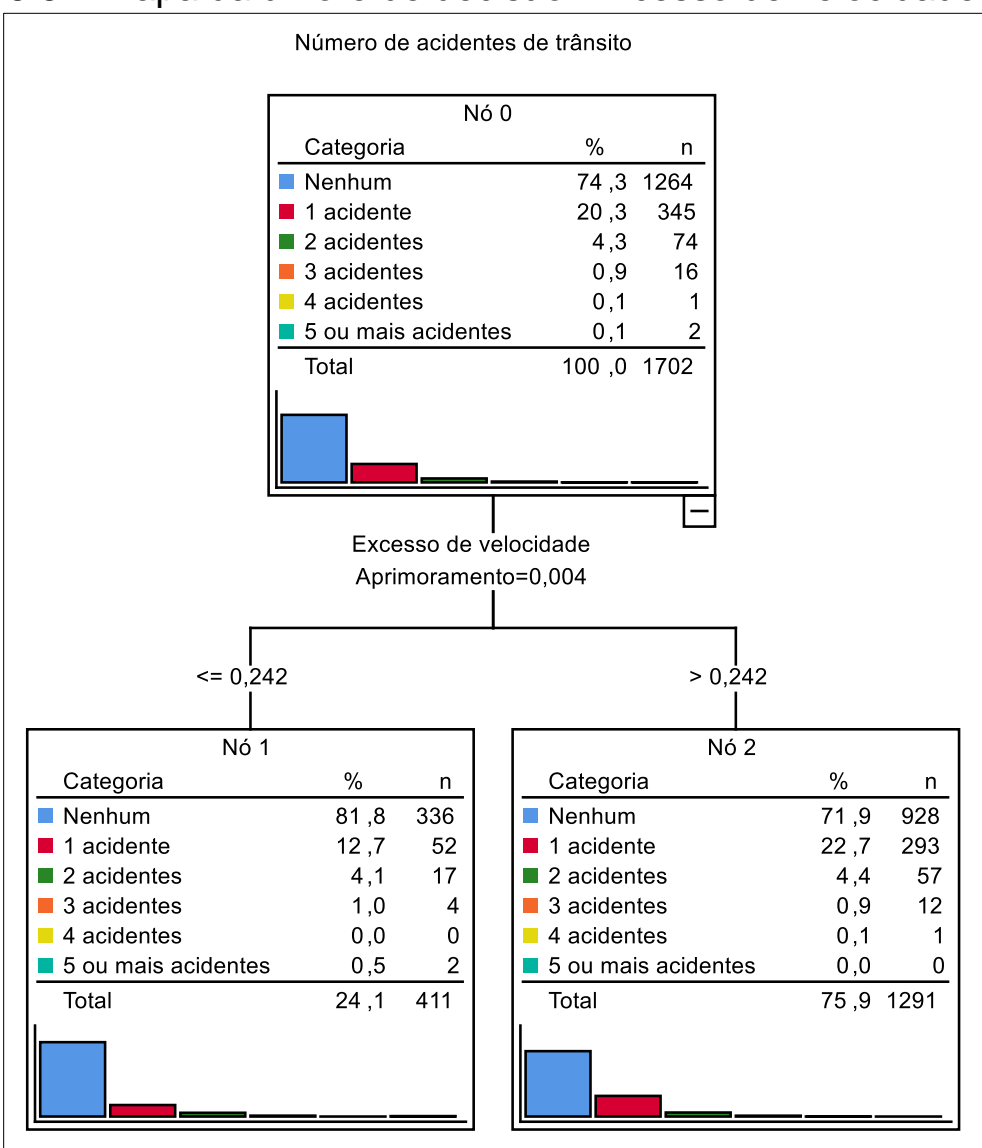

Ao analisar as multas, o teste Mann-Whitney indicou uma diferença significativa $(U=297.584 ; p<0,001)$ para multas por excesso de velocidade, que foram reportadas com mais frequência para o Nó $2(M=0,976)$ do que o Nó $1(M=0,611)$, corroborando a classificação do Nó 2 para condutores com comportamentos mais frequentes de excesso de velocidade.

Ao se analisar os demais comportamentos, o teste Mann-Whitney apresentou uma diferença significativa para os comportamentos "conduzir sob efeito de álcool" (U = 240.290; $p=0,004)$ e "não uso de cinto de segurança" ( $U=181.165 ; p<0,001)$ em relação aos nós de velocidade. O nível de álcool é um fator relacionado ao condutor que interfere na escolha pela velocidade (PEDEN et al., 2004).

O limite identificado para excesso de velocidade possibilitou não só confirmar a relação entre a frequência do comportamento de risco e dos acidentes, como também da severidade dos acidentes, corroborando com os resultados de diferentes estudos (DACOTA, 2012; PEDEN et al., 2004; SHINAR, 2017). 


\subsubsection{Classificação de conduzir sob efeito de álcool}

A classificação dos escores normalizados individuais do comportamento "conduzir sob efeito do álcool" resultou em nós classificados de acordo com o valor limítrofe 0,346 (Figura 6.4). Assim, o Nó 1 representa os indivíduos que bebem com uma frequência muito baixa ao conduzir, enquanto o Nó 2 representa os indivíduos que bebem como uma frequência um pouco maior, comparativamente, ao dirigir. Com relação ao envolvimento em acidentes de trânsito, 76,9\% dos condutores classificados no Nó 1 e 70,8\% do Nó 2 não estiveram envolvidos em acidentes.

Figura 6.4 - Mapa da árvore de decisão: Conduzir sob efeito de álcool

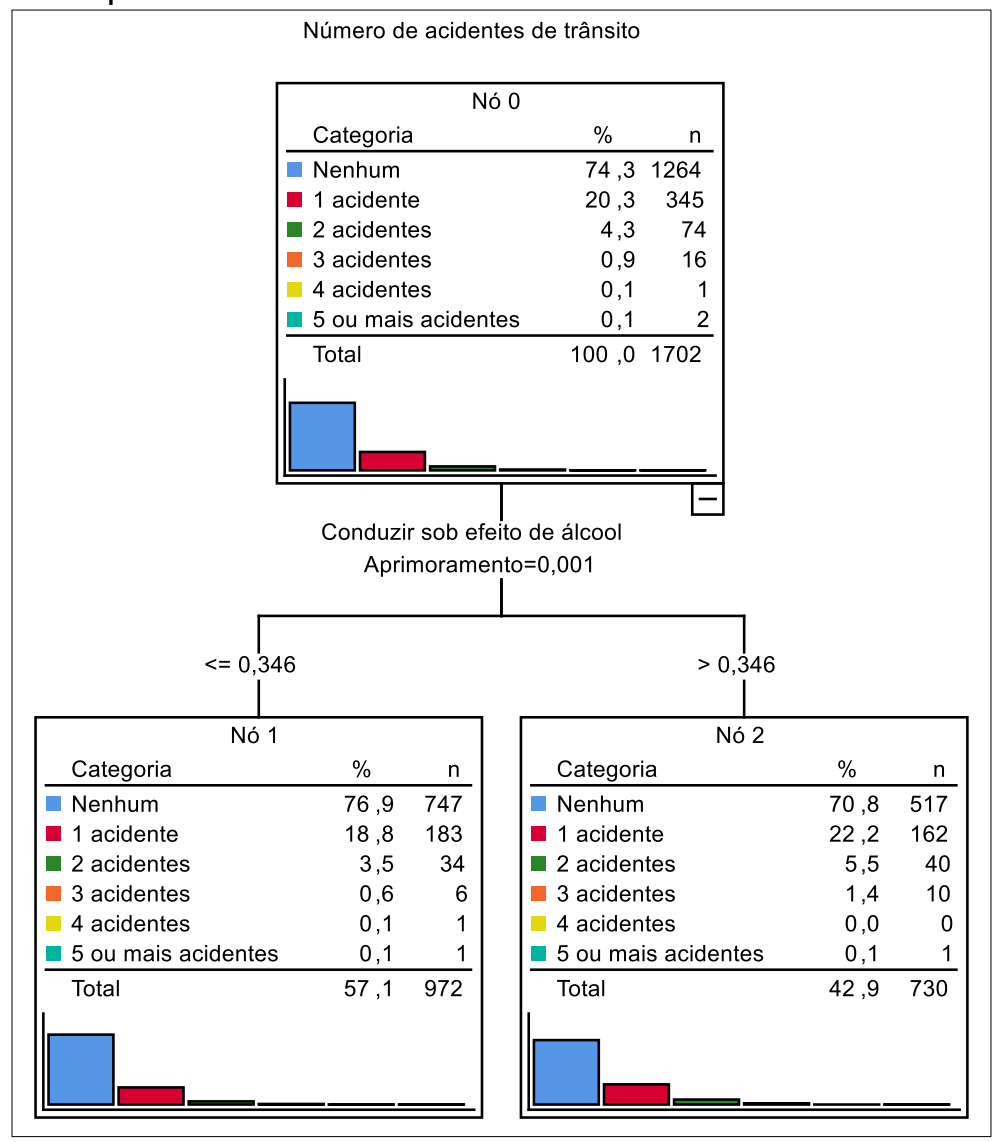

O teste de Mann-Whitney indicou a diferença significativa $(U=377.458, p=0,003)$ da distribuição populacional da variável frequência de acidentes entre os nós, sendo a média do Nó $2(M=0,379)$ maior que o Nó $1(M=0,286)$. Dessa forma, foi possível confirmar o padrão em que a maior frequência do comportamento de conduzir sob efeito de álcool está relacionada com a maior frequência de acidentes de trânsito.

O número de multas entre os nós é significativamente diferente para os motivos "conduzir sob efeito de álcool" ( $U=358.789 ; p=0,003)$, "excesso de velocidade" ( $U=$ 
405.088; $p<0,001)$ e "estacionar em local proibido" ( $U=376.151$; $p<0,001)$, cujas médias são maiores para o Nó 2. A diferença entre as médias do Nó $1(M=0,252)$ e Nó $2(\mathrm{M}=0,561)$ para o motivo de "conduzir sob efeito de álcool" corrobora a classificação determinada pela árvore de decisão, em que os condutores com comportamentos mais frequentes relacionados a conduzir sob efeito de bebida alcoólica foram classificados no Nó 2.

Ao se analisar a relação com os demais comportamentos, o teste Mann-Whitney indicou diferenças significativas para os comportamentos "erros" $(U=309.385$; p $<0,001)$, "excesso de velocidade" $(U=381,825$; $p=0,007)$ e "não usar o cinto de segurança" ( $U=237.537 ; p<0,001)$ em relação aos nós de classificação para condução sob efeito de álcool.

Esses resultados são coerentes com National Highway Traffic Safety Administration NHTSA (2016), que apresenta entre os efeitos típicos do consumo do álcool a redução da habilidade de julgamento, comportamento exagerado, dificuldade em identificar perigos, dificuldade em controlar a velocidade, redução do estado de alerta, entre outros. O álcool afeta capacidades relacionadas a tarefas de percepção, atenção, decisão, memória e psicomotoras, prejudicando as habilidades de condução e performance (ELVIK et al., 2009; SHINAR, 2017) que contribuem para o maior envolvimento em acidentes de trânsito (PEDEN et al., 2004).

\subsubsection{Classificação do não uso do cinto de segurança}

Os escores individuais normalizados do comportamento de não uso do cinto de segurança foram classificados de acordo com o valor limite 0,174 (Figura 6.5), que é o segundo limite mais baixo definido para classificação dos comportamentos. Assim como o comportamento "erros", os escores individuais referentes ao não uso do cinto de segurança ficaram concentrados, de forma que a maior parte da amostra obteve valores semelhantes (Figura 6.1).

No Nó 1 estão classificados $24,1 \%$ dos participantes da amostra total e, diferente dos demais comportamentos analisados, a proporção de condutores que não se envolveram em acidentes (66,8\%) é menor que a proporção do Nó 2 (76,6\%). A diferença é refletida na proporção dos envolvidos em acidentes, de forma que 25,6\% e 6,3\% dos condutores classificados no Nó 1 se envolveram em 1 e 2 acidentes, 
respectivamente, enquanto no Nó 2, a proporção foi de $18,6 \%$ e 3,7\% de envolvidos em 1 ou 2 acidentes, respectivamente.

Figura 6.5 - Mapa de árvore de decisão: Não usar cinto de segurança

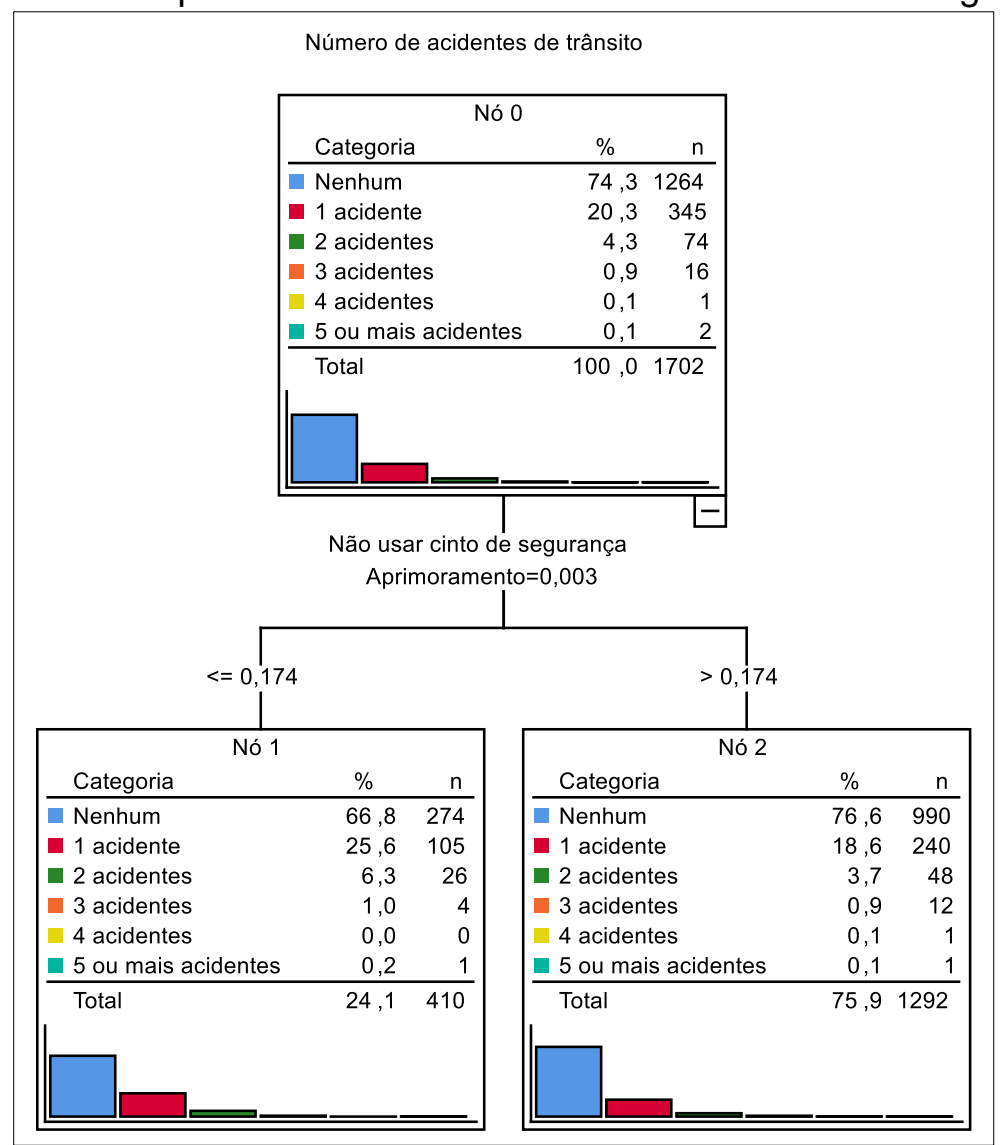

O gráfico da Figura 6.6 mostra a distribuição das respostas das perguntas que representam a variável latente do comportamento não usar o cinto de segurança, onde verifica-se que todos os condutores classificados no Nó 1 reportaram nunca deixar de usar o cinto de segurança. No Nó 2 , a frequência dos que reportaram nunca deixarem de usar o cinto de segurança também é maior, contudo, neste nó também estão classificados todos os participantes que reportaram não utilizar o cinto de segurança com alguma frequência. 
Figura 6.6 - Frequência de respostas para cada nó das variáveis que representam o comportamento do não uso de cinto de segurança

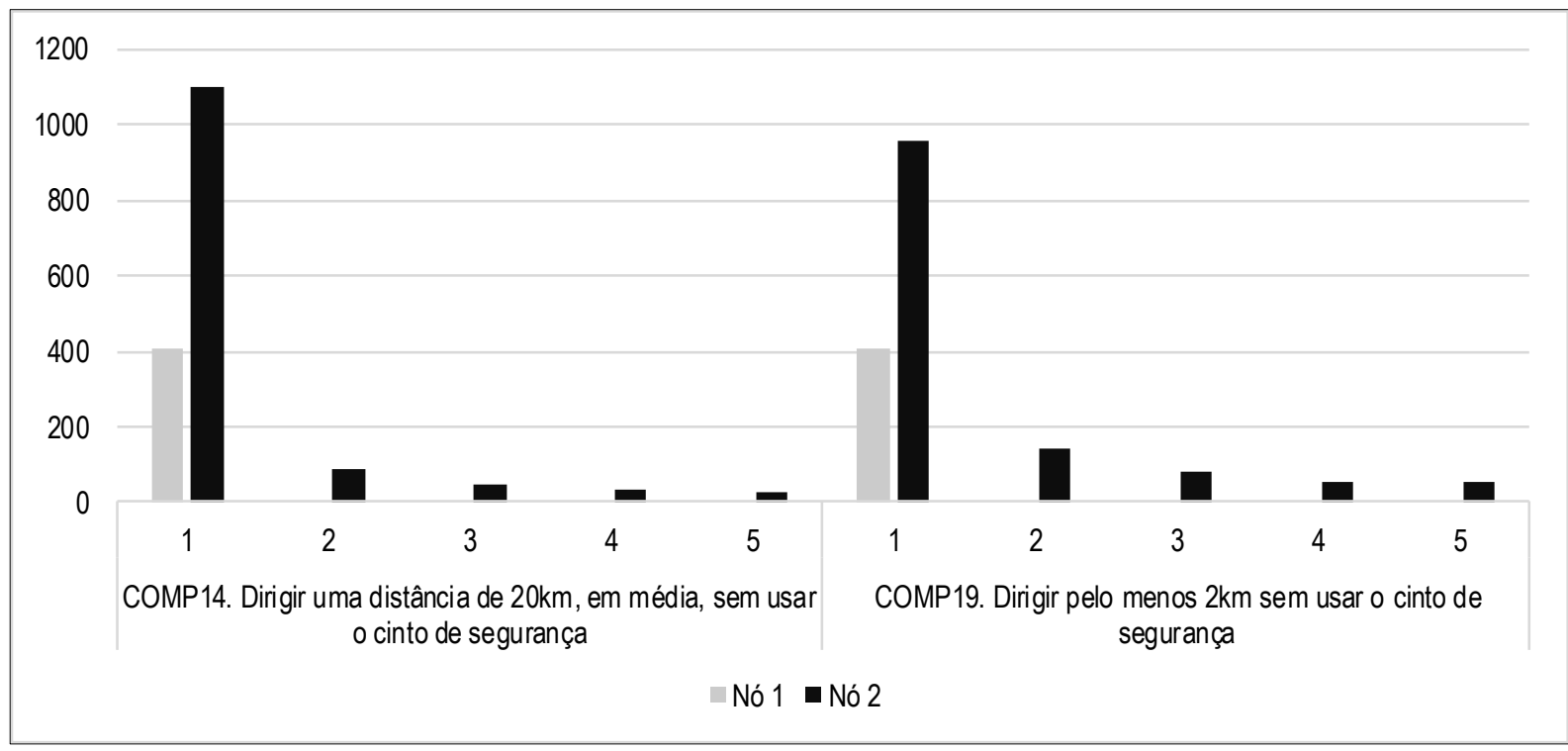

O teste de Mann-Whitney revelou uma diferença significativa $(U=238.508 ; p<0,001)$ entre os nós acerca da distribuição populacional da variável frequência de acidentes, sendo a média do Nó $1(0,424)$ maior que a média do Nó $2(0,295)$. Ou seja, condutores que reportaram sempre utilizar o cinto de segurança tiveram uma frequência maior de acidentes de trânsito. Embora não haja diferença significativa em relação à severidade dos acidentes, os 2 condutores que reportaram um total de 3 acidentes como severidade grave foram classificados no Nó 2.

Em relação à distribuição das multas entre os nós, o teste de Mann-Whitney revelou uma diferença significativa para multas por excesso de velocidade $(U=237.231 ; p$ $<0,001)$, uso do celular $(U=255.819 ; p=0,009)$ e estacionar em local proibido $(U=249.267 ; p=0,003)$, sendo que a média do número de multas é maior para o Nó 1 em todos os casos.

Ao avaliar as diferenças com relação aos demais comportamentos, o teste de MannWhitney indicou uma diferença significativa para os comportamentos "erros" $(U=247.351 ; p=0,043)$, "excesso de velocidade" $(U=132.989 ; p<0,001)$, "dirigir sob efeito de álcool" ( $U=131.288$; $p<0,001)$, "uso do celular" $(U=233.170 ; p<0,001)$ e "sonolência e cansaço" ( $U=213.309 ; p<0,001)$, de forma que as médias dos escores individuais são superiores no Nó 1 para todos os comportamentos. 
Apesar da relação entre a frequência do comportamento e o número de acidentes ser diferente do padrão apresentado pelos demais comportamentos, o resultado quanto à severidade, mesmo não apresentando diferenças significativas, corrobora com o HSM (2010). O não uso de cinto de segurança é apresentado como uma condição que afeta durante a ocorrência do acidente, especificamente na severidade, relacionada ao fator humano. De acordo com Elvik et al. (2009), estudos indicam que o uso do cinto de segurança reduz entre 20 e $30 \%$ a probabilidade de ferimentos leves em um acidente de trânsito, e entre $40 \%$ e $50 \%$ a probabilidade de ferimentos fatais.

\subsubsection{Classificação do uso do celular no modo viva voz ao conduzir}

A classificação do comportamento referente ao "uso do telefone celular enquanto conduz" ocorreu no valor limite 0,561 (Figura 6.7), que se configura como um ponto intermediário no intervalo entre 0 e 1 dos escores normalizados.

Os nós terminais apresentam tamanhos diferentes, onde 17,2\% dos participantes foram classificados no Nó 2 (uso mais frequente de celular em viva voz ao conduzir). O Nó 2 apresenta uma proporção com $66,2 \%$ de condutores sem histórico de envolvimento em acidentes de trânsito, enquanto o Nó 1, em que foram classificados $82,4 \%$ dos participantes, tem uma proporção de $76 \%$ de condutores que não se envolveram em acidentes de trânsito.

De acordo com o teste Mann-Whitney, a distribuição populacional da variável frequência de acidentes entre os nós tem uma diferença significativa $(U=231.522 ; p=$ $<0,001)$, de forma que o Nó 2 se configura como o nó com condutores que mais frequentemente usam o celular ao conduzir e se envolvem em acidentes de trânsito, com uma média de 0,468 acidentes, enquanto a média do Nó 1 é 0,296. Este resultado corrobora com outros estudos. De acordo com Peden et al. (2004), condutores que utilizam o celular ao conduzir apresentam um risco quatro vezes maior de se envolver em um acidente de trânsito. 
Figura 6.7 - Mapa de árvore de decisão: Uso do celular no modo viva voz

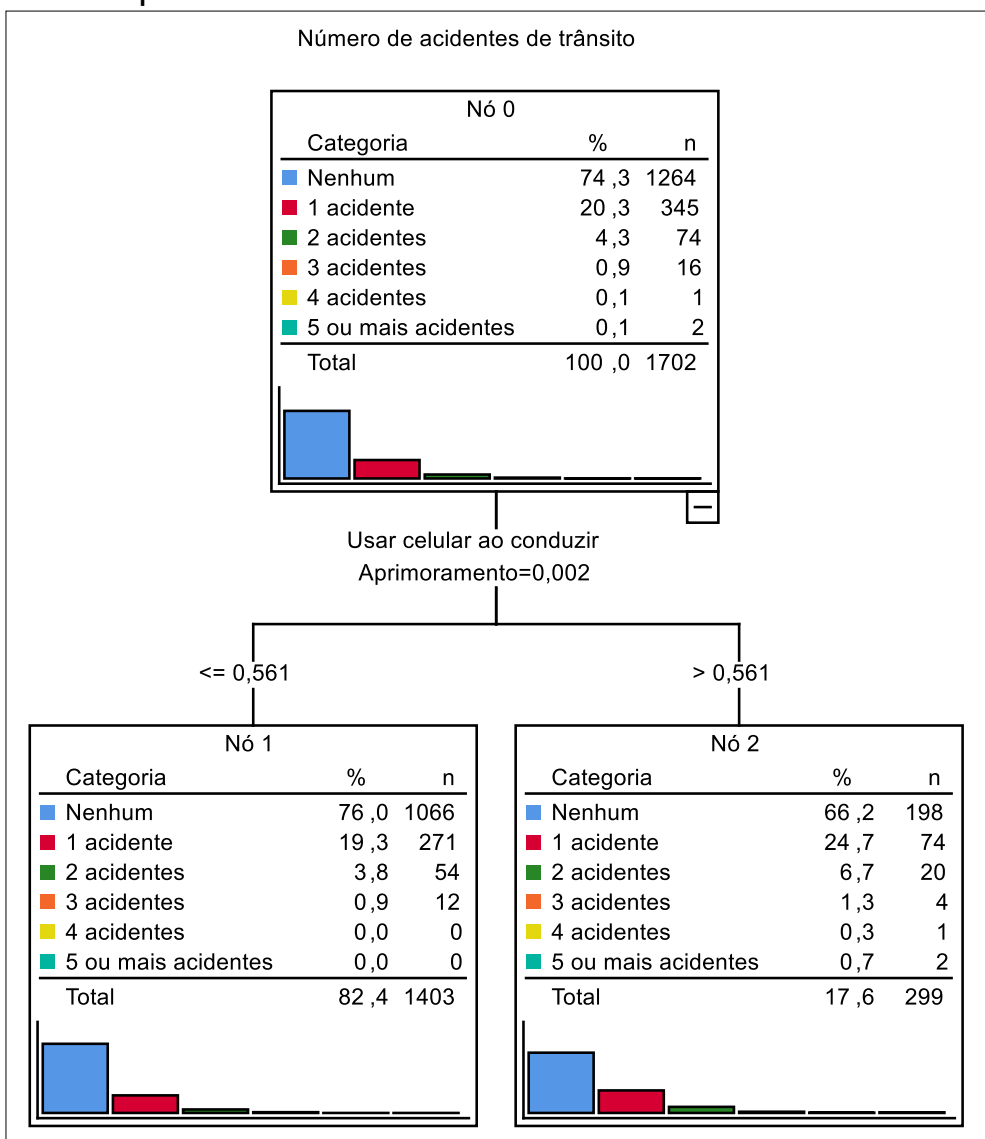

A distribuição também é significativamente diferente em relação às multas por excesso de velocidade $(U=224.502 ; p=0,026)$, com média maior no Nó $2(M=1,177)$. As multas por uso do celular estiveram próximas de serem significativamente diferentes $(p=0,054)$, com valores médios de 0,061 para o Nó 1 e 0,104 para o Nó 2 . Também se observa uma distribuição de escores significativamente diferente, indicado pelo teste Mann-Whitney, entre os nós para os comportamentos "não usar cinto de segurança" ( $U=169.536$; $p<0,001)$ e "excesso de velocidade" ( $U=235.022 ; p$ $=0,001)$, que possui uma média maior no Nó $2(\mathrm{M}=0,439)$. O resultado se mostra coerente com estudos que indicam que o uso de celular afeta a performance do condutor com respeito a manter a velocidade apropriada, manter o veículo na faixa e julgar e aceitar situações seguras no trânsito (PEDEN et al., 2004), contribuindo para maior ocorrência de acidentes. 


\subsubsection{Classificação de sonolência e cansaço}

O valor limite dos escores individuais normalizados do comportamento de sonolência e cansaço foi definido como 0,350 (Figura 6.8). No Nó 1 foram classificados 34,7\% dos condutores da amostra, dos quais $79 \%$ não se envolveram em acidentes de trânsito enquanto no Nó 2, dos $65,3 \%$ condutores restantes, $71.8 \%$ relataram não terem se envolvido em acidentes de trânsito.

Figura 6.8 - Mapa de árvore de decisão: Sonolência e cansaço

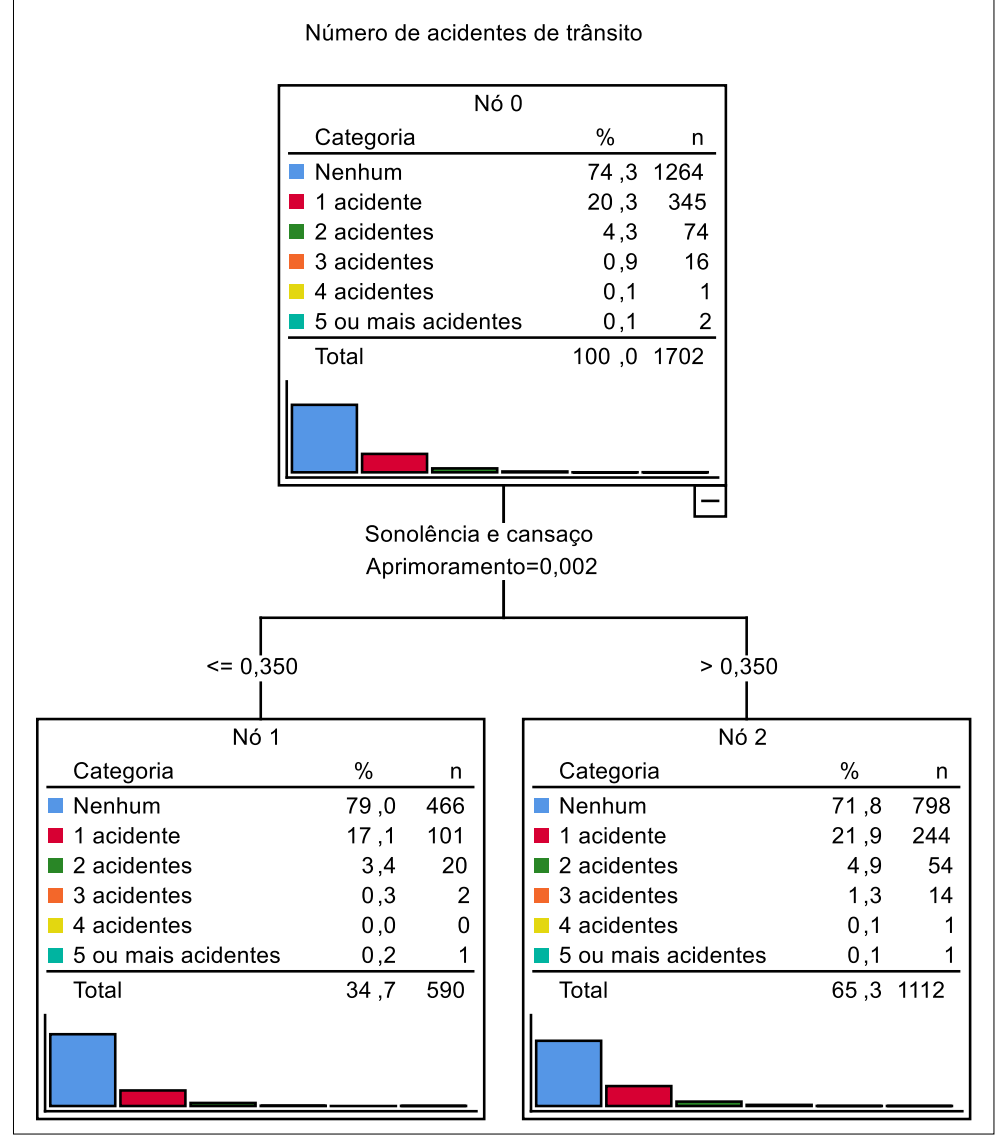

Em relação à distribuição populacional da variável frequência de acidentes de trânsito, o teste de Mann-Whitney indicou uma diferença significativa $(U=352.528 ; p=0,001)$ entre os nós, sendo que o Nó $2(\mathrm{M}=0,362)$ possui mais condutores envolvidos em acidentes, comparado ao Nó $1(\mathrm{M}=0,258)$. Este resultado corrobora outros estudos que apresentam a sonolência e cansaço, ou fadiga, como um fator de risco associado à ocorrência do acidente de trânsito (PEDEN et al., 2004).

Apesar de não haver uma diferença significativa com relação à severidade dos acidentes, observa-se que os acidentes com maior severidade ficaram 
majoritariamente concentrados no Nó 2, onde estiveram 24 dos 31 acidentes reportados como ferimento leve e os 3 acidentes reportados como ferimento grave.

A média de multas por velocidade é mais alta no Nó 2, e, de acordo com o teste de Mann-Whitney, a distribuição é significativamente diferente entre os nós $(U=352.852$; $p=0,003)$.

Ao analisar as diferenças em relação aos demais comportamentos, o teste de MannWhitney indicou diferenças significativas em relação aos comportamentos "excesso de velocidade" ( $U=350.165 ; p=0,022)$, "não uso do cinto de segurança" ( $U=$ 264.732; $p<0,001)$ e "erros" $(U=362.052 ; p<0,001)$. O primeiro efeito da sonolência e cansaço, ou fadiga, está relacionado ao domínio da atenção, acarretando no comprometimento das informações capturadas devido ao fechamento parcial das pálpebras, ou pelo processamento parcial e lento dos estímulos aos sistemas sensoriais (SHINAR, 2017) que impactam na performance de conduzir.

\subsubsection{Classificação da expressão de raiva ao conduzir}

Os escores individuais normalizados relativos ao comportamento de risco representando a expressão de raiva do condutor foram divididos de acordo com o valor limite 0,483 (Figura 6.9), que também está próximo ao ponto intermediário para o intervalo entre 0 e 1 dos valores normalizados.

No Nó 1 estão classificados 62,9\% dos condutores, dos quais $77,5 \%$ não se envolveram em acidentes de trânsito. Entre os $37,1 \%$ condutores classificados no Nó 2, 68,8\% não se envolveram em acidentes.

O teste de Mann-Whitney indicou que é significativa a diferença do número de acidentes entre os nós $(U=; 368.503 ; p=<0,001)$, de forma que a proporção de condutores envolvidos em acidentes é maior no Nó $2(\mathrm{M}=0,362)$. Assim, foi possível identificar o padrão onde a maior frequência de expressão de raiva do condutor está relacionada à maior frequência de envolvimento em acidentes de trânsito, corroborando o estudo de Özkan et al. (2006), em que o comportamento de violações agressivas foi significativo para explicar o envolvimento em acidentes de trânsito.

De acordo com os resultados do teste de Mann-Whitney, não há diferença significativa entre nós em relação aos acidentes mais severos e ao número de multas. Ao avaliar as diferenças relacionadas aos demais comportamentos de risco, a distribuição do 
comportamento de "excesso de velocidade" é significativamente diferente $(\mathrm{U}=$ 359.620; $p=0,027)$, com média superior no Nó $2(M=0,419)$. Este resultado está de acordo com o estudo de Wells-Parker et al. (2002), onde além de se confirmar a relação entre agressividade e o envolvimento em acidentes, os condutores mais agressivos também reportaram excesso de velocidade como um comportamento habitual.

Figura 6.9 - Mapa de árvore de decisão: Expressão de raiva ao conduzir

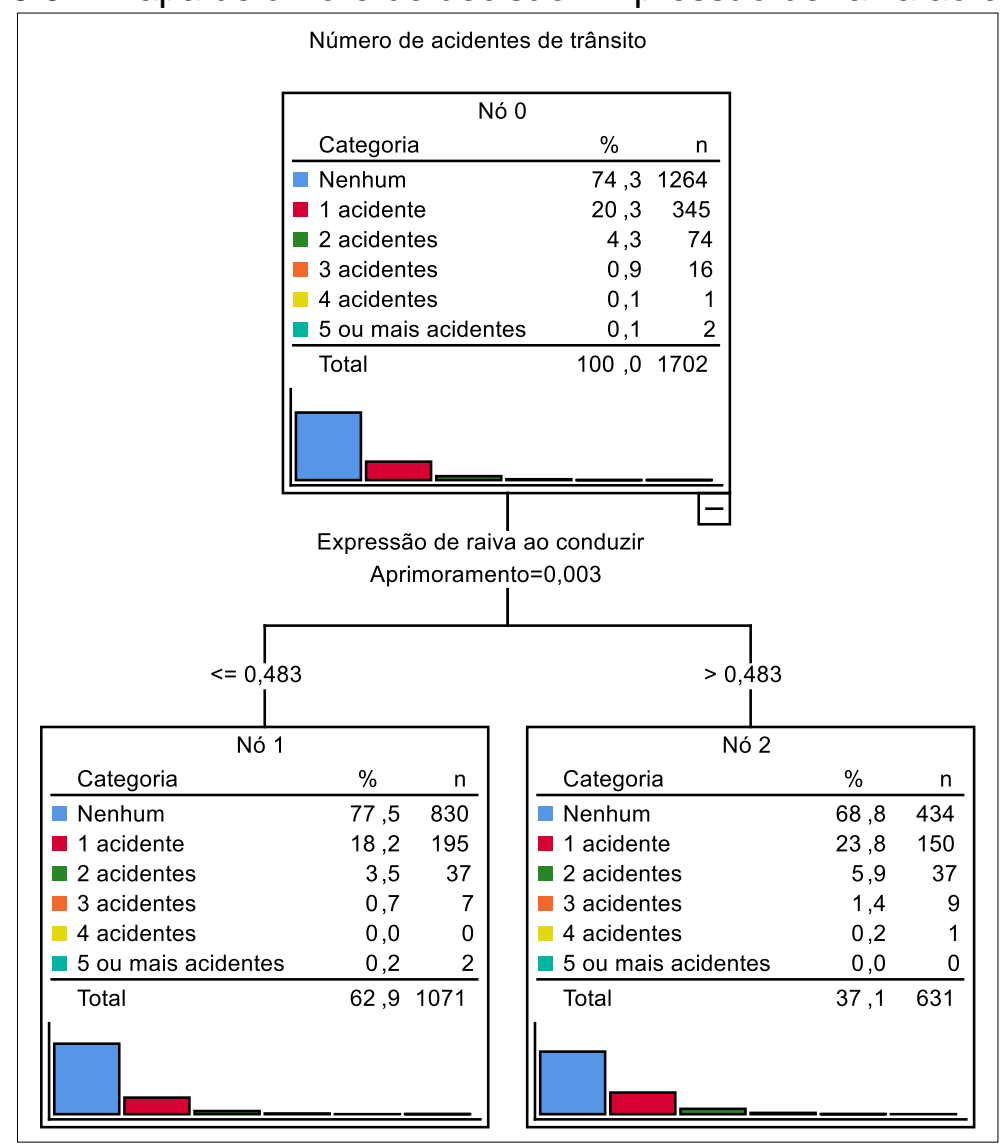

\subsection{Considerações do Capítulo 6}

Os resultados mostram que foi possível identificar um padrão coerente entre os comportamentos de risco e a frequência de acidentes de trânsito, de forma a determinar valores limites para a frequência dos comportamentos, com aplicação do algoritmo CART da Árvore de Decisão.

Corroborando os resultados, o teste não paramétrico de Mann-Whitney indicou, para todos os comportamentos analisados, diferenças estatisticamente significativas acerca da distribuição populacional da frequência de acidentes de trânsito e dos 
escores individuais entre os nós terminais, confirmando a classificação da Árvore de Decisão. Além dos acidentes de trânsito, foi possível, inclusive, identificar a relação do comportamento "excesso de velocidade" com acidentes mais severos.

De modo geral, a classificação demonstrou um padrão, onde a maior frequência do comportamento analisado estava relacionada à maior frequência de acidentes de trânsito. O comportamento de uso do cinto de segurança apresentou uma relação contrária para as frequências, mas coerente quanto à severidade. Além de confirmar a relação dos comportamentos de risco com a ocorrência de acidentes de trânsito, esta abordagem permitiu identificar um valor limite para frequência do comportamento de risco, a partir do qual a frequência de envolvimento em acidentes de trânsito é maior.

A avaliação realizada com auxílio do teste não paramétrico de Mann-Whitney e análise das médias das variáveis "número de acidentes", "severidade", "multas" e demais comportamentos possibilitaram caracterizar os nós. Sabe-se que o histórico de multas tem relação direta com a fiscalização. Contudo, neste caso, as multas reportadas pelos condutores corroboram os resultados da classificação.

No Quadro 6.1 são apresentados os limites identificados e um resumo das relações analisadas para caracterização dos nós terminais de cada comportamento de risco.

Quadro 6.1 - Resumo dos limites e caracterizações dos nós terminais

\begin{tabular}{|c|c|c|c|c|c|c|c|c|c|}
\hline \multirow[t]{2}{*}{ Comportamentos } & \multirow[t]{2}{*}{ Limite } & \multicolumn{2}{|c|}{$\begin{array}{c}\text { Distribuição } \\
\text { do nó (\%) }\end{array}$} & \multicolumn{2}{|c|}{$\begin{array}{l}\text { Envolvidos } \\
\text { em AT (\%) }\end{array}$} & \multicolumn{2}{|c|}{ Média de AT } & \multirow[t]{2}{*}{ Multas } & \multirow{2}{*}{$\begin{array}{c}\text { Diferença dos } \\
\text { demais } \\
\text { comportamentos }\end{array}$} \\
\hline & & 1 & 2 & 1 & 2 & 1 & 2 & & \\
\hline (1) Erros & 0,039 & 47,7 & 52,3 & 22,9 & 28,3 & 0,289 & 0,360 & Cel & 3 e 6 \\
\hline (2) Excesso de velocidade & 0,242 & 24,1 & 75,9 & 18,2 & 28,1 & 0,263 & 0,346 & Veloc & 3 e 4 \\
\hline (3) Conduzir sob efeito de álcool & 0,346 & 57,1 & 42,9 & 23,1 & 29,2 & 0,286 & 0,379 & Álc, veloc, estac & 1,2 e 4 \\
\hline (4) Não usar cinto de segurança & 0,174 & 24,1 & 75,9 & 33,2 & 23,4 & 0,424 & 0,295 & Veloc, cel, estac & $1,2,3,5$ e 6 \\
\hline (5) Uso do celular no viva voz & 0,561 & 82,4 & 17,6 & 24,0 & 33,8 & 0,296 & 0,468 & Cel & 2 e 5 \\
\hline (6) Sonolência e cansaço & 0,350 & 34,7 & 65,3 & 21,0 & 28,2 & 0,258 & 0,362 & Veloc & 1,2 e 5 \\
\hline (7) Expressar raiva ao conduzir & 0,483 & 62,9 & 37,1 & 22,5 & 31,2 & 0,280 & 0,404 & - & 2 \\
\hline
\end{tabular}

Considerando os resultados alcançados, é possível afirmar que foi possível classificar os comportamentos de risco de acordo com o envolvimento em acidentes de trânsito relatados, com auxílio do algoritmo CART da Árvore de Decisão, de forma a identificar relações coerentes que corroboram estudos realizados com outras abordagens, e valores limítrofes para frequência de comportamentos com maior envolvimento em acidentes de trânsito. 
Os grupos, encontrados através dos nós terminais do algoritmo CART, são as categorias (0 ou 1 ) das variáveis dependentes binárias a serem utilizadas na modelagem paramétrica na etapa posterior. Em seguida, os fatores que contribuem para maior e menor frequência dos comportamentos de risco foram analisados com o auxílio do modelo Logit Binomial, e os resultados serão apresentados no próximo capítulo. 


\section{MODELOS PARAMÉTRICOS: CALIBRAÇÃO E ANÁLISE}

Os sete comportamentos, identificados e classificados previamente nesta pesquisa, foram utilizados como variáveis dependentes dos modelos Logit Binomiais, para identificação e análise das relações entre comportamentos de risco e dados individuais, do local e ambiente viário. Neste capítulo são apresentadas as descrições dos parâmetros estimados, associados às variáveis independentes dos modelos e os resultados obtidos.

\subsection{Considerações iniciais}

Os modelos, avaliados neste trabalho, foram calibrados no software PandaBiogeme (BIERLAIRE, 2018) pelo método de estimação de Máxima Verossimilhança. A variável dependente corresponde à classificação prévia dos comportamentos (Nós terminais 1 e 2 das sete Árvores de Decisão, obtidas anteriormente), totalizando sete variáveis dependentes binárias. As variáveis independentes foram agrupadas de acordo com as características das variáveis e foram inseridas nos modelos em 16 combinações diferentes, seguindo a ordem apresentada no Quadro 7.1, conforme também descrito no Capítulo 3.

\begin{tabular}{|c|c|c|}
\hline Ordem & $\begin{array}{l}\text { Código do } \\
\text { modelo }\end{array}$ & Grupo de variáveis independentes \\
\hline 1 & A1 & Socioeconômico \\
\hline 2 & $\mathrm{~A} 2$ & Experiência do condutor \\
\hline 3 & A3 & Histórico de multas \\
\hline 4 & A4 & Construtos psicológicos \\
\hline 5 & A5 & Ambiente Viário \\
\hline 6 & B1 & País \\
\hline 7 & B2 & Região \\
\hline 8 & B3 & Distrito \\
\hline 9 & B4 & Variáveis agregadas primárias e secundárias \\
\hline 10 & $\mathrm{C} 1$ & $A 1+A 2+A 3$ \\
\hline 11 & $\mathrm{C} 2$ & $A 1+A 2+A 3+A 4+A 5$ \\
\hline 12 & $\mathrm{C} 3$ & $A 1+A 2+A 3+A 4+A 5+B 1$ \\
\hline 13 & C4 & $A 1+A 2+A 3+A 4+A 5+B 2$ \\
\hline 14 & C5 & $A 1+A 2+A 3+A 4+A 5+B 3$ \\
\hline 15 & $\mathrm{C} 6$ & $A 1+A 2+A 3+A 4+A 5+B 4$ \\
\hline 16 & $D$ & Todos os conjuntos de variáveis \\
\hline
\end{tabular}

Onde os modelos " $\mathrm{A}$ " correspondem às variáveis independentes do mesmo grupo; os modelos "B" às variáveis relacionadas ao local de residência; modelos "C" 
correspondem a combinações dos grupos A e B; e modelo "D" corresponde a todas as variáveis.

Dessa forma, para cada uma das sete variáveis dependentes, correspondentes a cada um dos comportamentos de risco, 16 configurações de modelos foram analisadas. As combinações dos modelos serão apresentadas com mais detalhes na Seção 7.1.3.

\subsubsection{Variável dependente}

A variável dependente é binária e corresponde ao resultado da classificação do comportamento de risco, realizada na etapa anterior, com a aplicação do algoritmo CART da Árvore de Decisão. Dessa forma, para cada modelo, adotou-se a Função Utilidade $0\left(\mathrm{FU}_{0}\right)$ igual a zero $\left(\mathrm{FU}_{0}=0\right)$, que corresponde ao Nó 1 (terminal) da Árvore de Decisão, e os parâmetros foram estimados para Função Utilidade $1\left(\mathrm{FU}_{1}\right)$, que corresponde ao Nó 2 (terminal) (Figura 7.1). Este procedimento foi realizado, repetidamente, para cada comportamento, até a obtenção das sete variáveis dependentes.

Figura 7.1 - Relação entre os nós terminais e as funções utilidade

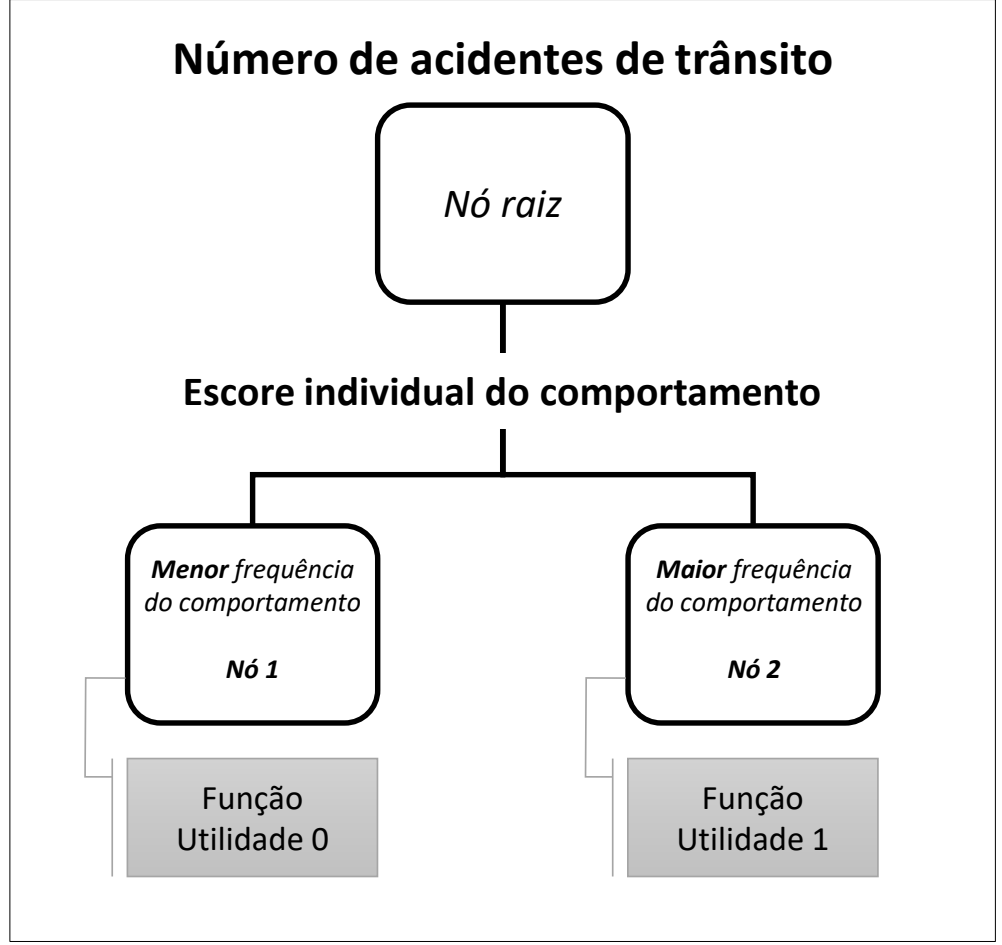


Cabe relembrar que o principal padrão identificado na Árvore de Decisão consiste em menor frequência do comportamento de risco e menor envolvimento em acidentes de trânsito no Nó 1, enquanto no Nó 2 foram classificados os condutores que reportaram maior frequência do comportamento de risco e maior frequência de acidentes de trânsito.

O comportamento referente ao "não uso do cinto de segurança" foi o único a apresentar uma relação contrária da frequência dos acidentes de trânsito, de forma que o Nó 1 consiste em menores frequências de comportamento e maior frequência de acidentes e o Nó 2, maior frequência de comportamento e menor frequência de acidentes de trânsito, porém, de maior severidade.

\subsubsection{Variáveis independentes}

As variáveis independentes foram agrupadas para serem incluídas nos modelos de acordo com a característica que representavam. Dessa forma, foram utilizados 9 agrupamentos de variáveis, denominados como: socioeconômicas, experiência de condução, histórico de multas, país, regiões, estados/distritos, agregadas, caracterização do ambiente viário e construtos psicológicos.

No caso das variáveis categóricas nominais, cada categoria foi incluída no modelo como variável dummy. As variáveis numéricas foram incluídas no modelo como numéricas ou, em alguns casos, foram discretizadas com auxílio das opções de categorização visual ou ideal, do software IBM SPSS 25 e, posteriormente, também incluídas como variável dummy nos modelos.

Um quadro resumo das variáveis independentes é apresentado na Figura 7.2, seguido de uma breve descrição dos grupos das variáveis independentes. 
Figura 7.2 - Variáveis independentes utilizadas na calibração dos modelos

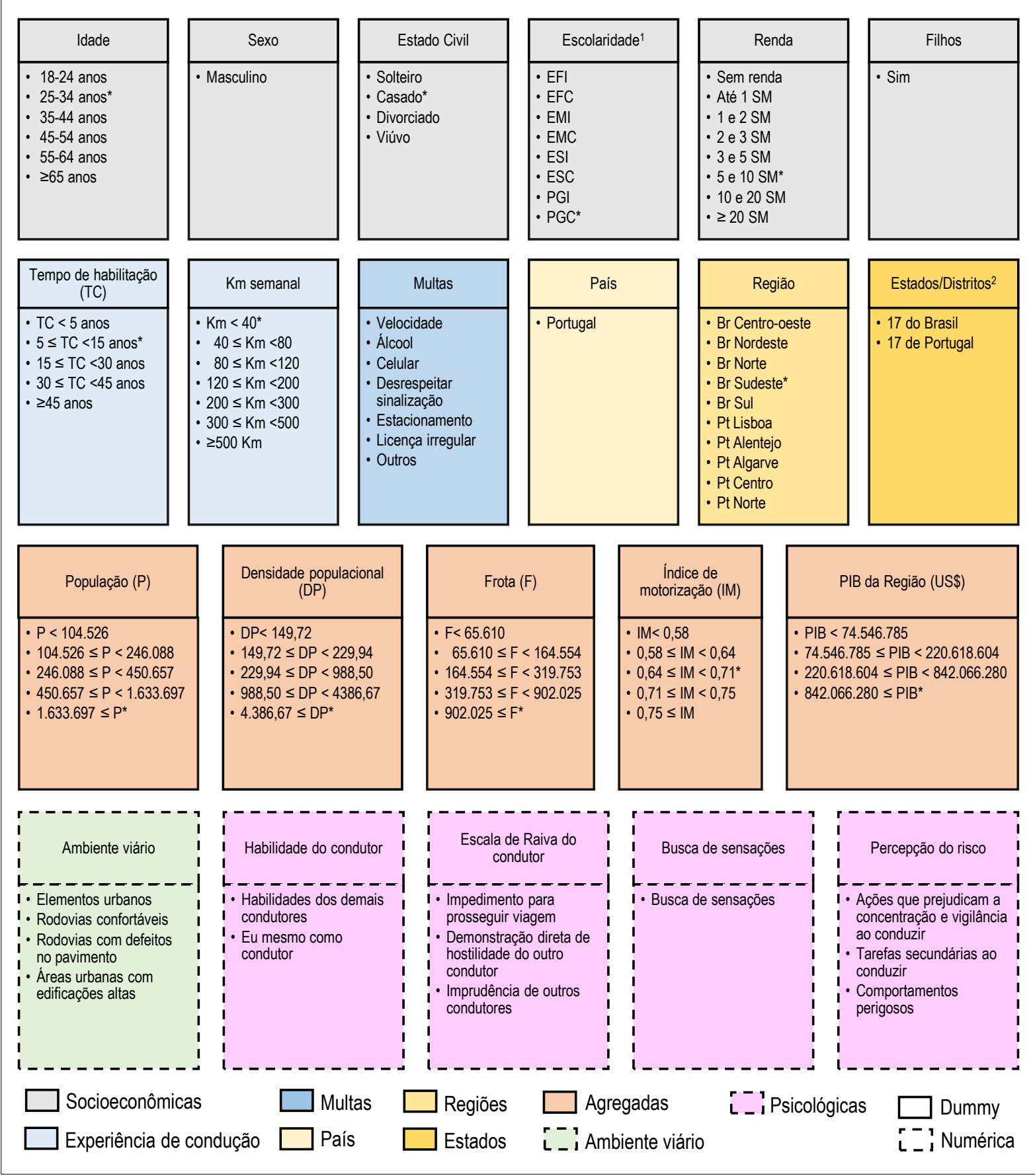

Nota: 1) EFI - Ensino Fundamental Incompleto; EFC: Ensino Fundamental Completo; EMI: Ensino Médio Incompleto; EMC: Ensino Médio Completo; ESI: Ensino Superior Incompleto; ESC: Ensino Superior Completo: PGI: Pós-graduação Incompleto; PGC: Pós-graduação Completo. 2) Brasil: Amazonas, Bahia, Distrito Federal, Espirito Santo, Goiás, Mato Grosso, Minas Gerais, Paraná, Paraíba, Pará, Pernambuco, Piauí, Rio Grande do Sul, Roraima, Santa Catarina, São Paulo, Tocantins; Portugal: Aveiro, Beja, Braga, Castelo Branco, Coimbra, Faro, Guarda, Leiria, Lisboa, Portalegre, Porto, Santarém, Setúbal, Viana do Castelo, Vila Real, Viseu, Évora.

\section{- Variáveis socioeconômicas}

As variáveis socioeconômicas correspondem às variáveis categóricas "sexo", "estado civil", "escolaridade", "renda" e "filhos", e também à variável numérica "idade" $(M=36,29 ; D P=11,674)$. Entretanto, a variável idade foi discretizada em 6 níveis 
(Figura 7.3) para ser incluída nos modelos. As distribuições das categorias das demais variáveis foram apresentadas na Seção 3.3.2.2, na caracterização da amostra.

Figura 7.3 - Distribuição da variável idade

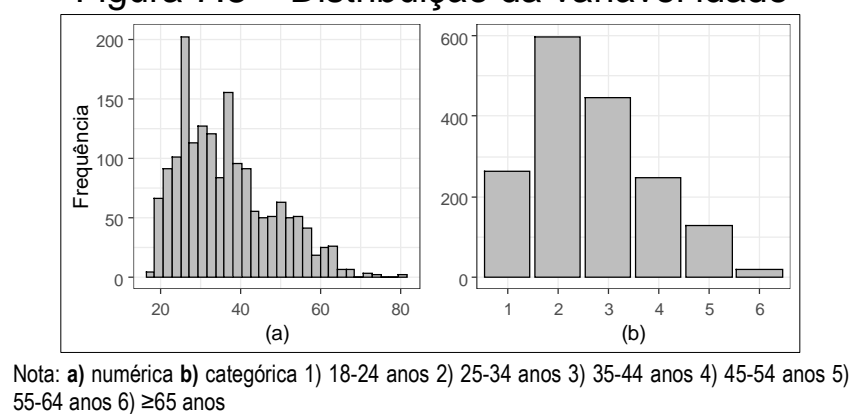

- Variáveis de experiência de condução

As variáveis determinadas para caracterizar a experiência de condução foram as variáveis numéricas "tempo de habilitação" $(M=14,81$; $D P=11,337)$ e "quilometragem percorrida semanalmente" $(M=226,18$; $D P=315,139)$. Contudo, para inclusão nos modelos, essas variáveis foram discretizadas com auxílio da opção categorização visual, que resultou em 5 categorias para tempo de habilitação e 7 categorias para quilometragem (Figura 7.4). Cada categoria foi incluída como variável dummy nos modelos.

Figura 7.4 - Distribuição das variáveis tempo de habilitação e distância percorrida

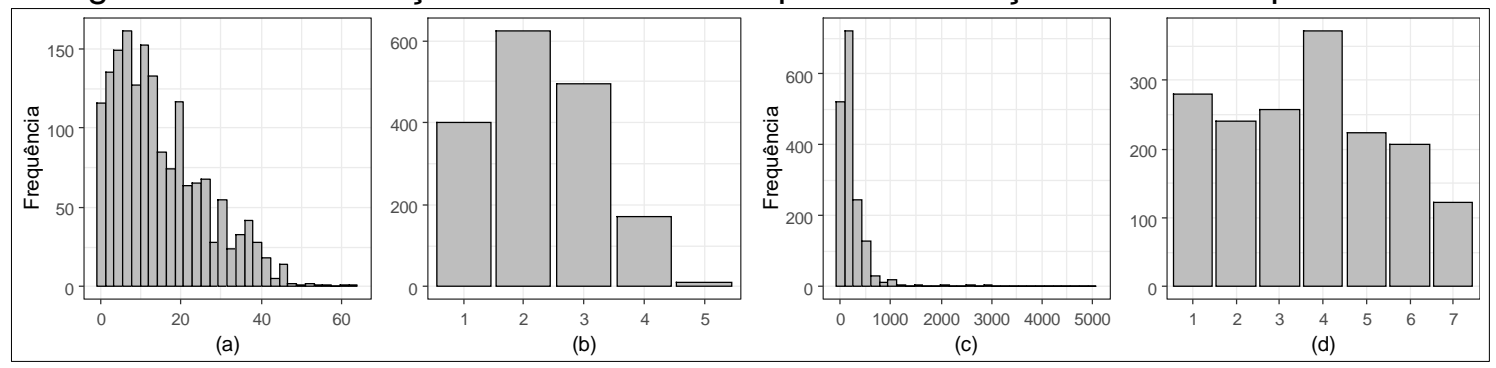

Nota: a) variável numérica: tempo de habilitação; b) variável categórica: tempo de habilitação 1) TC $<5$ anos, 2) $5 \leq \mathrm{TC}<15$ anos 3 ) $15 \leq \mathrm{TC}<30$ anos 4$) 30 \leq \mathrm{TC}<45$ anos 5 ) $\geq 45$ anos; c) variável numérica: distância percorrida; d) variável categórica: distância percorrida 1) $\mathrm{km}<40$ 2) $40 \leq \mathrm{km}<803) 80 \leq \mathrm{km}<1204) 120 \leq \mathrm{km}<2005) 200 \leq \mathrm{km}<300$ 6) $300 \leq \mathrm{km}<5007) \geq 500 \mathrm{~km}$

- Variáveis relacionadas às multas

As multas foram representadas neste banco de dados de acordo com os motivos da infração. Dessa forma, o dado incluído no modelo corresponde a variáveis dummy para cada uma das seis categorias: velocidade, celular, álcool, estacionar em local proibido, carteira de habilitação irregular e outros motivos. 
- Variáveis de localização

As variáveis para representar a localização do condutor foram analisadas em 3 níveis de divisão geográfica diferentes, sendo os níveis "país", "região" e "estado/distrito" incluídos como variável dummy. Para o nível "país" se considerou a dummy "Portugal" (0: Não (Brasil); 1: Sim (Portugal).

Para o nível "região" foram consideradas 10 categorias, sendo cinco do Brasil (Norte, Nordeste, Centro-Oeste, Sudeste e Sul) e cinco de Portugal (Norte, Centro, Lisboa, Algarve e Alentejo).

Para o nível de "estado/distrito", 17 estados de cada país foram considerados: Brasil - Amazonas, Bahia, Distrito Federal, Espirito Santo, Goiás, Mato Grosso, Minas Gerais, Paraná, Paraíba, Pará, Pernambuco, Piauí, Rio Grande do Sul, Roraima, Santa Catarina, São Paulo e Tocantins; e Portugal - Aveiro, Beja, Braga, Castelo Branco, Coimbra, Faro, Guarda, Leiria, Lisboa, Portalegre, Porto, Santarém, Setúbal, Viana do Castelo, Vila Real, Viseu, Évora.

- Variáveis agregadas

As variáveis agregadas, consideradas neste trabalho, foram as variáveis numéricas "população" $\quad(\mathrm{M}=1.644 .357 ; \quad \mathrm{DP}=3.341 .600,70)$, "densidade populacional" $(M=2.092,24 ; D P=2.790,22)$, frota veicular $(M=1.064 .874 ; D P=2.258 .223,30)$, "índice de motorização" ( $M=0,6481$; $D P=0,1369)$ e "Produto Interno Bruto $(P I B)$ das regiões" (US\$, M=443.346.835; DP=346.281.251). Como os valores de PIB estavam em real e euro, os valores foram convertidos para dólar americano (US\$) para padronização de unidade de valor. Todas as variáveis foram discretizadas por meio da opção categorização ideal do software IBM SPSS 25.0. As distribuições dos dados e categorias são apresentadas na Figura 7.5. 
Figura 7.5 - Distribuição das variáveis agregadas

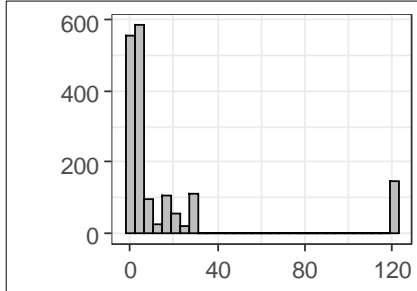

(a)

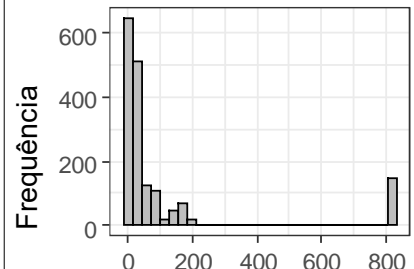

(e)

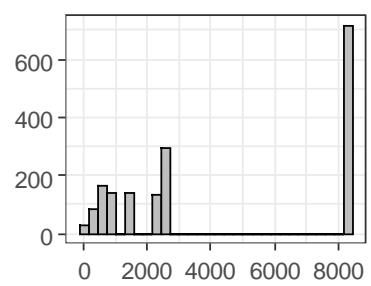

(i)

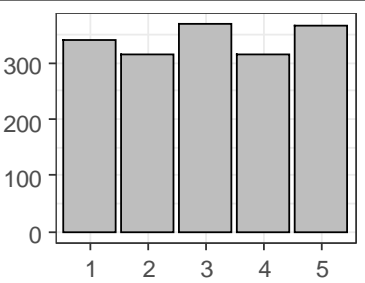

(b)

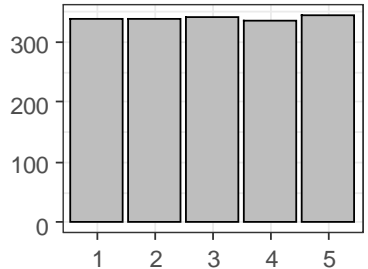

(f)

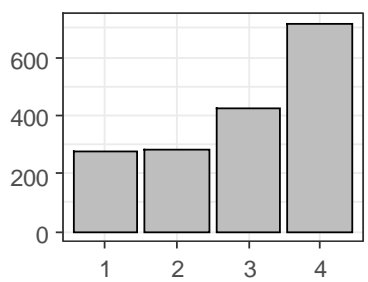

(j)

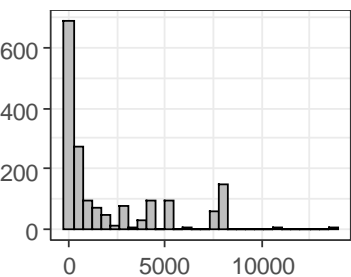

(c)

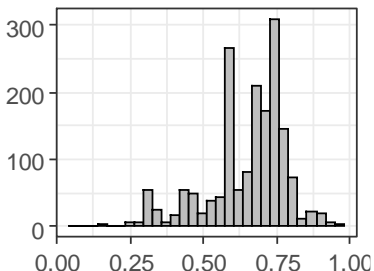

(g)

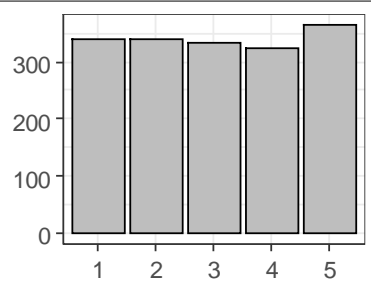

(d)

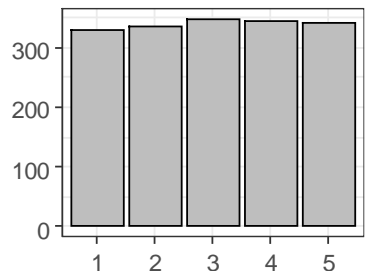

(h)

Nota: a) População numérica (x100.000); b) População categórica: 1) $P<104.526$ 2) $104.526 \leq P<246.088$ 3) $246.088 \leq P<450.6574) 450.657 \leq P<1.633 .6975$ ) 1.633 .697 $\leq \mathrm{P}$; c) Densidade populacional numérica; d) Densidade populacional categórica 1) $\mathrm{DP}<149,72$ 2) $149,72 \leq \mathrm{DP}<229,943) 229,94 \leq \mathrm{DP}<988,504$ ) $988,50 \leq \mathrm{DP}<4.386,675$ ) $4.386,67 \leq \mathrm{DP}$; e) Frota veicular numérica (x10.000); f) Frota Veicular categórica 1) $F<65.610$ 2) $65.610 \leq F<164.5543) 164.554 \leq F<319.7534) 319.753 \leq F<902.0255$ ) $902.025 \leq \mathrm{F} ; \mathrm{g}$ ) Índice de Motorização numérica; $\mathrm{h}$ ) Índice de motorização categórica 1) $\mathrm{IM}<0,58$ 2) $0,58 \leq \mathrm{IM}<0,643) 0,64 \leq \mathrm{IM}<0,714) 0,71 \leq \mathrm{IM}<0,75$ 5) $0,75 \leq \mathrm{IM}$; i) $\mathrm{PIB}$ da região numérica (x100.000); j) PIB da região categórica 1) $\mathrm{PIB}<74.546 .785,00$ 2) $74.546 .785 \leq \mathrm{PIB}<220.618 .6043) 220.618 .604 \leq \mathrm{PIB}<842.066 .2804$ ) $842.066 .280 \leq \mathrm{PIB}$

- Caracterização do ambiente viário

As variáveis de caracterização do ambiente viário correspondem aos escores individuais das quatro variáveis latentes identificadas com a CATPCA e normalizadas entre 0 e 1. Assim, as variáveis latentes "elementos urbanos" ( $M=0,698 ; D P=0,223)$, "rodovias confortáveis" ( $M=0,346$; $\mathrm{DP}=0,210)$, "rodovias com defeitos no pavimento" $(M=0,457 ; D P=0,203)$ e "áreas urbanas com edificações altas" $(M=0,451 ; D P=0,214)$ representam a frequência que os condutores conduzem nas condições apresentadas e foram incluídas como numéricas nos modelos. As distribuições das variáveis são apresentadas na Figura 7.6. 
Figura 7.6 - Distribuição das variáveis de caracterização do ambiente

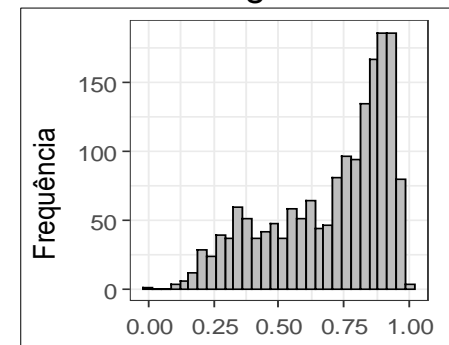

(a)

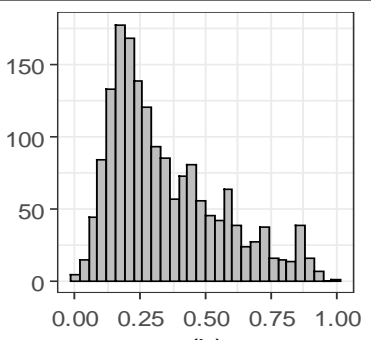

(b)

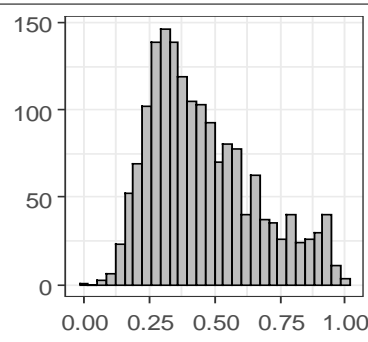

(c)

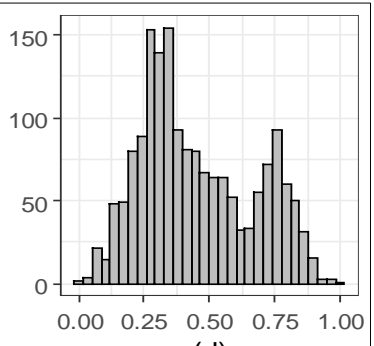

(d)

Nota: a) Elementos urbanos; b) Rodovias confortáveis; c) rodovias com defeito no pavimento; d) Áreas urbanas com edificações altas

- Variáveis de construtos psicológicos

As variáveis de construtos psicológicos são aquelas relacionadas à: "busca de sensações" ( $M=0,204$; $D P=0,202)$, "raiva ao conduzir": Impedimento para prosseguir viagem $(M=0,544 ; D P=0,188)$, Demonstração direta de hostilidade do outro condutor $(M=0,569 ; D P=0,201)$, Imprudência de outros condutores $(M=0,497 ; D P=0,178)$; "percepção do risco": ações que prejudicam a concentração e vigilância ao conduzir $(\mathrm{M}=0,881$; $\mathrm{DP}=0,128)$, tarefas secundárias ao conduzir e comportamentos perigosos $(\mathrm{M}=0,519$; $\mathrm{DP}=0,137)$; e "habilidades de condução": Habilidades dos demais condutores $(M=0,637 ; D P=0,189)$ e eu mesmo como condutor $(M=0,621 ; D P=0,195)$.

Os valores correspondem aos escores individuais obtidos com a CATPCA e normalizados entre 0 e 1 . As variáveis foram incluídas como numéricas nos modelos e as distribuições são apresentadas na Figura 7.7. 
Figura 7.7 - Distribuição das variáveis de construto psicológico

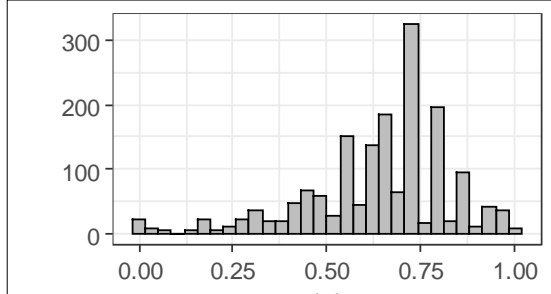

(a)

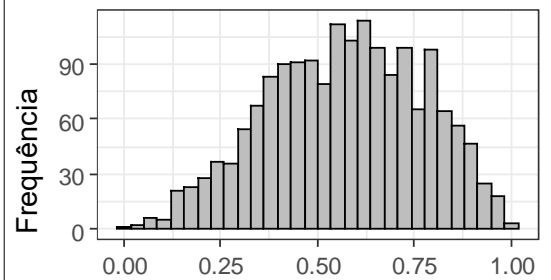

(d)

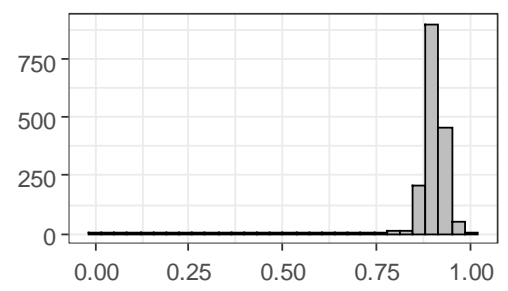

(g)

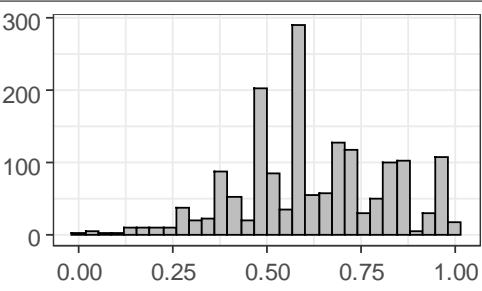

(b)

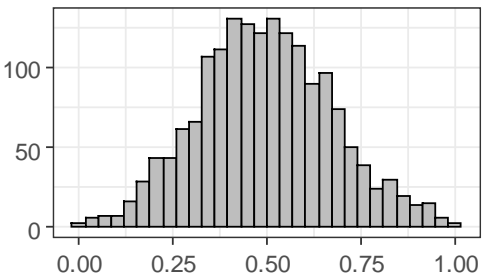

(e)

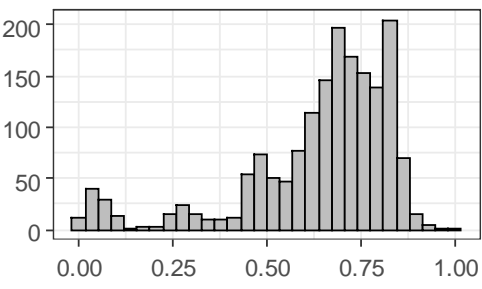

(h)

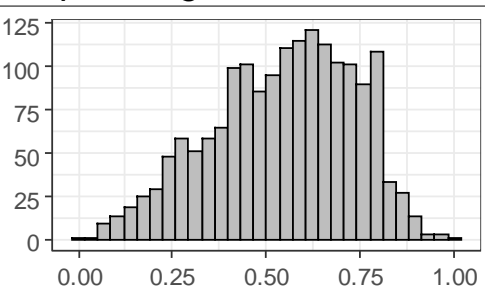

(c)

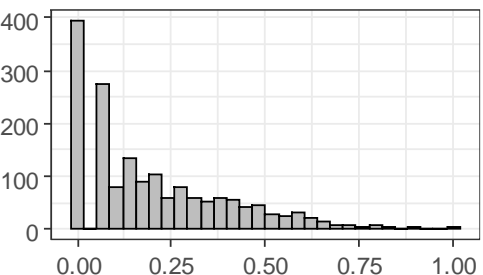

(f)

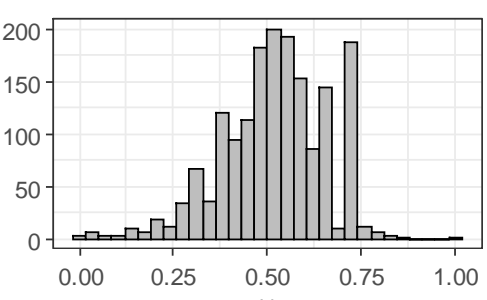

(i)

Nota: a) Habilidades dos demais condutores b) Eu mesmo como condutor c) Impedimento para prosseguir viagem d) Demonstração direta de hostilidade e) Imprudência de outros condutores f) Busca de sensações g) Ações que prejudicam a concentração e vigilância ao conduzir h) Tarefas secundárias ao conduzir i) Comportamentos perigosos

\subsubsection{Planejamento dos modelos}

Devido ao número de variáveis independentes e dependentes estudadas, optou-se por elaborar um planejamento acerca da inclusão das variáveis independentes nos modelos, de modo a avaliar o desempenho dos mesmos e os valores e os efeitos dos parâmetros calibrados significativos. Com isso, optou-se por avaliar as variáveis independentes de acordo com os 9 agrupamentos, resultando em 16 modelos para cada comportamento de risco.

Primeiramente, os parâmetros foram calibrados para cada grupo de variáveis independentes. $O$ grupo denominado como $A$, de $A 1$ até $A 5$, corresponde às variáveis socioeconômicas, traços de personalidade, experiência de condução e ambiente viário (Figura 7.8). 
Figura 7.8 - Variáveis independentes dos modelos "A"

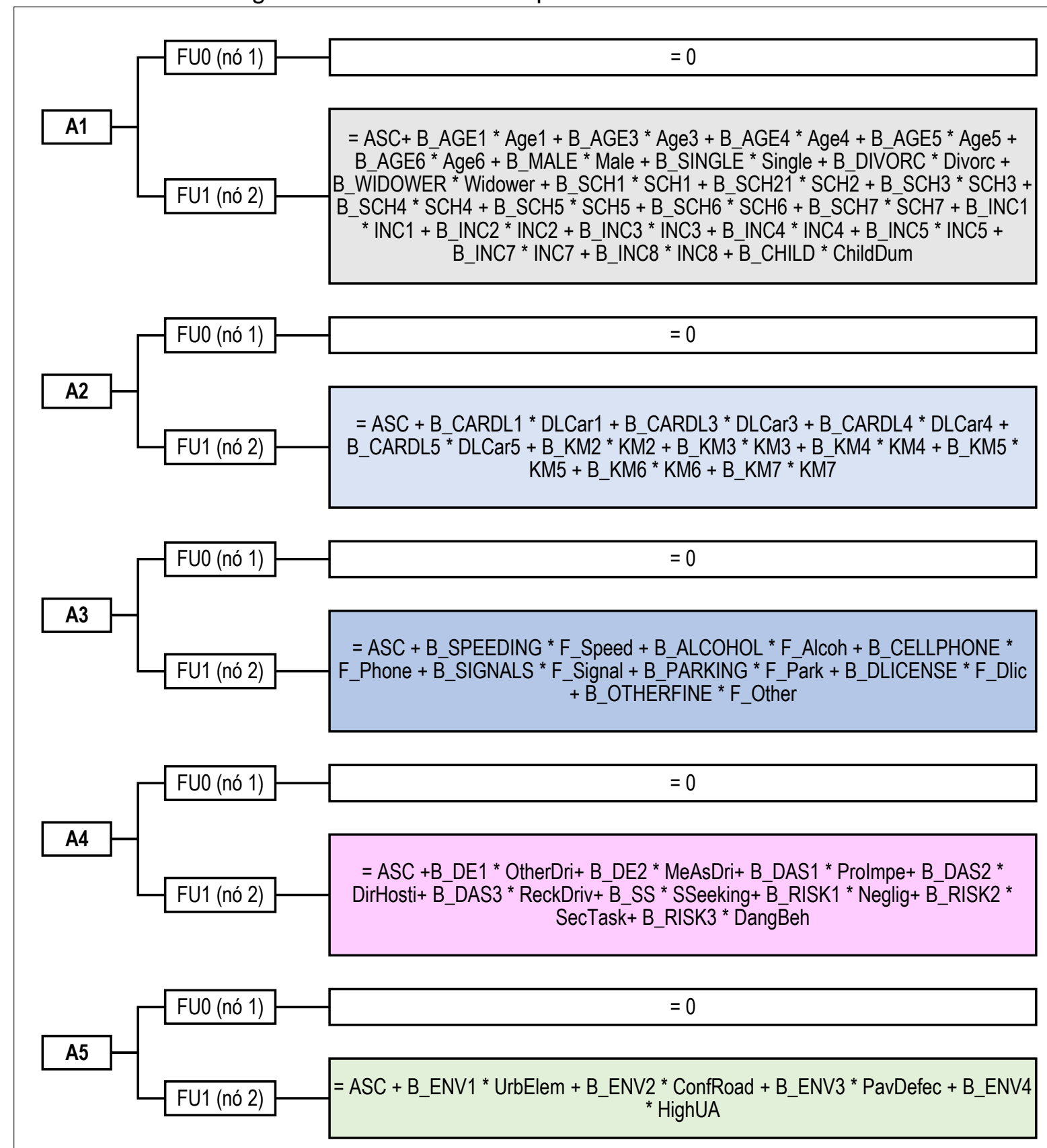

Nota: ASC= constante; A1. B_AGE1= Parâmetro estimado para idade de 18 a 24 anos; B_AGE3= Parâmetro estimado para idade de 35 a 44 anos; $B \_A G E 4=$ Parâmetro estimado

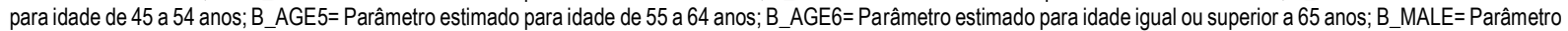
estimado para sexo masculino; $B$ SINGLE= Parâmetro estimado para estado civil solteiro; $B$ DIVORC= Parâmetro estimado para esta do civil divorciado; $B$ WIDOWER= Parâmetro estimado para estado civil viúvo; B_SCH1= Parâmetro estimado para escolaridade Ensino Fundamental Incompleto; B_SCH1= Parâmetro estimado para escolaridade Ensino Fundamental Completo; B_SCH3= Parâmetro estimado para escolaridade Ensino Médio Incompleto; B_SCH4 = Parâmetro estimado para escolaridade Ensino Médio Completo; B_SCH5= Parâmetro estimado para escolaridade Ensino Superior Incompleto; B_SCH6= Parâmetro estimado para escolaridade Ensino Superior Completo; B_SCH7= Parâmetro estimado para escolaridade Pós graduação Incompleto; B_INC1= Parâmetro estimado para nenhuma renda; B_INC2= Parâmetro estimado para renda até 1 salário mínimo; B INC3= Parâmetro estimado para renda de 1 a 2 salários mínimos; $B$ INC4= Parâmetro estimado para renda de 2 a 3 salários mínimos; $B$ INC5= Parâmetro estimado para renda de 3 a 5 salários mínimos; B_INC7= Parâmetro estimado para renda de 10 a 20 salários mínimos; B_INC8= Parâmetro estimado para renda igual ou superior a 2 salários mínimos; B_CHILD= Parâmetro estimado para condutor com filho; A2. B_CARDL1 = Parâmetro estimado para tempo de habilitação até 5 anos; $B$ _CARDL3= Parâmetro estimado para tempo de habilitação de 15 a 30 anos; $B$ CARDL4= Parâmetro estimado para tempo de habilitação de 30 a 45 anos; B CARDL5= Parâmetro estimado para tempo de habilitação mais de 45 anos; B KM2= Parâmetro estimado para distância semanal entre $40 \mathrm{~km}$ e $80 \mathrm{~km} ; \mathrm{B} \_\mathrm{KM} 3=$ Parâmetro estimado para distância semanal entre $80 \mathrm{~km}$ e $120 \mathrm{~km} ; \mathrm{B}$ KM4= Parâmetro estimado para distância semanal entre 120 km e 200 km; B_KM5= Parâmetro estimado para distância semanal entre 200 km e 300 km; B_KM6= Parâmetro estimado para distância semanal entre $300 \mathrm{~km}$ e 500 km; B_KM7= Parâmetro estimado para distância semanal entre superior a 500 km; A3. B_SPEEDING= Parâmetro estimado para multa por excesso de velocidade; B_ALCOHOL= Parâmetro estimado para multa por álcool; B_CELLPHONE= Parâmetro estimado para multa por celular; B_SIGNALS= Parâmetro estimado para multa por desrespeito ao sinal de trânsito; B_PARKING= Parâmetro estimado para multa por estacionar em local proibido; B_DLICENSE= Parâmetro estimado para multa por habilitação irregular; $B$ OTHERFINE= Parâmetro estimado para multa por outros motivos; $A 4$. B DE1= Parâmetro estimado para habilidades do outro condutor; $B$ DE2= Parâmetro estimado para eu mesmo como condutor; B_DAS1= Parâmetro estimado para raiva por impedimento de prosseguir; B_DAS2= Parâmetro estimado para raiva por hostilidade direta; B_DAS3 = Parâmetro estimado para raiva por imprudência do outro condutor; B_SS = Parâmetro estimado para busca de sensações; $B \_R I S K 1=$ Parâmetro estimado para percepção de risco de ações que prejudicam a vigilância; B RISK2 = Parâmetro estimado para percepção de risco de tarefas secundárias; $B$ RISK3 = Parâmetro estimado para percepcão de risco de comportamentos perigosos; A5. B ENV1 = Parâmetro estimado para ambiente viário elementos urbanos; B ENV2 = Parâmetro estimado para ambiente viário rodovias confortáveis; $B \_E N V 3=$ Parâmetro estimado para ambiente viário rodovias com defeitos no pavimento; B_ENV4 = Parâmetro estimado para ambiente viário áreas urbanas com edificações altas. 
A calibração dos Modelos "B" contemplou quatro configurações (B1 a B4) referentes às variáveis independentes de localização, especificamente as divisões geográficas país, região e estado/distrito, e as variáveis agregadas também relacionadas ao local de residência do condutor (Figura 7.9).

Figura 7.9 - Variáveis independentes dos modelos "B"

\begin{tabular}{|c|c|}
\hline FU0 (nó 1) & $=0$ \\
\hline FU1 (nó 2) & $=A S C+B \_P T$ * $P T$ \\
\hline FU0 (nó 1) & $=0$ \\
\hline FU1 (nó 2) & $\begin{array}{c}=\text { B_BRWC1 * BRWestCe + B_BRNE1 * BRNeast + B_BRN1 * BRNorth + B_BRS1 * BRSouth + } \\
\text { B_PTL1 }{ }^{*} \text { PTLisbon + B_PTAJ1 * PTAlent + B_PTAG1 * PTAlgar + B_PTC1 * PTCenter + } \\
\text { B_PTN1 * } \text { PTNorth }\end{array}$ \\
\hline FU0 (nó 1) & $=0$ \\
\hline FU1 (nó 2) & 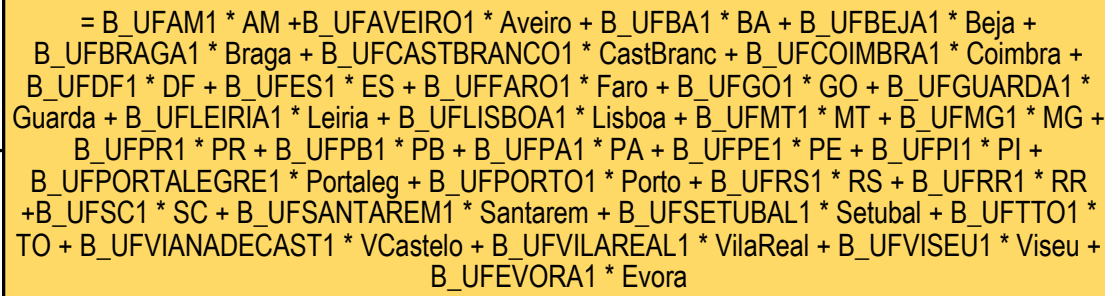 \\
\hline FU0 (nó 1) & $=0$ \\
\hline FU1 (nó 2) & 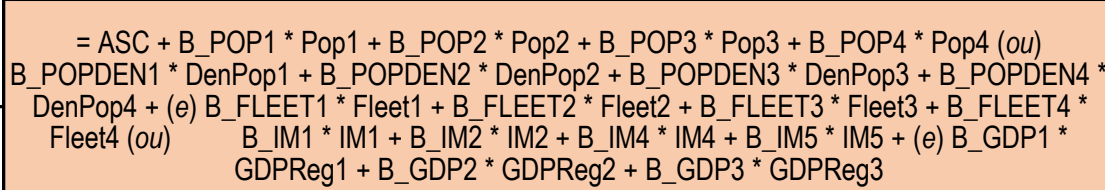 \\
\hline
\end{tabular}

Nota: $\mathrm{ASC}=$ constante; B1. B_PT = Parâmetro estimado para Portugal; $B 2$. B_BRWC = Parâmetro estimado para região Centro Oeste do Brasil; $B \_B R N E=$ Parâmetro estimado para região nordeste do Brasil; B_BRN = Parâmetro estimado para região Norte do Brasil; B_BRS = Parâmetro estimado para região Sul do Brasil; $B \_P T L=$ Parâmetro estimado para região de Lisboa de Portugal; B_PTAJ = Parâmetro estimado para região do Alentejo de Portugal; B_PTAG = Parâmetro estimado para região do Algarve de Portugal; B_PTC = Parâmetro estimado para região Centro de Portugal; B PTN = Parâmetro estimado para região Norte de Portugal; B3. B UFAM = Parâmetro estimado para estado do Amazonas (BR) $\cdot \mathrm{B}$ UFAVEIRO = Parâmetro estimado para distrito de Aveiro (PT) $B$ UFBA = Parâmetro estimado para estado da Bahia (BR); $B$ UFBEJA = Parâmetro estimado para distrito Beja (PT); B_UFBRAGA = Parâmetro estimado para distrito de Braga (PT); B_UFCASTBRANCO = Parâmetro estimado para distrito de Castelo Branco (PT); B_UFCOIMBRA = Parâmetro estimado para distrito de Coimbra (PT); B_UFDF = Parâmetro estimado para Distrito Federal (BR); B_UFES = Parâmetro estimado para estado do Espírito Santo (BR); B_UFFARO = Parâmetro estimado para distrito de Faro (PT); B_UFGO = Parâmetro estimado para estado de Goiás (BR); B_UFGUARDA = Parâmetro estimado para distrito de Guarda (PT); B UFLEIRIA = Parâmetro estimado para distrito de Leiria (PT); B UFLISBOA = Parâmetro estimado para distrito de Lisboa (PT); B UFMT = Parâmetro estimado para estado do Mato Grosso (BR); B_UFMG = Parâmetro estimado para o estado de Minas Gerais (BR); B UFPR = Parâmetro estimado para o estado do Paraná (BR); PR B_UFPB = Parâmetro estimado para o estado da Paraíba (BR); PB; B_UFPA = Parâmetro estimado para o estado do Pará (BR); B_UFPE = Parâmetro estimado para o estado de Pernambuco (BR); B_UFPI = Parâmetro estimado para o estado do Piaú (BR); B_UFPORTALEGRE = Parâmetro estimado para distrito de Portalegre (PT); B_UFPORTO = Parâmetro estimado para o distrito do Porto (PT); B_UFRS = Parâmetro estimado para o estado do Rio Grande do Sul (BR); B_UFRR = Parâmetro estimado para o estado de Roraima (BR);B UFSC = Parâmetro estimado para o estado de Santa Catarina (BR); B UFSANTAREM = Parâmetro estimado para o distrito de Santarém (PT); B UFSETUBAL = Parâmetro estimado para o distrito de Setúbal (PT); B_UFTTO = Parâmetro estimado para o estado do Tocantins (BR); B_UFVIANADECAST = Parâmetro estimado para 0 distrito Viana do Castelo (PT); B_UFVILAREAL = Parâmetro estimado para o distrito Vila Real (PT); B_UFVISEU = Parâmetro estimado para o distrito Viseu (PT); $B \_$UFEVORA = Parâmetro estimado para o distrito Évora (PT); B4. B POP1 = Parâmetro estimado para população menor que 104.526 habitantes; B POP2= Parâmetro estimado para população entre 104.526 e 246.088 habitantes; B POP3 = Parâmetro estimado para população entre 246.088 e 450.657 habitantes; B POP4 = Parâmetro estimado para população entre 450.657 e 1.633 .697 habitantes; $B$ POPDEN1 = Parâmetro estimado para densidade populacional menor 149,72; B POPDEN2 = Parâmetro estimado para densidade populacional entre 149,72 e 229,92; B_POPDEN3 = Parâmetro estimado para densidade populacional entre 229,92 e 988,50; B_POPDEN4 = Parâmetro estimado para densidade populacional entre 988,50 e 4.386,67; B_FLEET1 = Parâmetro estimado para frota menor 65.610; B_FLEET2 = Parâmetro estimado para frota entre 65.610 e 164.554 veículos; B_FLEET3 = Parâmetro estimado para frota entre 164.554 e 319.753 veículos; B_FLEET4 = Parâmetro estimado para frota entre 319.753 e 902.025 ; B_IM1 = Parâmetro estimado para índice de motorização menor 0,58; B IM2 = Parâmetro estimado para índice de motorização entre 0,58 e 0,$64 ; \mathrm{B} I \mathrm{IM} 4=$ Parâmetro estimado para índice de motorização entre 0,71 e 0,$75 ;$ B_IM5 = Parâmetro estimado para índice de motorização maior que 0,75; B_GDP1 = Parâmetro estimado para PIB regional menor US\$ 74.546.785; B_GDP2 = Parâmetro estimado para PIB regional entre US\$ 74.546.785 e US\$220.618.604 B_GDP3 = Parâmetro estimado para PIB regional entre US\$220.618.604 e US\$ 842.066.280 
Os parâmetros significativos identificados nos modelos A e B foram combinados de acordo com a sequência apresentada no grupo de modelos C (Figura 7.10).

Figura 7.10 - Variáveis independentes dos modelos "C"

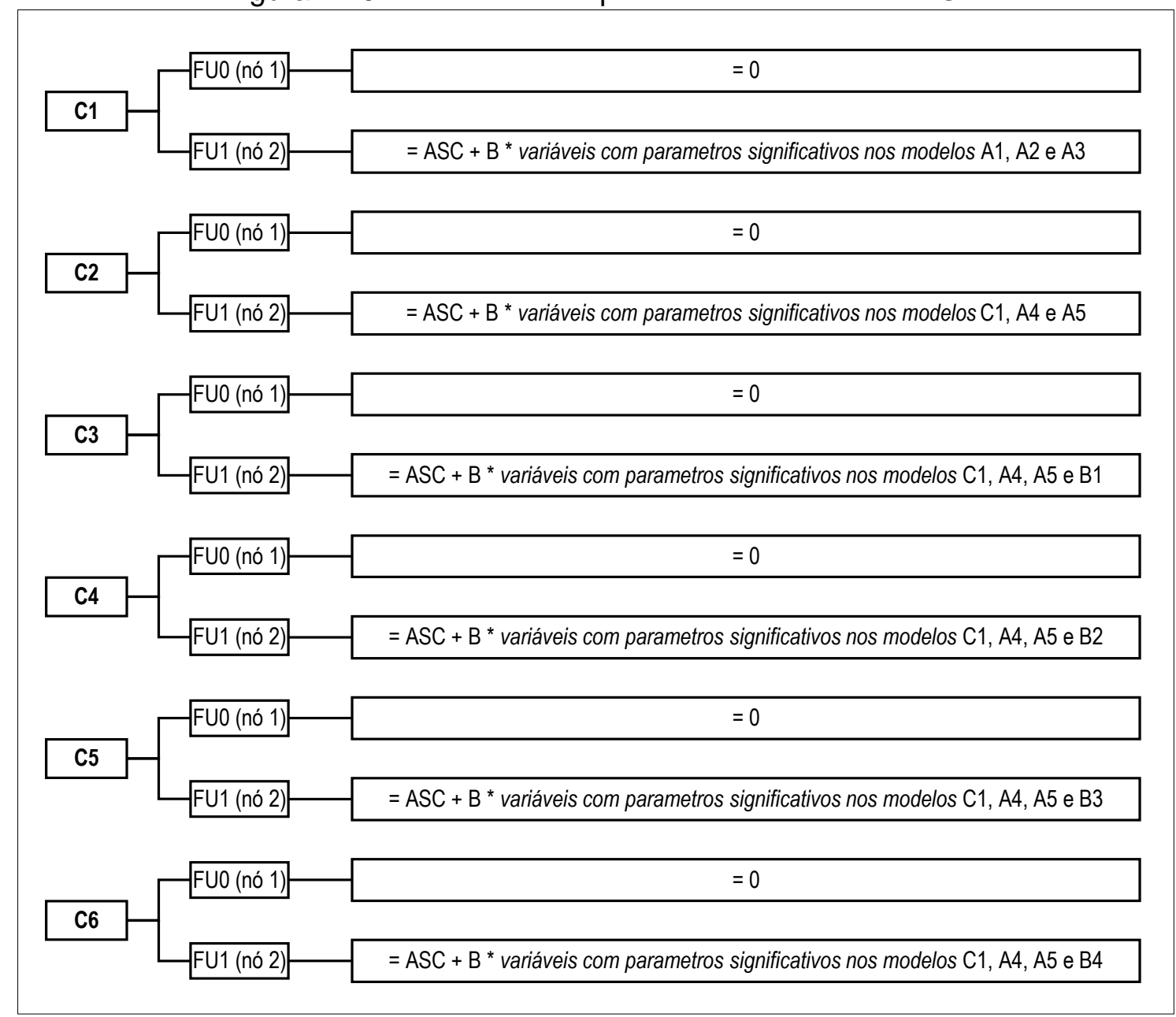

Finalmente, o modelo D (Figura 7.11) corresponde ao modelo onde todas as variáveis independentes foram incluídas no início da calibração.

Figura 7.11 - Variáveis independentes do modelo "D"

D

Em todos os modelos, os parâmetros não significativos foram excluídos de modo iterativo até se obter um modelo em que todos os parâmetros estimados fossem significativos. 


\subsection{Resultados}

Os resultados acerca das métricas de ajuste dos modelos calibrados e parâmetros significativos estimados serão apresentados para cada comportamento na sequência desta seção.

\subsubsection{Erros}

Ao analisar as 16 configurações de modelos para variável dependente do comportamento "erros", os modelos B1, B2, B4, C3, C4 e C6 não resultaram em parâmetros estimados significativos. Ao realizar uma análise geral das métricas dos 10 modelos com parâmetros significativos (Tabela 7.1), foi possível identificar o modelo $\mathrm{D}$ como de melhor ajuste. Os dados indicam menor valor de verossimilhança final, melhor Rho-quadrado-ajustado e menor valor do Critério de Informação de Akaike.

\begin{tabular}{|c|c|c|c|c|}
\hline Modelo & $\begin{array}{l}\text { Número de } \\
\text { parâmetros }\end{array}$ & $\begin{array}{c}\text { Log } \\
\text { Verossimilhança }\end{array}$ & $\begin{array}{l}\text { Rho- } \\
\text { quadrado- }\end{array}$ & $\begin{array}{c}\text { Critério de Informação } \\
\text { de Akaike }\end{array}$ \\
\hline A1 Socioeconômico & 4 & $-1.169,06$ & 0,006 & $2.346,12$ \\
\hline A2 Experiência do condutor & 2 & $-1.175,04$ & 0,002 & $2.354,08$ \\
\hline A3 Histórico de multas & 1 & $-1.175,93$ & 0,002 & $2.353,86$ \\
\hline A4 Construtos psicológicos & 5 & $-1.116,93$ & 0,049 & $2.243,85$ \\
\hline A5 Ambiente viário & 3 & $-1.166,68$ & 0,009 & $2.339,36$ \\
\hline B1 País & \multicolumn{4}{|c|}{ Não houve parâmetros significativos } \\
\hline B2 Região & \multicolumn{4}{|c|}{ Não houve parâmetros significativos } \\
\hline B3 Distrito & 1 & $-1.173,01$ & 0,005 & $2.348,03$ \\
\hline B4 Agregadas & \multicolumn{4}{|c|}{ Não houve parâmetros significativos } \\
\hline $\mathrm{C} 1(\mathrm{~A} 1, \mathrm{~A} 2, \mathrm{~A} 3)$ & 6 & $-1.163,97$ & 0,008 & $2.339,93$ \\
\hline $\mathrm{C} 2(\mathrm{C} 1, \mathrm{~A} 4, \mathrm{~A} 5)$ & 9 & $-1.101,54$ & 0,059 & $2.221,08$ \\
\hline $\mathrm{C} 3(\mathrm{C} 1, \mathrm{~A} 4, \mathrm{~A} 5, \mathrm{~B} 1)$ & \multicolumn{4}{|c|}{ Não houve parâmetros significativos } \\
\hline $\mathrm{C} 4(\mathrm{C} 1, \mathrm{~A} 4, \mathrm{~A} 5, \mathrm{~B} 2)$ & \multicolumn{4}{|c|}{ Não houve parâmetros significativos } \\
\hline $\mathrm{C} 5(\mathrm{C} 1, \mathrm{~A} 4, \mathrm{~A} 5, \mathrm{~B} 3)$ & 11 & $-1.093,73$ & 0,064 & $2.209,45$ \\
\hline $\mathrm{C} 6(\mathrm{C} 1, \mathrm{~A} 4, \mathrm{~A} 5, \mathrm{~B} 4)$ & \multicolumn{4}{|c|}{ Não houve parâmetros significativos } \\
\hline D & 12 & $-1.091,71$ & 0,064 & $2.207,42$ \\
\hline
\end{tabular}

$\mathrm{Na}$ Tabela 7.12, são apresentados os valores dos parâmetros estimados e significativos para o modelo $D$. 


\begin{tabular}{|c|c|c|c|c|}
\hline Variável & Parâmetro & $\begin{array}{c}\text { Valor } \\
\text { estimado }\end{array}$ & Erro & $\mathrm{p}$-valor \\
\hline Homem & $\beta_{\text {Male }}$ & $-0,272$ & 0,102 & 0,008 \\
\hline$>20$ S.M. & $\beta_{\text {Income8 }}$ & $-0,694$ & 0,278 & 0,012 \\
\hline Filhos & $\beta_{\text {Child }}$ & 0,320 & 0,115 & 0,005 \\
\hline TC_15-30 anos & $\beta_{\text {CarDL3 }}$ & $-0,242$ & 0,121 & 0,046 \\
\hline Eu mesmo como condutor & $\beta_{D S 2}$ & $-1,950$ & 0,257 & 0,000 \\
\hline Impedimento para prosseguir viagem & $\beta_{D A S 1}$ & 1,470 & 0,258 & 0,000 \\
\hline Demonstração direta de hostilidade do outro condutor & $\beta_{D A S 2}$ & 0,774 & 0,247 & 0,002 \\
\hline Ações que prejudicam a concentração e vigilância ao conduzir & $\beta_{\text {Risk } 1}$ & 0,940 & 0,289 & 0,001 \\
\hline Elementos urbanos & $\beta_{E n v 1}$ & $-0,667$ & 0,225 & 0,003 \\
\hline Rodovias confortáveis & $\beta_{\text {Env2 }}$ & $-0,652$ & 0,246 & 0,008 \\
\hline Coimbra & $\beta_{U F_{-} \text {Coimbra }}$ & 2,640 & 1,050 & 0,012 \\
\hline Minas Gerais & $\beta_{U F_{-} M G}$ & 0,416 & 0,202 & 0,039 \\
\hline
\end{tabular}

Em específico, as variáveis socioeconômicas "homem" e "renda maior de 20 salários mínimos", quando assumem valor 1, apresentam uma relação negativa com os comportamentos de erros e acidentes mais frequentes. Já a variável "filhos", ao assumir valor 1 , contribui positivamente.

Condutores com experiência de condução entre 15 e 30 anos (de carteira de habilitação/carta de condução) apresentaram uma relação negativa com comportamento de erros e envolvimento de acidentes mais frequentes ao assumirem valor 1. Este fato demonstra que condutores experientes estão menos propensos a cometer comportamentos de erros.

A auto percepção de condutor resultou em parâmetro estimado positivo e alto, com nível de significância de $p<0,001$. Dessa forma, quanto melhor 0 condutor se auto avalia, menor a possibilidade de cometer erros com maior frequência.

Os traços de personalidade associados à raiva (impedimento para prosseguir viagem e demonstração direta de hostilidade do outro condutor) apresentam uma relação positiva com a maior ocorrência de erros e acidentes de trânsito. Este resultado indica a propensão de condutores mais agressivos cometerem erros com maior frequência, destacando-se a forte relação do impedimento de prosseguir viagem, que resultou em valor estimado e significância alta. Este comportamento pode refletir um perfil de falta de paciência do condutor e agitação, que podem levar à menor concentração e à maior ocorrência de erros.

A percepção de risco de ações que prejudicam a concentração e vigilância ao conduzir (ações imprudentes/negligentes) também apresentam uma relação positiva. 
Os parâmetros das variáveis de caracterização do ambiente viário, elementos urbanos e rodovias confortáveis são negativamente relacionados ao comportamento frequente de erros e acidentes de trânsito. Nota-se, a partir dessa relação, que ambientes viários com melhor infraestrutura estão relacionados à menor frequência de erros.

Finalmente, a divisão geográfica apresentou parâmetros significativos para o nível de estado/distrito, representados por Coimbra e Minas Gerais, ambos com sinais positivos. Destaca-se que o parâmetro associado à variável "Coimbra" também foi significativo nos modelos B3 e C5, com sinais e valores dos parâmetros coerentes. Também foi o coeficiente que apresentou o maior valor no modelo, que pode ser explicado pelo fato de 14 dos 15 condutores de Coimbra estarem classificados no Nó 2 da Árvore de Decisão para definição da variável dependente relativa ao comportamento "erros".

Nos demais modelos calibrados com parâmetros significativos, os sinais e valores dos parâmetros foram coerentes com os apresentados no modelo D.

\subsubsection{Excesso de velocidade}

Os 16 modelos calibrados para variável dependente do comportamento "excesso de velocidade" apresentaram parâmetros significativos para as variáveis independentes. Ao analisar as medidas de ajuste do modelo, o modelo C3 alcançou o melhor ajuste (Tabela 7.3) com os menores valores do Log de Verossimilhança Final e critério de informação Akaike e melhor valor para o Rho-quadrado-ajustado. Apesar do modelo C4 ser semelhante quanto aos valores das medidas analisadas, foi penalizado pelo Critério de Informação de Akaike.

Tabela 7.3 - Medidas de estimação dos modelos associados ao comportamento "Excesso

\begin{tabular}{|c|c|c|c|c|}
\hline Modelos & $\begin{array}{c}\text { No. de } \\
\text { parâmetros } \\
\text { estimados }\end{array}$ & $\begin{array}{c}\text { Log } \\
\text { Verossimilhança } \\
\text { Final }\end{array}$ & $\begin{array}{l}\text { Rho- } \\
\text { quadrado- } \\
\text { ajustado }\end{array}$ & $\begin{array}{l}\text { Critério de } \\
\text { Informação } \\
\text { de Akaike }\end{array}$ \\
\hline A1 Socioeconômico & 6 & $-912,10$ & 0,222 & $1.836,19$ \\
\hline A2 Experiência do condutor & 8 & $-919,40$ & 0,214 & $1.854,80$ \\
\hline A3 Histórico de multas & 2 & $-931,45$ & 0,209 & $1.866,90$ \\
\hline A4 Construtos psicológicos & 7 & $-795,11$ & 0,320 & $1.604,22$ \\
\hline A5 Ambiente viário & 3 & $-935,12$ & 0,205 & $1.876,24$ \\
\hline B1 País & 2 & $-930,57$ & 0,210 & $1.865,14$ \\
\hline B2 Região & 4 & $-924,71$ & 0,213 & $1.857,43$ \\
\hline B3 Distrito & 4 & $-929,77$ & 0,208 & $1.867,53$ \\
\hline B4 Agregadas & 2 & $-929,96$ & 0,210 & $\begin{array}{c}1.863,92 \\
\text { Continua }\end{array}$ \\
\hline
\end{tabular}




\begin{tabular}{|c|c|c|c|c|}
\hline \multicolumn{5}{|l|}{ Continuação } \\
\hline Modelos & $\begin{array}{l}\text { No. de } \\
\text { parâmetros } \\
\text { estimados }\end{array}$ & $\begin{array}{l}\log \\
\text { Verossimilhança } \\
\text { Final }\end{array}$ & $\begin{array}{l}\text { Rho- } \\
\text { quadrado- } \\
\text { ajustado }\end{array}$ & $\begin{array}{l}\text { Critério de } \\
\text { Informação } \\
\text { de Akaike }\end{array}$ \\
\hline $\mathrm{C} 1(\mathrm{~A} 1, \mathrm{~A} 2, \mathrm{~A} 3)$ & 14 & $-883,12$ & 0,240 & $1.794,24$ \\
\hline $\mathrm{C} 2(\mathrm{C} 1, \mathrm{~A} 4, \mathrm{~A} 5)$ & 11 & $-782,31$ & 0,328 & $1.586,62$ \\
\hline $\mathrm{C} 3(\mathrm{C} 1, \mathrm{~A} 4, \mathrm{~A} 5, \mathrm{~B} 1)$ & 12 & $-765,46$ & 0,341 & $1.554,93$ \\
\hline $\mathrm{C} 4(\mathrm{C} 1, \mathrm{~A} 4, \mathrm{~A} 5, \mathrm{~B} 2)$ & 14 & $-764,45$ & 0,340 & $1.556,91$ \\
\hline $\mathrm{C} 5(\mathrm{C} 1, \mathrm{~A} 4, \mathrm{~A} 5, \mathrm{~B} 3)$ & 12 & $-778,78$ & 0,330 & $1.581,55$ \\
\hline $\mathrm{C} 6(\mathrm{C} 1, \mathrm{~A} 4, \mathrm{~A} 5, \mathrm{~B} 4)$ & 12 & $-768,37$ & 0,339 & $1.560,73$ \\
\hline D & 10 & $-785,70$ & 0,326 & $1.591,41$ \\
\hline
\end{tabular}

Os parâmetros significativos do comportamento C3 são apresentados na Tabela 7.4.

Tabela 7.4 - Parâmetros estimados para o modelo C3, associado ao comportamento "excesso de velocidade"

\begin{tabular}{|c|c|c|c|c|}
\hline Variável & $\begin{array}{c}\text { Parâmetro } \\
\text { estimado }\end{array}$ & $\begin{array}{c}\text { Valor } \\
\text { estimado }\end{array}$ & Erro & $\mathrm{p}$-valor \\
\hline Constante & $A S C$ & 1,700 & 0,538 & 0,002 \\
\hline $45-54$ anos & $\beta_{\text {Age } 4}$ & $-0,457$ & 0,172 & 0,008 \\
\hline $55-64$ anos & $\beta_{\text {Age } 5}$ & $-0,722$ & 0,220 & 0,001 \\
\hline$>65$ anos & $\beta_{\text {Age6 }}$ & $-1,080$ & 0,506 & 0,033 \\
\hline $200-300 \mathrm{~km} / \mathrm{semana}$ & $\beta_{K m 5}$ & 0,414 & 0,207 & 0,045 \\
\hline M_Velocidade & $\beta_{F_{-} \text {speed }}$ & 0,703 & 0,144 & 0,000 \\
\hline Eu mesmo como condutor & $\beta_{D S 2}$ & $-0,825$ & 0,331 & 0,013 \\
\hline Demonstração direta de hostilidade do outro condutor & $\beta_{D A S 2}$ & 0,843 & 0,319 & 0,008 \\
\hline Busca de sensações & $\beta_{S S}$ & 3,380 & 0,415 & 0,000 \\
\hline Ações que prejudicam a concentração e vigilância ao conduzir & $\beta_{\text {Risk1 }}$ & 1,770 & 0,440 & 0,000 \\
\hline Comportamentos perigosos & $\beta_{\text {Risk3 }}$ & $-5,390$ & 0,545 & 0,000 \\
\hline Portugal & $\beta_{P t}$ & 1,100 & 0,187 & 0,000 \\
\hline
\end{tabular}

A relação da variável "idade", representada pelas faixas etárias entre "45-54", "55-64" e "maiores de 65 anos", é negativa e os valores dos parâmetros aumentam à medida que os condutores são mais velhos. Este fato indica que quanto mais velho o condutor, maior a possibilidade de não assumir o risco de conduzir em excesso de velocidade frequentemente.

A experiência do condutor, representada pela variável de distância percorrida semanalmente, "entre 200 e 300 quilômetros", demonstra relação positiva, indicando que condutores experientes tendem a assumir o risco de exceder a velocidade no trânsito mais frequentemente. Condutores com histórico de multas por excesso de velocidade também apresentam uma relação positiva com o comportamento, corroborando o resultado prévio obtido através do algoritmo de Árvore de Decisão. 
O parâmetro de autopercepção como bom condutor indica uma relação negativa, de forma que, quanto mais hábil o condutor se considera, menor a propensão em assumir o risco de exceder a velocidade com frequência. Este fato pode estar relacionado com a cautela desses condutores, que era um dos itens avaliados acerca da habilidade de condução.

A demonstração direta de hostilidade do outro condutor, que representa o construto raiva, apresentou uma relação positiva, em que quanto maior a manifestação de raiva, ou seja, perfil de agressividade, maior a possibilidade de assumir o risco de exceder a velocidade com frequência.

O parâmetro estimado para o traço de personalidade busca de sensações demonstra uma relação positiva, de forma que quanto mais presente esse traço na personalidade do condutor, maior a propensão a assumir o risco de exceder a velocidade com mais frequência. Nota-se também que o valor deste parâmetro é alto e significativo com $p<0,001$, indicando forte relação entre o perfil da busca de emoções do usuário e o comportamento de risco mais frequente.

A percepção de risco de ações que prejudicam a concentração e a vigilância ao conduzir demonstra relação positiva com a maior frequência do comportamento de excesso de velocidade. Este fato pode indicar que os condutores que excedem velocidade com mais frequência tendem a atribuir maior risco a comportamentos que não têm controle.

Contudo, a percepção de risco de comportamentos perigosos apresenta relação negativa e valor alto do parâmetro estimado e significativo com $p<0,001$. Este fato indica que, possivelmente, a consciência do perigo associado ao comportamento de excesso de velocidade contribui fortemente para o condutor não assumir o risco de exceder a velocidade com frequência.

Com relação à localização, condutores Portugueses estão positivamente relacionados ao comportamento de conduzir com mais frequência com excesso de velocidade, com uma relação forte representada pelo valor estimado e significativo a um nível de confiança de $99 \%$.

Os valores estimados para os parâmetros do modelo C3 mantêm os mesmos sinais e a mesma ordem de grandeza nos demais modelos, calibrados para o comportamento "excesso de velocidade", em que são significativos. 


\subsubsection{Conduzir sob efeito de álcool}

Entre os modelos calibrados para variável dependente do comportamento "conduzir sob efeito de álcool", os modelos A2 e C3 não resultaram em parâmetros estimados significativos. Ao analisar os 14 modelos calibrados (Tabela 7.5), o modelo D resultou em melhor ajuste, com os menores valores do Log de Verossimilhança Final e Critério de Informação de Akaike e melhor Rho-quadrado-ajustado. Nota-se que semelhante ao comportamento erros, os valores do Rho-quadrado-ajustado foram baixos.

Tabela 7.5 - Medidas de estimação dos modelos associados ao comportamento "conduzir sob influência de álcool"

\begin{tabular}{lccrr}
\hline \multicolumn{1}{c}{ Modelo } & $\begin{array}{c}\text { Número de } \\
\text { parâmetros } \\
\text { estimados }\end{array}$ & $\begin{array}{c}\text { Log } \\
\text { Verossimilhança } \\
\text { Final }\end{array}$ & $\begin{array}{c}\text { Rho- } \\
\text { quadrado- } \\
\text { ajustado }\end{array}$ & $\begin{array}{c}\text { Critério de } \\
\text { Informação } \\
\text { de Akaike }\end{array}$ \\
\hline A1 Socioeconômico & 3 & $-1.151,53$ & 0,021 & $2.309,06$ \\
A3 Histórico de multas & 4 & $-1.138,99$ & 0,031 & $2.285,98$ \\
A4 Construtos psicológicos & 3 & $-1.133,49$ & 0,037 & $2.272,98$ \\
A5 Ambiente viário & 1 & $-1.160,31$ & 0,016 & $2.322,62$ \\
B1 País & 2 & $-1.159,71$ & 0,015 & $2.323,42$ \\
B2 Região & 3 & $-1.157,09$ & 0,017 & $2.320,19$ \\
B3 Distrito & 4 & $-1.150,94$ & 0,021 & $2.309,87$ \\
B4 Agregadas & 2 & $-1.160,01$ & 0,015 & $2.324,02$ \\
C1 (A1, A2, A3) & 7 & $-1.127,49$ & 0,038 & $2.268,98$ \\
C2 (C1, A4, A5) & 9 & $-1.110,16$ & 0,051 & $2.238,32$ \\
C4 (C1, A4, A5, B2) & 7 & $-1.111,85$ & 0,052 & $2.237,69$ \\
C5 (C1, A4, A5, B3) & 8 & $-1.106,40$ & 0,055 & $2.228,81$ \\
C6 (C1, A4, A5, B4) & 7 & $-1.111,36$ & 0,052 & $2.236,73$ \\
D & 11 & $-1.101,24$ & 0,057 & $\mathbf{2 . 2 2 4 , 4 8}$ \\
\hline Nota: *Log de Verossimilhança Inicial: -1179,74 & & & &
\end{tabular}

Na Tabela 7.6 são apresentados os parâmetros significativos estimados para 0 modelo D, associado ao comportamento "conduzir sob efeito de álcool".

Tabela 7.6 - Parâmetros estimados para o modelo D, relativo ao comportamento "conduzir sob efeito de álcool"

\begin{tabular}{|c|c|c|c|c|}
\hline Variável & Parâmetro & $\begin{array}{c}\text { Valor } \\
\text { estimado }\end{array}$ & Erro & p-valor \\
\hline Constante & $A S C$ & $-0,659$ & 0,269 & 0,014 \\
\hline Solteiro & $\beta_{\text {Single }}$ & 0,231 & 0,105 & 0,028 \\
\hline$>20$ S.M. & $\beta_{\text {Income } 8}$ & 0,593 & 0,264 & 0,025 \\
\hline M_Álcool & $\beta_{F_{-} \text {Alcohol }}$ & 2,330 & 1,060 & 0,029 \\
\hline M_Estacionar & $\beta_{F_{-} \text {Parking }}$ & 0,444 & 0,149 & 0,003 \\
\hline M_Velocidade & $\beta_{F_{-} \text {Speed }}$ & 0,473 & 0,108 & 0,000 \\
\hline Demonstração direta de hostilidade do outro condutor & $\beta_{D A S 2}$ & 0,649 & 0,254 & 0,011 \\
\hline Comportamentos perigosos & $\beta_{\text {Risk3 }}$ & $-1,380$ & 0,382 & 0,000 \\
\hline Busca de sensações & $\beta_{S S}$ & 1,130 & 0,256 & 0,000 \\
\hline Santa Catarina & $\beta_{U F S C}$ & 0,782 & 0,272 & 0,004 \\
\hline Den Pop< 149,72 & $\beta_{\text {PopDen } 1}$ & 0,374 & 0,127 & 0,003 \\
\hline
\end{tabular}


Ao analisar os parâmetros das variáveis socioeconômicas, verifica-se que condutores solteiros e de alta renda (acima de 20 salários mínimos) apresentam relação positiva com o comportamento de risco de, mais frequentemente, conduzir sob efeito de álcool.

O parâmetro significativo para multas por álcool indicou relação positiva e forte com o comportamento mais frequente de conduzir sob efeito de álcool, corroborando a diferença significativa apresentada na análise anterior dos nós terminais do algoritmo de Árvore de Decisão. As multas por estacionar em local proibido e exceder a velocidade também apresentam relação positiva com o comportamento mais arriscado. Este fato pode revelar a relação entre condutores com tendência a cometer infrações, mais frequentemente, adotarem o comportamento de risco de conduzir alcoolizado.

A percepção de risco de comportamentos perigosos apresenta relação negativa e forte (valor estimado alto ao nível de significância de 99\%), de forma que condutores com maior percepção desse risco estão menos propensos a assumir o risco de conduzir sob efeito de álcool com maior frequência.

O traço de personalidade "busca de sensações" apresenta relação positiva, indicando que o condutor com perfil de busca por emoções tende a assumir, mais frequentemente, o risco de conduzir sob efeito de álcool. A relação é forte, visto o alto valor do parâmetro e nível de significância $(p<0,001)$.

O parâmetro da demonstração direta de hostilidade do outro condutor, referente ao traço de personalidade de raiva, indicou uma relação positiva com a maior frequência de conduzir sob efeito de álcool. Este fator indica a propensão de condutores com perfil agressivo, mais frequentemente, assumirem o comportamento de risco.

As variáveis relacionadas à localização do condutor indicam que condutores de Santa Catarina e densidade populacional baixa, ao assumirem valor 1, contribuem positivamente para maior frequência de comportamentos de risco. Baixa densidade populacional indica municípios de menor porte, que podem apresentar menos fiscalizações.

Os parâmetros estimados para o modelo D mostram-se coerentes quanto ao sinal e valor nos demais modelos em que também foram significativos. 


\subsubsection{Não usar cinto de segurança ao conduzir}

Todos os modelos apesentaram parâmetros estimados significativos para 0 comportamento associado a "não usar o cinto de segurança ao conduzir". O modelo C3 (Tabela 7.7) apresentou o melhor ajuste de acordo com as métricas, de forma a obter o menor Log de Verossimilhança Final, menor valor para o Critério de Informação de Akaike e maior valor para o Rho-quadrado-ajustado.

Tabela 7.7 - Medidas de estimação dos modelos associados ao comportamento "não usar cinto de segurança"

\begin{tabular}{lcccc}
\hline \multicolumn{1}{c}{ Modelo } & $\begin{array}{c}\text { Número de } \\
\text { parâmetros } \\
\text { estimados }\end{array}$ & $\begin{array}{c}\text { Log de } \\
\text { Verossimilhança } \\
\text { Final }\end{array}$ & $\begin{array}{c}\text { Rho- } \\
\text { quadrado- } \\
\text { ajustado }\end{array}$ & $\begin{array}{c}\text { Critério de } \\
\text { Informação de } \\
\text { Akaike }\end{array}$ \\
\hline A1 Socioeconômico & 5 & $-929,05$ & 0,208 & $1.868,09$ \\
A2 Experiência do condutor & 6 & $-924,93$ & 0,211 & $1.861,87$ \\
A3 Histórico de multas & 3 & $-930,54$ & 0,209 & $1.867,08$ \\
A4 Construtos psicológicos & 7 & $-873,38$ & 0,254 & $1.760,76$ \\
A5 Ambiente viário & 2 & $-933,29$ & 0,207 & $1.870,58$ \\
B1 País & 2 & $-933,70$ & 0,207 & $1.871,39$ \\
B2 Região & 3 & $-932,62$ & 0,207 & $1.871,24$ \\
B3 Distrito & 3 & $-931,00$ & 0,208 & $1.867,99$ \\
B4 Agregadas & 2 & $-932,42$ & 0,208 & $1.868,85$ \\
C1 (A1, A2, A3) & 8 & $-915,48$ & 0,217 & $1.846,95$ \\
C2 (C1, A4, A5) & 10 & $-864,03$ & 0,259 & $1.748,06$ \\
C3 (C1, A4, A5, B1) & 10 & $-856,76$ & 0,265 & $1.733,52$ \\
C4 (C1, A4, A5, B2) & 12 & $-857,11$ & 0,263 & $1.738,22$ \\
C5 (C1, A4, A5, B3) & 11 & $-858,56$ & 0,263 & $1.739,12$ \\
C6 (C1, A4, A5, B4) & 11 & $-859,44$ & 0,262 & $1.740,89$ \\
D & 12 & $-857,27$ & 0,263 & $1.738,54$ \\
\hline Nota: *Log de Verossimilhança Inicial: -1179,74 & & & &
\end{tabular}

Os parâmetros estimados para o modelo C3, relativo ao comportamento "não uso do cinto de segurança", são apresentados na Tabela 7.8. Contudo, antes de apresentálos, cabe relembrar que no caso do comportamento de não uso de cinto de segurança, a variável dependente e as funções utilidade seguiram o mesmo padrão dos demais comportamentos, em que a função utilidade 1 (Nó 2) está associada à maior frequência do comportamento de não usar o cinto de segurança. Entretanto, neste grupo, há menor ocorrência de acidentes de trânsito.

Tabela 7.8 - Parâmetros estimados para os modelos C3, associados ao comportamento "não usar o cinto de segurança"

\begin{tabular}{|c|c|c|c|c|}
\hline Variável & Parâmetros & $\begin{array}{c}\text { Valor } \\
\text { estimado }\end{array}$ & Erro & p-valor \\
\hline Constante & $A S C$ & 3,890 & 0,833 & 0,000 \\
\hline $200-300$ km/semana & $\beta_{K m 5}$ & $-0,450$ & 0,163 & 0,006 \\
\hline M_Estacionar & $\beta_{F_{-} \text {Parking }}$ & $-0,431$ & 0,165 & 0,009 \\
\hline \multirow[t]{2}{*}{ M_Velocidade } & $\beta_{F_{-} \text {Speed }}$ & $-0,402$ & 0,131 & 0,002 \\
\hline & & & \multicolumn{2}{|c|}{ Continua } \\
\hline
\end{tabular}




\begin{tabular}{lcrrr}
\hline Continuação & & & & \\
\multicolumn{1}{c}{ Variável } & Parâmetros & $\begin{array}{c}\text { Valor } \\
\text { estimado }\end{array}$ & Erro & p-valor \\
Ações que prejudicam a concentração e vigilância ao conduzir & $\beta_{\text {Risk1 } 1}$ & $-2,670$ & 0,839 & 0,001 \\
Comportamentos perigosos & $\beta_{\text {Risk } 3}$ & 2,460 & 0,461 & 0,000 \\
Busca de sensações & $\beta_{S S}$ & $-1,740$ & 0,284 & 0,000 \\
Demonstração direta de hostilidade do outro condutor & $\beta_{D A S 2}$ & $-0,893$ & 0,304 & 0,003 \\
Rodovias confortáveis & $\beta_{E n v 2}$ & $-0,715$ & 0,281 & 0,011 \\
Portugal & $\beta_{P t}$ & $-0,726$ & 0,152 & 0,000 \\
\hline
\end{tabular}

O parâmetro relacionado à quilometragem percorrida indica uma relação negativa para categoria de 200 a 300 quilômetros semanalmente. Este fato indica que ao assumir valor 1, os condutores com experiência tendem a não assumir o risco de não utilizar o cinto de segurança frequentemente.

Os parâmetros negativos estimados para multas por estacionamento em local proibido e excesso de velocidade, indicam que condutores com histórico dessas multas apresentam menor propensão de não utilizar o cinto de segurança com mais frequência.

Em relação à percepção de risco, quanto maior a classificação de risco para ações que prejudicam a concentração e vigilância ao conduzir, menor a propensão em não usar o cinto de segurança. Contudo, a maior percepção de risco de comportamentos perigosos aumenta a propensão do condutor conduzir sem o cinto de segurança.

Com relação ao traço de personalidade busca de sensações e de raiva devido à demonstração direta de hostilidade do outro condutor, verifica-se uma relação negativa, em que quanto maior a presença desses traços de personalidade no condutor, menor a possibilidade de assumir o comportamento de risco de não utilizar o cinto de segurança frequentemente.

Nota-se, novamente, relação negativa para rodovias confortáveis, em que quanto mais o condutor conduz em rodovias de boa qualidade, menor a possibilidade de não usar o cinto de segurança com maior frequência.

Condutores de Portugal demonstram uma relação negativa de forma que se mostram menos propensos a, mais frequentemente, não utilizar o cinto de segurança.

Ao analisar esses resultados, nota-se padrões entre as variáveis e a frequência do comportamento de risco pouco intuitivos, como é o caso da maior percepção de risco de comportamentos perigosos contribuírem positivamente para o condutor assumir o 
risco de não utilizar o cinto de segurança com maior frequência, ou ainda traços de personalidade, como busca de sensações ou raiva, contribuírem de forma negativa, ou seja, diminuir a propensão do condutor a assumir o risco de conduzir sem o cinto de segurança.

Contudo, verifica-se que ao relacionar esses resultados com os obtidos para os modelos do comportamento "excesso de velocidade", os parâmetros apresentam relação contrária entre eles. Este fato pode indicar uma relação entre 0 comportamento de não uso de cinto de segurança e excesso de velocidade. Os condutores que reportaram sempre utilizar o cinto de segurança (Nó 1 e FUn) apresentam as mesmas variáveis e padrões de influência que os condutores que excedem a velocidade mais frequentemente. Este resultado corrobora Janssen (1994) que, em um estudo naturalístico, identificou que condutores que naturalmente não utilizavam cinto de segurança, ao serem obrigados a utilizar o tempo todo, passaram a desempenhar maiores velocidades, e esse comportamento se manteve ao longo do tempo.

\subsubsection{Usar o celular no modo viva voz enquanto conduz}

Entre os modelos estimados para variável dependente associada ao comportamento referente ao uso do celular no modo viva voz enquanto conduz, os modelos A3 e C1 não apresentaram parâmetros significativos para as variáveis independentes (Tabela 7.9).

Entre os 14 modelos calibrados, o modelo C4 apresentou o melhor ajuste quanto ao Log de Verossimilhança Final, Rho-quadrado-ajustado e Critério de Informação de Akaike. Cabe ressaltar que as métricas do modelo $D$ foram semelhantes, entretanto, superiores àquelas obtidas a partir do modelo C4.

Tabela 7.9 - Medidas de estimação dos modelos associados ao comportamento "usar o celular no modo viva voz ao conduzir"

\begin{tabular}{lcccc}
\hline \multicolumn{1}{c}{ Modelo } & $\begin{array}{c}\text { Número de } \\
\text { parâmetros } \\
\text { estimados }\end{array}$ & $\begin{array}{c}\text { Log } \\
\text { Verossimilhança } \\
\text { Final }\end{array}$ & $\begin{array}{c}\text { Rho- } \\
\text { quadrado- } \\
\text { ajustado }\end{array}$ & $\begin{array}{c}\text { Critério de } \\
\text { Informação } \\
\text { de Akaike }\end{array}$ \\
\hline A1 Socioeconômico & 2 & $-788,64$ & 0,330 & $1.581,28$ \\
A2 Experiência do condutor & 7 & $-770,96$ & 0,341 & $1.555,91$ \\
A3 Histórico de multas & & Não houve parâmetros significativos & \\
A4 Construtos psicológicos & 5 & $-720,69$ & 0,385 & $1.451,37$ \\
A5 Ambiente viário & 4 & $-757,08$ & 0,355 & $1.522,17$ \\
& & & & Continua \\
\hline
\end{tabular}




\begin{tabular}{lcccc}
\hline Continuação & $\begin{array}{c}\text { Número de } \\
\text { parâmetros } \\
\text { estimados }\end{array}$ & $\begin{array}{c}\text { Log } \\
\text { Verossimilhança } \\
\text { Final }\end{array}$ & $\begin{array}{c}\text { Rho- } \\
\text { quadrado- } \\
\text { ajustado }\end{array}$ & $\begin{array}{c}\text { Critério de } \\
\text { Informação } \\
\text { de Akaike } \\
\text { B1 País }\end{array}$ \\
B2 Região & 2 & $-767,47$ & 0,348 & $1.538,94$ \\
B3 Distrito & 7 & $-758,14$ & 0,351 & $1.530,29$ \\
B4 Agregadas & 10 & $-762,23$ & 0,345 & $1.544,47$ \\
C1 (A1, A2, A3) & 4 & $-766,51$ & 0,347 & $1.541,02$ \\
C2 (C1, A4, A5) & 10 & Não houve parâmetros significativos & \\
C3 (C1, A4, A5, B1) & 11 & $-686,51$ & 0,410 & $1.393,02$ \\
C4 (C1, A4, A5, B2) & 13 & $-680,14$ & 0,414 & $1.382,28$ \\
C5 (C1, A4, A5, B3) & 13 & $-674,23$ & 0,417 & $1.374,47$ \\
C6 (C1, A4, A5, B4) & 11 & $-676,48$ & 0,416 & $1.378,97$ \\
D & 13 & $-680,24$ & 0,414 & $1.382,48$ \\
\hline Nota: *Log de Verossimilhança Inicial: & $-1179,74$ & $-676,27$ & 0,416 & $1.378,54$ \\
\hline
\end{tabular}

Os parâmetros estimados e significativos para o modelo C4, relativo ao comportamento "uso do celular", são apresentados na Tabela 7.10.

Tabela 7.10 - Parâmetros estimados para o modelo C4, relativo ao comportamento "uso do celular no modo viva voz ao conduzir"

\begin{tabular}{|c|c|c|c|c|}
\hline Variável & Parâmetros & Valor estimado & Erro & p-valor \\
\hline Constante & $A S C$ & $-3,390$ & 0,464 & 0,000 \\
\hline $120-200$ km/semana & $\beta_{K m 4}$ & 0,441 & 0,170 & 0,009 \\
\hline $200-300$ km/semana & $\beta_{K m 5}$ & 0,533 & 0,198 & 0,007 \\
\hline$>500$ km/semana & $\beta_{K m 7}$ & 0,676 & 0,252 & 0,007 \\
\hline Impedimento para prosseguir viagem & $\beta_{D A S 1}$ & 0,954 & 0,391 & 0,015 \\
\hline Tarefas secundárias ao conduzir & $\beta_{\text {Risk2 }}$ & $-2,740$ & 0,305 & 0,000 \\
\hline Busca de sensações & $\beta_{S S}$ & 1,010 & 0,332 & 0,002 \\
\hline Elementos urbanos & $\beta_{E n v 1}$ & 1,510 & 0,350 & 0,000 \\
\hline Rodovias confortáveis & $\beta_{E n v 2}$ & 1,430 & 0,316 & 0,000 \\
\hline Áreas urbanas com edificações altas & $\beta_{\text {Env4 }}$ & 1,420 & 0,318 & 0,000 \\
\hline BR_Nordeste & $\beta_{B r_{-} \text {northeast }}$ & 0,965 & 0,240 & 0,000 \\
\hline PT_Centro & $\beta_{P t \_c e n t e r}$ & 0,694 & 0,273 & 0,011 \\
\hline PT_Norte & $\beta_{P t \_n o r t h}$ & 0,621 & 0,206 & 0,003 \\
\hline
\end{tabular}

Os parâmetros positivos para quilometragem percorrida e o aumento no valor dos parâmetros acompanhando o aumento das categorias, indicam uma relação positiva, de forma que quanto mais experiente o condutor, maior a possibilidade de assumir o risco de usar o celular ao conduzir.

O parâmetro negativo, relacionado à percepção de risco de tarefas secundárias, onde estão concentradas especificamente o uso do celular no modo viva voz, indica que 
condutores que consideram estes atos com maior nível de risco apresentam menor propensão em assumir o risco de utilizar o celular ao conduzir com maior frequência.

Os traços de personalidade de raiva, representados pela variável latente de impedimento de prosseguir viagem e o traço de busca de sensações, apresentaram parâmetros positivos. A demonstração de raiva por ter o caminho impedido poderia indicar uma possível falta de paciência, ou tédio, por parte do condutor, que o levam a buscar alternativas como utilizar mais frequentemente o celular, assim como o traço de busca de sensações revela o desejo por emoções.

As relações positivas, indicadas pelos parâmetros da caracterização do ambiente viário, indicam maior propensão em adotar o comportamento do uso de celular, conforme a maior frequência de condução em locais com maior presença de elementos urbanos, áreas urbanas com edificações altas e rodovias confortáveis. Este fato pode estar relacionado à maior presença de dispositivos viários no caminho (semáforo, rotatórias, faixas de pedestre) que podem levar o condutor a parar o veículo, tendo oportunidade de usar o celular. As rodovias confortáveis apresentam boa qualidade de pavimento e traçados mais retos. Essas condições poderiam levar a redução da atenção do condutor, ou ao tédio e fadiga, favorecendo o uso do celular com maior frequência.

Os parâmetros de localização indicam relação positiva para as regiões Nordeste, do Brasil e Centro e Norte de Portugal e o comportamento, mais frequente, associado ao uso do celular em viva voz, ao conduzir.

\subsubsection{Cansaço e sonolência}

Os modelos B4 e C3, calibrados para a variável dependente associada ao comportamento referente ao cansaço e sonolência, não apresentaram parâmetros significativos (Tabela 7.11). Entre os demais modelos, o modelo D apresentou melhor ajuste com maior Rho-quadrado-ajustado e menor valor de Log de Verossimilhança Final e Critério de Informação de Akaike. 
Tabela 7.11 - Medidas de estimação dos modelos associados ao comportamento "Cansaço e sonolência"

\begin{tabular}{|c|c|c|c|c|}
\hline Modelo & $\begin{array}{l}\text { Número de } \\
\text { parâmetros } \\
\text { estimados }\end{array}$ & $\begin{array}{l}\text { Log } \\
\text { Verossimilhança } \\
\text { Final }\end{array}$ & $\begin{array}{l}\text { Rho- } \\
\text { quadrado- } \\
\text { ajustado }\end{array}$ & $\begin{array}{c}\text { Critério de } \\
\text { Informação } \\
\text { de Akaike }\end{array}$ \\
\hline A1 Socioeconômico & 7 & $-1.084,19$ & 0,075 & $2.182,37$ \\
\hline A2 Experiência do condutor & 10 & $-1.062,80$ & 0,091 & $2.145,60$ \\
\hline A3 Histórico de multas & 2 & $-1.094,49$ & 0,071 & $2.192,97$ \\
\hline A4 Construtos psicológicos & 4 & $-1.056,32$ & 0,101 & $2.120,64$ \\
\hline A5 Ambiente viário & 2 & $-1.090,87$ & 0,074 & $2.185,75$ \\
\hline B1 País & 2 & $-1.092,55$ & 0,072 & $2.189,10$ \\
\hline B2 Região & 2 & $-1.095,18$ & 0,070 & $2.194,35$ \\
\hline B3 Distrito & 3 & $-1.089,42$ & 0,074 & $2.184,85$ \\
\hline B4 Agregadas & \multicolumn{4}{|c|}{ Não houve parâmetros significativos } \\
\hline $\mathrm{C} 1(\mathrm{~A} 1, \mathrm{~A} 2, \mathrm{~A} 3)$ & 9 & $-1.069,67$ & 0,086 & $2.157,34$ \\
\hline $\mathrm{C} 2(\mathrm{C} 1, \mathrm{~A} 4, \mathrm{~A} 5)$ & 13 & $-1.025,79$ & 0,119 & $2.077,58$ \\
\hline $\mathrm{C} 3(\mathrm{C} 1, \mathrm{~A} 4, \mathrm{~A} 5, \mathrm{~B} 1)$ & \multicolumn{4}{|c|}{ Não houve parâmetros significativos } \\
\hline $\mathrm{C} 4(\mathrm{C} 1, \mathrm{~A} 4, \mathrm{~A} 5, \mathrm{~B} 2)$ & 13 & $-1.026,37$ & 0,119 & $2.078,73$ \\
\hline $\mathrm{C} 5(\mathrm{C} 1, \mathrm{~A} 4, \mathrm{~A} 5, \mathrm{~B} 3)$ & 15 & $-1.018,18$ & 0,124 & $2.066,36$ \\
\hline $\mathrm{C} 6(\mathrm{C} 1, \mathrm{~A} 4, \mathrm{~A} 5, \mathrm{~B} 4)$ & \multicolumn{4}{|c|}{ Não houve parâmetros significativos } \\
\hline $\mathrm{D}$ & 16 & $-1.015,94$ & 0,125 & $2.063,89$ \\
\hline
\end{tabular}

Nota: *Log de Verossimilhança Inicial: -1179,74

Na Tabela 7.12, são apresentados os valores dos parâmetros estimados para o modelo D, relativo ao comportamento "cansaço e sonolência".

Tabela 7.12 - Parâmetros estimados, relativos ao modelo D para o comportamento "Cansaço e Sonolência"

\begin{tabular}{|c|c|c|c|c|}
\hline Variável & Parâmetro & $\begin{array}{c}\text { Valor } \\
\text { estimado }\end{array}$ & Erro & p-valor \\
\hline Constante & $A S C$ & 0,782 & 0,285 & 0,006 \\
\hline 35-44 anos & $\beta_{\text {Age } 3}$ & $-0,458$ & 0,138 & 0,001 \\
\hline 45-54 anos & $\beta_{\text {Age } 4}$ & $-0,665$ & 0,169 & 0,000 \\
\hline $55-64$ anos & $\beta_{\text {Age } 5}$ & $-0,671$ & 0,214 & 0,002 \\
\hline$>65$ anos & $\beta_{\text {Age6 }}$ & $-1,490$ & 0,483 & 0,002 \\
\hline TC_0-5 anos & $\beta_{\text {CarDL1 }}$ & $-0,603$ & 0,139 & 0,000 \\
\hline 40-80 km/semana & $\beta_{k m 2}$ & 0,371 & 0,186 & 0,046 \\
\hline 80-120 km/semana & $\beta_{k m 4}$ & 0,728 & 0,188 & 0,000 \\
\hline 120-200 km/semana & $\beta_{k m 4}$ & 0,703 & 0,173 & 0,000 \\
\hline $200-300$ km/semana & $\beta_{k m 5}$ & 0,721 & 0,198 & 0,000 \\
\hline $300-500 \mathrm{~km} / \mathrm{semana}$ & $\beta_{k m 6}$ & 1,160 & 0,215 & 0,000 \\
\hline$>500$ km/semana & $\beta_{k m 7}$ & 0,860 & 0,251 & 0,001 \\
\hline Eu mesmo como condutor & $\beta_{D S 2}$ & $-1,620$ & 0,284 & 0,000 \\
\hline Busca de sensações & $\beta_{S S}$ & 1,130 & 0,299 & 0,000 \\
\hline Impedimento para prosseguir viagem & $\beta_{D A S 1}$ & 1,020 & 0,294 & 0,001 \\
\hline Paraná & $\beta_{U F P R}$ & $-0,736$ & 0,211 & 0,000 \\
\hline
\end{tabular}

Os parâmetros relacionados à idade a partir dos 35 anos indicam uma relação negativa, sendo que o valor do parâmetro aumenta a cada faixa etária. Desta forma, 
condutores mais velhos apresentam menor propensão a assumir esse comportamento de risco.

Com relação à experiência de condução, os condutores de até 5 anos de carteira de habilitação apresentam uma relação negativa. Assim, este fato indica que os condutores menos experientes tendem a não assumir esse comportamento de risco. Ao observar os parâmetros relacionados à quilometragem percorrida semanalmente, nota-se que, a partir dos 40 quilômetros, todas as categorias são significativas e influenciam positivamente o comportamento de risco relacionado ao cansaço e sonolência quando assumem valor 1 , de forma que, quanto maior a quilometragem percorrida, maior o valor do parâmetro. Este fato confirma a importância da distância percorrida para o condutor assumir o risco de conduzir cansado ou com sono, com mais frequência.

O parâmetro relacionado à autopercepção como condutor indica uma relação negativa e forte com a maior frequência de comportamentos de risco. Este fato indica que quanto mais hábil o condutor se considera, menor a propensão de que ele assuma 0 comportamento de risco "cansaço e sonolência" mais frequentemente.

O parâmetro positivo para a raiva devido ao impedimento de prosseguir viagem indica que os condutores que assumem mais frequentemente o risco de conduzir cansado e com sono, possivelmente, têm a preferência de não parar durante a viagem.

\subsubsection{Expressão de raiva do condutor}

Os modelos A2, A5, B2, B3 e C5 não apresentaram parâmetros significativos associados às variáveis independentes para o comportamento "expressão de raiva do condutor". Os modelos C6 e D obtiveram o melhor ajuste e contemplaram os mesmos parâmetros significativos. Nota-se que esta configuração apresenta o maior número de parâmetros, com os melhores valores para Log de Verossimilhança Final, Rhoquadrado-ajustado e o Critério de Informação de Akaike (Tabela 7.13). 
Tabela 7.13 - Medidas de estimação dos modelos do comportamento expressão de raiva do

\begin{tabular}{|c|c|c|c|c|}
\hline \multicolumn{5}{|c|}{ condutor } \\
\hline Modelo & $\begin{array}{l}\text { Número de } \\
\text { parâmetros } \\
\text { estimados }\end{array}$ & $\begin{array}{c}\log \\
\text { Verossimilhança } \\
\text { Final }\end{array}$ & $\begin{array}{l}\text { Rho- } \\
\text { quadrado- } \\
\text { ajustado }\end{array}$ & $\begin{array}{l}\text { Critério de } \\
\text { Informação } \\
\text { de Akaike }\end{array}$ \\
\hline A1 Socioeconômico & 2 & $-1.118,78$ & 0,050 & $2.241,56$ \\
\hline A2 Experiência do condutor & \multicolumn{4}{|c|}{ Não houve parâmetros significativos } \\
\hline A3 Histórico de multas & 2 & $-1.117,07$ & 0,051 & $2.238,14$ \\
\hline A4 Construtos psicológicos & 7 & $-1.050,07$ & 0,104 & $2.114,13$ \\
\hline A5 Ambiente viário & \multicolumn{4}{|c|}{ Não houve parâmetros significativos } \\
\hline B1 País & 2 & $-1.119,05$ & 0,050 & $2.242,10$ \\
\hline B2 Região & \multicolumn{4}{|c|}{ Não houve parâmetros significativos } \\
\hline B3 Distrito & \multicolumn{4}{|c|}{ Não houve parâmetros significativos } \\
\hline B4 Agregadas & 4 & $-1.113,02$ & 0,053 & $2.234,03$ \\
\hline $\mathrm{C} 1(\mathrm{~A} 1, \mathrm{~A} 2, \mathrm{~A} 3)$ & 3 & $-1.113,50$ & 0,054 & $2.233,00$ \\
\hline $\mathrm{C} 2(\mathrm{C} 1, \mathrm{~A} 4, \mathrm{~A} 5)$ & 8 & $-1.044,62$ & 0,108 & $2.105,24$ \\
\hline $\mathrm{C} 3(\mathrm{C} 1, \mathrm{~A} 4, \mathrm{~A} 5, \mathrm{~B} 1)$ & 9 & $-1.041,84$ & 0,109 & $2.101,67$ \\
\hline $\mathrm{C} 4(\mathrm{C} 1, \mathrm{~A} 4, \mathrm{~A} 5, \mathrm{~B} 2)$ & 9 & $-1.041,48$ & 0,110 & $2.100,95$ \\
\hline $\mathrm{C} 5(\mathrm{C} 1, \mathrm{~A} 4, \mathrm{~A} 5, \mathrm{~B} 3)$ & \multicolumn{4}{|c|}{ Não houve parâmetros significativos } \\
\hline $\mathrm{C} 6(\mathrm{C} 1, \mathrm{~A} 4, \mathrm{~A} 5, \mathrm{~B} 4)$ & 11 & $-1.036,99$ & 0,112 & $2.095,98$ \\
\hline D & 11 & $-1.036,99$ & 0,112 & $2.095,98$ \\
\hline
\end{tabular}

A Tabela 7.14 mostra os valores dos parâmetros significativos para o modelo C6, relativo ao comportamento de risco "expressão de raiva ao conduzir". Nota-se que no modelo de melhor ajuste não houve parâmetros significativos relacionados às variáveis socioeconômicas e experiência de condução.

Tabela 7.14 - Parâmetros estimados para o modelo C6, relativo ao comportamento

"Expressão de raiva do condutor"

\begin{tabular}{|c|c|c|c|c|}
\hline Variável & Parâmetro & Valor estimado & Erro & p-valor \\
\hline Constante & $A S C$ & $-3,210$ & 0,559 & 0,000 \\
\hline M_Outros & $\beta_{F_{-} \text {others }}$ & 0,512 & 0,181 & 0,005 \\
\hline Impedimento para prosseguir viagem & $\beta_{D A S 1}$ & 1,030 & 0,296 & 0,001 \\
\hline Demonstração direta de hostilidade do outro condutor & $\beta_{D A S 2}$ & 1,300 & 0,267 & 0,000 \\
\hline Imprudência de outros condutores & $\beta_{D A S 3}$ & 1,980 & 0,309 & 0,000 \\
\hline Ações que prejudicam a concentração e vigilância ao conduzir & $\beta_{\text {Risk } 1}$ & 1,210 & 0,486 & 0,013 \\
\hline Busca de sensações & $\beta_{S S}$ & 1,180 & 0,265 & 0,000 \\
\hline Habilidades dos demais condutores & $\beta_{D S 1}$ & $-1,200$ & 0,283 & 0,000 \\
\hline Frota $<65.610$ & $\beta_{\text {Fleet } 1}$ & $-0,475$ & 0,148 & 0,001 \\
\hline $65.610 \leq$ Frota $<164.554$ & $\beta_{\text {Fleet2 }}$ & $-0,413$ & 0,147 & 0,005 \\
\hline $164.554 \leq$ Frota $<319.753$ & $\beta_{\text {Fleet } 3}$ & $-0,367$ & 0,145 & 0,011 \\
\hline
\end{tabular}

Outras multas, que incluem o desrespeito ao rodizio de placa e conduzir na faixa de ônibus exclusiva, indicam uma relação positiva com o comportamento de expressar raiva no trânsito. 
Os parâmetros referentes às três variáveis latentes que representam o traço de personalidade "raiva do condutor" são significativos e positivos, e exercem forte influência para a maior frequência do comportamento de expressar raiva no trânsito. De forma semelhante, o traço de personalidade "busca de sensações" também apresenta uma relação forte e positiva com este comportamento de risco.

A relação entre a percepção das habilidades dos demais condutores e a maior frequência do comportamento de expressão de raiva é negativa. Este fato indica que quanto melhor a percepção do condutor em relação às habilidades dos outros condutores, menor a frequência em que expressa raiva no trânsito.

Nota-se que os parâmetros significativos para as variáveis relacionadas à frota veicular, quando assumem valor 1 , indicam uma relação negativa com os comportamentos mais frequentes e com maior envolvimento em acidentes, de forma que quanto menor a frota, maior é o valor do parâmetro. Assim, essa relação demonstra que o tamanho da frota influencia a expressão de raiva dos condutores, de forma que frotas maiores influenciam a maior frequência do comportamento de expressar raiva.

\subsection{Considerações do Capítulo 7}

De modo geral, ao analisar as métricas de ajuste dos modelos, verifica-se que os valores eram muito próximos. Entretanto, a inclusão das variáveis independentes, propostas neste trabalho, contribuiu para o melhor ajuste dos modelos, de modo a alcançar menores valores de Log de Verossimilhança Final e Critério de Informação de Akaike e melhores valores para Rho-quadrado-ajustado.

Além disso, de modo geral, as relações demonstradas entre os parâmetros estimados e as variáveis dependentes de cada modelo mostraram-se coerentes com relação à variável dependente e entre os modelos calibrados. Nota-se, também, que a coerência dos parâmetros significativos e as variáveis dependentes corroboram a classificação prévia do algoritmo de Árvore de Decisão, realizada na etapa anterior.

Ao considerar as relações entre os dados individuais dos condutores, do local de residência e do ambiente viário e os comportamentos de risco avaliados, pode-se verificar em relação ao conjunto de variáveis que: 
- As variáveis socioeconômicas apresentaram parâmetros significativos e coerentes na calibração dos modelos, destacando-se a predominância da relação entre a variável dependente idade, com os comportamentos de cansaço e sonolência e excesso de velocidade. Quanto mais velhos os condutores, e, possivelmente, mais experimentes, menor a possibilidade de adotarem esses comportamentos. Não se destacaram, neste trabalho, as variáveis relacionadas à renda, escolaridade e estado civil.

- As variáveis de experiência de condução referentes à distância percorrida semanalmente demonstraram relação com o comportamento de cansaço e sonolência, de forma que os parâmetros aumentaram o valor acompanhando o aumento da distância percorrida semanalmente.

- As variáveis relacionadas ao histórico de multas indicaram uma possível relação do perfil de condutores infratores e a maior propensão em assumir o risco de conduzir sob efeito de álcool.

- As variáveis relacionadas aos construtos psicológicos destacaram-se pela importância observada em todos os comportamentos, tanto em relação aos valores dos parâmetros, como no nível de significância.

- Destaca-se a importância do construto "busca de sensações", que se mostrou significativo para quase todos os comportamentos, salvo comportamento "erros", demonstrando relações fortes e coerentes onde destaca-se o valor alto para o parâmetro do comportamento "excesso de velocidade".

- A escala de habilidades de condução, que foi adaptada para este estudo, demonstrou resultados coerentes e foram fortemente associadas aos comportamentos "erros", "excesso de velocidade", "cansaço e sonolência" e "expressão de raiva ao conduzir". Destaca-se a relação negativa entre a percepção das habilidades dos outros condutores e o comportamento de expressão de raiva ao conduzir.

- As relações apresentadas pelas variáveis relacionadas à percepção de risco também possibilitaram verificar a importância acerca da consciência dos riscos para que os comportamentos sejam menos frequentes. Destaca-se a relação apresentada entre a variável "tarefas secundárias ao conduzir", em que a maior percepção desse risco contribuiu fortemente para redução da frequência do comportamento de uso do celular, e a percepção de comportamentos perigosos 
que também demonstrou relação forte e negativa com "excesso de velocidade" e "conduzir sob efeito de álcool". A relação apresentada entre a percepção de risco de ações que prejudicam a concentração e vigilância ao conduzir e o comportamento "erros" necessita de maior investigação.

- As variáveis latentes relacionadas à dimensão referente à "raiva", ou seja, ao perfil agressivo do condutor, mostraram-se fortemente relacionadas com quase todos os comportamentos. Destaca-se a coerência entre a escala psicológica e a de comportamento de expressão de raiva ao conduzir, onde os parâmetros das três variáveis latentes foram significativos e positivos.

- As variáveis de "caracterização do ambiente" mostraram-se fortemente relacionadas ao comportamento de uso do celular enquanto conduz, onde três dos quatro parâmetros associados às variáveis latentes do ambiente viário foram significativos. A relação com os comportamentos "erros" e "não usar o cinto de segurança" também foram coerentes.

- Com relação às variáveis de localização, foi possível identificar as diferenças entre os locais estudados, no âmbito país, para os comportamentos de "excesso de velocidade" e "não uso do cinto de segurança". No âmbito de região, observaram-se diferenças para o "uso de celular no modo viva voz" enquanto conduz. No âmbito de estado ou distrito, foram verificadas diferenças para os comportamentos "erros", "conduzir sob efeito de álcool" e "cansaço e sonolência".

- O parâmetro da variável agregada de baixa densidade populacional foi significativo e positivo para o comportamento "conduzir sob efeito de álcool", e da variável frota foi negativo para "expressão de raiva do condutor", demonstrando coerência em ambas as relações.

Dessa forma, verifica-se que as variáveis socioeconômicas, experiência de condução e construtos psicológicos, amplamente exploradas em outros estudos, demonstram relações com diferentes comportamentos de risco, com parâmetros significativos e coerentes. Especificamente com relação às variáveis de caracterização do ambiente e localização propostas para este estudo, além do que já foi apresentado, verifica-se que:

- As dimensões de caracterização do ambiente viário resultaram em parâmetros coerentes e significativos que contribuíram para melhorar o ajuste dos modelos. 
Entretanto, a dimensão de rodovias com defeitos no pavimento não foi significativa em nenhum modelo.

- O parâmetro associado à variável "país" se mostrou significativa para diferenciar os comportamentos de "excesso de velocidade" e "não usar o cinto de segurança", que se mostraram estritamente relacionados. $O$ excesso de velocidade positivo e fortemente associado ao país Portugal pode ser justificado pela infraestrutura viária do país. Corroborando esta afirmação, o parâmetro de rodovias confortáveis foi positivo e significativo no modelo que considerava apenas as variáveis do ambiente (A5).

- A diferença entre os países também pôde ser observada pelos parâmetros associados às variáveis que caracterizam as regiões e estados, sendo que os resultados foram coerentes com as diferenças identificadas no âmbito do país em outros modelos diferentes daqueles de melhor ajuste.

- O comportamento "uso de celular no modo viva voz ao conduzir" foi o que demonstrou maior influência das variáveis de localização e caracterização do ambiente viário. O comportamento "excesso de velocidade" demonstrou forte relação com as variáveis de localização e o comportamento "erros" com as variáveis de caracterização do ambiente. Quanto às variáveis agregadas, destaca-se a relação do comportamento "expressão de raiva ao conduzir" e o tamanho das frotas.

Dessa forma, foi possível identificar as diferenças entre os países e verificar que, além das variáveis relacionadas ao condutor, as variáveis de caracterização do ambiente viário e de localização contribuíram para compreender o comportamento de risco do condutor, especificamente com maior impacto para os comportamentos "uso de celular", "excesso de velocidade", "erros" e "expressão de raiva ao conduzir".

A Tabela 7.15 apresenta um resumo dos parâmetros significativos dos modelos de melhor ajuste e as relações encontradas nos demais modelos calibrados. 
Tabela 7.15 - Relação entre os parâmetros significativos dos modelos

\begin{tabular}{|c|c|c|c|c|c|c|c|}
\hline Descrição & $\stackrel{\mathscr{2}}{\stackrel{2}{W}}$ & 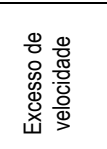 & 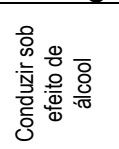 & 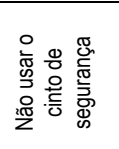 & 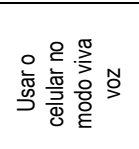 & 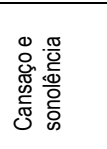 & 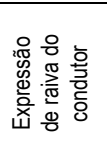 \\
\hline \multicolumn{8}{|c|}{ Sociodemográficas } \\
\hline Homem & $-0,272$ & $(+)$ & $(+)$ & $(-)$ & $(-)$ & $(+)$ & \\
\hline Solteiro & & & 0,231 & & & & \\
\hline 18-24 anos & & & & & $(-)$ & $(-)$ & \\
\hline $35-44$ anos & & & & $(+)$ & & $-0,458$ & \\
\hline 45-54 anos & & $-0,457$ & & $(+)$ & & $-0,665$ & \\
\hline 55-64 anos & & $-0,722$ & & $(+)$ & & $-0,671$ & $(-)$ \\
\hline$>65$ anos & & $-1,080$ & & & & $-1,490$ & \\
\hline Filhos & 0,320 & & & & & & \\
\hline Ensino médio incompleto & & & & $(-)$ & & & \\
\hline Sem renda & & & & & $(-)$ & & \\
\hline$>20$ S.M. & $-0,694$ & & 0,593 & & & & \\
\hline \multicolumn{8}{|c|}{ Experiência de condutor } \\
\hline 40-80 km/semana & & & & & & 0,371 & \\
\hline $80-120 \mathrm{~km} / \mathrm{semana}$ & & $(+)$ & & & $(+)$ & 0,728 & \\
\hline $120-200 \mathrm{~km} / \mathrm{semana}$ & & $(+)$ & & $(-)$ & 0,441 & 0,703 & \\
\hline $200-300 \mathrm{~km} / \mathrm{semana}$ & & 0,414 & & $-0,450$ & 0,533 & 0,721 & \\
\hline $300-500 \mathrm{~km} / \mathrm{semana}$ & $(-)$ & $(+)$ & & & $(+)$ & 1,160 & \\
\hline$>500 \mathrm{~km} / \mathrm{semana}$ & & $(+)$ & & & 0,676 & 0,860 & \\
\hline TC_0-5 anos & & & & $(+)$ & $(-)$ & $-0,603$ & \\
\hline TC_15-30 anos & $-0,242$ & $(-)$ & & $(+)$ & & $(-)$ & \\
\hline TC_30-45 anos & & $(-)$ & & $(+)$ & & $(-)$ & \\
\hline \multicolumn{8}{|c|}{ Multas } \\
\hline M_Álcool & & & 2,330 & & $(+)$ & & \\
\hline M_Celular & $(+)$ & & & & & & \\
\hline M_Estacionar & & & 0,444 & $-0,431$ & & & \\
\hline M_Velocidade & & 0,703 & 0,473 & $-0,402$ & & $(+)$ & \\
\hline M_Outros & & & & & & & 0,512 \\
\hline \multicolumn{8}{|c|}{ Construtos psicológicos } \\
\hline Eu mesmo como condutor & $-1,950$ & $-0,825$ & & & & $-1,620$ & \\
\hline Habilidades dos demais condutores & & & & & & & $-1,200$ \\
\hline Busca de sensações & & 3,380 & 1,130 & $-1,740$ & 1,010 & 1,130 & 1,180 \\
\hline $\begin{array}{l}\text { Ações que prejudicam a concentração e vigilância ao } \\
\text { conduzir }\end{array}$ & 0,940 & 1,770 & & $-2,670$ & $(+)$ & & 1,210 \\
\hline Tarefas secundárias ao conduzir & & $(-)$ & & $(+)$ & $-2,740$ & & \\
\hline Comportamentos perigosos & & $-5,390$ & $-1,380$ & 2,460 & & & \\
\hline $\begin{array}{l}\text { Demonstração direta de hostilidade do outro } \\
\text { condutor }\end{array}$ & 0,774 & 0,843 & 0,649 & $-0,893$ & & $(+)$ & 1,300 \\
\hline Impedimento para prosseguir viagem & 1,470 & & & $(-)$ & 0,954 & 1,020 & 1,030 \\
\hline Imprudência de outros condutores & & & & & & & 1,980 \\
\hline \multicolumn{8}{|c|}{ Ambiente viário } \\
\hline Áreas urbanas com edificações altas & \multicolumn{3}{|c|}{$(-)$} & & 1,420 & & \\
\hline Elementos urbanos & $-0,667$ & & $(-)$ & & 1,510 & $(-)$ & \\
\hline Rodovias confortáveis & $-0,652$ & $(+)$ & & $-0,715$ & 1,430 & & \\
\hline & & & & & & & Continua \\
\hline
\end{tabular}




\begin{tabular}{|c|c|c|c|c|c|c|c|}
\hline \multicolumn{8}{|l|}{ Continuação } \\
\hline Descrição & 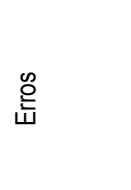 & 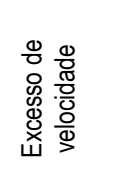 & 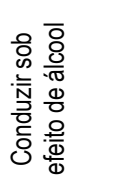 & 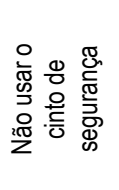 & 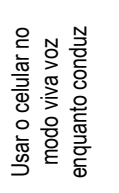 & 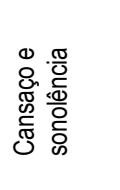 & 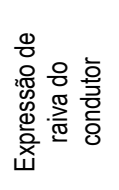 \\
\hline \multicolumn{8}{|c|}{ País } \\
\hline Portugal & & 1,100 & $(-)$ & $-0,726$ & $(+)$ & $(+)$ & $(-)$ \\
\hline \multicolumn{8}{|c|}{ Regiões } \\
\hline BR_Centro-oeste & & & & & & $(-)$ & \\
\hline BR_Nordeste & & $(-)$ & $(-)$ & $(+)$ & 0,965 & & $(+)$ \\
\hline BR_Norte & & & & & $(-)$ & & \\
\hline PT_Alentejo & & & & & $(+)$ & & \\
\hline PT_Centro & & $(+)$ & & & 0,694 & $(+)$ & \\
\hline PT_Lisboa & & $(+)$ & & & $(+)$ & & \\
\hline PT_Norte & & $(+)$ & & $(-)$ & 0,621 & & \\
\hline \multicolumn{8}{|c|}{ Estados/Distritos } \\
\hline PT_Aveiro & & & & & $(+)$ & & \\
\hline BR_Bahia & & $(-)$ & & $(+)$ & & & \\
\hline PT_Castelo branco & & & & & $(+)$ & & \\
\hline PT_Coimbra & 2,640 & & & & & & \\
\hline PT_Leiria & & & & & $(+)$ & $(+)$ & \\
\hline PT_Lisboa & & $(+)$ & & & $(+)$ & & \\
\hline BR_Mato Grosso & & & & $(-)$ & & & \\
\hline BR_Minas Gerais & 0,416 & & & & & & \\
\hline BR_Paraíba & & & & & $(+)$ & & \\
\hline BR_Paraná & & & & & & $-0,736$ & \\
\hline BR_Pernambuco & & $(-)$ & $(-)$ & & $(+)$ & & \\
\hline BR_Piauí & & & & $(-)$ & & & \\
\hline PT_Porto & & $(+)$ & & $(-)$ & $(+)$ & & \\
\hline BR_Santa Catarina & & & 0,782 & & & & \\
\hline PT_Setúbal & & & & & $(+)$ & & \\
\hline PT_Vila Real & & & & & $(+)$ & & \\
\hline \multicolumn{8}{|c|}{ Agregadas } \\
\hline $\mathrm{IM}<0,58$ & & & $(+)$ & $(-)$ & & & \\
\hline Frota $<65.610$ & & & & & & & $-0,475$ \\
\hline $65.610 \leq$ Frota $<164.554$ & & & & & & & $-0,413$ \\
\hline $164.554 \leq$ Frota $<319.753$ & & & & & & & $-0,367$ \\
\hline $319.753 \leq$ Frota $<902.025$ & & & & & $(+)$ & & \\
\hline Den Pop < 149,72 & & & 0,374 & & $(-)$ & & \\
\hline $988,5 \leq$ Den Pop< 4.386,67 & & $(+)$ & & & & & \\
\hline PIB_reg $<74.546 .785$ & & $(+)$ & & & $(+)$ & & \\
\hline $74.546 .785 \leq$ PIB_reg $<220.618 .604$ & & $(+)$ & & & & & \\
\hline
\end{tabular}

Nota: Os sinais (+) e (-) corresponderam às relações identificadas e não contempladas nos modelos de melhor ajuste

Em seguida, o Quadro 7.2 apresenta uma síntese das relações encontradas para os sete comportamentos analisados. 
Quadro 7.2 - Resumo das relações significativas identificadas

\begin{tabular}{|c|c|c|}
\hline $\begin{array}{l}\text { Comportamentos de } \\
\text { risco }\end{array}$ & Relações positivas & Relações negativas \\
\hline Erros & $\begin{array}{l}\text { Filhos } \\
\text { Ações que prejudicam a concentração e vigilância ao } \\
\text { conduzir (PR) } \\
\text { Demonstração direta de hostilidade } \\
\text { Impedimento para prosseguir viagem (R) } \\
\text { PT-Coimbra } \\
\text { BR-Minas Gerais }\end{array}$ & $\begin{array}{l}\text { Homem } \\
\text { Renda alta (> } 20 \text { S. M.) } \\
15 \text { a } 30 \text { anos de experiência } \\
\text { Eu mesmo como condutor } \\
\text { Elementos urbanos } \\
\text { Rodovias confortáveis }\end{array}$ \\
\hline Excesso de velocidade & $\begin{array}{l}200-300 \text { km semanal } \\
\text { Multa por velocidade } \\
\text { Busca de sensações } \\
\text { Ações que prejudicam a concentração e vigilância ao } \\
\text { conduzir (PR) } \\
\text { Demonstração direta de hostilidade (R) } \\
\text { Portugal }\end{array}$ & $\begin{array}{l}\text { Maiores de } 45 \text { anos } \\
\text { Eu mesmo como condutor } \\
\text { Comportamentos perigosos (PR) }\end{array}$ \\
\hline $\begin{array}{l}\text { Conduzir sob efeito de } \\
\text { álcool }\end{array}$ & $\begin{array}{l}\text { Solteiro } \\
\text { Renda alta (>20 S. M.) } \\
\text { Multa por álcool } \\
\text { Multa por estacionamento } \\
\text { Multa por velocidade } \\
\text { Busca de sensações } \\
\text { Demonstração direta de hostilidade }(\mathrm{R}) \\
\text { BR-Santa Catarina } \\
\text { Densidade populacional baixa }(<149,72)\end{array}$ & Comportamentos perigosos (PR) \\
\hline $\begin{array}{l}\text { Não usar o cinto de } \\
\text { segurança }\end{array}$ & Comportamentos perigosos (PR) & $\begin{array}{l}200-300 \text { km semanal } \\
\text { Multa por estacionamento } \\
\text { Multa por velocidade } \\
\text { Busca de sensações } \\
\text { Ações que prejudicam a concentração e vigilância ao } \\
\text { conduzir (PR) } \\
\text { Demonstração direta de hostilidade (R) } \\
\text { Rodovias confortáveis } \\
\text { Portugal }\end{array}$ \\
\hline $\begin{array}{l}\text { Usar o celular no modo } \\
\text { viva voz }\end{array}$ & $\begin{array}{l}120-300 \mathrm{~km} \text { semanal } \\
\text { Mais de } 500 \mathrm{~km} \text { semanal } \\
\text { Busca de sensações } \\
\text { Impedimento para prosseguir viagem (R) } \\
\text { Áreas urbanas como edificações altas } \\
\text { Elementos urbanos } \\
\text { Rodovias confortáveis } \\
\text { BR-Centro Oeste } \\
\text { PT-Centro } \\
\text { PT-Norte }\end{array}$ & Tarefas secundárias ao conduzir (PR) \\
\hline Cansaço e sonolência & $\begin{array}{l}\text { Km percorrida semanalmente } \\
\text { Busca de sensações } \\
\text { Impedimento para prosseguir viagem }(R)\end{array}$ & $\begin{array}{l}\text { Maiores de } 35 \text { anos } \\
\text { Tempo de condução (até } 5 \text { anos) } \\
\text { Eu mesmo como condutor } \\
\text { BR-Paraná }\end{array}$ \\
\hline $\begin{array}{l}\text { Expressão de raiva do } \\
\text { condutor }\end{array}$ & $\begin{array}{l}\text { Multa por outros motivos } \\
\text { Busca de sensações } \\
\text { Ações que prejudicam a concentração e vigilância ao } \\
\text { conduzir (PR) } \\
\text { Demonstração direta de hostilidade }(R) \\
\text { Impedimento para prosseguir viagem }(R) \\
\text { Imprudência de outros condutores }(R)\end{array}$ & $\begin{array}{l}\text { Habilidades dos demais condutores } \\
\text { Frota veicular }\end{array}$ \\
\hline
\end{tabular}

Nota: (PR) Percepção de risco; (R) Raiva; BR: Brasil; PT: Portugal; S.M.: Salário Mínimo 


\section{CONSIDERAÇÕES FINAIS}

Neste capítulo, apresenta-se, inicialmente, uma síntese do trabalho. Em seguida, são respondidas as questões de pesquisa e corroboradas as hipóteses levantadas no início desse texto. Finalmente, são descritas as conclusões gerais, limitações do trabalho e recomendações para trabalhos futuros.

\subsection{Síntese do trabalho}

Os acidentes de trânsito são eventos aleatórios e raros. Entretanto, os fatores humanos estão entre as principais causas que influenciam a sua ocorrência. Desta forma, compreender melhor o fator humano pode contribuir para redução de acidentes evitáveis. Com isso, este trabalho foi desenvolvido com a principal finalidade de investigar a relação entre diferentes variáveis e comportamentos de risco de condutores do Brasil e Portugal.

Para o desenvolvimento da pesquisa, algumas lacunas foram exploradas. Primeiramente, o uso de uma técnica exploratória adequada a dados ordinais para identificação das variáveis latentes e validação do questionário, o qual foi elaborado para obtenção de dados acerca do comportamento de risco do condutor. Assim, o questionário contempla fatores já investigados em outros estudos, como variáveis socioeconômicas, experiência de condução, traços de personalidade e o próprio comportamento de risco, além de outras questões elaboradas para investigação do ambiente viário, percepção de risco e frequência de comportamentos arriscados dos condutores de Brasil e Portugal.

Em virtude do uso da escala Likert nas questões (dados ordinais) e das restrições apresentadas pelas técnicas exploratórias usualmente utilizadas, neste trabalho utilizou-se a Análise de Componentes Principais Categórica (CATPCA) para identificação de variáveis latentes e validação do questionário. Os resultados permitiram confirmar a estrutura dos questionários já existentes e identificar variáveis latentes de caracterização do ambiente viário e comportamentos de risco coerentes e satisfatórios.

A segunda lacuna consistiu em definir níveis de risco para os comportamentos identificados, anteriormente, com a CATPCA. Assim, foi possível classificar os comportamentos de acordo com a frequência dos acidentes e variáveis latentes, 
permitindo identificar o grupo de condutores com maior risco de envolvimento em acidentes e maior frequência em determinado comportamento de risco, através do algoritmo Classification and Regression Tree (CART) de Árvore de Decisão. A classificação resultou em padrões de comportamentos coerentes, classificados em dois nós terminais, com menor e maior frequência de envolvimento em acidentes de trânsito e menor ou maior frequência de atitudes de risco ao conduzir. Tal classificação dos comportamentos foi a variável categórica, utilizada na modelagem paramétrica posterior.

A terceira lacuna consistiu em uma contribuição metodológica para avaliar as diferenças, em determinados comportamentos de risco, entre Brasil e Portugal, a partir de parâmetros estimados nos modelos Logit Binomiais. Através dos modelos calibrados, foi possível estimar relações entre grupos de variáveis e os sete comportamentos classificados. Entre os estudos realizados de comparação dos comportamentos de risco em diferentes países, o uso de um único banco de dados e modelo para tratar de ambas as populações é incomum. Neste trabalho, se propôs avaliar a diferença entre os países a partir da inclusão da variável dummy "país" nos modelos, bem como a inclusão de outros níveis de divisão geográfica, especificamente os níveis regional e estadual/distrital. Os resultados indicaram parâmetros significativos para variável "país" nos modelos de melhor ajuste dos comportamentos "excesso de velocidade" e "não uso do cinto de segurança". Entretanto, nos modelos com melhor ajuste dos demais comportamentos, os outros níveis de divisão geográfica também foram significativos.

Dessa forma, a partir da (1) elaboração do questionário, do (2) tratamento das variáveis latentes com a técnica adequada aos dados ordinais, da (3) classificação dos comportamentos de risco de acordo com a frequência de envolvimento em acidentes e variáveis latentes e da (4) calibração dos modelos para investigar os fatores que influenciam os comportamentos de risco, foi possível atender à principal finalidade deste trabalho e propor um procedimento sequencial metodológico, constituindo contribuição acadêmica.

Assim, a análise das relações entre as variáveis do indivíduo, do ambiente viário e do local de residência, e os diferentes comportamentos de risco assumidos, foi realizada por meio dos modelos Logit Binomiais, a partir de dados auto relatados e dados agregados, obtidos em fonte de dados secundários. Os resultados demonstraram que 
a caracterização do ambiente viário, segundo o relato dos condutores, e os dados agregados da localização são significativos para explicar a frequência dos comportamentos de risco dos condutores do Brasil e Portugal.

\subsection{Respostas às questões de pesquisa e análise das hipóteses}

Este trabalho de doutorado foi desenvolvido sob a motivação de quatro perguntas de pesquisa e suas respectivas hipóteses. Após aplicação do método proposto, foi possível responder às questões motivadoras, bem como corroborar as hipóteses de pesquisa levantadas.

- Questão específica I. A aplicação da Análise de Componentes Principais Categórica corrobora a determinação de variáveis latentes e validação de questionários para investigação do comportamento do condutor?

Os resultados alcançados com a Análise de Componentes Principais Categórica permitiram confirmar as variáveis latentes dos questionários já validados (busca de sensações e escala de raiva do condutor), bem como dos itens adaptados para investigação da habilidade do condutor e dos itens elaborados para este estudo (caracterização do ambiente, comportamento de risco específico e percepção de risco). Além disso, os resultados são coerentes com a literatura e com o esperado para este trabalho, atendendo aos critérios de interpretação das dimensões, confiabilidade da escala e variância explicada.

Dessa forma, em virtude dos resultados alcançados, considera-se que a hipótese I "O uso da técnica de Análise de Componentes Principais Categórica corrobora a definição das variáveis latentes e validade do questionário para investigação dos comportamentos de risco dos condutores" foi confirmada.

- Questão específica II. A classificação do comportamento do condutor de acordo com variáveis latentes e a frequência de envolvimento em acidentes de trânsito permite identificar padrões de risco?

Com o uso do algoritmo CART de Árvore de Decisão, foram classificados comportamentos de risco, segundo variáveis latentes, obtidas com a CATPCA, e frequência de envolvimento em acidentes de trânsito. Assim, tornou-se possível identificar padrões de risco de forma que, condutores que mais frequentemente 
adotam o comportamento de risco estiveram mais frequentemente envolvidos em acidentes de trânsito, salvo para o comportamento "não usar o cinto de segurança". Este comportamento manifestou a condição contrária, entretanto, mostrou-se coerente em relação à severidade do acidente. Além disso, a classificação possibilitou delimitar valores limites para a frequência de cada comportamento.

Assim, a partir dos resultados alcançados, a hipótese II - " Os comportamentos de risco do condutor podem ser classificados em níveis de risco de acordo com as variáveis latentes e a frequência de envolvimento em acidentes de trânsito relatado" foi confirmada.

- Questão específica III. Os parâmetros estimados indicam diferenças significativas entre Brasil e Portugal para os comportamentos de risco?

A partir dos modelos analisados, foi possível verificar que a propensão em adotar um comportamento de risco pode se diferenciar entre Brasil e Portugal. Entre os modelos referentes aos comportamentos "excesso de velocidade" e "não usar o cinto de segurança", os parâmetros estimados indicam que Portugal tende a, mais frequentemente, exceder a velocidade, levando-se em conta um valor positivo e elevado do parâmetro associado à variável "País" (0: Brasil; 1: Portugal) e nível de significância de $99 \%$. A diferença é coerente e pode ser justificada pela influência da qualidade da infraestrutura do país, que se manifestou como significante nos demais modelos calibrados. De forma contrária, o país Portugal possui uma relação negativa em relação ao comportamento "não usar o cinto de segurança". Nota-se que a diferença entre os países também se manifestou nos níveis regional e estadual/distrital. O uso do celular no modo viva voz enquanto conduz mostrou-se positivamente relacionado aos condutores da região Nordeste do Brasil e Centro e Norte de Portugal. Os comportamentos "erros", "conduzir sob efeito de álcool" e "cansaço e sonolência" mostraram-se significativos no nível estadual/distrital. Já o comportamento "expressão de raiva ao conduzir" manifestou diferenças em relação à localização, por meio dos parâmetros estimados para variável agregada "frota veicular".

Dessa forma, verifica-se que a Hipótese específica III -"Os parâmetros estimados indicam diferenças significativas entre Brasil e Portugal para os comportamentos de risco" - foi corroborada, ressaltando-se que essa diferença, entre países, é fortemente 
observada para o comportamento "excesso de velocidade" e "não uso de cinto de segurança". Para os demais comportamentos, verificaram-se diferenças no âmbito regional e estadual/distrital.

Finalmente, a questão geral desta tese de doutorado indagava:

- Quais variáveis relativas ao condutor, local de residência e ambiente viário influenciam os comportamentos de risco de condutores de Brasil e Portugal?

A partir da observação dos parâmetros estimados, associados às variáveis "socioeconômicas", "experiência de condução", "traços de personalidade" e "habilidades de condução", foi possível verificar valores e relações coerentes, destacando-se:

(1) Idade e os comportamentos "excesso de velocidade" e "não usar o cinto de segurança";

(2) Aumento da distância percorrida semanalmente e o comportamento "conduzir cansado e com sono";

(3) Maior ocorrência de multas, caracterizando o perfil de infrator dos condutores, e o comportamento "conduzir sob efeito de álcool";

(4) Habilidades de condução e o comportamento "erros", "excesso de velocidade", "cansaço e sonolência" e "expressão de raiva ao conduzir";

(5) Traços de personalidade, em específico "a busca de sensações", mostrou-se não relacionada apenas ao comportamento "erros", fazendo-se estatisticamente significativa, com valores altos estimados, para os demais comportamentos;

(6) Traços de personalidade, caracterizados como "raiva", estiveram presentes em todos os comportamentos, representando a agressividade do condutor, destacando-se os parâmetros significativos das três dimensões para o comportamento de expressão de raiva ao conduzir;

(7) A percepção de risco foi significativa e coerente para as relações entre a percepção de tarefas secundárias ao conduzir e o comportamento "uso do celular" e a percepção de comportamentos perigosos e os comportamentos "exceder a velocidade", "conduzir sob efeito de álcool" e "não uso do cinto de segurança". Contudo, maiores investigações são necessárias para melhor compreensão da relação entre a dimensão "ações que prejudicam a 
concentração e vigilância ao conduzir" e o comportamento "erros" e "expressão de raiva do condutor".

Os parâmetros das variáveis de caracterização do ambiente viário mostraram-se fortemente e estaticamente significativos para o comportamento "uso do celular no modo viva voz". A relação positiva demonstrou que as características do ambiente viário podem determinar oportunidades para que o condutor utilize o celular enquanto conduz. A relação também foi coerente para o comportamento "erros", demonstrando a importância da existência de infraestrutura (sinalizações e dispositivos) e a qualidade (pavimento e densidade da via) para diminuir a frequência desse comportamento. As variáveis de localização permitiram identificar diferenças entre os dois países, destacando-se a relação positiva de Portugal com o comportamento de excesso de velocidade, que se justifica pela relação com a qualidade da infraestrutura e, de forma consequente, a relação negativa com o não uso do cinto de segurança. Entre os três níveis de divisão geográfica avaliados, os parâmetros foram coerentes quanto aos sinais e resultados dos diferentes modelos calibrados para análise. Quanto aos dados agregados, referente à localização, nota-se a importância da relação do tamanho da frota e o comportamento "expressão de raiva do condutor", caracterizando a relação de estresse gerada pelo trânsito no condutor.

A partir dos resultados apresentados, pode-se concluir que os "Parâmetros relacionados à caracterização do ambiente viário e a localização contribuem para explicar os comportamentos de risco", confirmando a hipótese apresentada.

\subsection{Conclusões e propostas de intervenções mitigadoras}

Dentre as principais conclusões deste trabalho, está a sua contribuição acadêmica acerca do método proposto. Este trabalho apresentou um procedimento metodológico que pode ser replicado em outros trabalhos no intuito de: i) classificar comportamentos de risco, ii) analisar diferenças comportamentais no âmbito regional, distrital e nacional e iii) detectar influências de características individuais no comportamento de risco.

Ainda sob o ponto de vista de contribuição metodológica, este trabalho apresentou uma sequência de procedimentos no intuito de representar o ambiente viário por meio de dados obtidos com questionários, classificá-lo através de construtos e incluí-lo, como variável independente, em modelos para análise de comportamentos de risco. 
Para obtenção das variáveis latentes, este trabalho apresentou uma técnica de agrupamento de variáveis e redução de dados voltada para variáveis não quantitativas. Os resultados mostraram adequabilidade da técnica aos dados qualitativos ordinais. Desta forma, constitui uma contribuição importante, não somente para área comportamental e segurança viária, na qual encontram-se frequentemente questionários em escala Likert, como também para qualquer área do conhecimento, onde haja necessidade de extração de construtos e validação de questionários para dados qualitativos.

Finalmente, com a classificação dos comportamentos de risco, aqui proposta, foi possível assumir que indivíduos com comportamentos frequentemente arriscados tendem a, historicamente, se envolver, com maior frequência, em acidentes de trânsito. A técnica utilizada (algoritmo CART) viabilizou a obtenção de grupos de comportamentos de maneira elucidativa. Ainda, pode-se atribuir à aplicação do algoritmo a obtenção de valores limítrofes de frequência de comportamento e número de envolvimentos em acidentes de trânsito para composição dos grupos.

A abordagem, apresentada neste trabalho, proporcionou informações que podem contribuir para tomada de decisão dos gestores de trânsito, no âmbito de medidas para redução da ocorrência dos acidentes evitáveis, por meio da redução da frequência dos comportamentos de risco. A partir dos resultados apresentados para amostra desse estudo, pode-se sugerir que campanhas específicas para cada comportamento sejam vinculadas, iniciando pelos locais prioritários e atendendo às características identificadas, tais como as condições sugeridas a seguir:

- O comportamento de uso de celular no modo viva voz se mostrou mais relacionado a diferenças regionais e locais, expressas pelos parâmetros significativos de diferentes regiões e caracterização do ambiente viário. Essas relações demonstram a necessidade de implementar ações direcionadas e condizentes com a realidade no âmbito local, priorizando, dentre as regiões contempladas neste estudo, a região Nordeste do Brasil, e Centro e Norte de Portugal. Entre as medidas a serem adotadas, pode-se investir na promoção da conscientização dos condutores em relação aos perigos associados à execução de tarefas secundárias ao conduzir, uma vez que os condutores mais conscientes desse risco tendem a, menos frequentemente, adotar esse comportamento. 
- O comportamento de erros destacou-se entre os condutores de Coimbra e Minas Gerais, de modo que estes podem ser locais prioritários para avaliação da necessidade de possíveis adequações que promovam um ambiente viário com melhores infraestruturas visto que, vias urbanas sinalizadas e com dispositivos viários e rodovias confortáveis mostraram-se fortemente relacionadas à redução de erros no trânsito.

- O comportamento "conduzir sob efeito de álcool", mostrou-se relacionado ao perfil infrator dos condutores. Entretanto, a consciência de riscos associados a comportamentos perigosos contribui para menor frequência de adotar este comportamento. Com isso, sugere-se como possível intervenção o envio de informações acerca dos riscos associados a conduzir sob efeito de álcool, juntamente com as notificações de infração, como medida de conscientização direcionada aos condutores infratores.

- O comportamento "excesso de velocidade" está fortemente relacionado a condutores de Portugal. Visto que a percepção de risco de comportamentos perigosos contribui para reduzir a maior frequência deste comportamento, uma alternativa seria promover campanhas nacionais enfatizando os perigos associados ao excesso de velocidade e medidas de direção defensiva. Em virtude da forte relação apresentada com o comportamento de não usar o cinto de segurança, seria de grande importância contemplar informações acerca da importância do uso desse dispositivo de segurança como proteção quanto à severidade, mas não da ocorrência do acidente de trânsito.

- Em virtude da relação encontrada entre a expressão de raiva do condutor e o tamanho das frotas, sugere-se a promoção de campanhas educativas incentivando a busca de rotas com menos veículos, ou saída em horários alternativos para o trabalho, buscando a redução de estresse e raiva ocasionados pelo trânsito.

- Devido à relação identificada entre a distância percorrida semanalmente e a adoção mais frequente do comportamento de conduzir com sono e cansado e, o perfil da não preferência por parar durante uma viagem, poderiam ser promovidas campanhas em postos rodoviários de abastecimentos sobre a importância da pausa para descanso considerando a quilometragem percorrida. 
Dessa forma, essas são algumas medidas que poderiam ser adotadas a partir dos resultados obtidos para a amostra deste estudo. Nota-se que os resultados se mostraram coerentes e com potencial em contribuir como fonte de informações para apoiar a tomada de decisões dos gestores, no âmbito de ações para redução de acidentes evitáveis voltadas ao fator humano, considerando as características locais em que está inserido e o impacto no comportamento de risco em questão.

\subsubsection{Limitações}

A coleta de dados para este trabalho de doutorado foi realizada por meio de divulgação do questionário em diferentes mídias e meios de comunicação. Dessa forma, a amostra é constituída de condutores que se dispuseram a participar voluntariamente do estudo. Os participantes não foram selecionados por meio de um critério estatístico, configurando uma amostra não probabilística, em que os resultados não podem ser extrapolados para a população. A distribuição das categorias sexo, renda e escolaridade não correspondem à realidade dos países, entretanto, cabe ressaltar que a faixa etária com maior número de participantes corresponde à maior parcela de vítimas dos acidentes de trânsito e feridos fatalmente.

Os dados utilizados neste trabalho foram avaliados sob os critérios de confiabilidade da escala, contudo, como característica inerente aos dados auto relatados, as frequências reportadas pelos condutores podem não refletir totalmente a realidade dos comportamentos e atitudes, podendo ser afetadas pela própria falha de percepção, dificuldade em lembrar de fatos específicos ou respostas socialmente desejáveis.

O uso do indicador Alfa de Cronbach, para análise de confiabilidade da escala Likert na etapa de desenvolvimento do questionário, auxiliou na identificação dos itens que necessitavam de intervenção. Entretanto, por ser um indicador baseado em variância e covariância, os resultados devem ser avaliados com cautela, devido às restrições da escala Likert (dado ordinal). A partir da aplicação da CATPCA, em que são atribuídos valores métricos aos dados, os valores do Alfa de Cronbach podem ser considerados sem restrições.

Este trabalho apresenta como restrição metodológica a não separação aleatória da amostra para calibração e validação dos modelos. 


\subsubsection{Recomendações}

Como resultado deste trabalho, recomenda-se para estudos futuros que:

- A variável frota seja introduzida nos modelos, segregada por tipo de veículo, para avaliar o impacto específico no comportamento de expressão de raiva, bem como se os diferentes tipos de veículos influenciam em outros comportamentos.

- O índice de Desenvolvimento Humano, que contempla educação, renda e longevidade, seja incluído no grupo de dados agregados para avaliação da relação com os comportamentos de risco de condutores do Brasil. Neste trabalho, não foi possível utilizá-lo devido à indisponibilidade do dado para o âmbito municipal de Portugal.

- Sejam investigadas as relações entre as dimensões da percepção de risco e a influência nos comportamentos, principalmente a dimensão referente a ações que prejudicam a concentração e vigilância ao conduzir.

- Outros modelos sejam avaliados, como Modelo de Escolha Integrada e Variável Latente (ICLV - Integrated Choice and Latent Variable Model) e o Mixed Logit para comparação das relações identificadas e desempenho dos modelos. 


\section{REFERÊNCIAS}

AF WÅHLBERG, A. E.; BARRACLOUGH, P.; FREEMAN, J. The Driver behaviour questionnaire as accident predictor; a methodological re-meta-analysis. Journal of Safety Research, v. 55, p. 185-212, 2015.

ALFERES, V. R. Investigação científica em psicologia: teoria e prática. Coimbra: Almedina, 1997.

AL REESI, H.; AL MANIRI, A.; PLANKERMANN, K.; AL HINAI, M.; AL ADAWI, S.; DAVEY, J.; FREEMAN, J. Risky driving behavior among university students and staff in the sultanate of Oman. Accident Analysis and Prevention, v. 58, p. 1-9, 2013.

AL REESI, H.; FREEMAN, J.; DAVEY, J.; AL ADAWI, S.; AL MANIRI, A. Measuring risky driving behaviours among young drivers: development of a scale for the Oman setting. Transportation Research Part F: traffic psychology and behaviour, v. 55, p. 78-89, 2018.

ANTONOPOULOS, C. N.; GERMENI, E.; BACOPOULOU, F.; KALAMPOKI, V.; MALTEZOS, S.; SKALKIDIS, I.; DASKALOPOULOU, S.; NEGRI, E.; PETRIDOU, E. Assessing the impact of risk-taking behavior on road crash involvement among University students residing in two Mediterranean countries. Safety Science, v. 49, n. 6, p. 933-938, 2011.

AUTORIDADE DE SUPERVISÃO DE SEGUROS E FUNDOS DE PENSÕES. Parque de automóvel. 2017. Disponível em: https://www.asf.com.pt/NR/exeres/7D383D46-9431416E-98C7-395B0A9E7080.htm. Acesso em: 04 outubro 2018.

\section{AUTORIDADE NACIONAL DE SEGURANÇA RODOVIÁRIA. Anuário de segurança} rodoviária 2013. Barcarena: Ministério da Administração Interna; Autoridade Nacional Segurança Rodoviária, 2013.

AUTORIDADE NACIONAL DE SEGURANÇA RODOVIÁRIA. Estatísticas - relatórios de sinistralidade 2017. Barcarena: Ministério da Administração Interna; Autoridade Nacional Segurança Rodoviária, 2017.

BEN-AKIVA, M. E.; LERMAN, S. R. Discrete choice analysis: theory and application to travel demand. Cambridge: MIT, 1985.

BENER, A.; ÖZKAN, T.; LAJUNEN, T. The Driver behaviour questionnaire in Arab gulf countries: Qatar and United Arab Emirates. Accident Analysis and Prevention, v. 40, n. 4, p. 1411-1417, 2008.

BERDOULAT, E.; VAVASSORI, D.; SASTRE, M. T. M. Driving anger, emotional and instrumental aggressiveness, and impulsiveness in the prediction of aggressive and transgressive driving. Accident Analysis and Prevention, v. 50, p. 758-767, 2013.

BETH. Web server para trabalhos acadêmicos do departamento de engenharia de transportes da Escola de Engenharia de São Carlos da Universidade de São Paulo. 2019. Disponível em:https://beth.stt.eesc.usp.br/. 2019. Acesso em: 03 novembro 2019.

BIANCHI, A.; SUMMALA, H. Moral judgment and drivers' behavior among Brazilian students. Psychological Reports, v. 91, n. 3, p. 759-766, 2002.

BIANCHI, A.; SUMMALA, H. The "Genetics" of driving behavior: parents' driving style predicts their children's driving style. Accident Analysis and Prevention,

v. 36, n. 4, p. 655-659, 2004.

BIERLAIRE, M. PandasBiogeme: a short introduction. Lausanne: Transport and Mobility Laboratory, Ecole Polytechnique Fédérale de Lausanne, 2018. (Technical Report TRANSPOR 181219). 
BRASIL. (2008). Lei 11.705, de 19 de junho de 2008. Altera a Lei no 9.503, de 23 de setembro de 1997, que 'institui o Código de Trânsito Brasileiro', e a Lei no 9.294, de 15 de julho de 1996, que dispõe sobre as restrições ao uso e à propaganda de produtos fumígeros, bebidas alcoólicas, medicamentos, terapias e defensivos agrícolas, nos termos do $\S 40$ do art. 220 da Constituição Federal, para inibir o consumo de bebida alcoólica por condutor de veículo automotor, e dá outras providências. Diário Oficial da União, Brasília, DF, 20 jun. 2008. Disponível em:http://www.planalto.gov.br/ccivil_03/_ato20072010/2008/lei/l11705.htm>. Acesso em: 14 ago. 2019.

BREIMAN, L.; FRIEDMAN, J. H.; OLSHEN, R. A.; STONE, C. J. Classification and regression trees. Boca Raton: CRC Press, 1984.

CAMPBELL, K. L. The SHRP 2 naturalistic driving study: adressing driver performance and behavior in traffic safety. TR News, n. 282, p. 30-35, Sept./Oct., 2012. Disponível em:http://onlinepubs.trb.org/onlinepubs/trnews/trnews282SHRP2nds.pdf. Acesso em: 14 jul. 2017.

CANTINI, J. A.; SANTOS, G. O.; MACHADO, E. C.; NARDI, A. E.; SILVA, A. C. Translation and cross-cultural adaptation of the brazilian portuguese version of the driving anger scale (DAS): Long form and short form. Trends in Psychiatry and Psychotherapy, v. 37, n. 1, p. 42-46, 2015.

CESTAC, J.; PARAN, F.; DELHOMME, P. Young drivers' sensation seeking, subjective norms, and perceived behavioral control and their roles in predicting speeding intention: How risk-taking motivations evolve with gender and driving experience. Safety Science, v. 49, n. 3, p. 424-432, 2011.

CHICA-OLMO, J.; GACHS-SÁNCHEZ, H.; LIZARRAGA, C. Route effect on the perception of public transport services quality. Transport Policy, v. 67, p. 40-48, 2018.

CHU, W.; WU, C.; ATOMBO, C.; ZHANG, H.; ÖZKAN, T. Traffic climate, driver behaviour, and accidents involvement in China. Accident Analysis and Prevention, v. 122, p. 119126, 2019.

CHUNG, Y.; SONG, T. J. Safety analysis of motorcycle crashes in Seoul metropolitan area, South Korea: an application of nonlinear optimal scaling methods. International Journal of Environmental Research and Public Health, v. 15, n. 12, p. 2702, 2018.

CONFEDERAÇÃO NACIONAL DO TRANSPORTE. Pesquisa CNT de rodovias 2019: relatório gerencial. Brasília: CNT; SEST; SENAT, 2019.

CONSTANTINOU, E.; PANAYIOTOU, G.; KONSTANTINOU, N.; LOUTSIOU-LADD, A.; KAPARDIS, A. Risky and aggressive driving in young adults: personality matters. Accident Analysis and Prevention, v. 43, n. 4, p. 1323-1331, 2011.

CORDAZZO, S. T.; SCIALFA, C. T.; ROSS, R. J. Modernization of the driver behaviour questionnaire. Accident Analysis and Prevention, v. 87, p. 83-91, 2016.

CORDAZZO, S. T.; SCIALFA, C. T.; BUBRIC, K.; ROSS, R. J. The Driver behaviour questionnaire: a North American analysis. Journal of Safety Research, v. 50, p. 99-107, 2014.

CORTINA, J. M. What is coefficient alpha? An Examination of theory and applications. Journal of Applied Psychology, v. 78, p. 98-104, 1993.

DACOTA. Speed and speed management, deliverable $4.8 \mathrm{~s}$ of the EC FP7 project

DaCoTA. 2012. Disponível

em:https://safetyknowsys.swov.nl/Safety_issues/pdf/Speed\%20and\%20Speed\%20Managem ent.pdf. Acesso em: 20 nov. 2019. 
DAHLEN, E. R.; MARTIN, R. C.; RAGAN, K.; KUHLMAN, M. M. Driving anger, sensation seeking, impulsiveness, and boredom proneness in the prediction of unsafe driving.

Accident Analysis and Prevention, v. 37, n. 2, p. 341-348, 2005.

DATASUS. Sistema de informações sobre mortalidade - SIM óbitos por causas externas - Brasil. 2016. Disponível em:http://tabnet.datasus.gov.br/cgi/tabcgi.exe?sim/cnv/ext10uf.def. Acesso em: 11 mar. 2016.

DEFFENBACHER, J. L.; OETTING, E. R.; LYNCH, R. S. Development of a driving anger scale. Psychological Reports, v. 74, n. 1, p. 83-91, 1994.

DEFFENBACHER, J. L.; STEPHENS, A. N.; SULLMAN, M. J. M. Driving anger as a psychological construct: twenty years of research using the driving anger scale.

Transportation research part F: traffic psychology and behaviour, v. 42, p. 236-247, 2016.

DEFFENBACHER, J. L.; LYNCH, R. S.; OETTING, E. R.; YINGLING, D. A. Driving anger: correlates and a test of state-trait theory. Personality and Individual Differences, v. 31, n. 8, p. 1321-1331, 2001.

DELHOMME, P. Comparing one's driving with others': assessment of abilities and frequency of offences. Evidence for a superior conformity of self-bias?. Accident Analysis and Prevention, v. 6, p. 493-508, 1991.

DELHOMME, P.; CHAURAND, N.; PARAN, F. Personality predictors of speeding in young drivers: anger vs. sensation seeking. Transportation Research Part F: traffic psychology and behavior, v. 15, p. 654-666, 2012.

DELHOMME, P.; DOBBELEER, W.; FORWARD, S.; SIMÕES, A. (Ed.). Manual for designing, implementing and evaluating road safety communication campaigns. Brussels: Belgian Road Safety Institute (IBSR-BIVV); CAST Project (Campaigns and Awareness Raising Strategies in Traffic Safety); European Commission, 2009.

DEPARTAMENTO NACIONAL DE TRÂNSITO. Frota de veículos. 2016. Disponível em:http://www.denatran.gov.br/frota.htm. Acesso em: 14 mar. 2016.

DEPARTAMENTO NACIONAL DE TRÂNSITO. Frota de veículos. 2017. Disponível em:http://www.denatran.gov.br/index.php/estatistica/237-frota-veiculos. Acesso em: 02 março 2018.

DE WINTER, J. C. F.; DODOU, D. The Driver behaviour questionnaire as a predictor of accidents: a meta-analysis. Journal of Safety Research, v. 41, n. 6, p. 463-470, 2010.

DE WINTER, J. C.; DODOU, D. National correlates of self-reported traffic violations across 41 countries. Personality and Individual Differences, v. 98, p. 145-152, 2016.

DONÁRIO, A.; SANTOS, R. Custo económico e social dos acidentes de viação em Portugal. Lisboa: Ediual, 2012.

DORN, L.; AF WÅHLBERG, A. E. Behavioural culpability for traffic accidents.

Transportation Research Part F: traffic psychology and behaviour, v. 60, p. 505-514, 2019.

DOURADO, J. F.; PEREIRA, A. T.; NOGUEIRA, V.; BASTOS SILVA, A. M. C.; SECO, A. J. M. Personality and driver behaviour questionnaire: correlational exploratory study. Transport Infrastructure and Systems. In: INTERNATIONAL CONGRESS ON TRANSPORT INFRASTRUCTURE AND SYSTEMS, 2017, Rome. Proceedings [...] Rome: AIIT, 2017a. p. 787-79.

DOURADO, J. F.; MARQUES, C.; PEREIRA, A. T.; NOGUEIRA, V.; MACEDO, A.; SILVA, A. B.; SECO, A. J. M. Further validation of the driver behaviour questionnaire-confirmatory factor analysis in a portuguese sample. European Psychiatry, v.41, p.S694, 2017b. 
DOWNING, A. J.; BAGULEY, C. J.; HILLS, B. L. Road safety in developing countries: an overview. In: THE NINETEENTH TRANSPORT, HIGHWAYS AND PLANNING SUMMER ANNUAL MEETING, 1991, Brighton. Proceedings [...] London: PTRC Education Research Services, 1991.

ELVIK, R.; HOYE, A.; VAA, T.; SORENSEN, M. The Handbook of road safety measures. $2^{\text {nd }}$ ed. London: Emerald, 2009.

FERRAZ, A. C. P.; RAIA JUNIOR, A. A.; BEZERRA, B. S.; BASTOS, J. T.; SILVA, K. C. R. Segurança viária. 2.ed. São Carlos: Suprema, 2012.

FIELD, A. Discovering statistics using SPSS. Thousand Oaks: Sage, 2009.

GONZÁLEZ-IGLESIAS, B.; GÓMEZ-FRAGUELA, J. A.; LUENGO-MARTÍN, M. Á. Driving anger and traffic violations: gender differences. Transportation Research Part F: traffic psychology and behaviour, v. 15, n. 4, p. 404-412, 2012.

GREENE, W. H. Econometric analysis. London: Pearson Education, 2003.

GUÉHO, L.; GRANIÉ, M. A.; ABRIC, J. C. French validation of a new version of the driver behavior questionnaire (DBQ) for drivers of all ages and level of experiences. Accident Analysis and Prevention, v. 63, p. 41-48, 2014.

GUIA do usuário do sistema principal do IBM SPSS statistics 24. São Paulo: IBM SPSS Statistics. 2016. Disponível em:https://usermanual.wiki/Document/IBMSPSSStatisticsCoreSystemUserGuide.287155791 /view. Acesso em: 06 março 2019.

GUJARATI, D. N.; PORTER, D. C. Econometria básica. 5.ed. Porto Alegre: Amgh, 2011. HAIR, J. F.; BLACK, W. C.; BABIN, B. J.; ANDERSON, R. E.; TATHAM, R. L. Análise multivariada de dados. Porto Alegre: Bookman, 2009.

HIGHWAY Capacity Manual. Washington, DC: Transportation Research Board of the National Academies, 2010.

HIGHWAY Safety Manual. Washington, DC: American Association of State Highway \& Transportation Officials, 2010.

HILL, M. M.; HILL, A. Investigação por questionário. Lisboa: Sílabo, 2008.

HUANG, H.; SONG, B.; XU, P.; ZENG, Q.; LEE, J.; ABDEL-ATY, M. Macro and micro models for zonal crash prediction with application in hot zones identification. Journal of Transport Geography, v. 54, p. 248-256, 2016.

INSTITUTO BRASILEIRO DE GEOGRAFICA E ESTATÍSTICA. 2019. Disponível em: https://sidra.ibge.gov.br/tabela/6579. Acesso em: 03 outubro 2018.

INSTITUTO DE PESQUISA ECONÔMICA APLICADA. Acidentes de trânsito nas rodovias federais brasileiras - caracterização, tendências e custos para a sociedade relatório de pesquisa. Brasília, 2015.

INSTITUTO NACIONAL DE ESTATÍSTICA. 2019. Disponível em: https://ine.pt/._Acesso em: 29 outubro 2018.

IVERSEN, H. Risk-taking attitudes and risky driving behaviour. Transportation Research Part F: traffic psychology and behaviour, v. 7, n. 3, p. 135-150, 2004.

IVERSEN, H.; RUNDMO, T. Personality, risky driving and accident involvement among Norwegian drivers. Personality and Individual Differences, v. 33, n. 8, p. 1251-1263, 2002.

IVERSEN, H.; RUNDMO, T. Attitudes towards traffic safety, driving behaviour and accident involvement among the Norwegian public. Ergonomics, v. 47, n. 5,

p. 555-572, 2004. 
JANSSEN, W.H. Seatbelt wearing and driving behavior: An instrumented-vehicle study. Accident Analysis and Prevention, v. 26, p. 249-261, 1994.

JONAH, B. A. Accident risk and risk-taking behaviour among young drivers. Accident Analysis and Prevention, v. 18, n. 4, p. 255-271, 1986.

KOMBA, D. D. Risk judgement, risk taking behaviour and road traffic accidents in Tanzania: geographical analysis. 2016. Doctoral Thesis - Norwegian University of Science and Technology, Trondheim, 2016.

KOPPEL, S.; STEPHENS, A. N.; BEDARD, M.; CHARLTON, J. L.; DARZINS, P.; DI STEFANO, M.; GAGNON, S.; GÉLINAS, I.; HUA, P.; MACLEAY, L.; MAN-SON-HING, M.; MAZER, B.; MYERS, A.; NAGLIE, G.; ODELL, M.; PORTER, M. M.; RAPOPORT, M. J.; STINCHCOMB, A.; TUOKKO, H.; VRKJLAN, B.; MAN-SON-HING, M. Self-reported violations, errors and lapses for older drivers: measuring the change in frequency of aberrant driving behaviours across five time-points. Accident Analysis and Prevention, v. 123, p. 132-139, 2019.

KURODA, M.; MORI, Y.; MASAYA, I.; SAKAKIHARA, M. Alternating least squares in nonlinear principal components. Wiley Interdisciplinary Reviews: computational statistics, v. 5 , n. 6 , p. $456-464,2013$.

LAJUNEN, T.; OZKAN, T. Self-reported instruments and methods. In: PORTER, B. E. (Ed.). Handbook of Traffic Psychology. Amsterdam: Elsevier, 2011. p. 43-59.

LAJUNEN, T.; PARKER, D.; SUMMALA, H. The Manchester driver behaviour questionnaire: a cross-cultural study. Accident Analysis and Prevention, v. 36,

n. 2, p. 231-238, 2004.

LAWTON, R.; PARKER, D.; MANSTEAD, A. S.; STRADLING, S. G. The Role of affect in predicting social behaviors: The case of road traffic violations. Journal of Applied Social Psychology, v. 27, n. 14, p. 1258-1276, 1997.

LINTING, M. Nonparametric inference in nonlinear principal components analysis: exploration and beyond. 2007. Doctoral Thesis. Data Theory Group, Department of Education, Faculty of Social and Behavioural Sciences, Leiden University, Leiden, 2007.

LINTING, M.; VAN DER KOOIJ, A. Nonlinear principal components analysis with CATPCA: a tutorial. Journal of Personality Assessment, v. 94, n. 1, p. 12-25, 2012.

LINTING, M.; MEULMAN, J. J.; GROENEN, P. J.; VAN DER KOOJJ, A. J. Nonlinear principal components analysis: introduction and application. Psychological Methods, v. 12, n. 3, p. 336-358, 2007.

LONCZAK, H. S.; NEIGHBORS, C.; DONOVAN, D. M. Predicting risky and angry driving as a function of gender. Accident Analysis and Prevention, v. 39, n. 3, p. 536-545, 2007.

LUCIDI, F.; MALLIA, L.; LAZURAS, L.; VIOLANI, C. Personality and attitudes as predictors of risky driving among older drivers. Accident Analysis and Prevention, v. 72, p. 318-324, 2014.

MADSEN, B. S. Data collection. In: MADSEN, B.S. Statistics for non-statisticians. $2^{\text {nd }}$. ed. Heidelberg: Springer, 2016. p. 1-13.

MANZI, G.; SAIBENE, G. Are they telling the truth? Revealing hidden traits of satisfaction with a public bike-sharing service. International Journal of Sustainable Transportation, $v$. 12, n. 4, p. 253-270, 2018.

MARÔCO, J. Análise de equações estruturais: fundamentos teóricos, software e aplicações. Perô Pinheiro: ReportNumber, 2014. 
MARTINUSSEN, L. M.; HAKAMIES-BLOMQVIST, L.; MØLLER, M.; ÖZKAN, T.; LAJUNEN, T. Age, gender, mileage and the DBQ: the validity of the driver behavior questionnaire in different driver groups. Accident Analysis and Prevention, v. 52, p. 228-236, 2013.

MASLAĆ, M.; ANTIĆ, B.; LIPOVAC, K.; PEŠIĆ, D.; MILUTINOVIĆ, N. Behaviours of drivers in Serbia: non-professional versus professional drivers. Transportation Research Part F: traffic psychology and behaviour, v. 52, p. 101-111, 2018.

MATTSSON, M.; LAJUNEN, T.; GORMLEY, M.; SUMMALA, H. Measurement invariance of the driver behavior questionnaire across samples of young drivers from Finland and Ireland. Accident Analysis and Prevention, v. 78, p. 185-200, 2015.

MEHDIZADEH, M.; SHARIAT-MOHAYMANY, A.; NORDFJAERN, T. Accident involvement among Iranian lorry drivers: direct and indirect effects of background variables and aberrant driving behaviour. Transportation Research Part F: traffic psychology and behaviour, $v$. 58, p. 39-55, 2018.

MEKONNEN, T. H.; TESFAYE, Y. A.; MOGES, H. G.; GEBREMEDIN, R. B. Factors associated with risky driving behaviors for road traffic crashes among professional car drivers in Bahirdar city, northwest Ethiopia, 2016: a cross-sectional study. Environmental Health and Preventive Medicine, v. 24, n. 1, p. 17, 2019.

MEULMAN, J. J.; VAN DER KOOIJ, A. J.; HEISER, W. J. Principal components analysis with nonlinear optimal scaling transformations for ordinal and nominal data. In: KAPLAN, D. (Ed.). The Sage Handbook of Quantitative Methodology for the Social Sciences. London: Sage, 2004. p. 49-72.

MINISTÉRIO DAS RELAÇÕES EXTERIORES. República Portuguesa. Disponível em: http://www.itamaraty.gov.br/pt-BR/ficha-pais/5672-republica-portuguesa. Acesso em: 12 ago. 2019.

MOHAMADI HEZAVEH, A.; NORDFJÆERN, T.; MAMDOOHI, A. R.; ŞIMŞEKOĞLU, Ö. Predictors of self-reported crashes among Iranian drivers: exploratory analysis of an extended driver behavior questionnaire. Promet -Traffic and Transportation, v. 30, n. 1, p. 35-43, 2018.

MOHAN, D.; TIWARI, G.; KHAYESI, M.; NAFUKHO, F. M. Road traffic injury prevention training manual. Geneva: World Health Organization, 2006.

NATIONAL HIGHWAY TRAFFIC SAFETY ADMINISTRATION. A Guide to understanding blood alcohol concentration and alcohol impairment. 2016. Disponível em:

https://www.nhtsa.gov/staticfiles/nti/pdf/809844-TheABCsOfBAC.pdf. Acesso em: 1 out. 2019.

NORMAN, L. G. Road traffic accidents: epidemiology, control and prevention. Geneva: World Health Organization, 1962.

OLTEDAL, S.; RUNDMO, T. The Effects of personality and gender on risky driving behaviour and accident involvement. Safety Science, v. 44, n. 7, p. 621-628, 2006.

OPTIMAL BINNING. IBM SPSS statisctics 24.0.0 help - data preparation option. 2019. Disponível

em:https://www.ibm.com/support/knowledgecenter/en/SSLVMB_24.0.0/spss/data_validation/ idh_idd_vars_panel.html. Acesso em: 4 out. 2019.

ORGANIZATION FOR ECONOMIC CO-OPERATION AND DEVELOPMENT/

INTERNATIONAL TRANSPORT FORUM. Road safety annual report 2015. Paris: OECD, 2015.

ÖZKAN, T.; LAJUNEN, T.; CHLIAOUTAKIS, J. EL; PARKER, D.; SUMMALA, H. Crosscultural differences in driving behaviours: a comparison of six countries. Transportation Research Part F: traffic psychology and behaviour, v. 9, n. 3, p. 227-242, 2006. 
PARKER, D.; LAJUNEN, T.; STRADLING, S. Attitudinal predictors of interpersonally aggressive violations on the road. Transportation Research Part F: traffic psychology and behaviour, v. 1, p. 11-24, 1998.

PARKER, D.; REASON, J. T.; MANSTEAD, A. S.; STRADLING, S. G. Driving errors, driving violations and accident involvement. Ergonomics, v. 38, n. 5, p. 1036-1048, 1995a.

PARKER, D.; WEST, R.; STRADLING, S.; MANSTEAD, A. S. Behavioural characteristics and involvement in different types of traffic accident. Accident Analysis and Prevention, $v$. 27, n. 4, p. 571-581, 1995b.

PEDEN, M.; SCURFIELD, R.; SLEET, D.; MOHAN, D.; HYDER, A. A.; JARAWAN, E.; MATHERS, C. World Report on Road Traffic Injury Prevention. Geneva: World Health Organization, 2004.

PINATTI, A. Avaliação do questionário sobre comportamento de motoristas: uma distinção entre erros e violações. 2007. Dissertação (Mestrado) - Faculdade de Filosofia, Ciências e Letras de Ribeirão Preto, Universidade de São Paulo, Ribeirão Preto, 2007.

POÇAS CORREIA, J.; CUNHA HORTA, M. D. P. Personalidade e comportamentos de risco de motoristas: diferenças entre sexos. Psicologia: teoria e prática, v. 16, n. 1, 2014.

PORDATA: base de dados Portugal contemporâneo. Estatísticas, gráficos e indicadores de municípios. 2019. Disponível em: https://www.pordata.pt/. Acesso em: 29 outubro 2018.

QUINLAN, J. R. Learning efficient classification procedures and their application to chess end games. In: MICHALSKI, R.S.; CARSONELL, J.G.; MITCHELL, T.M. (Ed.). Machine learning: an artificial intelligence approach. Heidelberg: Springer, 1983. p. $463-482$.

REASON, J.; MANSTEAD, A.; STRADLING, S.; BAXTER, J.; CAMPBELL, K. Errors and violations on the roads- a real distinction?. Ergonomics, v. 33, p. 1315-1332, 1990.

RHODES, N.; PIVIK, K. Age and gender differences in risky driving: the roles of positive affect and risk perception. Accident Analysis and Prevention, v. 43, n. 3, p. 923-931, 2011.

ROKACH, L.; MAIMON, O. Z. Data mining with decision trees: theory and applications. New Jersey: World Scientific, 2008. (Series in Machine Perception and Artificial Intelligence, 81).

ROMÃO, M. N. P. V. Fundamentos metodológicos para a elaboração de campanhas de segurança viária. 2015. Tese (Doutorado em Engenharia de Transportes) - Escola de Engenharia de São Carlos, Universidade de São Paulo, São Carlos, 2015.

RUDIN-BROWN, C.; JAMSON, S. Behavioural adaptation and road safety: theory, evidence and action. New York: CRC Press, 2013.

RUDIN-BROWN, C. M.; EDQUIST, J.; LENNÉ, M. G. Effects of driving experience and sensation-seeking on drivers' adaptation to road environment complexity. Safety Science, v. 62, p. 121-129, 2014.

SÂRBESCU, P.; STANOJEVIĆ, P.; JOVANOVIĆ, D. A Cross-cultural analysis of aggressive driving: evidence from Serbia and Romania. Transportation Research Part F: traffic psychology and behaviour, v. 24, p. 210-217, 2014.

SCHWAB, K. (Ed.). The Global competitiveness report 2019. Switzerland: World Economic Forum; Committed to Improve the State of the World, 2019.

SCHWEBEL, D. C.; SEVERSON, J.; BALL, K.K.; RIZZO, M. Individual difference factors in risky driving: the roles of anger/hostility, conscientiousness, and sensation-seeking.

Accident Analysis and Prevention, v. 38, p. 801-810, 2006. 
SCOTT-PARKER, B.; WATSON, B.; KING, M. J.; HYDE, M. K. A Further exploration of sensation seeking propensity, reward sensitivity, depression, anxiety, and the risky behaviour of young novice drivers in a structural equation model. Accident Analysis and Prevention, v. 50, p. 465-471, 2013.

SHINAR, D. Traffic safety and human behavior. London: Emerald, 2017.

ŞIMŞEKOĞLU, Ö.; NORDFJÆRN, T.; ZAVAREH, M. F.; HEZAVEH, A. M.; MAMDOOHI, A. R.; RUNDMO, T. Risk perceptions, fatalism and driver behaviors in Turkey and Iran. Safety Science, v. 59, p. 187-192, 2013.

SOUZA, A. C.; ALEXANDRE, N. M. C; GUIRARDELLO, E. B. Propriedades psicométricas na avaliação de instrumentos: avaliação da confiabilidade e da validade. Epidemiologia e Serviços de Saúde, v. 26, p. 649-659, 2017.

STANOJEVIĆ, P.; LAJUNEN, T.; JOVANOVIĆ, D.; SÂRBESCU, P.; KOSTADINOV, S. The Driver behaviour questionnaire in South-East Europe countries: Bulgaria, Romania and Serbia. Transportation Research Part F: traffic psychology and behaviour, v. 53, p. 24-33, 2018.

STEPHENS, A. N.; FITZHARRIS, M. Validation of the driver behaviour questionnaire in a representative sample of drivers in Australia. Accident Analysis and Prevention, v. 86, p. 186-198, 2016.

STEVENS, N. J.; SALMON, P. M.; WALKER, G. H.; STANTON, N. A. Human factors in land use planning and urban design: methods, practical guidance, and applications. New York: CRC Press, 2018.

TAO, D.; ZHANG, R.; QU, X. The Role of personality traits and driving experience in selfreported risky driving behaviors and accident risk among Chinese drivers. Accident Analysis and Prevention, v. 99, p. 228-235, 2017.

ULLEBERG, P.; RUNDMO, T. Personality, attitudes and risk perception as predictors of risky driving behaviour among young drivers. Safety Science, v. 41, n. 5, p. 427-443, 2003.

ÜZÜMCÜOĞLU, Y.; ÖZKAN, T.; LAJUNEN, T. The Relationships between cultural variables, law enforcements and driver behaviours across 37 nations. Transportation Research Part F: traffic psychology and behaviour, v. 58, p. 743-753, 2018.

VAHEDI, J.; SHARIAT MOHAYMANY, A.; TABIBI, Z.; MEHDIZADEH, M. Aberrant driving behaviour, risk involvement, and their related factors among taxi drivers. International Journal Of Environmental Research and Public Health, v. 15, n. 8, p. 1626, 2018.

VELLOSO, M. S.; JACQUES, M. A. P.; TORRES, C. V. Intenção do condutor em respeitar a velocidade limite: estudo de caso em Brasília. In: CONGRESSO NACIONAL DE PESQUISA EM TRANSPORTE DA ANPET, 30., 2016. Anais[...] Rio de Janeiro: ANPET, 2016. p.1346-1357.

VIEIRA, S. Como elaborar questionários. São Paulo: Atlas, 2009.

WAISELFISZ, J. J. Mapa da violência 2013: acidentes de trânsito e motocicletas. Rio de Janeiro: CEBELA, 2013.

WARNER, H. W.; ÖZKAN, T.; LAJUNEN, T.; TZAMALOUKA, G. Cross-cultural comparison of drivers' tendency to commit different aberrant driving behaviours. Transportation

Research Part F: traffic psychology and behaviour,v. 14, n. 5, p. 390-399, 2011.

WELLS-PARKER, E.; CEMINSKY, J.; HALLBERG, V.; SNOW, R. W.; DUNAWAY, G.; GUILING, S.; MARSHA, W.; ANDERSON, B. An Exploratory study of the relationship between road rage and crash experience in a representative sample of US drivers.

Accident Analysis and Prevention, v. 34, n. 3, p. 271-278, 2002. 
WICKENS, C. M.; MANN, R. E.; STODUTO, G.; BUTTERS, J. E.; IALOMITEANU, A.; SMART, R. G. Does gender moderate the relationship between driver aggression and its risk factors?. Accident Analysis and Prevention, v. 45, p. 10-18, 2012.

WILDE, G. J. S. Homeostasis drives behavioural adaptation. In: RUDIN-BROWN,C.; JAMSON, S.L. (Ed.). Behavioural adaptation and road safety: theory, evidence and action. New York: CRCPress, 2013. Cp.5, p. 61-86.

WORLD HEALTH ORGANIZATION. Road safety - alcohol (facts). 2004. Disponível em:https://www.who.int/violence injury_prevention/publications/road_traffic/world_report/alco hol_en.pdf. Acesso em: 2 nov. 2019.

WORLD HEALTH ORGANIZATION. Global status report on road safety 2015 . Library Cataloguing-in-Publication Data Global, 2015.

WORLD HEALTH ORGANIZATION. Global status report on road safety 2018. Geneva: World Health Organization, 2018. Licence: CC BYNC-SA 3.0 IGO.

YAGIL, D. Reasoned action and irrational motives: a prediction of drivers' intention to violate traffic laws. Journal of Applied Social Psychology, v. 31, n. 4, p. 720-740, 2001.

YANG, J.; DU, F.; QU, W.; GONG, Z.; SUN, X. Effects of personality on risky driving behavior and accident involvement for chinese drivers. Traffic Injury Prevention, v. 14, n.6, p. 565-571, 2013.

ZHANG, T.; CHAN, A. H.; ZHANG, W. Dimensions of driving anger and their relationships with aberrant driving. Accident Analysis and Prevention, v. 81, p. 124-133, 2015.

ZHANG, W.; ZHANG, X.; FENG, Z.; LIU, J.; ZHOU, M.; WANG, K. The Fitness-to-drive of shift-work taxi drivers with obstructive sleep apnea: an investigation of self-reported driver behavior and skill. Transportation Research Part F: traffic psychology and behaviour, v. 59 , p. 545-554, 2018. 



\section{APÊNDICE A - QUESTIONÁRIO VERSÃO BRASIL}

\section{TERMO DE CONSENTIMENTO LIVRE E ESCLARECIDO}

Você está sendo convidado a responder um questionário como parte da pesquisa de doutorado "Modelos para previsão de tomada de risco de motoristas usando dados individuais, do local e do ambiente viário", que avalia a atitude e comportamento do motorista e poderá contribuir para um trânsito mais seguro.

Este questionário é composto por 20 questões que abrangem: características sociodemográficas, histórico como motorista, o ambiente em que dirige e seu comportamento no trânsito. 0 tempo de resposta é de 15 minutos, em média, e sua participação é voluntária.

Para participar desta pesquisa, você precisa ser maior de 18 anos e possuir carteira de habilitação. Todas as respostas têm caráter anônimo e confidencial, cujo respondente não será identificado.

0 preenchimento deste questionário não oferece risco direto, porém considera-se a possibilidade de um risco subjetivo, pois algumas perguntas podem remeter à algum desconforto, relembrar sentimentos ou lembranças desagradáveis. Você poderá interromper sua participação a qualquer momento.

Esta pesquisa é vinculada ao Departamento de Engenharia de Transportes da Escola de Engenharia de São Carlos (EESC/USP) e foi aprovada pelo Comitê de Ética da Faculdade de Zootecnia e Engenharia de Alimentos (FZEA-USP), de acordo com os requisitos da Resolução CNS 466/12. Caso tenha alguma dúvida ou consideração sobre a ética da pesquisa, entre em contato com o Comitê de Ética da Faculdade de Zootecnia e Engenharia de Alimentos (FZEAUSP), pelo telefone (19) 3565-4299 ou pelo e-mail cepfzea@usp.br

Sou a pesquisadora responsável, meu nome é Cintia Isabel de Campos e poderei ser contatada pelo e-mail cintiacampos@usp.br, ou telefone (16) 3373-9601.

Todas as respostas têm caráter anônimo e confidencial, cujo respondente não será identificado

Concordo em participar

Não concordo em participar

Onde você mora?

País

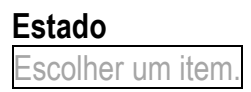

Cidade

Escolher um item.

Tema: Dados socioeconômicos e histórico como motorista

1. Idade

Escolher um item. anos

2.

Sexo
Feminino
Masculino

3.

Estado Civil

Solteiro(a)

Casado(a)/Amasiado(a)

Divorciado(a)

Viúvo(a)

4. Escolaridade

Ensino fundamental incompleto

Ensino fundamental completo

Ensino médio incompleto

Ensino médio completo

Ensino superior incompleto

Ensino superior completo

Pós-graduação incompleto

Pós-graduação completo

5. Renda (Salário líquido mensal)

Não possuo renda

Até um salário mínimo ( $\mathrm{R} \$ 937,00)$ 
Entre 1 e 2 salários mínimos $(R \$ 937,01$ - $R \$ 1874,00)$

Entre 2 e 3 salários mínimos (R\$1874,01 - R\$2811,00)

Entre 3 e 5 salários mínimos (R\$2811,01 - R\$ 4685,00)

Entre 5 e 10 salários mínimos ( $R \$ 4685,01$ - $R \$ 9370,00)$

Entre 10 e 20 salários mínimos (R\$ 9370,01 - R\$ 18740,00)

Mais de 20 salários mínimos (Mais de $\mathrm{R} \$ 18740,01$ )

6.

a) Quantos filhos você tem? Escolher um item.

7. b) Se tem filhos, qual a idade deles?

\begin{tabular}{ll}
\hline Idade do primeiro filho & Escolher um item. \\
Idade do segundo filho & Escolher um item. \\
Idade do terceiro filho & Escolher um item. \\
Idade do quarto filho & Escolher um item. \\
Idade do sexto filho & Escolher um item. \\
Idade do sétimo filho & Escolher um item. \\
Idade do oitavo filho & Escolher um item. \\
Idade do nono filho & Escolher um item. \\
Idade do décimo filho & Escolher um item. \\
\hline
\end{tabular}

8. Qual tipo de veículo você dirige? Para cada um, indique há quanto tempo você possui a Carteira Nacional de Habilitação (CNH)

\begin{tabular}{ll}
\hline Tipo de veículo & \multicolumn{1}{c}{ Tempo } \\
\hline Carro & Escolher um item. \\
Moto & Escolher um item. \\
Caminhão & Escolher um item. \\
Ônibus/Micro-ônibus & Escolher um item. \\
Reboque/Semirreboque & Escolher um item. \\
Outros, especifique & Escolher um item. \\
\hline
\end{tabular}

9. Quantos quilômetros você dirige semanalmente por veículo?

Considere a média de quilômetros percorridos em uma semana típica

\begin{tabular}{ll}
\hline Tipo de veículo & Quilômetros \\
\hline Carro & \\
Moto & \\
Caminhão & \\
Ônibus/Micro-ônibus & \\
Reboque/Semirreboque & \\
Outro & \\
\hline
\end{tabular}

10. A) Como motorista, quantas multas você teve nos últimos três anos enquanto dirigia um(a)...

\begin{tabular}{ll}
\hline \multicolumn{1}{c}{ Tipo de veículo } & \multicolumn{1}{c}{ Número de multas } \\
\hline Carro & Escolher um item. \\
Moto & Escolher um item. \\
Caminhão & Escolher um item. \\
Ônibus/Micro-ônibus & Escolher um item. \\
Reboque/Semirreboque & Escolher um item. \\
Outro & Escolher um item. \\
\hline
\end{tabular}

SE SUA RESPOSTA PARE PERGUNTA 10-A FOI "NENHUMA" EM TODAS AS OPÇÕES, PULE PARA PERGUNTA 11

$B$ ) Indique, para cada motivo, o número de multas que você teve nos últimos três anos

Excesso de velocidade

Álcool
Tipo de multa

Número de multas

Escolher um item.

Escolher um item. 


\begin{tabular}{ll}
\hline Uso de celular enquanto dirige & Escolher um item. \\
Não respeitar sinais de trânsito & Escolher um item. \\
Estacionar em local proibido & Escolher um item. \\
Irregularidade da Carteira Nacional de Habilitação $(\mathrm{CNH})$ & Escolher um item. \\
Outro, especifique & Escolher um item. \\
\hline
\end{tabular}

11. Considerando suas habilidades para dirigir e as dos demais motoristas responda, em uma escala de 1 (Discorda Totalmente) até 5 (Concorda Totalmente), se você concorda ou não com as afirmações abaixo

\begin{tabular}{lccccccc}
\hline & $\begin{array}{c}\text { Discordo } \\
\text { fortemente }\end{array}$ & $\mathbf{1}$ & $\mathbf{2}$ & $\mathbf{3}$ & $\mathbf{4}$ & $\mathbf{5}$ & Concordo fortemente \\
\hline Eu sou um ótimo motorista & & $\square$ & $\square$ & $\square$ & $\square$ & $\square$ & \\
Em geral, outras pessoas são ótimas motoristas & & $\square$ & $\square$ & $\square$ & $\square$ & $\square$ & \\
Eu dirijo muito cautelosamente & $\square$ & $\square$ & $\square$ & $\square$ & $\square$ \\
$\begin{array}{l}\text { Em geral, outras pessoas dirigem muito } \\
\text { cautelosamente }\end{array}$ & $\square$ & $\square$ & $\square$ & $\square$ & $\square$ \\
Meus reflexos enquanto dirijo são muito bons & & & & & & \\
Em geral, os reflexos das outras pessoas enquanto & & $\square$ & $\square$ & $\square$ & $\square$ & $\square$ \\
dirigem são muito bons & $\square$ & $\square$ & $\square$ & $\square$ & $\square$ \\
\hline
\end{tabular}

12. A) Quantas vezes você esteve envolvido em um acidente de trânsito como motorista nos últimos três anos?

Escolher um item. vez(es)

\section{SE SUA RESPOSTA FOI "NENHUMA”, PULE PARA PERGUNTA 13}

B) Qual foi a gravidade desse(s) acidente(s) de trânsito?

Considere a pior severidade de cada tipo de acidente que sofreu e indique o número de acidentes para cada severidade.

\begin{tabular}{ll}
\hline Gravidade & \multicolumn{1}{c}{ Número de acidentes } \\
\hline Danos materiais & Escolher um item. \\
Ferimentos leves & Escolher um item. \\
Ferimentos graves & Escolher um item. \\
Acidente com vítima fatal & Escolher um item. \\
\hline
\end{tabular}

\section{$20 \%$ Concluído}

Tema: Familiaridade com diferentes tipos de ambiente rodoviário

13. Considerando as ruas da cidade que você dirige, qual é a frequência que você dirige em ruas parecidas com as imagens abaixo? Avalie as imagens considerando a altura das construções e a largura das ruas em que dirige

Classifique a frequência em uma escala de 5 pontos, onde 1 é "Nunca" (Eu nunca dirijo em uma rua parecida) e 5 é "Muito frequentemente" (Eu muito frequentemente dirijo em uma rua parecida).

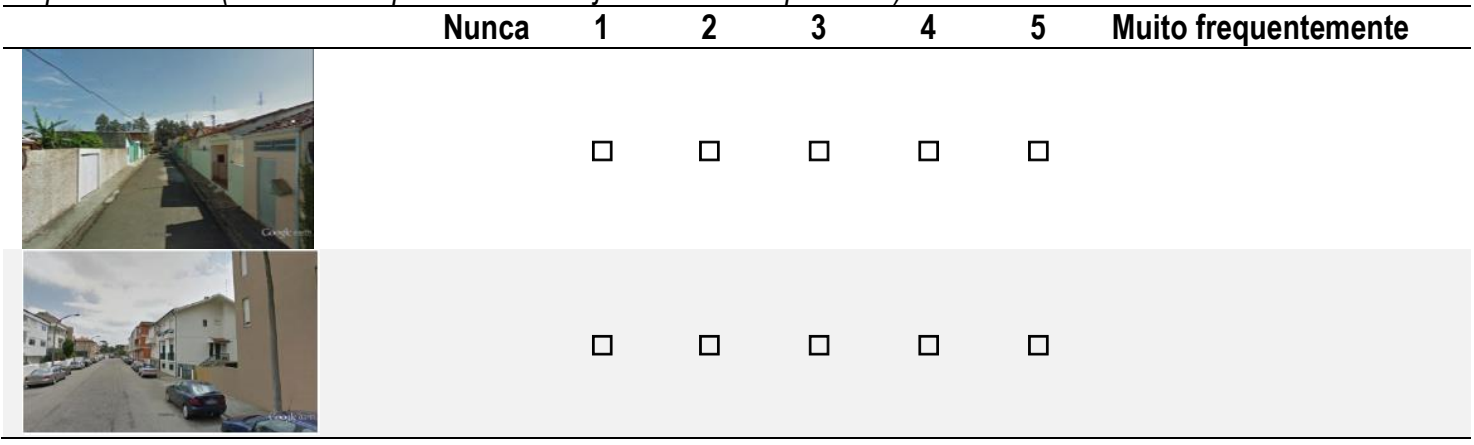




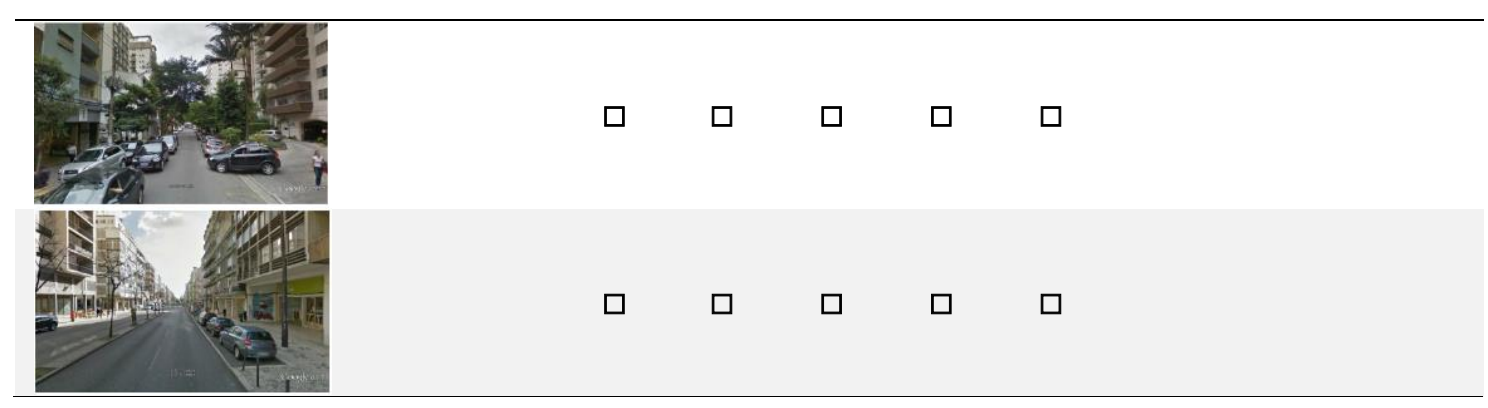

14. Qual é a frequência que os elementos rodoviários listados abaixo estão presentes nos caminhos que percorre?

Considere uma escala de 5 pontos, onde 1 é "Nunca" e 5 é "Muito frequentemente"

\begin{tabular}{|c|c|c|c|c|c|c|c|}
\hline & Nunca & 1 & 2 & 3 & 4 & 5 & Muito frequentemente \\
\hline Rotatória & & $\square$ & $\square$ & $\square$ & $\square$ & $\square$ & \\
\hline Faixa de pedestre & & $\square$ & $\square$ & $\square$ & 口 & $\square$ & \\
\hline Semáforo & & ㅁ & $\square$ & $\square$ & 口 & $\square$ & \\
\hline Lombada/Redutor de velocidade & & 口 & $\square$ & $\square$ & 口 & 口 & \\
\hline Sinalização vertical (placas de sinalização) & & 口 & $\square$ & $\square$ & 口 & 口 & \\
\hline Sinalização horizontal (pinturas nas ruas) & & 口 & $\square$ & $\square$ & 口 & 口 & \\
\hline Asfalto nas ruas & & $\square$ & $\square$ & $\square$ & $\square$ & $\square$ & \\
\hline Cruzamentos com sinalização & & $\square$ & $\square$ & $\square$ & 口 & $\square$ & \\
\hline
\end{tabular}

15. Qual é a frequência (em média) que você dirige em rodovias?

Responda essa questão em uma escala de 1 até 5 pontos. Considere 1 como "Nunca" e 5 como "Muito frequentemente"

\begin{tabular}{lllllll}
\hline Nunca & 1 & 2 & 3 & 4 & 5 & Muito frequentemente \\
\hline & $\square$ & $\square$ & $\square$ & $\square$ & $\square$ & \\
\hline
\end{tabular}

\section{SE SUA RESPOSTA PARA QUESTÃO 14 FOI "NUNCA" (1), PULE PARA QUESTÃO 16}

16. Qual é a frequência que você dirige em rodovias parecidas com as imagens abaixo?

a) Considere o número de veículos de cada imagem

Classifique a frequência em uma escala de 5 pontos, onde 1 é "Nunca" (Eu nunca dirijo em uma rodovia parecida) e 5 é "Muito frequentemente" (Eu muito frequentemente dirijo em uma rodovia parecida)

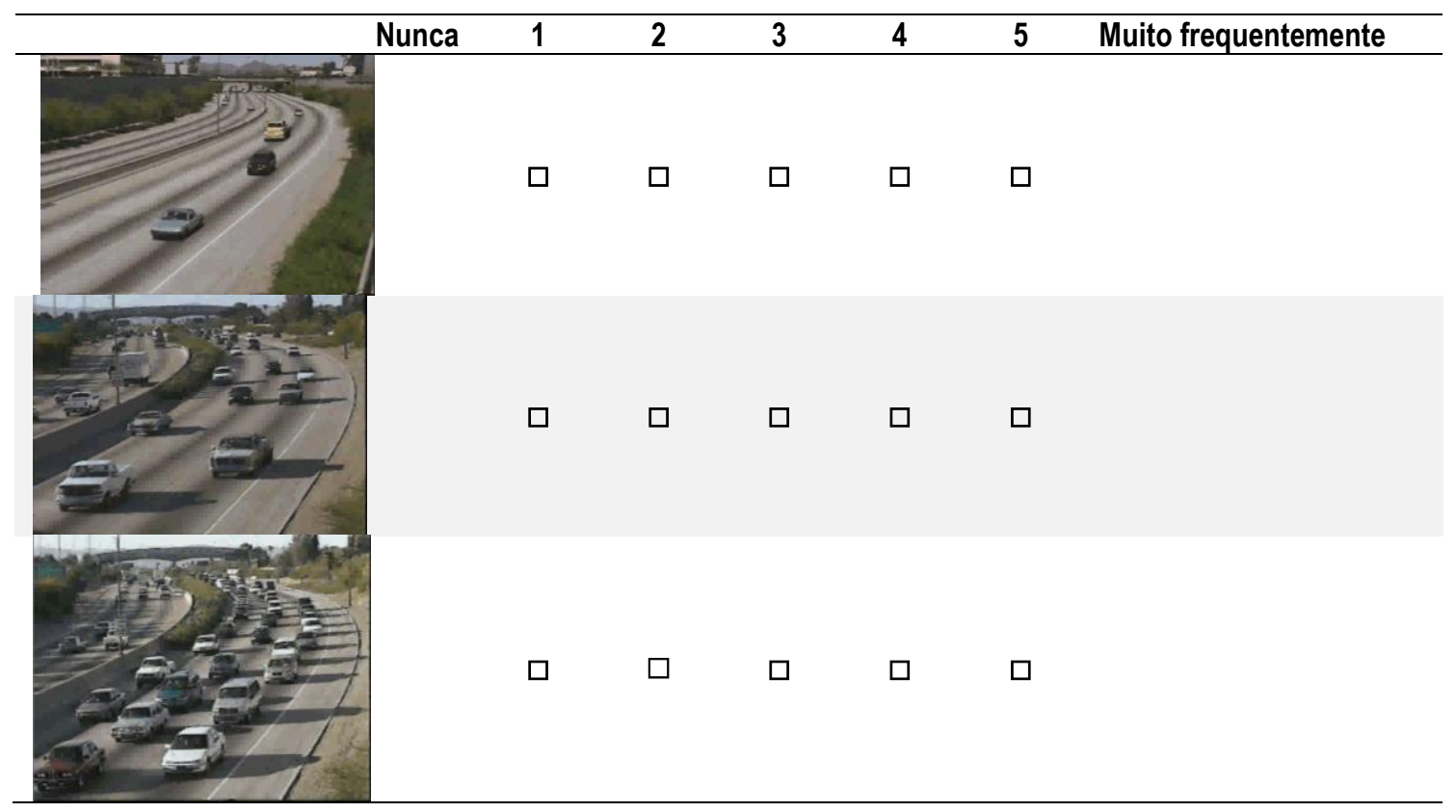

b) Considere a qualidade do pavimento (asfalto) de cada imagem 
Classifique a frequência em uma escala de 5 pontos, onde 1 é "Nunca" (Eu nunca dirijo em uma rodovia parecida) e 5 é "Muito frequentemente" (Eu muito frequentemente dirijo em uma rodovia parecida)

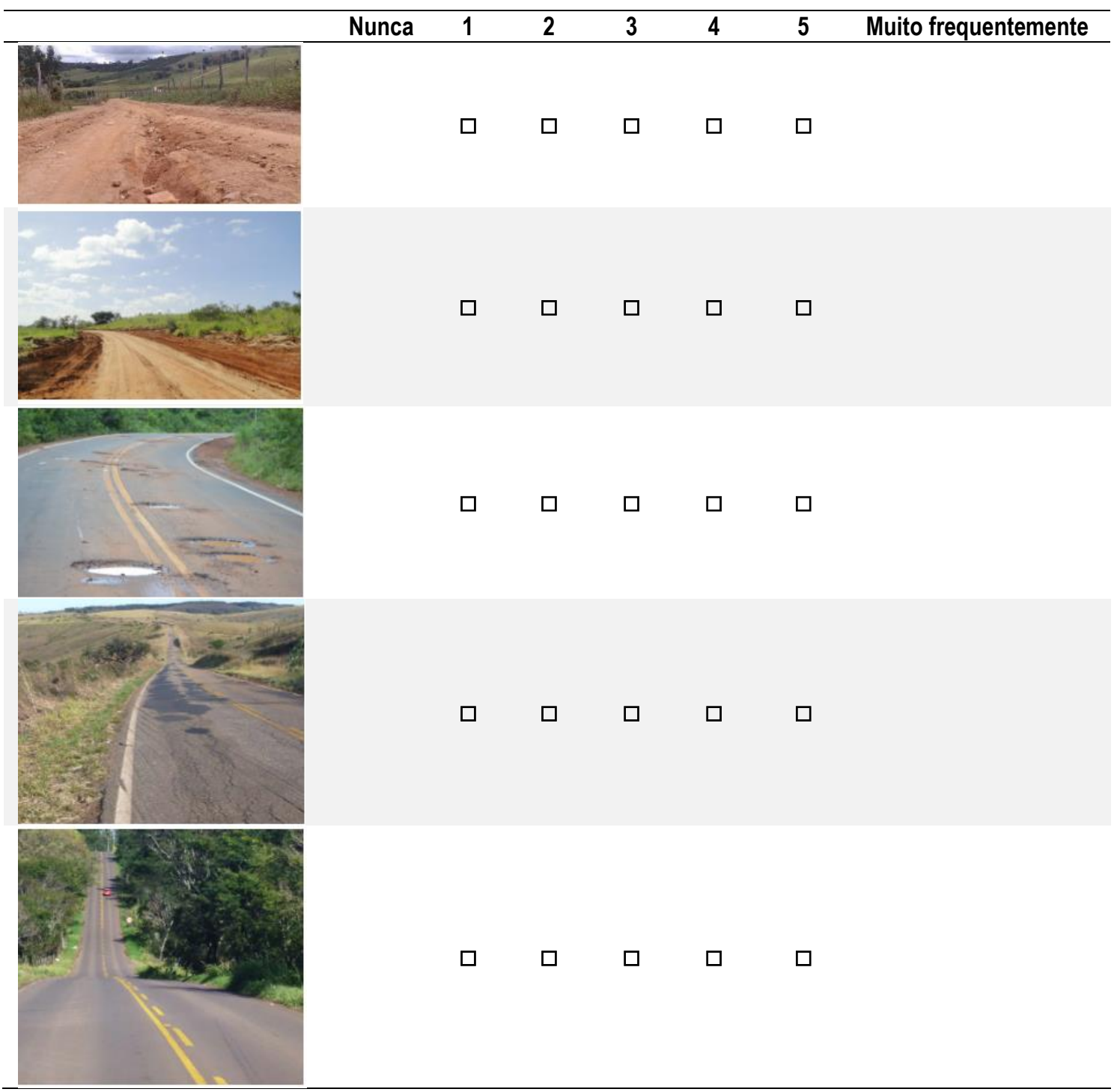

c) Considerando o traçado da via (reta, curvas suaves e, sinuosa) de cada imagem Classifique a frequência em uma escala de 5 pontos, onde 1 é "Nunca" (Eu nunca dirijo em uma rodovia parecida) e 5 é "Muito frequentemente" (Eu muito frequentemente dirijo em uma rodovia parecida

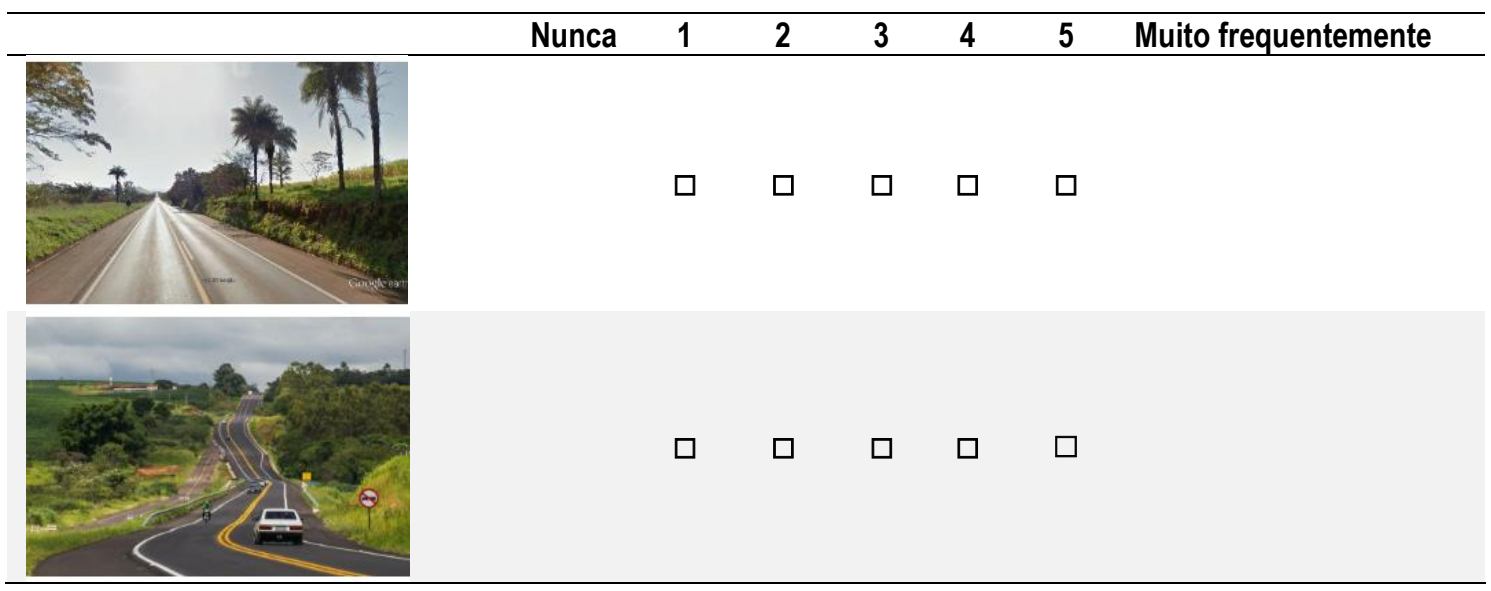




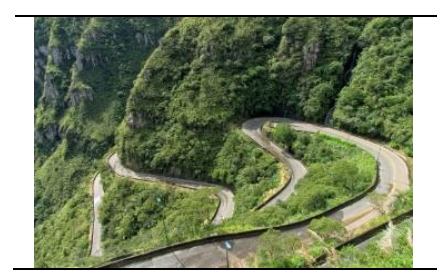

$60 \%$ Concluído

\section{Tema: Você mesmo como motorista}

17. Abaixo estão várias situações em que você pode encontrar quando está dirigindo em situações consideradas normais. Tente imaginar que os incidentes descritos estão realmente acontecendo com você, e então indique a intensidade de raiva que cada situação provocaria em você. Marque sua resposta preenchendo o quadrado correspondente à direita.

\begin{tabular}{|c|c|c|c|c|c|}
\hline & Nada & Pouco & Razoável & Muita & Muitissima \\
\hline Alguém está "costurando" o trânsito & $\square$ & $\square$ & $\square$ & $\square$ & $\square$ \\
\hline $\begin{array}{l}\text { Um veículo lento na subida da serra não oferece } \\
\text { passagem para os demais motoristas passarem }\end{array}$ & $\square$ & $\square$ & $\square$ & $\square$ & $\square$ \\
\hline Alguém dá marcha ré em sua direção sem olhar & 口 & 口 & $\square$ & 口 & $\square$ \\
\hline Você passa por um radar de velocidade & 口 & $\square$ & 口 & 口 & $\square$ \\
\hline $\begin{array}{l}\text { Alguém faz um gesto obsceno para você por causa } \\
\text { da sua maneira de dirigir }\end{array}$ & $\square$ & $\square$ & $\square$ & $\square$ & $\square$ \\
\hline Um policial manda você encostar & 口 & $\square$ & $\square$ & $\square$ & $\square$ \\
\hline $\begin{array}{l}\text { Um caminhão joga areia ou cascalho no carro que } \\
\text { você está dirigindo }\end{array}$ & $\square$ & $\square$ & $\square$ & $\square$ & $\square$ \\
\hline $\begin{array}{l}\text { Alguém avança o sinal de trânsito } \\
\text { (semáforo/sinaleira) vermelho ou a placa de "pare" }\end{array}$ & 口 & $\square$ & $\square$ & $\square$ & $\square$ \\
\hline $\begin{array}{l}\text { Alguém buzina para você por causa da sua } \\
\text { maneira de dirigir }\end{array}$ & $\square$ & $\square$ & $\square$ & $\square$ & $\square$ \\
\hline $\begin{array}{l}\text { Você está dirigindo atrás de um caminhão grande } \\
\text { e não consegue ver ao redor dele }\end{array}$ & 口 & $\square$ & $\square$ & $\square$ & $\square$ \\
\hline $\begin{array}{l}\text { Um ciclista está andando no meio da pista e } \\
\text { congestionando o trânsito }\end{array}$ & $\square$ & $\square$ & $\square$ & $\square$ & $\square$ \\
\hline Você está preso no congestionamento & ㅁ & $\square$ & $\square$ & $\square$ & $\square$ \\
\hline $\begin{array}{l}\text { Alguém aumenta a velocidade quando você tenta } \\
\text { ultrapassá-lo }\end{array}$ & $\square$ & $\square$ & $\square$ & $\square$ & $\square$ \\
\hline Alguém demora ao estacionar, atrasando o trânsito & $\square$ & ㅁ & $\square$ & $\square$ & $\square$ \\
\hline
\end{tabular}

$70 \%$ Concluído

Tema: Você mesmo como motorista

18. Considere suas preferências enquanto dirige e responda considerando o que é verdadeiro para você.

Considere a escala de 5 pontos, onde 1 é "Totalmente falso" e 5 é "Totalmente verdadeiro"

\begin{tabular}{|c|c|c|c|c|c|c|c|}
\hline & $\begin{array}{l}\text { Totalmente } \\
\text { falso }\end{array}$ & 1 & 2 & 3 & 4 & 5 & $\begin{array}{l}\text { Totalmente } \\
\text { verdadeiro }\end{array}$ \\
\hline $\begin{array}{l}\text { Eu gostaria de dirigir sem uma rota pré-definida e } \\
\text { um tempo para chegar }\end{array}$ & & $\square$ & $\square$ & $\square$ & $\square$ & $\square$ & \\
\hline $\begin{array}{l}\text { Muitas vezes eu me sinto como um piloto de } \\
\text { corrida }\end{array}$ & & $\square$ & $\square$ & $\square$ & $\square$ & $\square$ & \\
\hline Eu gosto de dirigir perigosamente & & $\square$ & $\square$ & $\square$ & $\square$ & $\square$ & \\
\hline $\begin{array}{l}\text { Eu gosto de dirigir em estradas com muitas } \\
\text { curvas fechadas }\end{array}$ & & $\square$ & $\square$ & $\square$ & $\square$ & $\square$ & \\
\hline $\begin{array}{l}\text { Eu gostaria de aprender a dirigir carros que } \\
\text { podem exceder a velocidade de } 300 \mathrm{~km} / \mathrm{h}\end{array}$ & & $\square$ & $\square$ & $\square$ & $\square$ & $\square$ & \\
\hline
\end{tabular}




\begin{tabular}{lllllll}
\hline $\begin{array}{l}\text { Eu não tenho paciência para pessoas que dirigem } \\
\text { o carro de maneira previsível e chata }\end{array}$ & $\square$ & $\square$ & $\square$ & $\square$ & $\square$ \\
$\begin{array}{l}\text { Eu acho que eu gostaria da experiência de dirigir } \\
\text { muito rápido em uma rua íngreme }\end{array}$ & $\square$ & $\square$ & $\square$ & $\square$ & $\square$ \\
\hline
\end{tabular}

$75 \%$ Concluído

\section{Tema: Você mesmo como motorista}

19. Para cada uma das sentenças abaixo, indique a frequência que você adotou estes comportamentos no último ano

Considere a escala de 5 pontos, onde 1 é "Nunca" e 5 é "Muito frequentemente"

\begin{tabular}{|c|c|c|c|c|c|c|c|}
\hline & Nunca & 1 & 2 & 3 & 4 & 5 & $\begin{array}{c}\text { Muito } \\
\text { frequentemente }\end{array}$ \\
\hline $\begin{array}{l}\text { Usar o celular, no modo viva voz, enquanto dirige em uma } \\
\text { área urbana }\end{array}$ & & $\square$ & $\square$ & $\square$ & $\square$ & $\square$ & \\
\hline $\begin{array}{l}\text { Exceder o limite de velocidade em pelo menos } 20 \mathrm{~km} / \mathrm{h} \\
\text { quando você está com pressa }\end{array}$ & & $\square$ & $\square$ & $\square$ & $\square$ & $\square$ & \\
\hline Dirigir muito próximo ao veículo da frente & & $\square$ & $\square$ & $\square$ & $\square$ & $\square$ & \\
\hline Mudar de faixa sem fazer sinal & & $\square$ & $\square$ & $\square$ & $\square$ & $\square$ & \\
\hline Dirigir com sono & & $\square$ & $\square$ & $\square$ & $\square$ & $\square$ & \\
\hline $\begin{array}{l}\text { Usar o celular, no modo viva voz, enquanto dirige em uma } \\
\text { rodovia }\end{array}$ & & $\square$ & $\square$ & $\square$ & $\square$ & $\square$ & \\
\hline Usar algum tipo de droga ilegal e dirigir & & $\square$ & $\square$ & $\square$ & $\square$ & $\square$ & \\
\hline Atravessar o semáforo com o sinal vermelho durante o dia & & $\square$ & $\square$ & $\square$ & $\square$ & $\square$ & \\
\hline Exceder a velocidade quando o tráfego está tranquilo & & $\square$ & $\square$ & $\square$ & $\square$ & $\square$ & \\
\hline Ignorar placas de sinalização & & $\square$ & $\square$ & $\square$ & $\square$ & $\square$ & \\
\hline Ultrapassar em local proibido & & $\square$ & $\square$ & $\square$ & $\square$ & $\square$ & \\
\hline $\begin{array}{l}\text { Usar o celular com as mãos enquanto você dirige em uma } \\
\text { área urbana }\end{array}$ & & $\square$ & $\square$ & $\square$ & $\square$ & $\square$ & \\
\hline Mudar de faixa sem olhar o espelho & & $\square$ & $\square$ & $\square$ & $\square$ & $\square$ & \\
\hline $\begin{array}{l}\text { Dirigir uma distância de } 20 \mathrm{~km} \text {, em média, sem usar o cinto } \\
\text { de segurança }\end{array}$ & & $\square$ & $\square$ & $\square$ & $\square$ & $\square$ & \\
\hline $\begin{array}{l}\text { Dirigir após beber pelo menos dois copos de bebida } \\
\text { alcoólica }\end{array}$ & & $\square$ & $\square$ & $\square$ & $\square$ & $\square$ & \\
\hline $\begin{array}{l}\text { Atravessar o semáforo com o sinal vermelho durante a } \\
\text { noite }\end{array}$ & & $\square$ & $\square$ & $\square$ & $\square$ & $\square$ & \\
\hline Ignorar limites de velocidade para andar mais rápido & & $\square$ & $\square$ & $\square$ & $\square$ & $\square$ & \\
\hline $\begin{array}{l}\text { Continuar dirigindo quando você está cansado e precisaria } \\
\text { de uma pausa }\end{array}$ & & $\square$ & $\square$ & $\square$ & $\square$ & $\square$ & \\
\hline Dirigir pelo menos 2 km sem usar o cinto de segurança & & $\square$ & $\square$ & $\square$ & $\square$ & $\square$ & \\
\hline $\begin{array}{l}\text { Usar o celular com as mãos enquanto você dirige em uma } \\
\text { rodovia }\end{array}$ & & $\square$ & $\square$ & $\square$ & $\square$ & $\square$ & \\
\hline
\end{tabular}

$80 \%$ Concluído

\section{Tema: Você mesmo como motorista}

20. De acordo com a sua opinião, os comportamentos abaixo são...

\begin{tabular}{|c|c|c|c|c|c|c|c|}
\hline & Não é arriscado & 1 & 2 & 3 & 4 & 5 & Arriscado \\
\hline $\begin{array}{l}\text { Usar o celular, no modo viva voz, enquanto } \\
\text { dirige em uma área urbana }\end{array}$ & & $\square$ & $\square$ & $\square$ & $\square$ & $\square$ & \\
\hline $\begin{array}{l}\text { Exceder o limite de velocidade em pelo } \\
\text { menos } 20 \mathrm{~km} / \mathrm{h} \text { quando você está com pressa }\end{array}$ & & $\square$ & $\square$ & $\square$ & $\square$ & $\square$ & \\
\hline Dirigir muito próximo ao veículo da frente & & $\square$ & $\square$ & $\square$ & $\square$ & $\square$ & \\
\hline Mudar de faixa sem fazer sinal & & $\square$ & $\square$ & $\square$ & $\square$ & $\square$ & \\
\hline Dirigir com sono & & $\square$ & $\square$ & $\square$ & $\square$ & $\square$ & \\
\hline
\end{tabular}




\begin{tabular}{|c|c|c|c|c|c|}
\hline $\begin{array}{l}\text { Usar o celular, no modo viva voz, enquanto } \\
\text { dirige em uma rodovia }\end{array}$ & $\square$ & $\square$ & $\square$ & $\square$ & $\square$ \\
\hline Usar algum tipo de droga ilegal e dirigir & $\square$ & $\square$ & $\square$ & $\square$ & $\square$ \\
\hline $\begin{array}{l}\text { Atravessar o semáforo com o sinal vermelho } \\
\text { durante o dia }\end{array}$ & $\square$ & $\square$ & $\square$ & $\square$ & $\square$ \\
\hline $\begin{array}{l}\text { Exceder a velocidade quando o tráfego está } \\
\text { tranquilo }\end{array}$ & $\square$ & $\square$ & $\square$ & $\square$ & $\square$ \\
\hline Ignorar placas de sinalização & $\square$ & 口 & $\square$ & $\square$ & $\square$ \\
\hline Ultrapassar em local proibido & $\square$ & 口 & $\square$ & $\square$ & $\square$ \\
\hline $\begin{array}{l}\text { Usar o celular com as mãos enquanto você } \\
\text { dirige em uma área urbana }\end{array}$ & $\square$ & 口 & $\square$ & $\square$ & $\square$ \\
\hline Mudar de faixa sem olhar o espelho & $\square$ & 口 & $\square$ & $\square$ & $\square$ \\
\hline $\begin{array}{l}\text { Dirigir uma distância de } 20 \text { km, em média, } \\
\text { sem usar o cinto de segurança }\end{array}$ & $\square$ & $\square$ & $\square$ & $\square$ & $\square$ \\
\hline $\begin{array}{l}\text { Dirigir após beber pelo menos dois copos de } \\
\text { bebida alcoólica }\end{array}$ & $\square$ & $\square$ & $\square$ & $\square$ & $\square$ \\
\hline $\begin{array}{l}\text { Atravessar o semáforo com o sinal vermelho } \\
\text { durante a noite }\end{array}$ & $\square$ & $\square$ & $\square$ & $\square$ & $\square$ \\
\hline $\begin{array}{l}\text { Ignorar limites de velocidade para andar mais } \\
\text { rápido }\end{array}$ & $\square$ & $\square$ & $\square$ & $\square$ & $\square$ \\
\hline $\begin{array}{l}\text { Continuar dirigindo quando você está } \\
\text { cansado e precisaria de uma pausa }\end{array}$ & $\square$ & $\square$ & $\square$ & $\square$ & $\square$ \\
\hline $\begin{array}{l}\text { Dirigir pelo menos } 2 \mathrm{~km} \text { sem usar o cinto de } \\
\text { segurança }\end{array}$ & $\square$ & $\square$ & $\square$ & $\square$ & $\square$ \\
\hline $\begin{array}{l}\text { Usar o celular com as mãos enquanto você } \\
\text { dirige em uma rodovia }\end{array}$ & $\square$ & $\square$ & $\square$ & $\square$ & $\square$ \\
\hline
\end{tabular}

$90 \%$ Concluído

Tema: Você mesmo como motorista

21. Durante o último ano, qual a frequência que esse tipo de coisa aconteceu para você enquanto dirigia

\begin{tabular}{|c|c|c|c|c|c|c|c|}
\hline & Nunca & 1 & 2 & 3 & 4 & 5 & Sempre \\
\hline Dirigir após consumir bebida alcoólica & & $\square$ & $\square$ & $\square$ & $\square$ & $\square$ & \\
\hline $\begin{array}{l}\text { Estar em uma fila para entrar à direita em uma rua } \\
\text { principal e prestar tanta atenção no trânsito dessa rua, } \\
\text { que quase bate na traseira do carro à sua frente }\end{array}$ & & $\square$ & $\square$ & $\square$ & $\square$ & $\square$ & \\
\hline $\begin{array}{l}\text { Não perceber que pedestres estão atravessando, ao } \\
\text { entrar em uma rua lateral, vindo de uma rua principal }\end{array}$ & & 口 & 口 & 口 & $\square$ & $\square$ & \\
\hline $\begin{array}{l}\text { Buzinar para indicar sua contrariedade com relação a } \\
\text { outro usuário da via }\end{array}$ & & $\square$ & 口 & 口 & $\square$ & $\square$ & \\
\hline $\begin{array}{l}\text { Não verificar seu espelho retrovisor antes de sair com o } \\
\text { carro, mudar de faixa etc }\end{array}$ & & $\square$ & $\square$ & $\square$ & 口 & $\square$ & \\
\hline $\begin{array}{l}\text { Frear muito rápido em uma estrada escorregadia, ou } \\
\text { girar o volante para o lado errado em uma derrapagem }\end{array}$ & & $\square$ & 口 & 口 & 口 & $\square$ & \\
\hline $\begin{array}{l}\text { Parar em um cruzamento tão para a frente que o } \\
\text { motorista que tem preferência precisa parar e deixar } \\
\text { você passar }\end{array}$ & & $\square$ & $\square$ & $\square$ & $\square$ & $\square$ & \\
\hline $\begin{array}{l}\text { Desrespeitar o limite de velocidade em uma rua de área } \\
\text { residencial }\end{array}$ & & $\square$ & $\square$ & $\square$ & $\square$ & $\square$ & \\
\hline $\begin{array}{l}\text { Ao virar à direita, quase bater em um ciclista que } \\
\text { apareceu do seu lado }\end{array}$ & & $\square$ & 口 & $\square$ & $\square$ & $\square$ & \\
\hline $\begin{array}{l}\text { Não prestar atenção aos sinais de "Dê a preferência" e } \\
\text { evitar, por pouco, colidir com outro veículo que tem a } \\
\text { preferência }\end{array}$ & & $\square$ & $\square$ & $\square$ & $\square$ & $\square$ & \\
\hline $\begin{array}{l}\text { Tentar ultrapassar alguém que você não viu estar } \\
\text { sinalizando para entrar à esquerda }\end{array}$ & & $\square$ & $\square$ & $\square$ & $\square$ & $\square$ & \\
\hline
\end{tabular}




\begin{tabular}{|c|c|c|c|c|c|}
\hline $\begin{array}{l}\text { Ficar muito bravo por causa de outro(a) motorista e } \\
\text { persegui-lo(a) com a intenção de dizer o que você } \\
\text { pensou dele/dela }\end{array}$ & $\square$ & $\square$ & $\square$ & $\square$ & $\square$ \\
\hline $\begin{array}{l}\text { Ficar em uma faixa da pista, que você sabe que estará } \\
\text { interrompida adiante, e forçar sua entrada na outra faixa } \\
\text { no último instante }\end{array}$ & $\square$ & $\square$ & $\square$ & $\square$ & $\square$ \\
\hline Ultrapassar um motorista lento pelo lado direito & $\square$ & $\square$ & $\square$ & $\square$ & $\square$ \\
\hline $\begin{array}{l}\text { Arrancar nos semáforos com a intenção de ser mais } \\
\text { rápido que o motorista ao seu lado }\end{array}$ & $\square$ & $\square$ & $\square$ & $\square$ & $\square$ \\
\hline $\begin{array}{l}\text { Dirigir tão próximo ao veículo da frente que seria difícil } \\
\text { parar em uma situação de emergência }\end{array}$ & $\square$ & $\square$ & $\square$ & $\square$ & $\square$ \\
\hline $\begin{array}{l}\text { Atravessar o cruzamento sabendo que o semáforo já } \\
\text { fechou para você }\end{array}$ & $\square$ & $\square$ & $\square$ & $\square$ & $\square$ \\
\hline $\begin{array}{l}\text { Ficar muito bravo com um determinado tipo de } \\
\text { motorista e indicar sua hostilidade de qualquer maneira }\end{array}$ & $\square$ & $\square$ & $\square$ & $\square$ & $\square$ \\
\hline $\begin{array}{l}\text { Subestimar a velocidade de um veículo que está vindo } \\
\text { no sentido contrário ao iniciar uma ultrapassagem }\end{array}$ & $\square$ & $\square$ & $\square$ & $\square$ & $\square$ \\
\hline Desrespeitar o limite de velocidade em uma rodovia & $\square$ & $\square$ & $\square$ & $\square$ & $\square$ \\
\hline
\end{tabular}





\section{APÊNDICE B - QUESTIONÁRIO VERSÃO PORTUGAL}

\section{TERMO DE CONSENTIMENTO LIVRE E ESCLARECIDO}

Convidamo-lo a responder um questionário no âmbito da pesquisa de doutoramento "Modelos para previsão de tomada de risco de motoristas usando dados individuais, do local e do ambiente viário", que avalia a atitude e comportamento do condutor e poderá vir a contribuir para a melhoria da segurança viária.

Este questionário é composto por 20 questões que abrangem: características sociodemográficas, histórico como condutor, o ambiente em que conduz e o seu comportamento no trânsito. 0 tempo de resposta é, em média, de 15 minutos sendo a sua resposta voluntária.

Para participar desta pesquisa, deverá ter idade superior a 18 anos e possuir carta de condução. Todas as informações recolhidas neste questionário serão anónimas de acordo com a lei da proteção de dados pessoais.

0 preenchimento deste questionário não tem risco direto, porém é de salientar a possibilidade de risco subjetivo, na medida em que algumas perguntas podem remeter à algum desconforto emocional, lembrar situações ou sentimentos desagradáveis. Caso alguma destas situações ocorram, poderá interromper imediatamente a sua participação.

Esta pesquisa é vinculada ao Departamento de Engenharia de Transportes da Escola de Engenharia de São Carlos (EESC/USP) e foi aprovada pelo Comitê de Ética da Faculdade de Zootecnia e Engenharia de Alimentos (FZEA-USP), de acordo com os requisitos da Resolução CNS 466/12. Caso tenha alguma dúvida ou consideração sobre a ética da pesquisa, entre em contato com o Comitê de Ética da Faculdade de Zootecnia e Engenharia de Alimentos (FZEAUSP), pelo telefone (19) 3565-4299 ou pelo e-mail cepfzea@usp.br

Sou a investigadora responsável, meu nome é Cintia Isabel de Campos e poderei ser contactada pelo e-mail cintiacampos@usp.br, ou telefone +55 (16) 3373-9601.

Concordo em participar

Não concordo em participar

Onde é que vive?

País

Escolher um item.

Distrito

Cidade

Escolher um item.

Escolher um item.

Tema: Dados sociodemográficos e histórico como condutor

\begin{tabular}{lll} 
1. $\quad$ Idade & \\
\hline & & \\
2. Sexo & anos \\
& $\square \quad$ Feminino \\
& $\square \quad$ Masculino
\end{tabular}

3. Estado Civil

$\begin{array}{ll}\square & \text { Solteiro(a) } \\ \square & \text { Casado(a) / Em união } \\ \square & \text { Divorciado(a) } \\ \square & \text { Viúvo(a) }\end{array}$

4. Escolaridade

$\square \quad$ Ensino básico incompleto

Ensino básico completo

Ensino secundário incompleto

Ensino secundário completo

Ensino superior incompleto

Ensino superior completo

Pós-graduação incompleta

Pós-graduação completa

5. Salário (Valor líquido mensal)

Não possuo qualquer rendimento mensal

Até um salário mínimo $(€ 557,00)$

Entre 1 e 2 salários mínimos (€557,01 - €1114,00) 
$\square \quad$ Entre 2 e 3 salários mínimos (€1114,01 - €1671,00)

$\square \quad$ Entre 3 e 5 salários mínimos (€1671,01 - €2785,00)

Entre5 e 10 salários mínimos (€2785,01 - €5570,00)

Entre 10 e 20 salários mínimos ( $€ 5570,01$ - €11140,00)

Mais de 20 salários mínimos (€11140,01)

6. Quantos filhos tem? Escolher um item.

b) Se tem filhos, qual a idade deles?

\begin{tabular}{ll}
\hline Idade do primeiro filho & Escolher um item. \\
\hline Idade do segundo filho & Escolher um item. \\
Idade do terceiro filho & Escolher um item. \\
Idade do quarto filho & Escolher um item. \\
Idade do sexto filho & Escolher um item. \\
Idade do sétimo filho & Escolher um item. \\
Idade do oitavo filho & Escolher um item. \\
Idade do nono filho & Escolher um item. \\
Idade do décimo filho & Escolher um item. \\
\hline
\end{tabular}

7. Que tipo de veículo conduz? Indique, para cada tipo, há quanto tempo possui a carta de condução

\begin{tabular}{ll}
\multicolumn{1}{c}{ Tipo de veículo } & \multicolumn{1}{c}{ Tempo } \\
\hline Carro & Escolher um item. \\
Motociclo igual ou superior a 125cc & Escolher um item. \\
Camião (pesado de mercadorias) & Escolher um item. \\
Autocarro (pesado de passageiros) & Escolher um item. \\
Reboque/Semirreboque & Escolher um item. \\
Outros, especifique: & Escolher um item. \\
\hline
\end{tabular}

8. Quantos quilómetros conduz por veículo semanalmente?

Considere a média de quilómetros percorridos em uma semana típica

\begin{tabular}{ll}
\multicolumn{1}{c}{ Tipo de veículo } & Quilómetros \\
\hline Carro & \\
Motociclo igual ou superior a 125cc & \\
Camião (pesado de mercadorias) \\
Autocarro (pesado de passageiros) \\
Reboque/Semirreboque \\
Outros, especifique
\end{tabular}

9. Como condutor, quantas multas teve nos últimos três anos enquanto conduzia um(a)...

\begin{tabular}{ll}
\hline \multicolumn{1}{c}{ Tipo de veículo } & \multicolumn{1}{c}{ Número de multas } \\
\hline Carro & Escolher um item. \\
Motociclo igual ou superior a $125 \mathrm{cc}$ & Escolher um item. \\
Camião (pesado de mercadorias) & Escolher um item. \\
Autocarro (pesado de passageiros) & Escolher um item. \\
Reboque/Semirreboque & Escolher um item. \\
Outros, especifique & Escolher um item. \\
\hline
\end{tabular}

SE A RESPOSTA PARA A QUESTÃO 9-A FOI "NENHUMA" EM TODAS AS OPÇÔES, SALTE PARA PERGUNTA 10 
9B) Indique, para cada motivo, o número de multas que teve nos últimos três anos

\begin{tabular}{ll}
\hline \multicolumn{1}{c}{ Tipo de multa } & \multicolumn{1}{c}{ Número de multas } \\
\hline Excesso de velocidade & Escolher um item. \\
Álcool & Escolher um item. \\
Uso de telemóvel durante a condução & Escolher um item. \\
Desrespeito pelos sinais de trânsito & Escolher um item. \\
Estacionamento em local proibido & Escolher um item. \\
Irregularidades na carta de condução & Escolher um item. \\
Outro, especifique & Escolher um item. \\
\hline
\end{tabular}

10. Considerando suas habilidade de condução e as dos demais condutores responda, numa escala de 1 (Discordo fortemente) até 5 (Concordo fortemente), se concorda ou não, com as seguintes declarações

\begin{tabular}{|c|c|c|c|c|c|c|c|}
\hline & $\begin{array}{l}\text { Discordo } \\
\text { fortemente }\end{array}$ & 1 & 2 & 3 & 4 & 5 & $\begin{array}{l}\text { Concordo } \\
\text { fortemente }\end{array}$ \\
\hline Eu sou muito bom condutor & & $\square$ & $\square$ & $\square$ & $\square$ & $\square$ & \\
\hline No geral, as outras pessoas conduzem muito bem & & $\square$ & $\square$ & $\square$ & $\square$ & $\square$ & \\
\hline Eu conduzo muito cuidadosamente & & $\square$ & $\square$ & $\square$ & $\square$ & $\square$ & \\
\hline $\begin{array}{l}\text { Em geral, as outras pessoas conduzem muito } \\
\text { cuidadosamente }\end{array}$ & & $\square$ & $\square$ & $\square$ & $\square$ & $\square$ & \\
\hline Enquanto conduzo os meus reflexos são muito bons & & $\square$ & $\square$ & $\square$ & $\square$ & $\square$ & \\
\hline $\begin{array}{l}\text { Em geral, os reflexos das outras pessoas enquanto } \\
\text { conduzem são muito bons }\end{array}$ & & $\square$ & $\square$ & $\square$ & $\square$ & $\square$ & \\
\hline
\end{tabular}

11. Quantas vezes esteve envolvido num acidente de trânsito como condutor nos últimos três anos? vez(es)

\section{SE A RESPOSTA PARA A QUESTÃO 11 FOI "NENHUMA", SALTE PARA A PERGUNTA 12.}

Qual foi a gravidade do(s) acidente(s) de trânsito?

Considere a pior gravidade de cada tipo de acidente que sofreu e indique o número de acidentes para cada nível de gravidade.

\begin{tabular}{ll}
\multicolumn{1}{c}{ Gravidade } & \multicolumn{1}{c}{ Número de acidentes } \\
\hline Danos materiais & Escolher um item. \\
Ferimentos ligeiros & Escolher um item. \\
Ferimentos graves & Escolher um item. \\
Acidente com vítima fatal & Escolher um item. \\
\hline
\end{tabular}

$20 \%$ Concluído

12. Considerando as ruas da cidade em que conduz, qual é a frequência que conduz em ruas parecidas com as das imagens abaixo? Avalie as imagens considerando a altura das construcõos e a largura das ruas em que conduz

Classifique a frequência numa escala de 5 pontos, onde 1 é "Nunca" (Eu nunca conduzo numa rua parecida) e 5 é "Muito frequentemente" (Eu muito frequentemente conduzo numa rua parecida) 


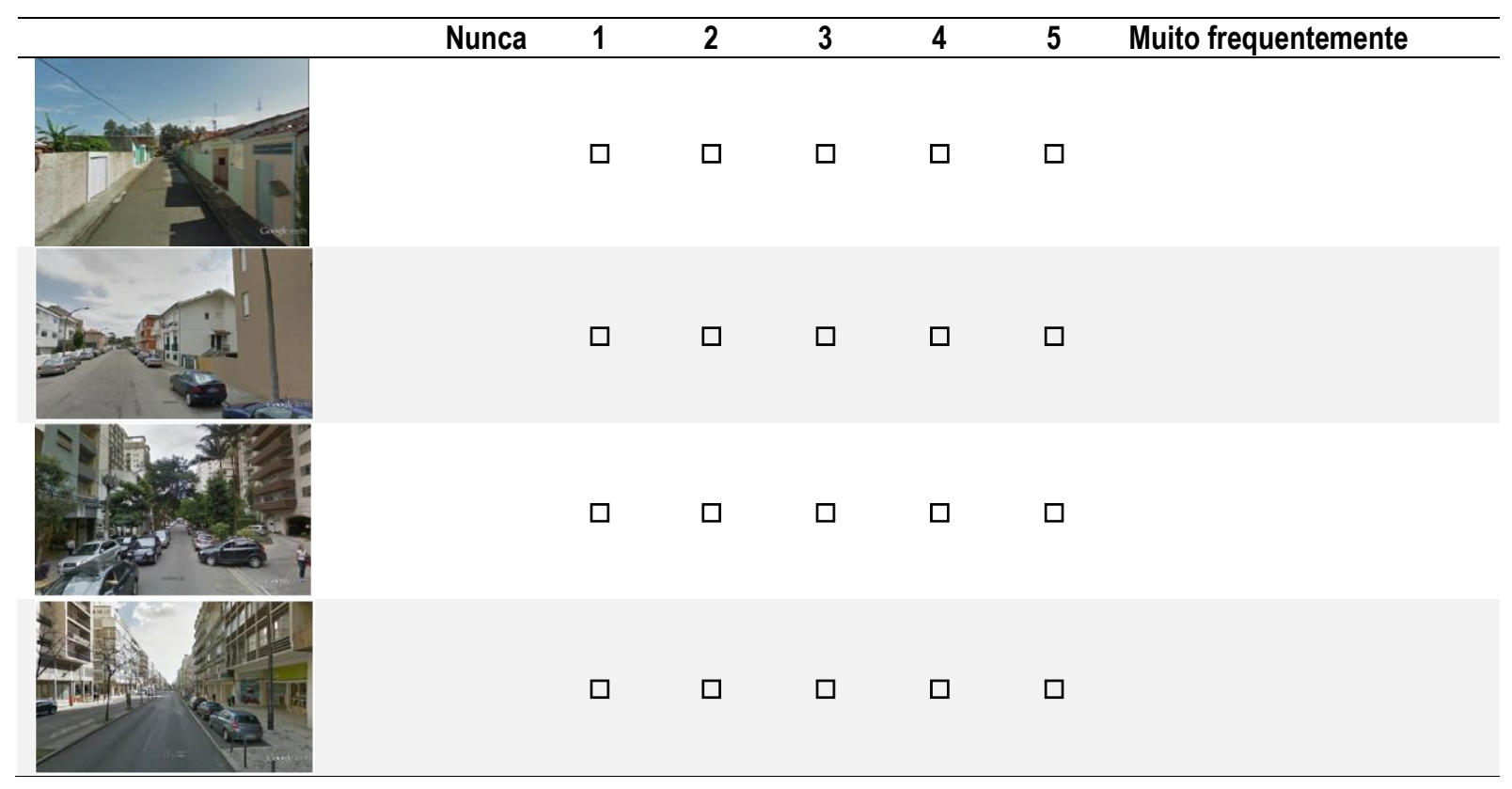

13. Qual é a frequência em que os elementos de vias de comunicação listados abaixo estão presentes nos caminhos que percorre?

Considere uma escala de 5 pontos, onde 1 é "Nunca" e 5 é "Muito frequentemente"

\begin{tabular}{|c|c|c|c|c|c|c|c|}
\hline & Nunca & 1 & 2 & 3 & 4 & 5 & Muito frequentemente \\
\hline Rotunda & & $\square$ & $\square$ & $\square$ & $\square$ & $\square$ & \\
\hline Passadeira & & $\square$ & $\square$ & $\square$ & $\square$ & $\square$ & \\
\hline Semáforo & & $\square$ & $\square$ & $\square$ & $\square$ & $\square$ & \\
\hline Lombas/Redutores de velocidade & & $\square$ & $\square$ & $\square$ & $\square$ & $\square$ & \\
\hline Sinalização vertical (sinais de trânsito) & & $\square$ & $\square$ & $\square$ & $\square$ & $\square$ & \\
\hline $\begin{array}{l}\text { Sinalização horizontal (marcas } \\
\text { rodoviárias/pintura no pavimento) }\end{array}$ & & $\square$ & $\square$ & $\square$ & $\square$ & $\square$ & \\
\hline Rua pavimentada & & $\square$ & $\square$ & $\square$ & $\square$ & $\square$ & \\
\hline Sinalização em cruzamentos & & $\square$ & $\square$ & $\square$ & $\square$ & $\square$ & \\
\hline
\end{tabular}

14. Qual é a frequência com que conduz em autoestradas/estradas nacionais, em média?

Responda à questão numa escala de 1 até 5 pontos. Considere 1 como "Nunca" 55 como "Muito frequentemente"

\begin{tabular}{lllllll}
\hline Nunca & 1 & 2 & 3 & 4 & 5 & Muito frequentemente \\
\hline & $\square$ & $\square$ & $\square$ & $\square$ & $\square$ & \\
\hline
\end{tabular}

SE A RESPOSTA PARA A QUESTÃO 14 FOI "NUNCA" (1), SALTE PARA QUESTÃO 16.

15. Qual é a frequência com que conduz em autoestradas/estradas nacionais parecidas com as imagens abaixo? Considere o número de veículos em cada imagem

Classifique a frequência numa escala de 5 pontos, onde 1 é "Nunca" (Eu nunca conduzo numa autoestrada/estrada nacional parecida) e 5 é "Muito frequentemente" (Eu muito frequentemente conduzo numa autoestrada/estrada nacional parecida) 


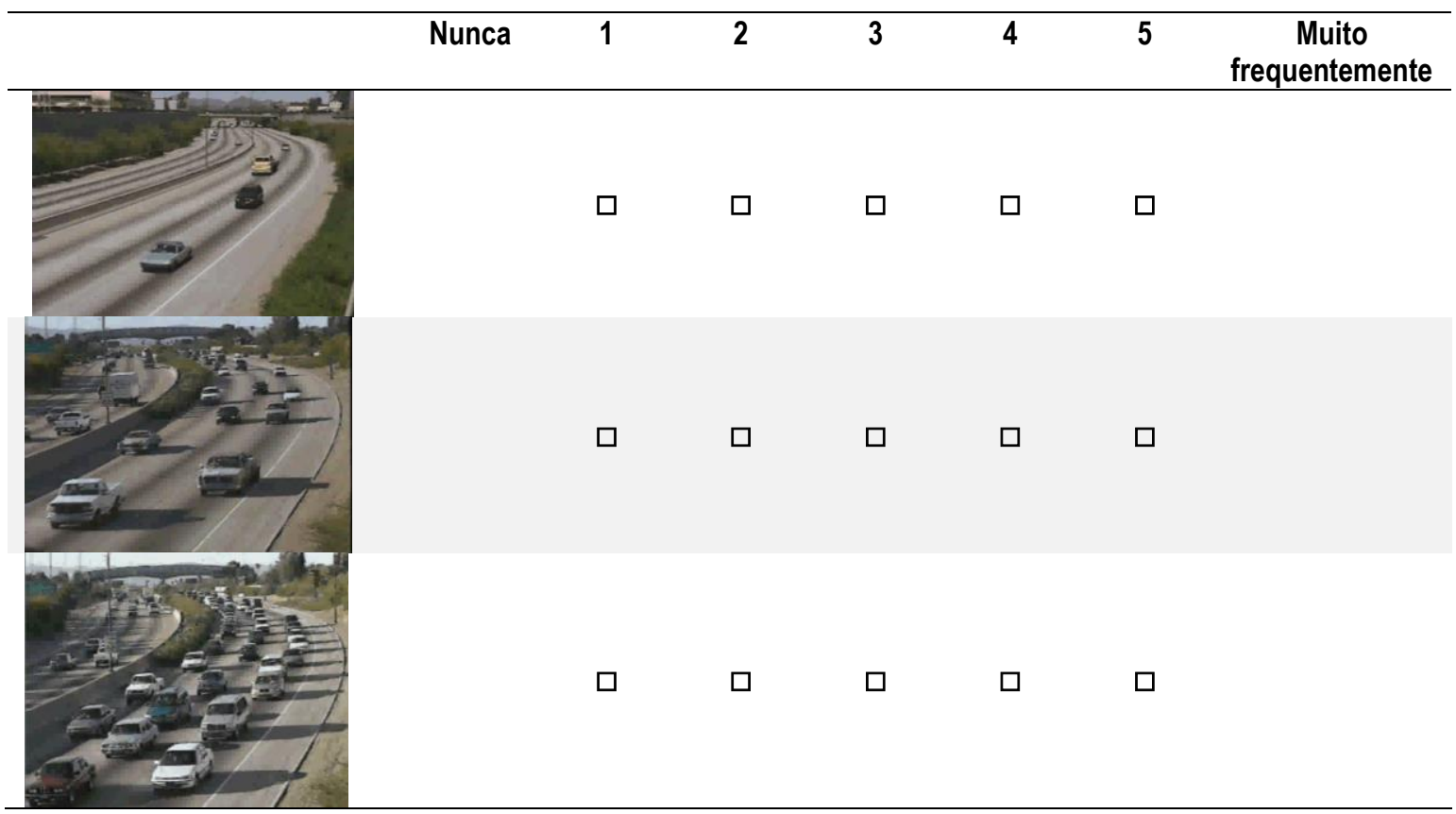

\section{Considere a qualidade do pavimento (asfalto) de cada imagem}

Classifique a frequência numa escala de 5 pontos, onde 1 é "Nunca" (Eu nunca conduzo numa autoestrada/estrada nacional parecida) e 5 é "Muito frequentemente" (Eu muito frequentemente conduzo numa autoestrada/estrada nacional parecida)

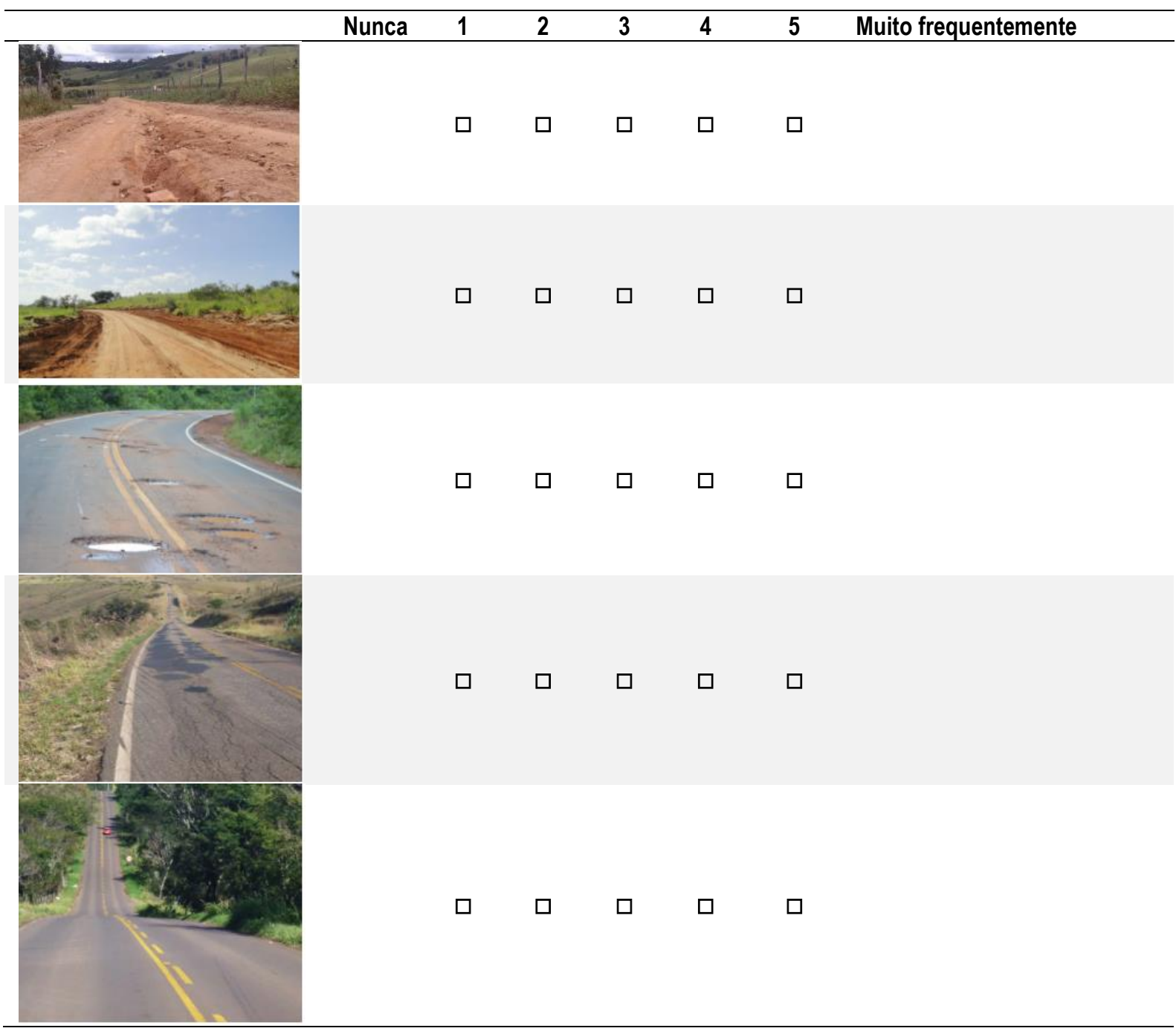


Considere o traçado da via (reta, curvas suaves e, sinuosa) de cada imagem Classifique a frequência numa escala de 5 pontos, onde 1 é "Nunca" (Eu nunca conduzo numa autoestrada/estrada nacional parecida) e 5 é "Muito frequentemente" (Eu muito frequentemente conduzo numa autoestrada/estrada nacional parecida)

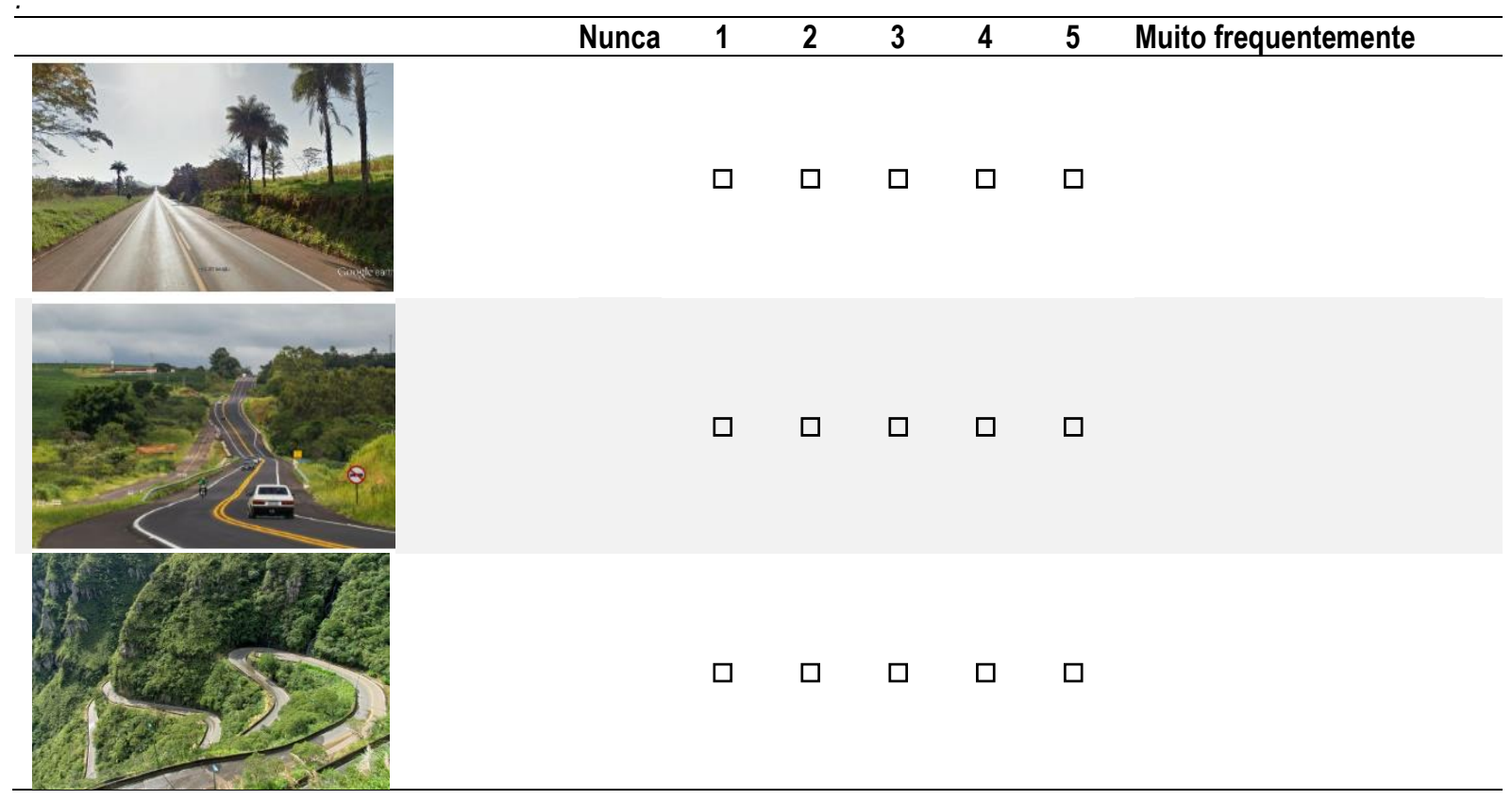

$60 \%$ Concluído

Como se descreve enquanto condutor

16. Em baixo estão descritas várias situações em que se pode encontrar quando está a conduzir em situações consideradas normais. Tente imaginar que os incidentes descritos estão realmente a acontecer consigo, e indique a intensidade de raiva que cada situação Ihe provocaria. Indique a sua resposta preenchendo o quadrado correspondente à direita.

\begin{tabular}{|c|c|c|c|c|c|}
\hline & Nada & Pouco & Razoável & Muita & Muitissima \\
\hline $\begin{array}{l}\text { Alguém está a mudar de via constantemente no } \\
\text { trânsito }\end{array}$ & $\square$ & $\square$ & $\square$ & $\square$ & $\square$ \\
\hline $\begin{array}{l}\text { Um veículo lento na subida de uma estrada } \\
\text { montanhosa não permite a passagem dos outros } \\
\text { condutores }\end{array}$ & $\square$ & $\square$ & $\square$ & $\square$ & $\square$ \\
\hline $\begin{array}{l}\text { Alguém inicia uma "marcha a trás" na sua direção, } \\
\text { sem olhar }\end{array}$ & $\square$ & $\square$ & $\square$ & $\square$ & $\square$ \\
\hline $\begin{array}{l}\text { Apercebe-se que passou por um radar de } \\
\text { velocidade }\end{array}$ & $\square$ & $\square$ & 口 & $\square$ & $\square$ \\
\hline $\begin{array}{l}\text { Alguém lhe dirige um gesto obsceno, por causa da } \\
\text { sua maneira de conduzir }\end{array}$ & $\square$ & $\square$ & $\square$ & $\square$ & $\square$ \\
\hline Um polícia manda-o encostar & 口 & 口 & 口 & $\square$ & $\square$ \\
\hline $\begin{array}{l}\text { Um camião despeja areia ou cascalho no carro que } \\
\text { você está a conduzir }\end{array}$ & $\square$ & $\square$ & $\square$ & $\square$ & 口 \\
\hline $\begin{array}{l}\text { Alguém passa, sem parar, um sinal de trânsito } \\
\text { (semáforo) vermelho ou uma placa de "stop" }\end{array}$ & $\square$ & $\square$ & 口 & $\square$ & $\square$ \\
\hline $\begin{array}{l}\text { Alguém lhe buzina por causa da sua forma de } \\
\text { conduzir }\end{array}$ & $\square$ & $\square$ & $\square$ & $\square$ & $\square$ \\
\hline $\begin{array}{l}\text { Você está a conduzir atrás de um veículo longo que } \\
\text { Ihe tapa a visibilidade de forma considerável }\end{array}$ & $\square$ & 口 & $\square$ & $\square$ & $\square$ \\
\hline $\begin{array}{l}\text { Um ciclista está a circular no meio da via, } \\
\text { congestionando o trânsito }\end{array}$ & $\square$ & $\square$ & $\square$ & $\square$ & $\square$ \\
\hline Está preso num congestionamento & $\square$ & $\square$ & $\square$ & $\square$ & $\square$ \\
\hline $\begin{array}{l}\text { Alguém aumenta a velocidade quando você o tenta } \\
\text { ultrapassar }\end{array}$ & $\square$ & $\square$ & $\square$ & $\square$ & $\square$ \\
\hline
\end{tabular}




\begin{tabular}{llllll}
\hline Alguém demora a estacionar, atrasando o trânsito & $\square$ & $\square$ & $\square$ & $\square$ & $\square$ \\
\hline
\end{tabular}

$70 \%$ Concluído

Tema: Como se descreve enquanto condutor

17. Considere suas preferências enquanto conduz e responda considerando o que é verdadeiro para si.

Considere a escala de 5 pontos, onde 1 é "Totalmente falso" e 5 é "Totalmente verdade"

\begin{tabular}{|c|c|c|c|c|c|c|c|}
\hline & $\begin{array}{l}\text { Totalmente } \\
\text { falso }\end{array}$ & 1 & 2 & 3 & 4 & 5 & $\begin{array}{l}\text { Totalmente } \\
\text { verdade }\end{array}$ \\
\hline $\begin{array}{l}\text { Eu gostaria de conduzir sem uma rota pré-definida } \\
\text { e sem um tempo para chegar }\end{array}$ & & $\square$ & 口 & $\square$ & $\square$ & $\square$ & \\
\hline Muitas vezes sinto-me como um piloto de corrida & & 口 & 口 & 口 & $\square$ & $\square$ & \\
\hline Eu gosto de conduzir perigosamente & & 口 & 口 & 口 & $\square$ & 口 & \\
\hline $\begin{array}{l}\text { Eu gosto de conduzir em estradas com muitas } \\
\text { curvas fechadas }\end{array}$ & & 口 & 口 & $\square$ & $\square$ & $\square$ & \\
\hline $\begin{array}{l}\text { Eu gostaria de aprender a conduzir carros que } \\
\text { podem exceder a velocidade de } 300 \mathrm{~km} / \mathrm{h}\end{array}$ & & 口 & 口 & $\square$ & $\square$ & $\square$ & \\
\hline $\begin{array}{l}\text { Eu não tenho paciência para pessoas que } \\
\text { conduzem de maneira previsível e aborrecida }\end{array}$ & & $\square$ & $\square$ & $\square$ & $\square$ & $\square$ & \\
\hline $\begin{array}{l}\text { Eu acho que gostaria da experiência de conduzir } \\
\text { a alta velocidade numa rua íngreme }\end{array}$ & & $\square$ & $\square$ & $\square$ & $\square$ & $\square$ & \\
\hline
\end{tabular}

$75 \%$ Concluído

\section{Tema: Como se descreve enquanto condutor}

18. Para cada uma das declarações abaixo, indique a frequência com que adotou estes comportamentos no último ano

Considere a escala de 5 pontos, onde 1 é "Nunca" e 5 é "Muito frequentemente"

\begin{tabular}{|c|c|c|c|c|c|c|}
\hline Nunca & 1 & 2 & 3 & 4 & 5 & $\begin{array}{l}\text { Muito } \\
\text { frequentemente }\end{array}$ \\
\hline $\begin{array}{l}\text { Usar o telemóvel em alta voz (mãos livres) } \\
\text { enquanto conduz numa área urbana }\end{array}$ & $\square$ & $\square$ & $\square$ & $\square$ & $\square$ & \\
\hline $\begin{array}{l}\text { Exceder o limite de velocidade em pelo menos } \\
20 \mathrm{~km} / \mathrm{h} \text { quando está com pressa }\end{array}$ & $\square$ & $\square$ & $\square$ & $\square$ & $\square$ & \\
\hline Conduzir muito próximo ao carro da frente & $\square$ & $\square$ & $\square$ & $\square$ & $\square$ & \\
\hline Mudar de via sem sinalizar & $\square$ & $\square$ & $\square$ & $\square$ & $\square$ & \\
\hline Conduzir com sono & $\square$ & $\square$ & $\square$ & $\square$ & $\square$ & \\
\hline $\begin{array}{l}\text { Usar o telemóvel em alta voz (mãos livres) } \\
\text { enquanto conduz fora da área urbana }\end{array}$ & $\square$ & $\square$ & $\square$ & $\square$ & $\square$ & \\
\hline Usar algum tipo de droga ilegal e conduzir & $\square$ & $\square$ & $\square$ & $\square$ & $\square$ & \\
\hline $\begin{array}{l}\text { Atravessar o semáforo com o sinal vermelho } \\
\text { durante o dia }\end{array}$ & $\square$ & $\square$ & $\square$ & $\square$ & $\square$ & \\
\hline $\begin{array}{l}\text { Exceder a velocidade quando o trânsito está } \\
\text { tranquilo }\end{array}$ & $\square$ & $\square$ & $\square$ & $\square$ & $\square$ & \\
\hline Ignorar placas de sinalização vertical & $\square$ & $\square$ & $\square$ & $\square$ & $\square$ & \\
\hline Ultrapassar em local proibido & $\square$ & $\square$ & $\square$ & $\square$ & $\square$ & \\
\hline $\begin{array}{l}\text { Usar o telemóvel segurando com as mãos } \\
\text { enquanto conduz numa área urbana }\end{array}$ & $\square$ & $\square$ & $\square$ & $\square$ & $\square$ & \\
\hline Mudar de via sem olhar pelo espelho retrovisor & $\square$ & $\square$ & $\square$ & 口 & $\square$ & \\
\hline $\begin{array}{l}\text { Conduzir a distância de } 20 \mathrm{~km} \text {, em média, sem } \\
\text { usar o cinto de segurança }\end{array}$ & $\square$ & $\square$ & $\square$ & $\square$ & $\square$ & \\
\hline $\begin{array}{l}\text { Conduzir após beber pelo menos } 2 \text { copos de } \\
\text { bebida alcoólica }\end{array}$ & $\square$ & $\square$ & $\square$ & $\square$ & $\square$ & \\
\hline $\begin{array}{l}\text { Atravessar o semáforo com o sinal vermelho } \\
\text { durante a noite }\end{array}$ & $\square$ & $\square$ & $\square$ & $\square$ & $\square$ & \\
\hline $\begin{array}{l}\text { Ignorar limites de velocidade para andar mais } \\
\text { rápido }\end{array}$ & $\square$ & $\square$ & $\square$ & $\square$ & $\square$ & \\
\hline
\end{tabular}




\begin{tabular}{llllll}
\hline $\begin{array}{l}\text { Continuar a conduzir quando está cansado e } \\
\text { precisaria de uma pausa }\end{array}$ & $\square$ & $\square$ & $\square$ & $\square$ & $\square$ \\
$\begin{array}{l}\text { Conduzir pelo menos } 2 \mathrm{~km} \text { sem usar } 0 \text { cinto de } \\
\text { segurança }\end{array}$ & $\square$ & $\square$ & $\square$ & $\square$ & $\square$ \\
$\begin{array}{l}\text { Usar o telemóvel segurando com as mãos } \\
\text { enquanto conduz fora da área urbana }\end{array}$ & $\square$ & $\square$ & $\square$ & $\square$ & $\square$ \\
\hline
\end{tabular}

$80 \%$ Concluído

\begin{tabular}{|c|c|c|c|c|c|c|}
\hline \multicolumn{7}{|c|}{ Tema: Como se descreve enquanto condutor } \\
\hline 19. De acordo com a sua opinião, os comportamentos abaixo s & & & & & & \\
\hline Não é arriscado & 1 & 2 & 3 & 4 & 5 & Arriscado \\
\hline $\begin{array}{l}\text { Usar o telemóvel em alta voz (mãos livres) } \\
\text { enquanto conduz numa área urbana }\end{array}$ & $\square$ & $\square$ & $\square$ & $\square$ & $\square$ & \\
\hline $\begin{array}{l}\text { Exceder o limite de velocidade em pelo menos } \\
20 \mathrm{~km} / \mathrm{h} \text { quando está com pressa }\end{array}$ & $\square$ & $\square$ & $\square$ & $\square$ & $\square$ & \\
\hline Conduzir muito próximo ao carro da frente & $\square$ & $\square$ & 口 & $\square$ & $\square$ & \\
\hline Mudar de via sem sinalizar & $\square$ & 口 & 口 & 口 & 口 & \\
\hline Conduzir com sono & $\square$ & 口 & 口 & 口 & 口 & \\
\hline $\begin{array}{l}\text { Usar o telemóvel em alta voz (mãos livres) } \\
\text { enquanto conduz fora da área urbana }\end{array}$ & $\square$ & 口 & 口 & 口 & $\square$ & \\
\hline Usar algum tipo de droga ilegal e conduzir & $\square$ & 口 & 口 & $\square$ & $\square$ & \\
\hline $\begin{array}{l}\text { Atravessar o semáforo com o sinal vermelho } \\
\text { durante o dia }\end{array}$ & $\square$ & $\square$ & $\square$ & $\square$ & $\square$ & \\
\hline $\begin{array}{l}\text { Exceder a velocidade quando o trânsito está } \\
\text { tranquilo }\end{array}$ & $\square$ & $\square$ & $\square$ & $\square$ & $\square$ & \\
\hline Ignorar placas de sinalização vertical & $\square$ & 口 & 口 & 口 & 口 & \\
\hline Ultrapassar em local proibido & $\square$ & $\square$ & $\square$ & $\square$ & $\square$ & \\
\hline $\begin{array}{l}\text { Usar o telemóvel segurando com as mãos } \\
\text { enquanto conduz numa área urbana }\end{array}$ & $\square$ & $\square$ & $\square$ & $\square$ & $\square$ & \\
\hline Mudar de via sem olhar pelo espelho retrovisor & $\square$ & $\square$ & 口 & 口 & $\square$ & \\
\hline $\begin{array}{l}\text { Conduzir a distância de } 20 \mathrm{~km} \text {, em média, sem } \\
\text { usar o cinto de segurança }\end{array}$ & $\square$ & $\square$ & 口 & $\square$ & $\square$ & \\
\hline $\begin{array}{l}\text { Conduzir após beber pelo menos } 2 \text { copos de } \\
\text { bebida alcoólica }\end{array}$ & $\square$ & $\square$ & $\square$ & $\square$ & $\square$ & \\
\hline $\begin{array}{l}\text { Atravessar o semáforo com o sinal vermelho } \\
\text { durante a noite }\end{array}$ & $\square$ & $\square$ & $\square$ & $\square$ & $\square$ & \\
\hline $\begin{array}{l}\text { Ignorar limites de velocidade para andar mais } \\
\text { rápido }\end{array}$ & $\square$ & $\square$ & $\square$ & 口 & $\square$ & \\
\hline $\begin{array}{l}\text { Continuar a conduzir quando está cansado e } \\
\text { precisaria de uma pausa }\end{array}$ & $\square$ & $\square$ & $\square$ & $\square$ & $\square$ & \\
\hline $\begin{array}{l}\text { Conduzir pelo menos } 2 \mathrm{~km} \text { sem usar o cinto de } \\
\text { segurança }\end{array}$ & $\square$ & $\square$ & $\square$ & $\square$ & $\square$ & \\
\hline $\begin{array}{l}\text { Usar o telemóvel segurando com as mãos } \\
\text { enquanto conduz fora da área urbana }\end{array}$ & $\square$ & $\square$ & $\square$ & $\square$ & $\square$ & \\
\hline
\end{tabular}

$90 \%$ Concluído

Tema: Como se descreve enquanto condutor

20. Durante o último ano, qual a frequência com que estas situações aconteceram consigo

\begin{tabular}{|c|c|c|c|c|c|c|c|}
\hline & Nunca & 1 & 2 & 3 & 4 & 5 & $\begin{array}{c}\text { Muito } \\
\text { frequentemente }\end{array}$ \\
\hline $\begin{array}{l}\text { Conduzir quando suspeitava que poderia estar acima do } \\
\text { limite legal de álcool no sangue }\end{array}$ & & $\square$ & $\square$ & $\square$ & $\square$ & $\square$ & \\
\hline $\begin{array}{l}\text { Estar numa fila para entrar à direita numa rua principal, } \\
\text { e prestar tanta atenção ao fluxo de trânsito desta rua que } \\
\text { quase bate na traseira do carro da frente }\end{array}$ & & $\square$ & $\square$ & $\square$ & $\square$ & $\square$ & \\
\hline
\end{tabular}




\begin{tabular}{|c|c|c|c|c|c|}
\hline $\begin{array}{l}\text { Não perceber que existem peões a atravessar quando } \\
\text { entra numa rua lateral, vindo de uma rua principal }\end{array}$ & $\square$ & $\square$ & $\square$ & $\square$ & $\square$ \\
\hline $\begin{array}{l}\text { Buzinar para indicar a sua discordância a outro utilizador } \\
\text { da via }\end{array}$ & $\square$ & $\square$ & $\square$ & $\square$ & $\square$ \\
\hline $\begin{array}{l}\text { Não verificar o espelho retrovisor antes de arrancar, } \\
\text { mudar de via, etc }\end{array}$ & $\square$ & $\square$ & $\square$ & $\square$ & $\square$ \\
\hline $\begin{array}{l}\text { Travar muito rapidamente numa estrada com piso } \\
\text { escorregadio, ou rodar o volante para o lado errado } \\
\text { numa derrapagem }\end{array}$ & $\square$ & $\square$ & $\square$ & $\square$ & $\square$ \\
\hline $\begin{array}{l}\text { Parar num cruzamento tão chegado à frente que } 0 \\
\text { condutor com direito de passagem tem que parar para o } \\
\text { deixar passar }\end{array}$ & $\square$ & $\square$ & $\square$ & $\square$ & $\square$ \\
\hline Desrespeitar o limite de velocidade numa rua residencial & $\square$ & $\square$ & $\square$ & $\square$ & 口 \\
\hline $\begin{array}{l}\text { Ao virar à direita, quase colide num ciclista que apareceu } \\
\text { desse lado }\end{array}$ & $\square$ & $\square$ & $\square$ & $\square$ & $\square$ \\
\hline $\begin{array}{l}\text { Ignorar um sinal de "cedência de passagem" e evitar, por } \\
\text { pouco, de colidir com o veículo que tem preferência de } \\
\text { passagem }\end{array}$ & $\square$ & $\square$ & $\square$ & $\square$ & $\square$ \\
\hline $\begin{array}{l}\text { Tentar ultrapassar alguém que você não viu que estava } \\
\text { a sinalizar uma viragem à esquerda }\end{array}$ & $\square$ & $\square$ & $\square$ & $\square$ & $\square$ \\
\hline $\begin{array}{l}\text { Ficar furioso com outro condutor e persegui-lo com a } \\
\text { intenção de dizer exatamente o que pensa dele/dela }\end{array}$ & $\square$ & $\square$ & $\square$ & $\square$ & $\square$ \\
\hline $\begin{array}{l}\text { Ficar numa via da estrada, que sabe que estará } \\
\text { interrompida mais a frente, e forçar a entrada na outra } \\
\text { via no último instante }\end{array}$ & $\square$ & $\square$ & $\square$ & $\square$ & $\square$ \\
\hline Ultrapassar um condutor lento pelo lado direito & $\square$ & 口 & 口 & $\square$ & $\square$ \\
\hline $\begin{array}{l}\text { Arrancar nos semáforos com a intenção de ser mais } \\
\text { rápido que o condutor ao seu lado }\end{array}$ & $\square$ & $\square$ & $\square$ & $\square$ & $\square$ \\
\hline $\begin{array}{l}\text { Conduzir tão próximo do carro da frente que seria difícil } \\
\text { de parar numa situação de emergência }\end{array}$ & $\square$ & $\square$ & $\square$ & $\square$ & $\square$ \\
\hline $\begin{array}{l}\text { Atravessar um cruzamento mesmo sabendo que } 0 \\
\text { semáforo já ficou vermelho para si }\end{array}$ & $\square$ & $\square$ & $\square$ & $\square$ & $\square$ \\
\hline $\begin{array}{l}\text { Ficar furioso com um determinado tipo de condutor e } \\
\text { indicar a sua hostilidade de qualquer maneira possível }\end{array}$ & $\square$ & $\square$ & $\square$ & $\square$ & $\square$ \\
\hline $\begin{array}{l}\text { Subestimar a velocidade de um veículo que vem em } \\
\text { sentido contrário, quando esta a fazer uma } \\
\text { ultrapassagem }\end{array}$ & $\square$ & $\square$ & $\square$ & $\square$ & $\square$ \\
\hline $\begin{array}{l}\text { Desrespeitar } 0 \text { limite de velocidade numa } \\
\text { autoestrada/estrada nacional }\end{array}$ & $\square$ & $\square$ & $\square$ & $\square$ & $\square$ \\
\hline $\begin{array}{l}\text { onduzir quando suspeitava que poderia estar acima do } \\
\text { limite legal de álcool no sangue }\end{array}$ & $\square$ & $\square$ & $\square$ & $\square$ & $\square$ \\
\hline
\end{tabular}





\section{APÊNDICE C - RESULTADOS DOS TESTES PILOTOS}

\begin{tabular}{|c|c|c|c|c|c|c|c|}
\hline \multirow{2}{*}{ Questão } & \multirow{2}{*}{ Item } & \multicolumn{3}{|c|}{ Teste Piloto 1} & \multicolumn{3}{|c|}{ Teste Piloto 2} \\
\hline & & M & $\mathrm{DP}$ & Var & M & $\mathrm{DP}$ & Var \\
\hline 10. a) & Eu sou um motorista muito bom & 4,00 & 0,426 & 0,182 & 4,08 & 0,289 & 0,083 \\
\hline 10. b) & Em geral, outras pessoas não muito boas motoristas & 2,75 & 0,622 & 0,386 & 2,67 & 0,778 & 0,606 \\
\hline 10. c) & Eu dirijo muito cautelosamente & 3,75 & 0,622 & 0,386 & 3,83 & 0,937 & 0,879 \\
\hline 10. d) & Em geral, outras pessoas dirigem muito cautelosamente & 2,58 & 0,793 & 0,629 & 2,25 & 0,754 & 0,568 \\
\hline 10. e) & Meus reflexos enquanto dirijo são muito bons & 3,83 & 0,577 & 0,333 & 3,75 & 0,754 & 0,568 \\
\hline 10. f) & Em geral, os reflexos das outras pessoas enquanto dirigem são muito bons & 2,92 & 0,669 & 0,447 & 2,67 & 0,651 & 0,424 \\
\hline 12. a) & Rua estreita e construções baixas & 2,25 & 1,357 & 1,841 & 3,25 & 1,288 & 1,659 \\
\hline 12. b) & Rua larga e construções baixas & 3,67 & 1,073 & 1,152 & 3,50 & 1,243 & 1,545 \\
\hline 12. c) & Rua estreita e construções altas & 3,67 & 0,888 & ,788 & 3,08 & 1,311 & 1,720 \\
\hline 12. d) & Rua larga e construções altas & 3,58 & 1,379 & 1,902 & 3,75 & 1,288 & 1,659 \\
\hline 13. a) & Rotatória & 4,58 & 0,900 & 0,811 & 4,50 & 0,905 & 0,818 \\
\hline 13. b) & Faixa de pedestre & 4,33 & 0,888 & 0,788 & 4,42 & 0,900 & 0,811 \\
\hline 13. c) & Semáforo & 4,33 & 0,651 & 0,424 & 4,42 & 0,900 & 0,811 \\
\hline 13. d) & Lombada/Redutor de velocidade & 3,67 & 0,985 & 0,970 & 3,50 & 1,243 & 1,545 \\
\hline 13. e) & Sinalização vertical (placas de sinalização) & 4,75 & 0,622 & 0,386 & 4,42 & 0,669 & 0,447 \\
\hline 13. f) & Sinalização horizontal (pinturas nas ruas) & 4,67 & 0,651 & 0,424 & 3,67 & 0,888 & 0,788 \\
\hline 13. g) & Asfalto nas ruas & 4,92 & 0,289 & 0,083 & 4,33 & 0,778 & 0,606 \\
\hline 13. h) & Cruzamentos com sinalização & 4,67 & 0,492 & 0,242 & 3,92 & 0,900 & 0,811 \\
\hline 14. & Qual é a frequência (em média) que você dirige em rodovias & 4,25 & 0,965 & 0,932 & 3,58 & 1,240 & 1,538 \\
\hline 15. a1) & Pequeno número de veículos (LOS-A) & 4,17 & 0,937 & 0,879 & 3,36 & 1,027 & 1,055 \\
\hline 15. a2) & Médio número de veículos (LOS-C) & 3,92 & 0,996 & 0,992 & 4,09 & 0,701 & 0,491 \\
\hline 15. a3) & Grande Número de veículos (LOS-F) & 2,67 & 1,670 & 2,788 & 2,91 & 1,221 & 1,491 \\
\hline 15. b1) & Estrada rural ruim & 1,25 & 0,622 & 0,386 & 1,18 & 0,603 & 0,364 \\
\hline 15. b2) & Estrada rural boa & 1,50 & 1,000 & 1,000 & 1,73 & 1,191 & 1,418 \\
\hline 15. b3) & Estrada com buracos & 2,50 & 1,446 & 2,091 & 1,91 & 1,221 & 1,491 \\
\hline 15. b4) & Estrada com trincas/remendos & 3,17 & 1,193 & 1,424 & 2,55 & 1,368 & 1,873 \\
\hline 15. b5) & Estrada sem problemas & 4,33 & 0,651 & 0,424 & 4,27 & 0,905 & 0,818 \\
\hline 15. c1) & Reta & 3,33 & 1,231 & 1,515 & 4,00 & 1,000 & 1,000 \\
\hline 15. c2) & Curvas leves & 3,83 & 0,937 & 0,879 & 3,36 & 0,924 & 0,855 \\
\hline 15. c3) & Sinuosa & 1,75 & 0,866 & 0,750 & 1,27 & 0,647 & 0,418 \\
\hline 1.1. & Alguém está "costurando" o trânsito. & 2,75 & 0,622 & 0,386 & 3,67 & 1,231 & 1,515 \\
\hline 1.2. & $\begin{array}{l}\text { Um veículo lento na subida da serra não oferece passagem para os demais } \\
\text { motoristas passarem }\end{array}$ & 2,83 & 0,937 & 0,879 & 3,50 & 1,168 & 1,364 \\
\hline 1.3. & Alguém dá marcha ré em sua direção sem olhar & 3,75 & 0,866 & 0,750 & 4,33 & 0,985 & 0,970 \\
\hline 1.4. & Você passa por um radar de velocidade & 2,67 & 1,303 & 1,697 & 2,75 & 1,055 & 1,114 \\
\hline 1.5. & Alguém faz um gesto obsceno para você por causa da sua maneira de dirigir & 3,50 & 1,382 & 1,909 & 3,42 & 1,165 & 1,356 \\
\hline 1.6. & Um policial manda você encostar & 2,25 & 1,288 & 1,659 & 2,25 & 1,215 & 1,477 \\
\hline 1.7. & Um caminhão joga areia ou cascalho no carro que você está dirigindo & 4,08 & 1,084 & 1,174 & 3,50 & 1,382 & 1,909 \\
\hline 1.8. & $\begin{array}{l}\text { Alguém avança o sinal de trânsito (semáforo/sinaleira) vermelho ou a placa } \\
\text { de "pare" }\end{array}$ & 3,83 & 1,193 & 1,424 & 3,75 & 1,055 & 1,114 \\
\hline 1.9. & Alguém buzina para você por causa da sua maneira de dirigir & 3,17 & 1,267 & 1,606 & 3,17 & 1,115 & 1,242 \\
\hline 1.10. & $\begin{array}{l}\text { Você está dirigindo atrás de um caminhão grande e não consegue ver ao } \\
\text { redor dele }\end{array}$ & 2,08 & 0,793 & 0,629 & 3,00 & 1,044 & 1,091 \\
\hline 1.11. & Um ciclista está andando no meio da pista e congestionando o trânsito & 2,75 & 0,965 & 0,932 & 3,08 & 1,240 & 1,538 \\
\hline 1.12. & Você está preso no congestionamento & 3,33 & 1,231 & 1,515 & 3,08 & 1,311 & 1,720 \\
\hline 1.13. & Alguém aumenta a velocidade quando você tenta ultrapassá-lo & 3,67 & 0,888 & 0,788 & 3,50 & 1,314 & 1,727 \\
\hline 1.14. & Alguém demora ao estacionar, atrasando o trânsito & 2,00 & 0,739 & 0,545 & 2,17 & 1,030 & 1,061 \\
\hline 2.1 & Eu gostaria de dirigir sem uma rota pré-definida e um tempo para chegar & 3,08 & 1,564 & 2,447 & 3,25 & 1,357 & 1,841 \\
\hline \multirow[t]{2}{*}{2.2} & Muitas vezes eu me sinto como um piloto de corrida & 2,17 & 1,193 & 1,424 & 2,00 & 0,953 & 0,909 \\
\hline & & & & & & \multicolumn{2}{|c|}{ Continua } \\
\hline
\end{tabular}




\begin{tabular}{|c|c|c|c|c|c|c|c|}
\hline \multicolumn{8}{|c|}{ Continuação } \\
\hline \multirow{2}{*}{ Questão } & \multirow{2}{*}{ Item } & \multicolumn{3}{|c|}{ Teste Piloto 1} & \multicolumn{3}{|c|}{ Teste Piloto 2} \\
\hline & & M & DP & Var & M & $\mathrm{DP}$ & Var \\
\hline 2.3 & Eu gosto de dirigir perigosamente & 1,92 & 1,379 & 1,902 & 1,33 & 0,492 & 0,242 \\
\hline 2.4 & Eu gosto de dirigir em estradas com muitas curvas fechadas & 1,50 & 0,674 & 0,455 & 1,17 & 0,389 & 0,152 \\
\hline 2.5 & $\begin{array}{l}\text { Eu gostaria de aprender a dirigir carros que podem exceder a velocidade de } \\
300 \mathrm{~km} / \mathrm{h}\end{array}$ & 2,42 & 1,379 & 1,902 & 1,75 & 1,138 & 1,295 \\
\hline 2.6 & $\begin{array}{l}\text { Eu não tenho paciência para pessoas que dirigem o carro de maneira } \\
\text { previsível e chata }\end{array}$ & 2,08 & 0,900 & 0,811 & 2,00 & 0,953 & 0,909 \\
\hline 2.7 & $\begin{array}{l}\text { Eu acho que eu gostaria da experiência de dirigir muito rápido em uma rua } \\
\text { íngreme }\end{array}$ & 2,08 & 1,240 & 1,538 & 2,00 & 1,537 & 2,364 \\
\hline 3.0 & Usar o celular, no modo viva voz, enquanto dirige em uma área urbana & - & - & - & 2,83 & 1,586 & 2,515 \\
\hline 3.1. & $\begin{array}{l}\text { Exceder o limite de velocidade em pelo menos } 20 \mathrm{~km} / \mathrm{h} \text { quando você está com } \\
\text { pressa }\end{array}$ & 4,00 & 0,953 & 0,909 & 3,17 & 1,267 & 1,606 \\
\hline 3.2. & Dirigir muito próximo ao veículo da frente & 2,58 & 1,084 & 1,174 & 2,42 & 1,311 & 1,720 \\
\hline 3.3. & Mudar de faixa sem fazer sinal & 2,42 & 0,793 & 0,629 & 2,33 & 1,155 & 1,333 \\
\hline \multirow[t]{2}{*}{3.4.} & Dirigir com sono & 2,67 &, 888 &, 788 & 2,50 & 1,382 & 1,909 \\
\hline & Usar o celular, no modo viva voz, enquanto dirige em uma rodovia & - & - & - & 2,50 & 1,508 & 2,273 \\
\hline 3.5. & Usar algum tipo de droga ilegal e dirigir & 1,00 & 0,000 & 0,000 & 1,00 & 0,000 & 0,000 \\
\hline 3.6. & Atravessar o semáforo com o sinal vermelho durante o dia & 1,83 & 1,193 & 1,424 & 1,67 & 0,778 & 0,606 \\
\hline 3.7. & Exceder a velocidade quando tráfego está tranquilo & 3,50 & 0,798 & 0,636 & 2,67 & 1,073 & 1,152 \\
\hline 3.8. & Ignorar placas de sinalização & 2,17 & 0,718 & 0,515 & 1,50 & 0,674 & 0,455 \\
\hline 3.9. & Ultrapassar em local proibido & 1,58 & 0,793 & 0,629 & 1,33 & 0,492 & 0,242 \\
\hline 3.10. & Usar o celular com as mãos enquanto você dirige em uma área urbana & 2,50 & 1,000 & 1,000 & 2,25 & 1,357 & 1,841 \\
\hline 3.11. & Mudar de faixa sem olhar o espelho & 1,83 & 0,718 & 0,515 & 1,67 & 0,651 & 0,424 \\
\hline 3.12. & Dirigir uma distância de $20 \mathrm{~km}$, em média, sem usar o cinto de segurança & 1,42 & 1,165 & 1,356 & 1,75 & 1,545 & 2,386 \\
\hline 3.13. & Dirigir após beber pelo menos dois copos de bebida alcoólica & 1,25 & 0,452 & 0,205 & 1,50 & 0,905 & 0,818 \\
\hline 3.14. & Atravessar o semáforo com o sinal vermelho durante a noite & 2,50 & 0,905 & 0,818 & 2,42 & 1,505 & 2,265 \\
\hline 3.15. & Ignorar limites de velocidade para andar mais rápido & 2,25 & 0,754 & 0,568 & 2,33 & 1,371 & 1,879 \\
\hline 3.16. & Continuar dirigindo quando você está cansado e precisaria de uma pausa & 2,25 & 1,215 & 1,477 & 2,08 & 0,900 & 0,811 \\
\hline 3.17. & Dirigir pelo menos $2 \mathrm{~km}$ sem usar o cinto de segurança & 2,00 & 1,537 & 2,364 & 2,00 & 1,651 & 2,727 \\
\hline 3.18. & Usar o celular com as mãos enquanto você dirige em uma rodovia & 2,00 & ,953 &, 909 & 1,42 & 0,669 & 0,447 \\
\hline 4.0 & Usar o celular, no modo viva voz, enquanto dirige em uma área urbana & - & - & - & 3,25 & 1,055 & 1,114 \\
\hline 4.1. & $\begin{array}{l}\text { Exceder o limite de velocidade em pelo menos } 20 \mathrm{~km} / \mathrm{h} \text { quando você está com } \\
\text { pressa }\end{array}$ & 3,08 & 0,996 & 0,992 & 3,67 & 1,231 & 1,515 \\
\hline 4.2. & Dirigir muito próximo ao veículo da frente & 4,08 & 0,996 & 0,992 & 4,17 & 1,115 & 1,242 \\
\hline 4.3. & Mudar de faixa sem fazer sinal & 4,08 & 1,165 & 1,356 & 3,92 & 1,084 & 1,174 \\
\hline \multirow[t]{2}{*}{4.4.} & Dirigir com sono & 4,75 & 0,622 & 0,386 & 4,00 & 1,348 & 1,818 \\
\hline & Usar o celular, no modo viva voz, enquanto dirige em uma rodovia & - & - & - & 3,75 & 1,138 & 1,295 \\
\hline 4.5. & Usar algum tipo de droga ilegal e dirigir & 5,00 & 0,000 & 0,000 & 4,42 & 1,240 & 1,538 \\
\hline 4.6. & Atravessar o semáforo com o sinal vermelho durante o dia & 4,50 & 0,798 & 0,636 & 4,25 & 1,138 & 1,295 \\
\hline 4.7. & Exceder a velocidade quando tráfego está tranquilo & 3,08 & 1,084 & 1,174 & 3,00 & 0,853 & 0,727 \\
\hline 4.8. & Ignorar placas de sinalização & 3,83 & 0,835 & 0,697 & 4,25 & 1,215 & 1,477 \\
\hline 4.9. & Ultrapassar em local proibido & 4,50 & 0,674 & 0,455 & 4,25 & 1,138 & 1,295 \\
\hline 4.10. & Usar o celular com as mãos enquanto você dirige em uma área urbana & 4,33 & 0,888 & 0,788 & 4,33 & 1,155 & 1,333 \\
\hline 4.11. & Mudar de faixa sem olhar o espelho & 4,42 & 0,793 & 0,629 & 4,42 & 0,996 & 0,992 \\
\hline 4.12. & Dirigir uma distância de $20 \mathrm{~km}$, em média, sem usar o cinto de segurança & 4,83 & 0,389 & 0,152 & 3,58 & 1,443 & 2,083 \\
\hline 4.13. & Dirigir após beber pelo menos dois copos de bebida alcoólica & 5,00 & 0,000 & 0,000 & 3,92 & 1,165 & 1,356 \\
\hline 4.14. & Atravessar o semáforo com o sinal vermelho durante a noite & 3,25 & 1,138 & 1,295 & 3,33 & 1,371 & 1,879 \\
\hline 4.15. & Ignorar limites de velocidade para andar mais rápido & 4,08 & 0,793 & 0,629 & 4,08 & 0,996 & 0,992 \\
\hline 4.16. & Continuar dirigindo quando você está cansado e precisaria de uma pausa & 4,67 & 0,651 & 0,424 & 4,33 & 0,888 & 0,788 \\
\hline 4.17. & Dirigir pelo menos2 km sem usar o cinto de segurança & 3,42 & 1,505 & 2,265 & 3,50 & 1,446 & 2,091 \\
\hline 4.18. & Usar o celular com as mãos enquanto você dirige em uma rodovia & 4,50 &, 674 & 0,455 & 4,50 & 1,168 & 1,364 \\
\hline 5.1. & Dirigir após consumir bebida alcoólica & 1,33 & 0,651 & 0,424 & 1,33 & 0,492 & 0,242 \\
\hline 5.2. & $\begin{array}{l}\text { Estar em uma fila para entrar à direita em uma rua principal e prestar tanta } \\
\text { atenção no trânsito dessa rua, que quase bate na traseira do carro à sua } \\
\text { frente }\end{array}$ & 2,25 & 0,754 & 0,568 & 1,67 & 0,778 & 0,606 \\
\hline
\end{tabular}




\begin{tabular}{|c|c|c|c|c|c|c|c|}
\hline \multicolumn{8}{|c|}{ Continuação } \\
\hline \multirow{2}{*}{ Questão } & \multirow{2}{*}{ Item } & \multicolumn{3}{|c|}{ Teste Piloto 1} & \multicolumn{3}{|c|}{ Teste Piloto 2} \\
\hline & & M & $\mathrm{DP}$ & Var & M & DP & Var \\
\hline 5.3 . & $\begin{array}{l}\text { Não perceber que pedestres estão atravessando, ao entrar em uma rua } \\
\text { lateral, vindo de uma rua principal }\end{array}$ & 1,83 & 0,835 & 0,697 & 1,67 & 0,651 & 0,424 \\
\hline 5.4. & Buzinar para indicar sua contrariedade com relação a outro usuário da via & 2,58 & 1,165 & 1,356 & 2,58 & 1,240 & 1,538 \\
\hline 5.5. & $\begin{array}{l}\text { Não verificar seu espelho retrovisor antes de sair com o carro, mudar de faixa } \\
\text { etc }\end{array}$ & 1,92 & 1,165 & 1,356 & 1,58 & 0,515 & 0,265 \\
\hline 5.6. & $\begin{array}{l}\text { Frear muito rápido em uma estrada escorregadia, ou girar o volante para o } \\
\text { lado errado em uma derrapagem }\end{array}$ & 1,33 & 0,492 & 0,242 & 1,25 & 0,452 & 0,205 \\
\hline 5.7. & $\begin{array}{l}\text { Parar em um cruzamento tão para a frente que o motorista que tem } \\
\text { preferência precisa parar e deixar você passar }\end{array}$ & 1,67 & 0,985 & 0,970 & 1,75 & 0,754 & 0,568 \\
\hline 5.8. & Desrespeitar o limite de velocidade em uma rua de área residencial & 2,50 & 1,000 & 1,000 & 2,75 & 1,288 & 1,659 \\
\hline 5.9. & Ao virar à direita, quase bater em um ciclista que apareceu do seu lado & 1,17 & 0,389 & 0,152 & 1,17 & 0,389 & 0,152 \\
\hline 5.10. & $\begin{array}{l}\text { Não prestar atenção aos sinais de "Dê a preferência" e evitar, por pouco, } \\
\text { colidir com outro veículo que tem a preferência }\end{array}$ & 1,50 & 0,522 & 0,273 & 1,50 & 0,798 & 0,636 \\
\hline 5.11. & $\begin{array}{l}\text { Tentar ultrapassar alguém que você não viu estar sinalizando para entrar à } \\
\text { esquerda }\end{array}$ & 1,75 & 0,622 & 0,386 & 1,33 & 0,888 & 0,788 \\
\hline 5.12. & $\begin{array}{l}\text { Ficar muito bravo por causa de outro (a) motorista e persegui-lo(a) com a } \\
\text { intenção de dizer o que você pensou dele/dela }\end{array}$ & 1,00 & 0,000 & 0,000 & 1,50 & 0,905 & 0,818 \\
\hline 5.13. & $\begin{array}{l}\text { Ficar em uma faixa da pista, que você sabe que estará interrompida adiante, } \\
\text { e forçar sua entrada na outra faixa no último instante }\end{array}$ & 1,58 & 0,900 & 0,811 & 1,50 & 0,674 & 0,455 \\
\hline 5.14. & Ultrapassar um motorista lento pelo lado direito & 1,92 & 0,996 & 0,992 & 1,58 & 0,793 & 0,629 \\
\hline 5.15. & $\begin{array}{l}\text { Arrancar nos semáforos com a intenção de ser mais rápido que o motorista } \\
\text { ao seu lado }\end{array}$ & 1,75 & 1,055 & 1,114 & 2,00 & 1,477 & 2,182 \\
\hline 5.16. & $\begin{array}{l}\text { Dirigir tão próximo ao veículo da frente que seria difícil parar em uma situação } \\
\text { de emergência }\end{array}$ & 1,42 & 0,515 & 0,265 & 1,25 & 0,452 & 0,205 \\
\hline 5.17. & Atravessar o cruzamento sabendo que o semáforo já fechou para você & 1,75 & 0,754 & 0,568 & 2,25 & 1,138 & 1,295 \\
\hline 5.18. & $\begin{array}{l}\text { Ficar muito bravo com um determinado tipo de motorista e indicar sua } \\
\text { hostilidade de qualquer maneira }\end{array}$ & 1,92 & 0,900 & 0,811 & 2,00 & 1,128 & 1,273 \\
\hline 5.19. & $\begin{array}{l}\text { Subestimar a velocidade de um veículo que está vindo no sentido contrário } \\
\text { ao iniciar uma ultrapassagem }\end{array}$ & 1,58 & 0,515 & 0,265 & 1,50 & 0,674 & 0,455 \\
\hline 5.20. & Desrespeitar o limite de velocidade em uma rodovia & 2,92 & 1,240 & 1,538 & 2,50 & 1,000 & 1,000 \\
\hline
\end{tabular}

Nota: Q=Questão; M=Média; DP=Desvio Padrão

Tabela C.2 - Caracterização das amostras dos testes pilotos

\begin{tabular}{|c|c|c|c|c|c|c|c|c|c|c|}
\hline & \multicolumn{5}{|c|}{ Teste Piloto 1} & \multicolumn{5}{|c|}{ Teste Piloto 2} \\
\hline & $n$ & Média & $\mathrm{DP}$ & Min. & Máx. & $n$ & Média & $\mathrm{DP}$ & Min. & Máx. \\
\hline Idade & 12 & 31,08 & 5,63 & 25 & 46 & 12 & 34,75 & 8,92 & 21 & 53 \\
\hline Tempo habilitação de carro & 12 & 10,58 & 5,79 & 2 & 22 & 12 & 14,25 & 8,52 & 3 & 33 \\
\hline Tempo habilitação de moto & 5 & 15 & 6,04 & 7 & 22 & 1 & 3 & 0 & 3 & 3 \\
\hline $\mathrm{Km} /$ semana (carro) & 12 & 204,83 & 246,24 & 28 & 800 & 12 & 160,58 & 132,55 & 10 & 450 \\
\hline Km/semana (moto) & 5 & 63,08 & 151,20 & 0 & 600 & 1 & 100 & 0 & 100 & 100 \\
\hline
\end{tabular}

Nota: $\mathrm{n}=$ número de indivíduos; $\mathrm{DP}=$ Desvio Padrão; Min=Mínimo; Máx=Máximo. 



\section{APÊNDICE D - DISTRIBUIÇÃO DOS ESCORES INDIVIDUAIS DA CATPCA}

Figura D. 1 - Distribuição dos escores individuais das variáveis latentes de habilidades do condutor

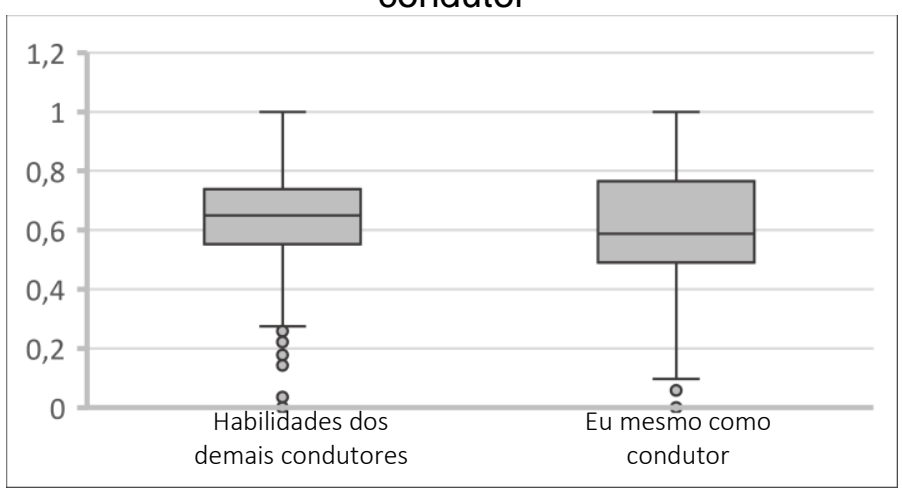

Figura D. 2 - Distribuição dos escores individuais das variáveis latentes da escala de raiva do condutor

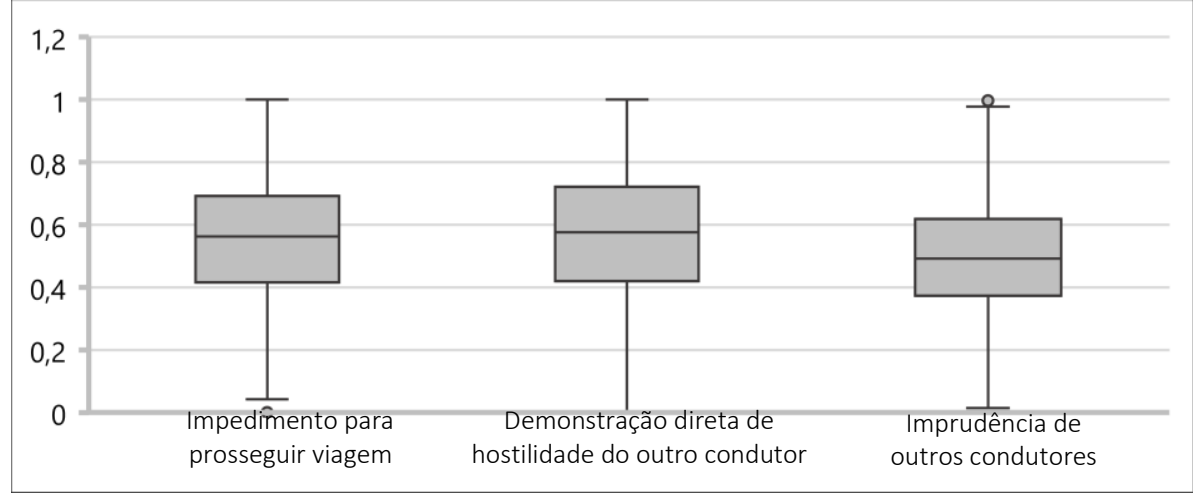

Figura D. 3 - Distribuição dos escores individuais da variável latente de busca de sensações

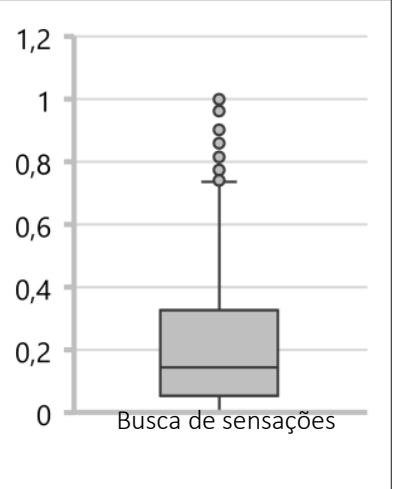


Figura D. 4 - Distribuição dos escores individuais das variáveis latentes da escala de raiva do condutor

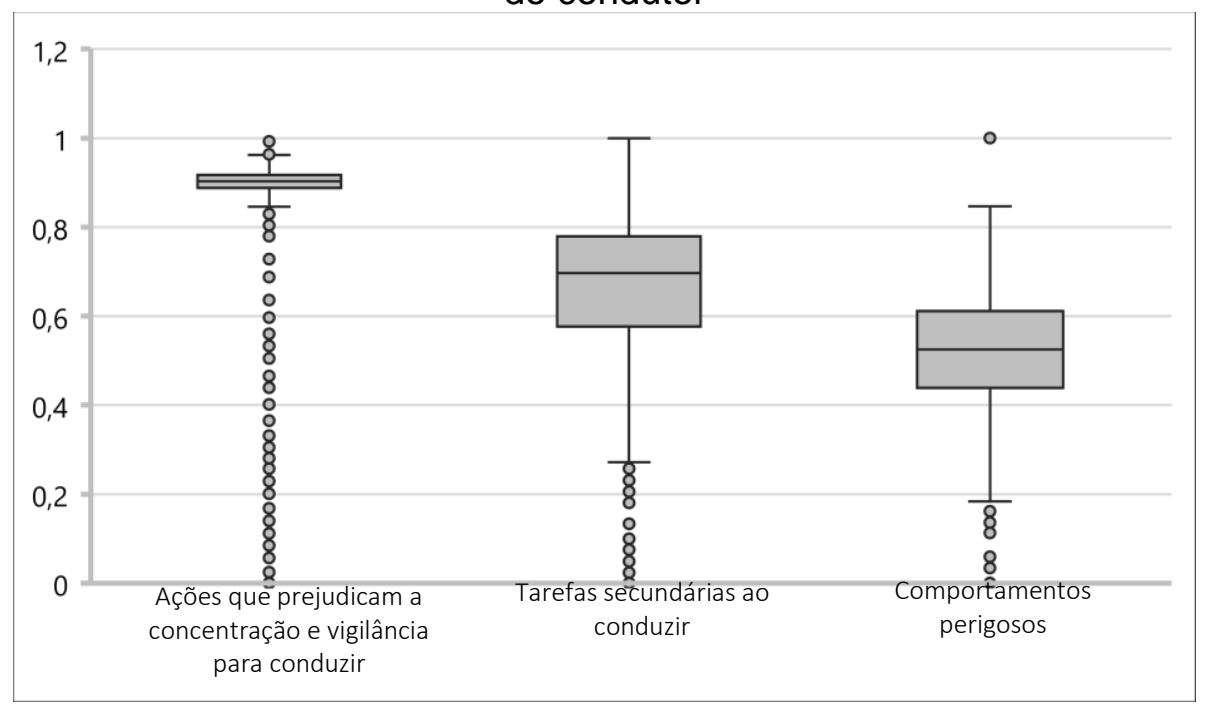

Figura D. 5 - Distribuição dos escores individuais das variáveis latentes da caracterização do ambiente viário

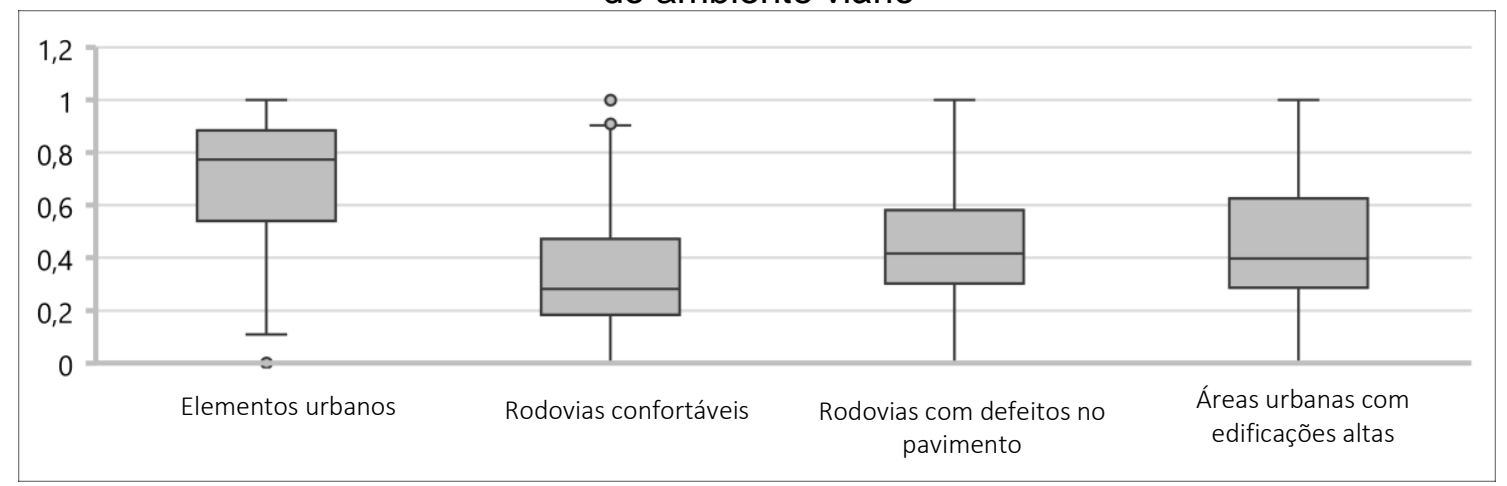

\section{Quadro D 1- Itens excluídos do Questionário de Comportamento do Condutor}

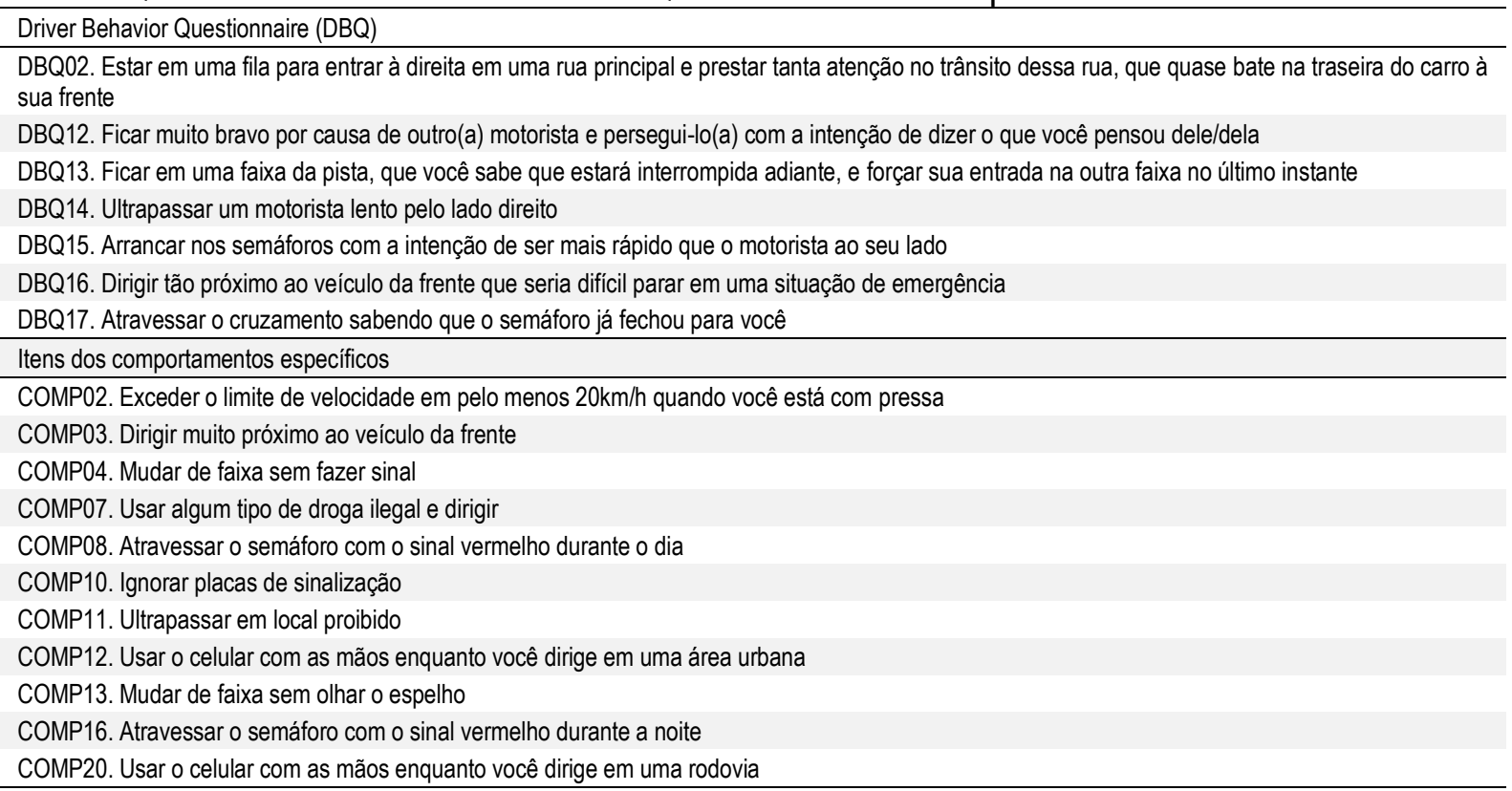




\section{APÊNDICE E - TESTES DE HIPÓTESE E MEDIDAS DE CARACTERIZAÇÃO DOS NÓS TERMINAIS DA ÁRVORE DE DECISÃO}

Tabela E.1- Teste U de Mann-Whitney de amostras independentes (Nó 1 e Nó 2) da classificação dos comportamentos de risco

\begin{tabular}{|c|c|c|c|c|c|c|c|c|c|c|}
\hline \multicolumn{4}{|c|}{$\stackrel{\substack{\frac{\infty}{\infty} \\
: \frac{\pi}{\frac{\pi}{N 0}}}}{>}$} & 冝 & 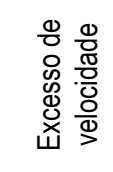 & 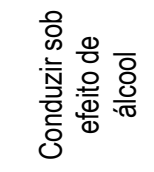 & 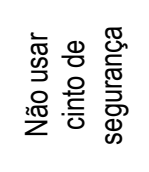 & 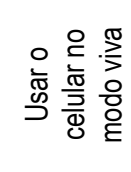 & 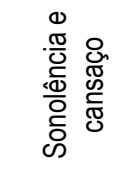 & 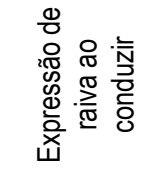 \\
\hline \multirow{4}{*}{ 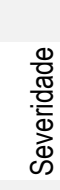 } & \multicolumn{3}{|c|}{ Número de acidentes de trânsito } & $0,016^{*}$ & $0,000^{*}$ & $0,003^{*}$ & $0,000^{*}$ & $0,000^{*}$ & $0,001^{*}$ & $0,000^{*}$ \\
\hline & \multicolumn{3}{|c|}{ Danos materiais } & $0,017^{*}$ & $0,001^{*}$ & $0,005^{*}$ & $0,000^{*}$ & $0,000^{*}$ & $0,002^{*}$ & $0,000^{*}$ \\
\hline & \multicolumn{3}{|l|}{ Lesões leves } & 0,536 & $0,049^{*}$ & 0,412 & 0,073 & 0,771 & 0,125 & 0,960 \\
\hline & \multicolumn{3}{|l|}{ Lesões graves } & 0,619 & 0,709 & 0,405 & 0,329 & 0,424 & 0,207 & 0,893 \\
\hline & \multicolumn{3}{|c|}{ Excesso de velocidade } & 0,466 & $0,000^{*}$ & $0,000^{*}$ & $0,000^{*}$ & $0,026^{*}$ & $0,003^{*}$ & 0,369 \\
\hline & \multicolumn{3}{|c|}{ Álcool } & 0,883 & 0,294 & $0,003^{*}$ & 0,296 & 0,062 & 0,721 & 0,642 \\
\hline 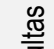 & \multicolumn{3}{|l|}{ Celular } & $0,019^{*}$ & 0,547 & 0,259 & $0,009^{*}$ & 0,054 & 0,747 & 0,276 \\
\hline$\stackrel{\vec{\Sigma}}{\Sigma}$ & \multicolumn{3}{|c|}{ Desrespeito a sinais de trânsito } & 0,254 & 0,672 & 0,724 & 0,197 & 0,059 & 0,608 & 0,784 \\
\hline & \multicolumn{3}{|c|}{ Estacionar em local proibido } & 0,222 & 0,055 & $0,000^{*}$ & $0,003^{*}$ & 0,291 & 0,255 & 0,228 \\
\hline & \multicolumn{3}{|c|}{ Carteira de habilitação irregular } & 0,562 & 0,110 & 0,757 & 0,373 & 0,709 & 0,567 & 0,449 \\
\hline & \multicolumn{3}{|l|}{ Erros } & $0,000^{*}$ & 0,421 & $0,000^{*}$ & $0,043^{*}$ & 0,325 & $0,000^{*}$ & 0,621 \\
\hline ֻ & \multicolumn{3}{|c|}{ Excesso de velocidade } & 0,670 & $0,000^{*}$ & $0,007^{*}$ & $0,000^{*}$ & $0,001^{*}$ & $0,022^{*}$ & $0,027^{*}$ \\
\hline$\stackrel{\bar{E}}{\Phi}$ & \multicolumn{3}{|c|}{ Dirigir sob efeito de álcool } & $0,000^{*}$ & $0,004^{*}$ & $0,000^{*}$ & $0,000^{*}$ & 0,101 & 0,398 & 0,161 \\
\hline 离 & \multicolumn{3}{|c|}{ Não usar cinto de segurança } & 0,175 & $0,000^{*}$ & $0,000^{*}$ & $0,000^{*}$ & $0,000^{*}$ & $0,000^{*}$ & 0,263 \\
\hline हू & \multicolumn{4}{|c|}{ Usar o celular no modo viva voz ao conduzir $\quad 0,056$} & 0,315 & 0,118 & $0,000^{*}$ & $0,000^{*}$ & 0,968 & 0,764 \\
\hline u & \multicolumn{3}{|c|}{ Sonolência e cansaço } & $0,000^{*}$ & 0,517 & 0,089 & $0,000^{*}$ & 0,444 & $0,000^{*}$ & 0,921 \\
\hline & \multicolumn{3}{|c|}{ Expressão de raiva ao conduzir } & 0,820 & 0,283 & 0,400 & 0,743 & 0,739 & 0,844 & $0,000^{*}$ \\
\hline \multicolumn{11}{|c|}{$\begin{array}{c}\text { Tabela E.2- Média de multas entre os nós dos comportamentos de risco classificados com a } \\
\text { árvore de decisão }\end{array}$} \\
\hline & \multicolumn{3}{|r|}{ 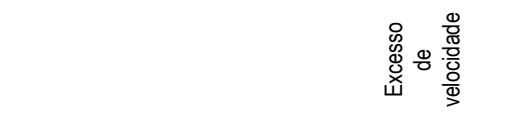 } & \multicolumn{2}{|l|}{$\begin{array}{l}\overline{\mathrm{o}} \\
\stackrel{\mathrm{u}}{\mathrm{\alpha}}\end{array}$} & 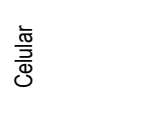 & 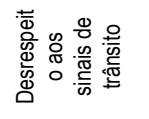 & \multicolumn{2}{|c|}{ 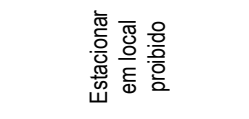 } & 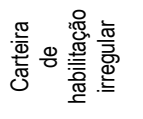 \\
\hline \multirow{2}{*}{\multicolumn{3}{|c|}{ Erros }} & 0,916 & \multicolumn{2}{|c|}{0,007} & 0,057 & \multicolumn{2}{|l|}{0,113} & 0,186 & 0,004 \\
\hline & & & 0,862 & & 06 & 0,080 & 0,102 & & 0,210 & 0,007 \\
\hline Exc & sso de velocidade & & 0,611 & & 02 & 0,056 & 0,124 & & 0,148 & 0,000 \\
\hline & & & 0,976 & & 08 & 0,073 & 0,102 & & 0,215 & 0,007 \\
\hline Diric & sob influência de álc & & 0,698 & & 01 & 0,064 & 0,105 & & 0,169 & 0,006 \\
\hline & & & 1,141 & & 14 & 0,075 & 0,111 & & 0,238 & 0,004 \\
\hline Não & Isar cinto de seguran & & 1,149 & & 02 & 0,100 & 0,078 & & 0,259 & 0,010 \\
\hline & & & 0,805 & & 08 & 0,059 & 0,117 & & 0,180 & 0,004 \\
\hline Usa & 0 celular no modo $v$ & & 0,826 & & 05 & 0,061 & 0,094 & & 0,193 & 0,005 \\
\hline VOZ & & & 1,177 & & 13 & 0,104 & 0,171 & & 0,224 & 0,007 \\
\hline Son & ência e cansaço & & 0,764 & & 08 & 0,075 & 0,117 & & 0,185 & 0,005 \\
\hline & & & 0,953 & & 05 & 0,066 & 0,103 & & 0,206 & 0,005 \\
\hline Exp & ssão de raiva & ao & 0,893 & & & 0,063 & 0,113 & & 0,192 & 0,005 \\
\hline cono & & & 0,880 & & 05 & 0,079 & 0,098 & & 0,209 & 0,006 \\
\hline
\end{tabular}


Tabela E.3- Média dos escores dos objetos entre os nós de comportamentos de risco classificados com a árvore de decisão

\begin{tabular}{|c|c|c|c|c|c|c|c|c|}
\hline & & & 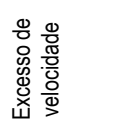 & 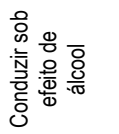 & 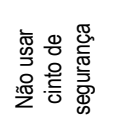 & 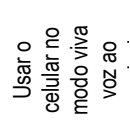 & 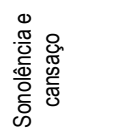 & 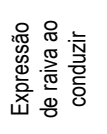 \\
\hline \multirow{2}{*}{ Erros } & 1 & 0,030 & 0,405 & 0,403 & 0,246 & 0,366 & 0,433 & 0,472 \\
\hline & 2 & 0,069 & 0,402 & 0,368 & 0,240 & 0,379 & 0,462 & 0,466 \\
\hline \multirow{2}{*}{ Excesso de velocidade } & 1 & 0,048 & 0,174 & 0,375 & 0,241 & 0,375 & 0,442 & 0,474 \\
\hline & 2 & 0,051 & 0,476 & 0,388 & 0,243 & 0,372 & 0,450 & 0,467 \\
\hline \multirow{2}{*}{ Dirigir sob efeito de álcool } & 1 & 0,049 & 0,395 & 0,252 & 0,237 & 0,367 & 0,442 & 0,466 \\
\hline & 2 & 0,052 & 0,414 & 0,561 & 0,251 & 0,381 & 0,456 & 0,473 \\
\hline \multirow{2}{*}{ Não usar cinto de segurança } & 1 & 0,060 & 0,535 & 0,530 & 0,153 & 0,416 & 0,492 & 0,474 \\
\hline & 2 & 0,047 & 0,362 & 0,339 & 0,271 & 0,359 & 0,434 & 0,467 \\
\hline \multirow{2}{*}{ Usar o celular no modo viva voz ao conduzir } & 1 & 0,050 & 0,396 & 0,383 & 0,243 & 0,296 & 0,445 & 0,468 \\
\hline & 2 & 0,053 & 0,439 & 0,392 & 0,242 & 0,734 & 0,460 & 0,473 \\
\hline \multirow{2}{*}{ Sonolência e cansaço } & 1 & 0,049 & 0,393 & 0,376 & 0,245 & 0,371 & 0,277 & 0,470 \\
\hline & 2 & 0,051 & 0,409 & 0,389 & 0,242 & 0,374 & 0,539 & 0,468 \\
\hline \multirow{2}{*}{ Expressão de raiva ao conduzir } & 1 & 0,049 & 0,394 & 0,383 & 0,241 & 0,371 & 0,446 & 0,385 \\
\hline & 2 & 0,054 & 0,419 & 0,388 & 0,247 & 0,377 & 0,451 & 0,612 \\
\hline
\end{tabular}

Tabela E.4- Acidentes e severidade em cada nó dos comportamentos de risco classificados com árvore de decisão

\begin{tabular}{|c|c|c|c|c|c|c|c|c|c|c|c|}
\hline \multirow{2}{*}{ Comportamento } & \multirow{2}{*}{ Nó } & \multicolumn{4}{|c|}{ Acidentes } & \multicolumn{2}{|c|}{$\begin{array}{c}\text { Danos } \\
\text { Materiais }\end{array}$} & \multicolumn{2}{|c|}{ Ferimento Leve } & \multicolumn{2}{|c|}{$\begin{array}{c}\text { Ferimento } \\
\text { Grave }\end{array}$} \\
\hline & & Não & Sim & $n$ & Média & $n$ & Média & $n$ & Média & $n$ & Média \\
\hline \multirow[t]{2}{*}{ Erros } & 1 & 626 & 186 & 235 & 0,289 & 168 & 0,266 & 17 & 0,021 & 1 & 0,002 \\
\hline & 2 & 638 & 252 & 320 & 0,360 & 236 & 0,340 & 14 & 0,017 & 2 & 0,002 \\
\hline \multirow[t]{2}{*}{ Excesso de velocidade } & 1 & 336 & 75 & 108 & 0,263 & 71 & 0,251 & 3 & 0,007 & 1 & 0,005 \\
\hline & 2 & 928 & 363 & 447 & 0,346 & 333 & 0,322 & 28 & 0,022 & 2 & 0,002 \\
\hline \multirow[t]{2}{*}{ Dirigir sob influência de álcool } & 1 & 747 & 225 & 278 & 0,286 & 208 & 0,269 & 16 & 0,016 & 1 & 0,001 \\
\hline & 2 & 517 & 213 & 277 & 0,379 & 196 & 0,353 & 15 & 0,022 & 2 & 0,004 \\
\hline \multirow[t]{2}{*}{ Não usar cinto de segurança } & 1 & 274 & 136 & 174 & 0,424 & 124 & 0,395 & 12 & 0,029 & 0 & 0,000 \\
\hline & 2 & 990 & 302 & 381 & 0,295 & 280 & 0,276 & 19 & 0,015 & 3 & 0,003 \\
\hline \multirow[t]{2}{*}{ Usar o celular no modo viva voz ao conduzir } & 1 & 1.066 & 337 & 415 & 0,296 & 308 & 0,274 & 26 & 0,019 & 3 & 0,003 \\
\hline & 2 & 198 & 101 & 140 & 0,468 & 96 & 0,452 & 5 & 0,017 & 0 & 0,000 \\
\hline \multirow[t]{2}{*}{ Sonolência e cansaço } & 1 & 466 & 124 & 152 & 0,258 & 117 & 0,246 & 7 & 0,012 & 0 & 0,000 \\
\hline & 2 & 798 & 314 & 403 & 0,362 & 287 & 0,336 & 24 & 0,022 & 3 & 0,004 \\
\hline \multirow[t]{2}{*}{ Expressão de raiva ao conduzir } & 1 & 830 & 241 & 300 & 0,280 & 220 & 0,259 & 19 & 0,019 & 2 & 0,003 \\
\hline & 2 & 434 & 197 & 255 & 0,404 & 184 & 0,384 & 12 & 0,019 & 1 & 0,002 \\
\hline
\end{tabular}

Nota: $n=$ número de acidentes 
Figura E. 1- Distribuição das respostas das questões originais do comportamento erros de acordo com os nós terminais
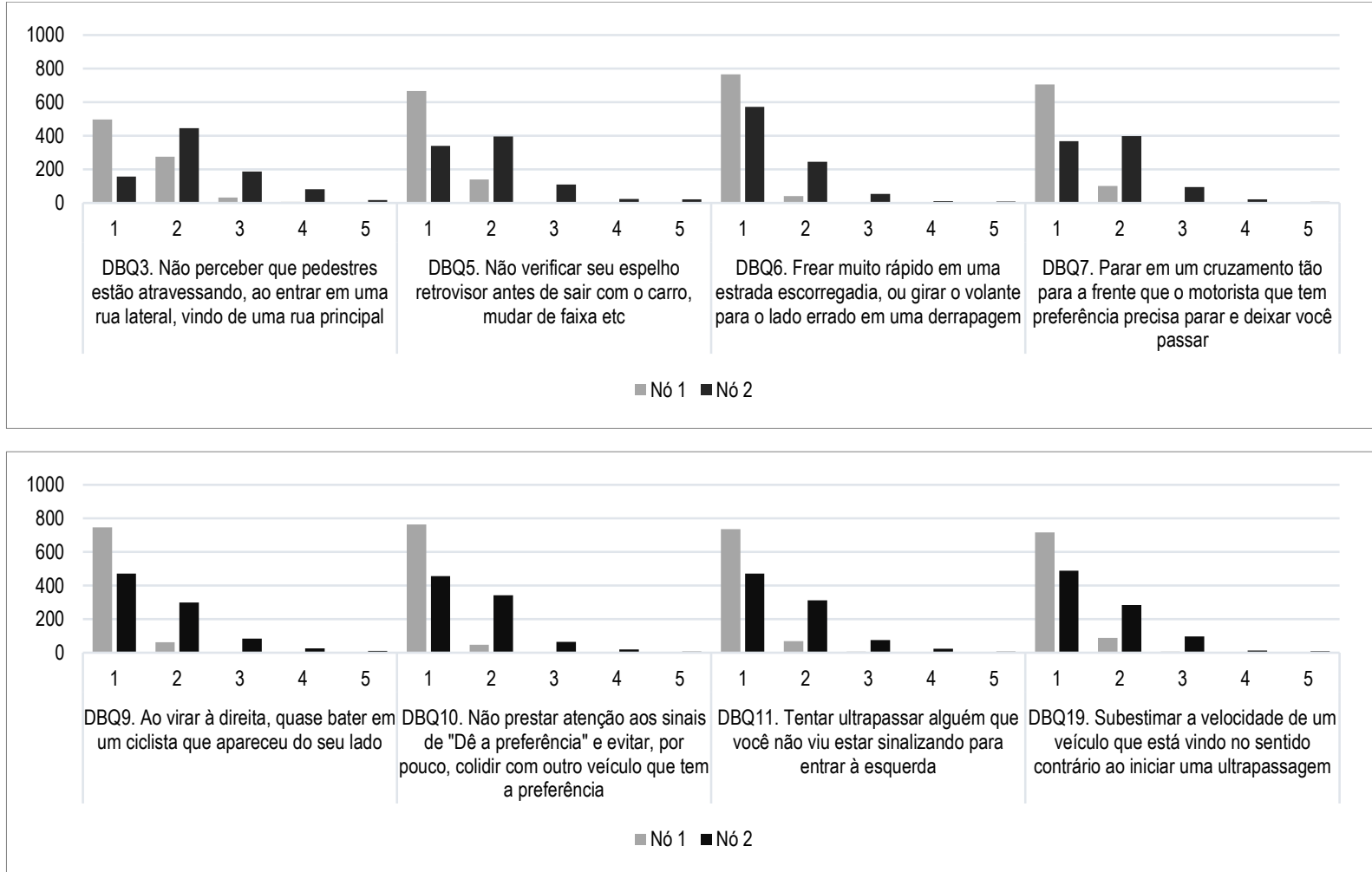

Figura E. 2 - Distribuição das respostas das questões originais do comportamento excesso de velocidade de acordo com os nós terminais

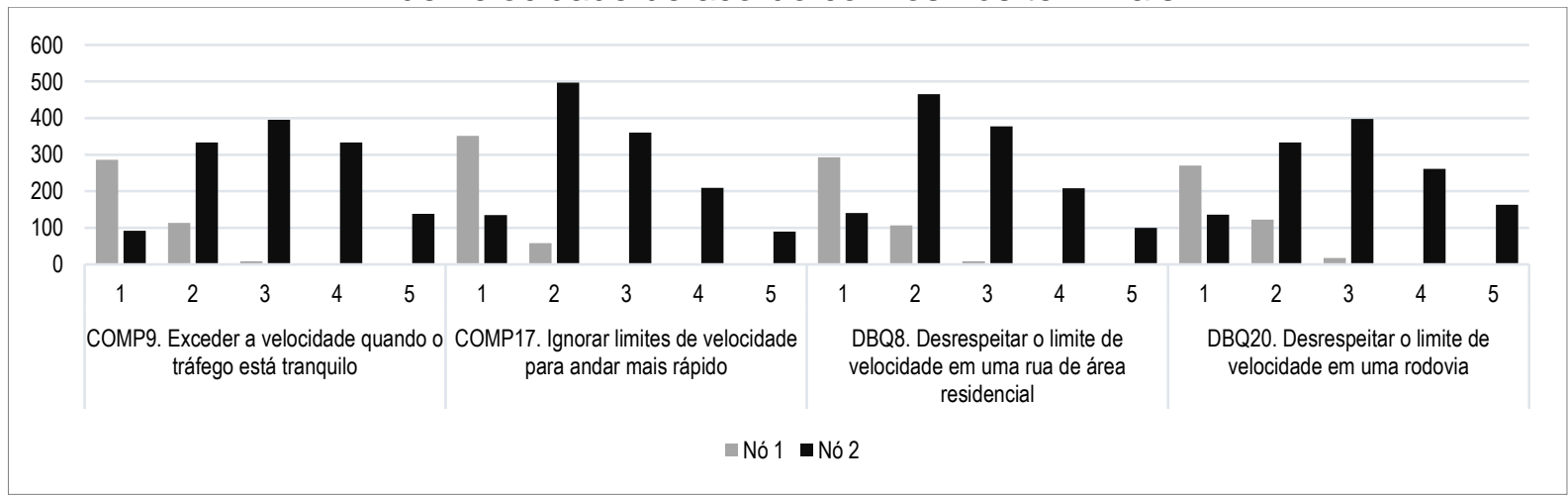


Figura E. 3 - Distribuição das respostas das questões originais do comportamento conduzir sob efeito de álcool de acordo com os nós terminais

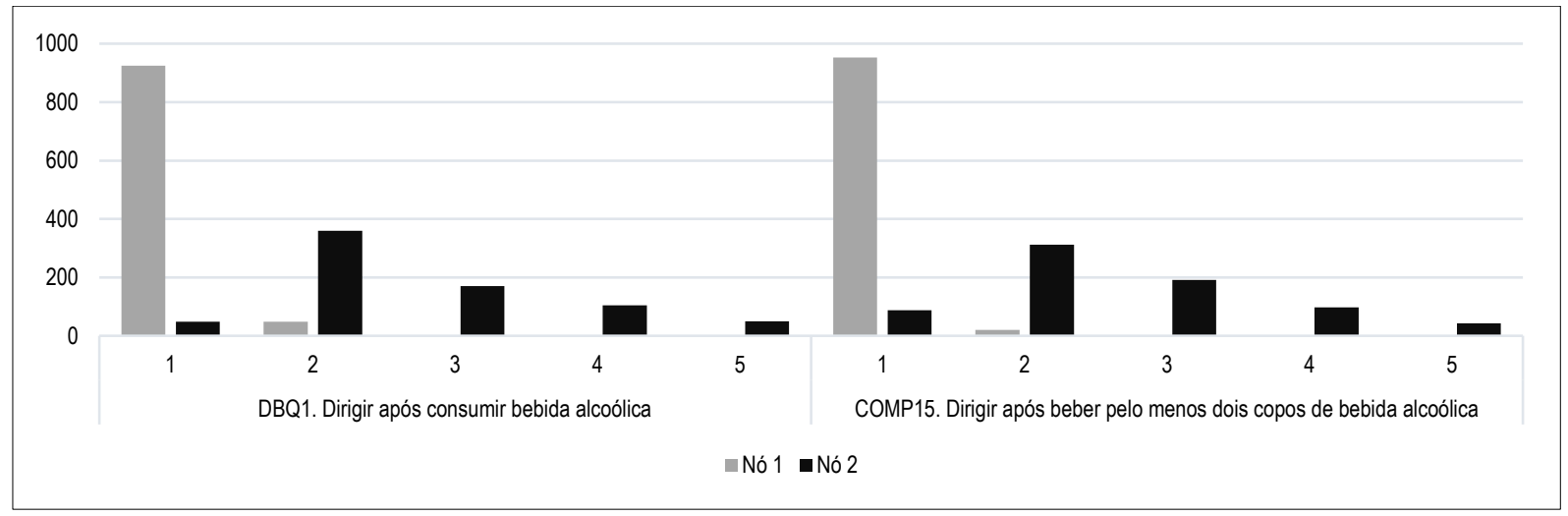

Figura E. 4 - Frequência de respostas para cada nó das variáveis que representam o comportamento do não uso de cinto de segurança

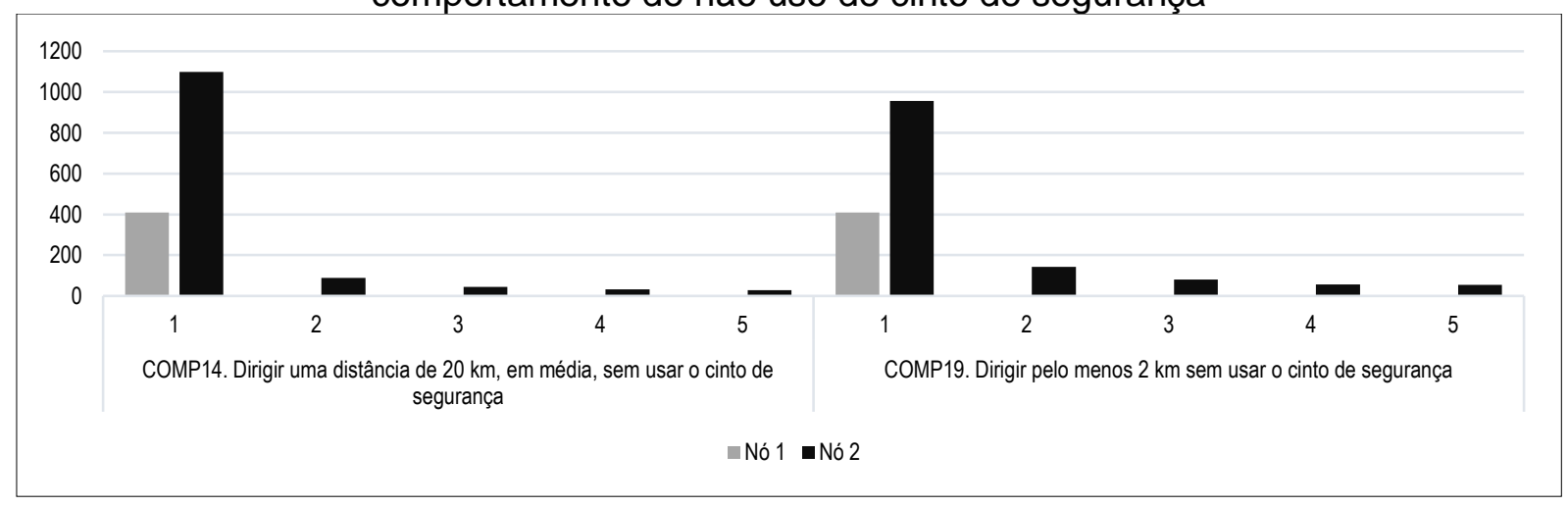

Figura E. 5 - Frequência de respostas para cada nó das variáveis que representam o comportamento Uso do celular no modo viva voz

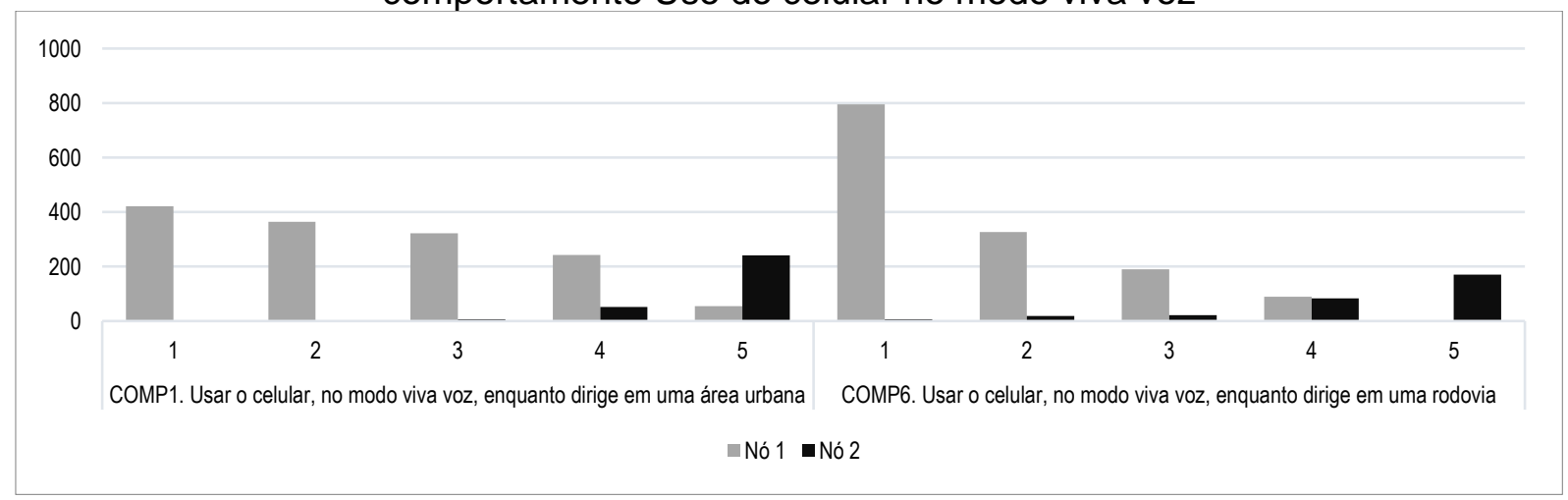


Figura E. 6 - Frequência de respostas para cada nó das variáveis que representam o comportamento sonolência e cansaço

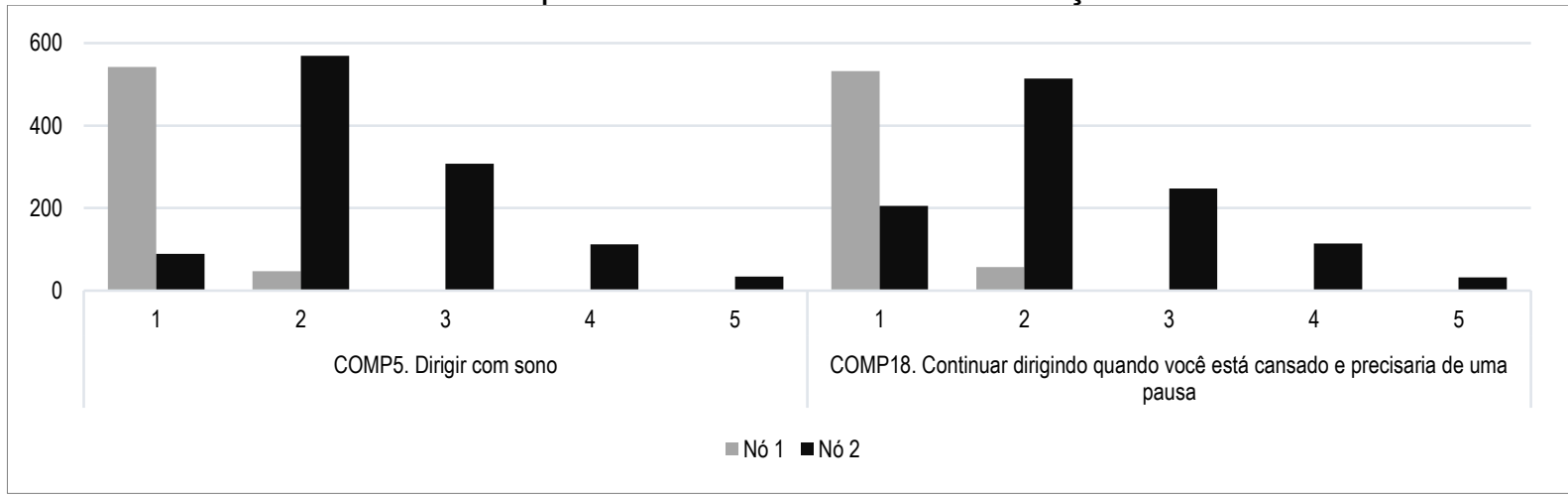

Figura E. 7 - Frequência de respostas para cada nó das variáveis que representam o comportamento expressão de raiva ao conduzir

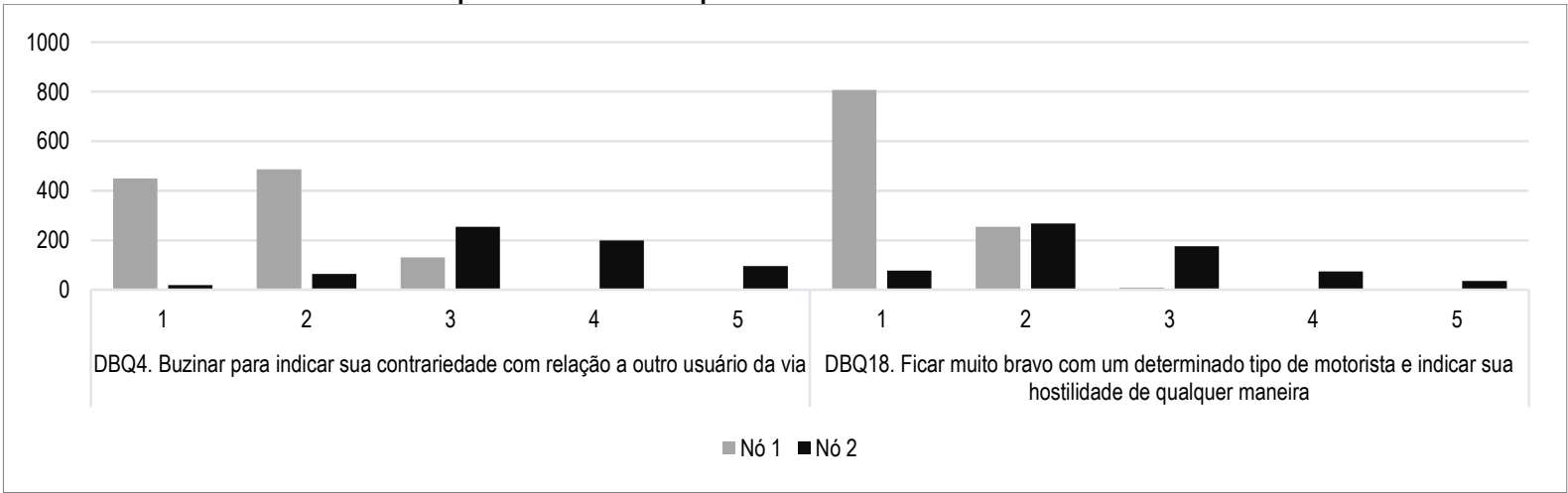


APÊNDICE F - PARÂMETROS ESTIMADOS

Tabela F. 1- Parâmetros estimados para os modelos do comportamento Erros

\begin{tabular}{|c|c|c|c|c|c|c|c|c|c|c|}
\hline & A1 & A2 & A3 & A4 & A5 & B3 & C1 & C2 & C5 & D \\
\hline Constante & $0,179^{*}$ & $0,135^{* *}$ & & $-0,924^{*}$ & 0,887 & & $0,173^{*}$ & $0,244^{*}$ & & \\
\hline Filhos & $0,210^{*}$ & & & & & & $0,212^{*}$ & & $0,248^{\star}$ & $0,320^{\star \star}$ \\
\hline$>20$ S.M. & $-0,612^{*}$ & & & & & & $-0,638^{*}$ & $-0,680^{*}$ & $-0,738^{\star *}$ & $-0,694^{*}$ \\
\hline Homem & $-0,293^{\star *}$ & & & & & & $-0,258^{* *}$ & $-0,269^{* *}$ & $-0,265^{\star *}$ & $-0,272^{* *}$ \\
\hline $300-500 \mathrm{~km} / \mathrm{semana}$ & & $-0,358^{* *}$ & & & & & $-0,327^{\star}$ & & & \\
\hline M_celular & & & $0,572^{* *}$ & & & & $0,524^{*}$ & & $0,461^{*}$ & \\
\hline Impedimento para prosseguir viagem & & & & $1,600^{* *}$ & & & & $1,470^{* *}$ & $1,400^{*}$ & $1,470^{\star \star}$ \\
\hline Demonstração direta de hostilidade do outro condutor & & & & $0,756^{\star *}$ & & & & $0,763^{* *}$ & $0,752^{\star \star}$ & $0,774^{* *}$ \\
\hline Eu mesmo como condutor & & & & $-1,970^{* *}$ & & & & $-1,920^{\star *}$ & $-1,910^{\star *}$ & $-1,950^{* *}$ \\
\hline Ações que prejudicam a concentração e vigilância ao conduzir & & & & $1,070^{*}$ & & & & $0,953^{* *}$ & $0,988^{* *}$ & $0,940^{* *}$ \\
\hline Elementos urbanos & & & & & $-0,766$ & & & $-0,698^{* *}$ & $-0,743^{* *}$ & $-0,667^{* \star}$ \\
\hline Rodovias confortáveis & & & & & $-0,747$ & & & $-0,650^{* *}$ & $-0,655^{* \star}$ & $-0,652^{* *}$ \\
\hline Coimbra & & & & & & $2,630^{*}$ & & & $2,610^{*}$ & $2,640^{*}$ \\
\hline Minas Gerais & & & & & & & & & & $0,416^{*}$ \\
\hline TC_15-30 anos & & & & & & & & & & $-0,242^{*}$ \\
\hline Número de parâmetros estimados & 4 & 2 & 1 & 5 & 3 & 1 & 6 & 9 & 11 & 12 \\
\hline Log de verossimilhança inicial & $-1.179,737$ & $-1.179,737$ & $-1.179,737$ & $-1.179,737$ & $-1.179,737$ & $-1.179,737$ & $-1.179,737$ & $-1.179,737$ & $-1.179,737$ & $-1.179,737$ \\
\hline Log de Verossimilhança Final & $-1.169,061$ & $-1.175,042$ & $-1.175,929$ & $-1.116,925$ & $-1.166,681$ & $-1.173,013$ & $-1.163,965$ & $-1.101,540$ & $-1.093,727$ & $-1.091,711$ \\
\hline Teste de razão de verossimilhança do modelo inicial & 21,350 & 9,389 & 7,616 & 125,622 & 26,111 & 13,446 & 31,543 & 156,393 & 172,020 & 176,051 \\
\hline Rho-quadrado & 0,009 & 0,004 & 0,003 & 0,053 & 0,011 & 0,006 & 0,013 & 0,066 & 0,073 & 0,075 \\
\hline Rho-quadrado ajustado & 0,006 & 0,002 & 0,002 & 0,049 & 0,009 & 0,005 & 0,008 & 0,059 & 0,064 & 0,064 \\
\hline Critério de Informação de Akaike (AIC) & $2.346,123$ & $2.354,084$ & $2.353,857$ & $2.243,851$ & $2.339,362$ & $2.348,027$ & $2.339,930$ & $2.221,080$ & $2.209,454$ & $2.207,422$ \\
\hline Critério de Informação Bayesiano (BIC) & $2.367,881$ & $2.364,963$ & $2.359,297$ & $2.271,048$ & $2.355,681$ & $2.353,466$ & $2.372,567$ & $2.270,036$ & $2.269,289$ & $2.272,697$ \\
\hline
\end{tabular}


Tabela F. 2 - Parâmetros estimados para os modelos do comportamento Excesso de velocidade

\begin{tabular}{|c|c|c|c|c|c|c|c|c|c|c|c|c|c|c|c|c|}
\hline & A1 & A2 & A3 & A4 & A5 & B1 & B2 & B3 & B4 & C1 & C2 & C3 & C4 & C5 & C6 & $\mathrm{D}$ \\
\hline $\begin{array}{l}\text { Constante } \\
35-44 \text { anos }\end{array}$ & $\begin{aligned} 1,330^{* *} \\
-0,033^{* *}\end{aligned}$ & $0,866^{* *}$ & $0,970^{\star *}$ & $2,250^{\star \star}$ & $1,190^{\star *}$ & $1,020^{\star *}$ & $1,130^{\star *}$ & $1,170^{* *}$ & $1,040^{\star *}$ & $0,875^{* *}$ & $2,130^{\star \star}$ & $1,700^{\star *}$ & $1,790^{\star *}$ & $2,120^{\star \star}$ & $1,960^{\star *}$ & $1,630^{\star \star}$ \\
\hline 45-54 anos & $\begin{array}{l}-0,837^{\star *} \\
-0.04\end{array}$ & & & & & & & & & $\begin{array}{l}-0,934^{* *} \\
-1150^{* *}\end{array}$ & $-0,382^{*}$ & $-0,457^{* *}$ & $-0439^{*}$ & $-0472^{* *}$ & $-0442^{* *}$ & $-0.370^{*}$ \\
\hline 55-64 anos & $-1,040^{* *}$ & & & & & & & & & $-1,700^{* *}$ & $-0,547^{*}$ & $-0,722^{\star *}$ & $\begin{array}{l}-0,405 * \\
-0,744^{* *}\end{array}$ & $\begin{array}{l}-0,708^{* *} \\
-0,12\end{array}$ & $-0,641^{* *}$ & $-0,541^{*}$ \\
\hline$>65$ anos & $-1,310^{\star *}$ & & & & & & & & & $-1,710^{* *}$ & & $-1,080^{*}$ & $-1,070^{*}$ & $-1,000^{*}$ & & \\
\hline Homem & $0,440^{* *}$ & & & & & & & & & $0,252^{*}$ & & & & & & \\
\hline TC_15-30 anos & & $-0,332^{*}$ & & & & & & & & $0,486^{* *}$ & & & & & & \\
\hline TC_-30-45 anos & & $-0,640^{* *}$ & & & & & & & & $0,582^{\star}$ & & & & & & \\
\hline $80-120 \mathrm{~km} / \mathrm{semana}$ & & $0,609^{* *}$ & & & & & & & & $0,627^{* *}$ & & & & & & \\
\hline $120-200 \mathrm{~km} / \mathrm{semana}$ & & $0,583^{* *}$ & & & & & & & & $0,591^{* *}$ & & & & & & \\
\hline $200-300$ km/semana & & $0,898^{* *}$ & & & & & & & & $0,859^{* *}$ & $0,462^{*}$ & $0,414^{*}$ & & $0,439^{*}$ & $0,425^{*}$ & $0,477^{*}$ \\
\hline $300-500 \mathrm{~km} / \mathrm{semana}$ & & $0,722^{* *}$ & & & & & & & & $0,612^{* *}$ & & & & & $1,960^{* *}$ & \\
\hline$>500 \mathrm{~km} / \mathrm{semana}$ & & $0,691^{* *}$ & & & & & & & & $0,671^{* *}$ & & & & & & \\
\hline Multa Velocidade & & & $0,527^{* *}$ & & & & & & & $0,505^{\star \star}$ & $0,481^{* \star}$ & $0,703^{* *}$ & $0,739^{* *}$ & $0,587^{* *}$ & $0,669^{* *}$ & $0,465^{* \star}$ \\
\hline $\begin{array}{l}\text { Demonstração direta de } \\
\text { hostilidade do outro condutor }\end{array}$ & & & & $0,897^{\star \star}$ & & & & & & & $0,898^{* \star}$ & $0,843^{* *}$ & $0,814^{*}$ & & & $0,916^{\star \star}$ \\
\hline Eu mesmo como condutor & & & & $-1,080^{* *}$ & & & & & & & $-1,190^{* *}$ & $-0,825^{*}$ & $-0,807^{*}$ & $-1,090^{* *}$ & $-0,936^{* *}$ & $-1,200^{* *}$ \\
\hline $\begin{array}{l}\text { Açöes que prejudicam a concentraçăo e } \\
\text { vigilância ao conduzir }\end{array}$ & & & & $2,000^{* *}$ & & & & & & & $2,000^{* *}$ & $1,770^{\star \star}$ & $1,770^{* *}$ & $1,910^{* *}$ & $1,980^{\star *}$ & $1,940^{* *}$ \\
\hline Tarefas secundárias ao conduzir & & & & $-0,801^{*}$ & & & & & & & $-0,847^{\star}$ & & & & & \\
\hline Comportamentos perigosos & & & & $-5,080^{* *}$ & & & & & & & $-4,810^{* *}$ & $-5,390^{* *}$ & $-5,320^{* *}$ & $-5,010^{* *}$ & $-5,240^{* *}$ & $-4,840^{* *}$ \\
\hline Busca de sensações & & & & $3,690^{* *}$ & & & & & & & $3,560^{* *}$ & $3,380^{* *}$ & $3,410^{* *}$ & $3,550^{* *}$ & $3,450^{* *}$ & $3,660^{* *}$ \\
\hline Rodovias confortáveis & & & & & $0,684^{*}$ & & & & & & & & & & & \\
\hline $\begin{array}{l}\text { Áreas urbanas com edificações } \\
\text { altas }\end{array}$ & & & & & $-0,606^{*}$ & & & & & & & & & & & \\
\hline Portugal & & & & & & $0,693^{* *}$ & & & & & & $1,100^{* *}$ & & & & \\
\hline BR Nordeste & & & & & & & $-0,729^{\star *}$ & & & & & & $-0,729^{* *}$ & & & \\
\hline $\begin{array}{l}\text { PT Centro } \\
\text { PT }\end{array}$ & & & & & & & $0,778^{*}$ & & & & & & $1,020^{* *}$ & & & \\
\hline PT Lisboa & & & & & & & & & & & & & $0,797^{\star}$ & & & \\
\hline PT Norte & & & & & & & $0,635^{* *}$ & & & & & & $1,090^{* *}$ & & & \\
\hline Bahia & & & & & & & & $-0,879^{* *}$ & & & & & & & & \\
\hline Pernambuco & & & & & & & & $-0,761^{*}$ & & & & & & & & \\
\hline Porto & & & & & & & & $0,625^{*}$ & & & & & & $1,010^{* *}$ & & \\
\hline Lisboa & & & & & & & & & & & & & & $0,996^{* *}$ & & \\
\hline PIB_reg< 74546785,00 & & & & & & & & & $0,802^{* \star}$ & & & & & & $1,200^{* \star}$ & \\
\hline $\begin{array}{l}74546785,00<=\text { PIB_reg }< \\
220618604,00\end{array}$ & & & & & & & & & & & & & & & $0,452^{* \star}$ & \\
\hline $988,50<=$ DenPop $<4386,67$ & & & & & & & & & & & & & & & $-0,336^{*}$ & \\
\hline Número de parâmetros estimados & 6 & 8 & 2 & 7 & 3 & 2 & 4 & 4 & 2 & 14 & 11 & 12 & 14 & 12 & 12 & 10 \\
\hline Log de verossimilhança inicial & $-1.179,737$ & $-1.179,737$ & $-1.179,737$ & $-1.179,737$ & $-1.179,737$ & $-1.179,737$ & $-1.179,737$ & $-1.179,737$ & $-1.179,737$ & $-1.179,737$ & $-1.179,737$ & $-1.179,737$ & $-1.179,737$ & $-1.179,737$ & $-1.179,737$ & $-1.179,737$ \\
\hline Log de Verossimilhança Final & $-912,095$ & $-919,398$ & $-931,451$ & $-795,109$ & $-935,118$ & $-930,568$ & $-924,714$ & $-929,766$ & $-929,959$ & $-883,121$ & $-782,311$ & $-765,463$ & $-764,455$ & $-778,775$ & $-768,366$ & $-785,705$ \\
\hline $\begin{array}{l}\text { Teste de razão de } \\
\text { verossimilhança do modelo inicial }\end{array}$ & 535,282 & 520,676 & 496,571 & 769,255 & 489,238 & 498,336 & 510,046 & 499,942 & 499,554 & 593,232 & 794,851 & 828,548 & 830,564 & 801,922 & 822,741 & 788,064 \\
\hline $\begin{array}{r}\text { Rho-quadrado } \\
\text { Rho-quadrado ajustado }\end{array}$ & $\begin{array}{l}0,227 \\
0,222\end{array}$ & $\begin{array}{l}0,221 \\
0,214\end{array}$ & $\begin{array}{l}0,210 \\
0,209\end{array}$ & $\begin{array}{l}0,326 \\
0,320\end{array}$ & $\begin{array}{l}0,207 \\
0,205\end{array}$ & $\begin{array}{l}0,211 \\
0,210\end{array}$ & $\begin{array}{l}0,216 \\
0,213\end{array}$ & $\begin{array}{l}0,212 \\
0,208\end{array}$ & $\begin{array}{l}0,212 \\
0,210\end{array}$ & $\begin{array}{l}0,251 \\
0,240\end{array}$ & $\begin{array}{l}0,337 \\
0,328\end{array}$ & $\begin{array}{l}0,351 \\
0,341\end{array}$ & $\begin{array}{l}0,352 \\
0,340\end{array}$ & $\begin{array}{l}0,340 \\
0,330\end{array}$ & $\begin{array}{l}0,349 \\
0,339\end{array}$ & $\begin{array}{l}0,334 \\
0,326\end{array}$ \\
\hline AIC & $1.836,191$ & $1.854,797$ & $1.866,902$ & $1.604,218$ & $1.876,235$ & $1.865,137$ & $1.857,427$ & $1.867,531$ & $1.863,919$ & $1.794,241$ & $1.586,622$ & $1.554,925$ & $1.556,909$ & $1.581,551$ & $1.560,732$ & $1.591,409$ \\
\hline $\mathrm{BIC}$ & $1.868,828$ & $1.898,313$ & $1.877,781$ & $1.642,295$ & $1.892,554$ & $1.876,016$ & $1.879,186$ & $1.889,290$ & $1.874,798$ & $1.870,395$ & $1.646,457$ & $1.620,200$ & $1.633,063$ & $1.646,826$ & $1.626,007$ & $1.645,805$ \\
\hline
\end{tabular}

* Significante ao nivel 0,$05 ;{ }^{* *}$ Significante ao nivel 0,01 
Tabela F. 3- Parâmetros estimados para os modelos do comportamento Conduzir sob efeito de álcool

\begin{tabular}{|c|c|c|c|c|c|c|c|c|c|c|c|c|c|c|}
\hline & $\mathrm{A} 1$ & A3 & A4 & A5 & B1 & B2 & B3 & B4 & $\mathrm{C} 1$ & $\mathrm{C} 2$ & C4 & $\mathrm{C5}$ & $\mathrm{C} 6$ & $\mathrm{D}$ \\
\hline Constante & $-0,607^{\star \star}$ & $-0,541^{\star *}$ & & & $-0,228^{* *}$ & $-0,226^{* *}$ & $-0,281^{* *}$ & $-0,341^{* *}$ & $-0,865^{* *}$ & $-0,657^{*}$ & & & & $-0,659^{*}$ \\
\hline Homem & $0,388^{\star *}$ & & & & & & & & $0,279^{\star *}$ & $0,228^{*}$ & & & & \\
\hline Solteiro & $0,268^{* *}$ & & & & & & & & $0,354^{* *}$ & $0,206^{*}$ & & & & $0,231^{*}$ \\
\hline$>20$ S.M. & & & & & & & & & $0,555^{*}$ & & & & & $0,593^{*}$ \\
\hline M_Álcool & & $2,440^{*}$ & & & & & & & $2,270^{*}$ & $2,240^{*}$ & $2,300^{*}$ & $2,340^{*}$ & $2,260^{*}$ & $2,330^{*}$ \\
\hline M_Estacionar & & $0,397^{\star \star}$ & & & & & & & $0,427^{\star *}$ & $0,420^{\star *}$ & $0,414^{\star *}$ & $0,429^{\star \star}$ & $0,412^{* *}$ & $0,444^{* *}$ \\
\hline M_Velocidade & & $0,509^{* \star}$ & & & & & & & $0,488^{* *}$ & $0,435^{* *}$ & $0,439^{\star *}$ & $0,422^{* *}$ & $0,434^{* \star}$ & $0,473^{* *}$ \\
\hline Demonstração direta de hostilidade do outro condutor & & & $0,588^{* *}$ & & & & & & & $0,696^{* *}$ & $0,462^{*}$ & $0,457^{\star}$ & $0,439^{*}$ & $0,649^{*}$ \\
\hline Comportamentos perigosos & & & $-1,690^{* *}$ & & & & & & & $-1,310^{* *}$ & $-1,830^{\star *}$ & $-1,910^{* *}$ & $-2,010^{\star *}$ & $-1,380^{* *}$ \\
\hline Busca de sensações & & & $1,250^{\star *}$ & & & & & & & $1,030^{\star *}$ & $1,060^{\star \star}$ & $1,100^{* *}$ & $1,060^{\star *}$ & $1,130^{\star *}$ \\
\hline Elementos urbanos & & & & $-0,415^{\star \star}$ & & & & & & & & & & \\
\hline Portugal & & & & & $-0,288^{*}$ & & & & & & & & & \\
\hline BR_Nordeste & & & & & & $-0,502^{\star \star}$ & & & & & $-0,520^{\star *}$ & & & \\
\hline PT_Centro & & & & & & $-0,485^{*}$ & & & & & & & & \\
\hline Leiria & & & & & & & $-1,450^{*}$ & & & & & & & \\
\hline Pernambuco & & & & & & & $-0,847^{*}$ & & & & & $-1,020^{* *}$ & & \\
\hline Santa Catarina & & & & & & & $0,767^{\star *}$ & & & & & $0,770^{* *}$ & & $0,782^{* *}$ \\
\hline Den Pop< 149,72 & & & & & & & & $0,270^{*}$ & & & & & $0,361^{* *}$ & $0,374^{\star *}$ \\
\hline Número de parâmetros estimados & 3 & 4 & 3 & 1 & 2 & 3 & 4 & 2 & 7 & 9 & 7 & 8 & 7 & 11 \\
\hline Log de verossimilhança inicial & $-1.179,737$ & $-1.179,737$ & $-1.179,737$ & $-1.179,737$ & $-1.179,737$ & $-1.179,737$ & $-1.179,737$ & $-1.179,737$ & $-1.179,737$ & $-1.179,737$ & $-1.179,737$ & $-1.179,737$ & $-1.179,737$ & $-1.179,737$ \\
\hline Log de Verossimilhança Final & $-1.151,532$ & $-1.138,988$ & $-1.133,488$ & $-1160,312$ & $-1159,712$ & $-1157,093$ & $-1150,935$ & $-1160,011$ & $-1127,491$ & $-1110,159$ & $-1111,846$ & $-1106,403$ & $-1111,363$ & $-1101,238$ \\
\hline Teste de razão de verossimilhança do modelo inicial & 56,409 & 81,497 & 92,498 & 38,849 & 40,050 & 45,287 & 57,604 & 39,450 & 104,491 & 139,155 & 135,781 & 146,667 & 136,748 & 156,998 \\
\hline Rho-quadrado & 0,024 & 0,035 & 0,039 & 0,017 & 0,017 & 0,019 & 0,024 & 0,017 & 0,044 & 0,059 & 0,058 & 0,062 & 0,058 & 0,067 \\
\hline Rho-quadrado ajustado & 0,021 & 0,031 & 0,037 & 0,016 & 0,015 & 0,017 & 0,021 & 0,015 & 0,038 & 0,051 & 0,052 & 0,055 & 0,052 & 0,057 \\
\hline Critério de Informação de Akaike (AIC) & $2.309,064$ & $2.285,976$ & $2.272,975$ & 2322,624 & 2323,423 & 2320,186 & 2309,869 & 2324,023 & 2268,982 & 2238,318 & 2237,692 & 2228,806 & 2236,725 & 2224,475 \\
\hline Critério de Informação Bayesiano (BIC) & $2.325,383$ & $2.307,734$ & $2.289,294$ & 2328,064 & 2334,302 & 2336,504 & 2331,627 & 2334,902 & 2307,059 & 2287,274 & 2275,769 & 2272,322 & 2274,802 & 2284,310 \\
\hline
\end{tabular}

* Significante ao nível 0,$05 ;{ }^{* *}$ Significante ao nivel 0,01 
Tabela F. 4 - Parâmetros estimados para os modelos do comportamento Não usar o cinto de segurança

\begin{tabular}{|c|c|c|c|c|c|c|c|c|c|c|c|c|c|c|c|c|}
\hline & A1 & A2 & A3 & A4 & A5 & B1 & B2 & B3 & B4 & C1 & $\mathrm{C} 2$ & C3 & $\mathrm{C} 4$ & $\mathrm{C5}$ & $\mathrm{C} 6$ & $\mathrm{D}$ \\
\hline Constante & $1,110^{\star \star}$ & $1,030^{\star \star}$ & $1,350^{* *}$ & $3,450^{* *}$ & $1,480^{* \star}$ & $1,250^{* *}$ & $1,150^{* *}$ & $1,170^{* \star}$ & $1,050^{* *}$ & $1,260^{* \star}$ & $3,430^{* *}$ & $3,890^{\star *}$ & $4,380^{* *}$ & $4,390^{* \star}$ & $3,620^{* *}$ & $4,010^{* *}$ \\
\hline 35-44 anos & $0,388^{* *}$ & & & & & & & & & $0,423^{\star \star}$ & & & & & & \\
\hline 45-54 anos & $0,497^{* *}$ & & & & & & & & & $0,613^{\star \star}$ & & & & & & \\
\hline 55-64 anos & $0,504^{*}$ & & & & & & & & & & & & & & & \\
\hline Homem & $-0,323^{* *}$ & & & & & & & & & $-0,233^{*}$ & & & & & & \\
\hline TC_ $0-5$ anos & & $0,444^{\star \star}$ & & & & & & & & $0,307^{*}$ & $0,299^{*}$ & & & & & \\
\hline TC_15-30 anos & & $0,400^{*}$ & & & & & & & & & & & & & & \\
\hline TC_30-45 anos & & $0,638^{* \star}$ & & & & & & & & & & & & & & \\
\hline $120-200 \mathrm{~km} / \mathrm{semana}$ & & $-0,296^{*}$ & & & & & & & & & & & & & & \\
\hline $200-300 \mathrm{~km} / \mathrm{semana}$ & & $-0,590^{* *}$ & & & & & & & & $-0,498^{* *}$ & $-0,458^{* *}$ & $-0,450^{\star *}$ & $-0,440^{* *}$ & $-0,448^{\star *}$ & $-0,474^{\star *}$ & $-0,494^{* *}$ \\
\hline M_Estacionar & & & $-0,385^{*}$ & & & & & & & $-0,406^{*}$ & $-0,396^{*}$ & $-0,431^{\text {**}}$ & $-0,426^{* \star}$ & $-0,409^{*}$ & $-0,464^{* *}$ & $-0,467^{* *}$ \\
\hline M_velocidade & & & $-0,362^{* *}$ & & & & & & & $-0,301^{*}$ & & $-0,402^{\star *}$ & $-0,314^{*}$ & $-0,287^{\star \star}$ & & \\
\hline $\begin{array}{l}\text { Impedimento para prosseguir } \\
\text { viagem }\end{array}$ & & & & $-0,948^{* *}$ & & & & & & & $-0,908^{* *}$ & & $-0,813^{\star}$ & $-0,779^{*}$ & $-0,895^{* \star}$ & $-0,847^{\star}$ \\
\hline $\begin{array}{l}\text { Demonstração direta de } \\
\text { hostilidade do outro condutor }\end{array}$ & & & & $-0,962^{* *}$ & & & & & & & $-0,998^{* *}$ & $-0,893^{* *}$ & $-0,910^{\star *}$ & $-0,955^{* \star}$ & $-0,908^{* *}$ & $-0,911^{\star *}$ \\
\hline Ações que prejudicam a [.... $]^{1}$ & & & & $-2,680^{* *}$ & & & & & & & $-2,590^{* *}$ & $-2,670^{\star \star}$ & $-2,750^{* *}$ & $-2,700^{\star *}$ & $-2,540^{* *}$ & $-2,850^{* *}$ \\
\hline Tarefas secundárias ao & & & & $0,783^{* *}$ & & & & & & & $0,687^{*}$ & & & & $0,713^{*}$ & \\
\hline Comportamentos perigosos & & & & $2,090^{\star \star}$ & & & & & & & $2,220^{\star *}$ & $2,460^{* *}$ & $2,160^{* *}$ & $2,160^{\star *}$ & $2,050^{\star \star}$ & $2,110^{* *}$ \\
\hline Busca de sensações & & & & $-1,730^{* *}$ & & & & & & & $-1,740^{* *}$ & $-1,740^{* *}$ & $-1,620^{* *}$ & $-1,660^{\star \star}$ & $-1,620^{* \star}$ & $-1,910^{* *}$ \\
\hline Rodovias confortáveis & & & & & $-0,944^{* \star}$ & & & & & & & $-0,715^{*}$ & $-0,724^{\star \star}$ & $-0,768^{\star \star}$ & $-0,671^{*}$ & \\
\hline Portugal & & & & & & $-0,467^{* *}$ & & & & & & $-0,726^{* \star}$ & & & & \\
\hline BR_Nordeste & & & & & & & $0,629^{*}$ & & & & & & $0,535^{\star}$ & & & \\
\hline PT_Norte & & & & & & & $-0,443^{*}$ & & & & & & $-0,602^{* *}$ & & & \\
\hline Bahia & & & & & & & & $1,150^{*}$ & & & & & & & & \\
\hline Porto & & & & & & & & $-0,599^{\star \star}$ & & & & & & $-0,762^{\star *}$ & & \\
\hline $\mathrm{IM}<0,58$ & & & & & & & & & $0,587^{* *}$ & & & & & & $0,431^{*}$ & $0,575^{\star \star}$ \\
\hline Ensino médio incompleto & & & & & & & & & & & & & & & & $0,419^{*}$ \\
\hline Mato Grosso & & & & & & & & & & & & & & & & $1,530^{*}$ \\
\hline Piauí & & & & & & & & & & & & & & & & $-1,240^{*}$ \\
\hline $\begin{array}{r}\text { Número de parâmetros } \\
\text { estimados }\end{array}$ & 5 & 6 & 3 & 7 & 2 & 2 & 3 & 3 & 2 & 8 & 10 & 10 & 12 & 11 & 11 & 12 \\
\hline Log de verossimilhança & $-1.179,737$ & $-1.179,737$ & $-1.179,737$ & $-1.179,737$ & $-1.179,737$ & $-1.179,737$ & $-1.179,737$ & $-1.179,737$ & $-1.179,737$ & $-1.179,737$ & $-1.179,737$ & $-1.179,737$ & $-1.179,737$ & $-1.179,737$ & $-1.179,737$ & $-1.179,737$ \\
\hline Log de Verossimilhança & $-929,046$ & $-924,934$ & $-930,538$ & $-873,379$ & $-933,290$ & $-933,696$ & $-932,622$ & $-930,997$ & $-932,423$ & $-915,476$ & $-864,029$ & $-856,757$ & $-857,108$ & $-858,562$ & $-859,444$ & $-857,269$ \\
\hline $\begin{array}{r}\text { Teste de razão de } \\
\text { verossimilhança do modelo }\end{array}$ & 501,381 & 509,606 & 498,397 & 612,715 & 492,893 & 492,081 & 494,230 & 497,480 & 494,628 & 528,521 & 631,415 & 645,958 & 645,258 & 642,349 & 640,584 & 644,934 \\
\hline Rho-quadrado & 0,212 & 0,216 & 0,211 & 0,260 & 0,209 & 0,209 & 0,209 & 0,211 & 0,210 & 0,224 & 0,268 & 0,274 & 0,273 & 0,272 & 0,271 & 0,273 \\
\hline Rho-quadrado ajustado & 0,208 & 0,211 & 0,209 & 0,254 & 0,207 & 0,207 & 0,207 & 0,208 & 0,208 & 0,217 & 0,259 & 0,265 & 0,263 & 0,263 & 0,262 & 0,263 \\
\hline AIC & $1.868,092$ & $1.861,867$ & $1.867,076$ & $1.760,758$ & $1.870,580$ & $1.871,392$ & $1.871,243$ & $1.867,993$ & $1.868,845$ & $1.846,952$ & $1.748,058$ & $1.733,515$ & $1.738,215$ & $1.739,124$ & $1.740,889$ & $1.738,539$ \\
\hline $\mathrm{BIC}$ & $1.895,290$ & $1.894,504$ & $1.883,395$ & $1.798,835$ & $1.881,459$ & $1.882,271$ & $1.887,562$ & $1.884,312$ & $1.879,724$ & $1.890,468$ & $1.802,454$ & $1.787,910$ & $1.803,490$ & $1.798,959$ & $1.800,724$ & $1.803,813$ \\
\hline
\end{tabular}


Tabela F. 5 - Parâmetros estimados para os modelos do comportamento Usar o celular no modo viva voz enquanto conduz

\begin{tabular}{|c|c|c|c|c|c|c|c|c|c|c|c|c|c|c|}
\hline & $\mathrm{A} 1$ & A2 & A4 & $\mathrm{A} 5$ & B1 & B2 & B3 & $\mathrm{B} 4$ & $\mathrm{C} 2$ & $\mathrm{C} 3$ & $\mathrm{C} 4$ & $\mathrm{C5}$ & $\mathrm{C} 6$ & $\mathrm{D}$ \\
\hline Constante & $-1,490^{\star \star}$ & $-2,030^{\star \star}$ & $-1,770^{\star \star}$ & $-3,740^{* \star}$ & $-1,800^{* \star}$ & $-1,820^{\star \star}$ & $-1,820^{* *}$ & $-1,770^{* *}$ & $-3,070^{* \star}$ & $-3,220^{\star \star}$ & $-3,390^{* *}$ & $-3,160^{* *}$ & $-3,230^{\star \star}$ & $-2,300^{\star \star}$ \\
\hline 18-24 anos & $-0,414^{*}$ & & & & & & & & & & & & & \\
\hline TC_0-5 anos & & $-0,376^{*}$ & & & & & & & & & & & & \\
\hline $80-120 \mathrm{~km} / \mathrm{semana}$ & & $0,449^{*}$ & & & & & & & & & & & & \\
\hline $120-200 \mathrm{~km} / \mathrm{semana}$ & & $0,795^{* *}$ & & & & & & & $0,440^{\star *}$ & $0,425^{*}$ & $0,441^{* *}$ & $0,404^{*}$ & $0,428^{*}$ & $0,456^{\star \star}$ \\
\hline $200-300 \mathrm{~km} / \mathrm{semana}$ & & $0,950^{* *}$ & & & & & & & $0,540^{* *}$ & $0,517^{* *}$ & $0,533^{* *}$ & $0,533^{* *}$ & $0,514^{* *}$ & $0,619^{* \star}$ \\
\hline $300-500 \mathrm{~km} / \mathrm{semana}$ & & $0,636^{* *}$ & & & & & & & & & & & & \\
\hline$>500 \mathrm{~km} / \mathrm{semana}$ & & $1,000^{* *}$ & & & & & & & $0,675^{\star \star}$ & $0,668^{\star *}$ & $0,676^{* *}$ & $0,697^{* *}$ & $0,658^{* *}$ & $0,748^{* \star}$ \\
\hline Impedimento para prosseguir viagem & & & $1,020^{* *}$ & & & & & & $1,100^{* \star}$ & $0,918^{*}$ & $0,954^{\star}$ & $0,968^{*}$ & $0,965^{*}$ & \\
\hline $\begin{array}{l}\text { Açōes que prejudicam a concentração e vigilância ao } \\
\text { conduzir }\end{array}$ & & & $1,340^{*}$ & & & & & & & & & & & \\
\hline Tarefas secundárias ao conduzir & & & $-2,930^{* *}$ & & & & & & $-2,840^{* *}$ & $-2,590^{* \star}$ & $-2,740^{* *}$ & $-2,800^{* \star}$ & $-2,660^{* *}$ & $-2,940^{\star \star}$ \\
\hline Busca de sensaçōes & & & $1,080^{* *}$ & & & & & & $0,946^{* *}$ & $0,955^{* *}$ & $1,010^{* *}$ & $0,976^{* *}$ & $0,924^{* *}$ & $1,370^{* *}$ \\
\hline Elementos urbanos & & & & $1,310^{* *}$ & & & & & $1,410^{\star *}$ & $1,360^{* *}$ & $1,510^{* *}$ & $1,430^{\star *}$ & $1,390^{* *}$ & $1,380^{\star *}$ \\
\hline Rodovias confortáveis & & & & $1,390^{* *}$ & & & & & $1,260^{\star *}$ & $1,260^{* *}$ & $1,430^{* *}$ & $1,380^{* *}$ & $1,290^{* *}$ & $1,400^{* *}$ \\
\hline Áreas urbanas com edificações altas & & & & $1,550^{* *}$ & & & & & $1,460^{\star \star}$ & $1,470^{* *}$ & $1,420^{* *}$ & $1,420^{* \star}$ & $1,510^{* \star}$ & $1,320^{* *}$ \\
\hline Portugal & & & & & $0,988^{* *}$ & & & & & $0,563^{* *}$ & & & & \\
\hline BR Norte & & & & & & $-1,720^{*}$ & & & & & & & & \\
\hline BR Nordeste & & & & & & $0,680^{* *}$ & & & & & $0,965^{* *}$ & & & $0,858^{\star *}$ \\
\hline Portugal Alentejo & & & & & & $1,640^{* *}$ & & & & & & & & \\
\hline PT Centro & & & & & & $0,943^{* *}$ & & & & & $0,694^{*}$ & & & \\
\hline Portugal Lisboa M. A. & & & & & & $1,020^{* *}$ & & & & & & & & \\
\hline PT Norte & & & & & & $0,995^{* *}$ & & & & & $0,621^{* *}$ & & & \\
\hline Aveiro PT & & & & & & & $1,420^{*}$ & & & & & & & \\
\hline Castelo Branco & & & & & & & $0,840^{*}$ & & & & & & & \\
\hline Leiria & & & & & & & $1,200^{*}$ & & & & & & & \\
\hline Lisboa & & & & & & & $0,904^{\star *}$ & & & & & & & \\
\hline Paraiba & & & & & & & $1,130^{*}$ & & & & & & & \\
\hline Pernambuco & & & & & & & $1,130^{* *}$ & & & & & $1,230^{\star \star}$ & & \\
\hline Porto & & & & & & & $1,100^{* *}$ & & & & & $0,550^{*}$ & & \\
\hline Setúbal & & & & & & & $1,820^{*}$ & & & & & $1,810^{*}$ & & \\
\hline Vila Real & & & & & & & $0,995^{*}$ & & & & & & & \\
\hline $319753<=$ Frota $<902025$ & & & & & & & & $0,382^{*}$ & & & & & & \\
\hline PIB_reg< 74546785,00 & & & & & & & & $1,080^{* *}$ & & & & & $0,595^{* *}$ & \\
\hline Den Pop< 149,72 & & & & & & & & $-0,436^{*}$ & & & & & & \\
\hline Multa Álcool & & & & & & & & & & & & & & 1,480 \\
\hline Sem renda & & & & & & & & & & & & & & $-0,607$ \\
\hline Homem & & & & & & & & & & & & & & $-0,410$ \\
\hline Número de parâmetros estimados & 2 & 7 & 5 & 4 & 2 & 7 & 10 & 4 & 10 & 11 & 13 & 13 & 11 & 13 \\
\hline Log de verossimilhança inicial & $-1.179,737$ & $-1.179,737$ & $-1.179,737$ & $-1.179,737$ & $-1.179,737$ & $-1.179,737$ & $-1.179,737$ & $-1.179,737$ & $-1.179,737$ & $-1.179,737$ & $-1.179,737$ & $-1.179,737$ & $-1.179,737$ & $-1.179,737$ \\
\hline Log de Verossimilhança Final & $-788,642$ & $-770,955$ & $-720,687$ & $-757,083$ & $-767,469$ & $-758,143$ & $-762,235$ & $-766,511$ & $-686,511$ & $-680,138$ & $-674,234$ & $-676,484$ & $-680,242$ & $-676,271$ \\
\hline Teste de razão de verossimilhança do modelo inicial & 782,189 & 817,563 & 918,100 & 845,307 & 824,534 & 843,188 & 835,003 & 826,451 & 986,450 & 999,198 & 1011,005 & 1006,504 & 998,989 & 1006,932 \\
\hline & & & & & & & & & & & & & & Continua \\
\hline
\end{tabular}




\begin{tabular}{|c|c|c|c|c|c|c|c|c|c|c|c|c|c|c|}
\hline Contianuação & & & & & & & & & & & & & & \\
\hline & A1 & A2 & A4 & A5 & B1 & B2 & B3 & B4 & $\mathrm{C} 2$ & C3 & C4 & C5 & C6 & D \\
\hline Rho-quadrado & 0,332 & 0,347 & 0,389 & 0,358 & 0,349 & 0,357 & 0,354 & 0,350 & 0,418 & 0,423 & 0,428 & 0,427 & 0,423 & 0,427 \\
\hline Rho-quadrado ajustado & 0,330 & 0,341 & 0,385 & 0,355 & 0,348 & 0,351 & 0,345 & 0,347 & 0,410 & 0,414 & 0,417 & 0,416 & 0,414 & 0,416 \\
\hline Critério de Informação de Akaike (AIC) & $1.581,284$ & $1.555,910$ & $1.451,373$ & $1.522,166$ & $1.538,939$ & $1.530,285$ & $1.544,470$ & $1.541,022$ & $1.393,023$ & $1.382,275$ & $1.374,468$ & $1.378,969$ & $1.382,484$ & $1.378,541$ \\
\hline Critério de Informação Bayesiano (BIC) & $1.592,163$ & $1.593,987$ & $1.478,571$ & $1.543,924$ & $1.549,818$ & $1.568,362$ & $1.598,865$ & $1.562,780$ & $1.447,418$ & $1.442,111$ & $1.445,182$ & $1.449,683$ & $1.442,319$ & $1.449,256$ \\
\hline
\end{tabular}

* Significante ao nivel 0,$05 ;{ }^{* *}$ Significante ao nivel 0,01

Tabela F. 6 - Parâmetros estimados para os modelos do comportamento cansaço e sonolência

\begin{tabular}{|c|c|c|c|c|c|c|c|c|c|c|c|c|c|}
\hline & A1 & A2 & A3 & A4 & A5 & B1 & B2 & B3 & C1 & C2 & C4 & C5 & D \\
\hline Constante & $0,836^{* *}$ & $0,483^{* \star}$ & $0,529^{\star \star}$ & & $1,270^{\star \star}$ & $0,548^{\star *}$ & $0,605^{\star *}$ & $0,656^{\star \star}$ & $0,421^{\star *}$ & $0,831^{*}$ & $1,220^{* *}$ & $1,300^{* *}$ & $0,782^{* *}$ \\
\hline 18-24 anos & $-0,438^{\star \star}$ & & & & & & & & & & & & \\
\hline 35-44 anos & $-0,403^{\star *}$ & & & & & & & & $-0,315^{\star}$ & & & $-0,262^{* *}$ & $-0,458^{* *}$ \\
\hline 45-54 anos & $-0,501^{* *}$ & & & & & & & & $-0,488^{* *}$ & $-0,342^{*}$ & $-0,332^{*}$ & $-0,440^{* *}$ & $-0,665^{* *}$ \\
\hline 55-64 anos & $-0,562^{* *}$ & & & & & & & & & & & & $-0,671^{\star *}$ \\
\hline$>65$ anos & $-1,470^{\star *}$ & & & & & & & & & & & & $-1,490^{* *}$ \\
\hline Homem & $0,232^{*}$ & & & & & & & & & & & & \\
\hline TC_ $0-5$ anos & & $-0,446^{* *}$ & & & & & & & $-0,324^{*}$ & $-0,441^{* *}$ & $-0,439^{* *}$ & $-0,536^{\star *}$ & $-0,603^{* \star}$ \\
\hline TC_15-30 anos & & $-0,398^{* *}$ & & & & & & & & & & & \\
\hline TC_30-45 anos & & $-0,678^{\star *}$ & & & & & & & & & & & \\
\hline TC_45 ou mais & & $-2,080^{* *}$ & & & & & & & & & & & \\
\hline 80-120 km/semana & & $0,573^{\star \star}$ & & & & & & & $0,555^{* *}$ & $0,543^{* *}$ & $0,547^{\star \star}$ & $0,536^{* *}$ & $0,728^{\star \star}$ \\
\hline $120-200 \mathrm{~km} / \mathrm{semana}$ & & $0,585^{* *}$ & & & & & & & $0,545^{* *}$ & $0,482^{* *}$ & $0,482^{\star *}$ & $0,487^{* *}$ & $0,703^{* \star}$ \\
\hline $200-300 \mathrm{~km} / \mathrm{semana}$ & & $0,597^{\star \star}$ & & & & & & & $0,597^{* *}$ & $0,516^{* *}$ & $0,520^{* *}$ & $0,514^{* *}$ & $0,721^{\text {**}}$ \\
\hline $300-500 \mathrm{~km} / \mathrm{semana}$ & & $1,050^{\star \star}$ & & & & & & & $1,040^{* *}$ & $0,974^{* *}$ & $0,976^{\star *}$ & $0,944^{* *}$ & $1,160^{* *}$ \\
\hline$>500 \mathrm{~km} / \mathrm{semana}$ & & $0,841^{* *}$ & & & & & & & $0,799^{* *}$ & $0,600^{*}$ & $0,618^{\star *}$ & $0,597^{*}$ & $0,860^{\star *}$ \\
\hline Multa velocidade & & & $0,299^{* *}$ & & & & & & & & & & \\
\hline Impedimento para prosseguir viagem & & & & $1,130^{\star *}$ & & & & & & $0,884^{* *}$ & $0,872^{* *}$ & $0,884^{* *}$ & $1,020^{* *}$ \\
\hline Demonstração direta de hostilidade do outro condutor & & & & $0,720^{* *}$ & & & & & & $0,588^{*}$ & & & \\
\hline Eu mesmo como condutor & & & & $-1,080^{\star \star}$ & & & & & & $-1,450^{* \star}$ & $-1,480^{\star *}$ & $-1,480^{* *}$ & $-1,620^{\star \star *}$ \\
\hline Busca de sensações & & & & $1,510^{\star \star}$ & & & & & & $1,300^{* \star}$ & $1,310^{* \star}$ & $1,290^{* *}$ & $1,130^{* *}$ \\
\hline Elementos urbanos & & & & & $-0,901^{\text {** }}$ & & & & & $-0,835^{\star *}$ & $-0,830^{* *}$ & $-0,800^{* *}$ & \\
\hline Portugal & & & & & & $0,446^{* *}$ & & & & & & & \\
\hline PT Centro & & & & & & & $0,640^{*}$ & & & & & & \\
\hline Leiria & & & & & & & & $2,290^{*}$ & & & & $2,060^{*}$ & \\
\hline Paraná & & & & & & & & $-0,547^{\star *}$ & & & & $-0,623^{* *}$ & $-0,736^{* *}$ \\
\hline BR Centro-oeste & & & & & & & & & & & $-0,370^{*}$ & & \\
\hline 40-80 km/semana & & & & & & & & & & & & & $0,371^{*}$ \\
\hline Número de parâmetros estimados & 7 & 10 & 2 & 4 & 2 & 2 & 2 & 3 & 9 & 13 & 13 & 15 & 16 \\
\hline & & & & & & & & & & & & & Continua \\
\hline
\end{tabular}




\begin{tabular}{|c|c|c|c|c|c|c|c|c|c|c|c|c|c|}
\hline \multicolumn{14}{|l|}{ Continuação } \\
\hline & A1 & A2 & A3 & A4 & A5 & B1 & B2 & B3 & C1 & C2 & C4 & C5 & D \\
\hline Log de verossimilhança inicial & $-1.179,737$ & $-1.179,737$ & $-1.179,737$ & $-1.179,737$ & $-1.179,737$ & $-1.179,737$ & $-1.179,737$ & $-1.179,737$ & $-1.179,737$ & $-1.179,737$ & $-1.179,737$ & $-1.179,737$ & $-1.179,737$ \\
\hline Log de Verossimilhança Final & $-1084,187$ & $-1.062,801$ & $-1.094,487$ & $-1.056,319$ & $-1.090,872$ & $-1.092,550$ & $-1.095,177$ & $-1.089,423$ & $-1.069,669$ & $-1.025,792$ & $-1.026,365$ & $-1.018,179$ & $-1.015,943$ \\
\hline Teste de razão de verossimilhança do modelo inicial & 191,099 & 233,871 & 170,499 & 246,835 & 177,728 & 174,373 & 169,120 & 180,627 & 220,136 & 307,889 & 306,742 & 323,115 & 327,587 \\
\hline Rho-quadrado & 0,081 & 0,099 & 0,072 & 0,105 & 0,075 & 0,074 & 0,072 & 0,077 & 0,093 & 0,130 & 0,130 & 0,137 & 0,139 \\
\hline Rho-quadrado ajustado & 0,075 & 0,091 & 0,071 & 0,101 & 0,074 & 0,072 & 0,070 & 0,074 & 0,086 & 0,119 & 0,119 & 0,124 & 0,125 \\
\hline Critério de Informação de Akaike (AIC) & 2182,374 & 2145,602 & 2192,974 & 2120,638 & 2185,745 & 2189,100 & 2194,353 & 2184,846 & 2157,337 & 2077,584 & 2078,731 & 2066,358 & 2063,886 \\
\hline Critério de Informação Bayesiano (BIC) & 2220,451 & 2199,998 & 2203,853 & 2142,397 & 2196,624 & 2199,979 & 2205,232 & 2201,165 & 2206,293 & 2148,298 & 2149,445 & 2147,951 & 2150,919 \\
\hline
\end{tabular}

${ }^{*}$ Significante ao nivel 0,$05 ;$ ** Significante ao nivel 0,01

Tabela F. 7 - Parâmetros estimados para os modelos do comportamento Expressão de raiva ao conduzir

\begin{tabular}{|c|c|c|c|c|c|c|c|c|c|c|c|}
\hline & A1 & A3 & A4 & B1 & B4 & C1 & C2 & C3 & C4 & C6 & D \\
\hline Constante & $-0,493^{* *}$ & $-0,580^{* \star}$ & $-3,260^{* *}$ & $-0,466^{* \star}$ & $-0,281^{* *}$ & $-0,544^{* *}$ & $-3,330^{* *}$ & $-3,420^{* *}$ & $-3,450^{\star \star}$ & $-3,210^{\star \star}$ & $-3,210^{* \star}$ \\
\hline 55-64 anos & $-0,524^{*}$ & & & & & $-0,537^{* *}$ & & & & & \\
\hline M_Outros & & $0,554^{* *}$ & & & & $0,563^{* *}$ & $0,595^{* *}$ & $0,541^{\star *}$ & $0,591^{\star *}$ & $0,512^{\star \star}$ & $0,512^{* \star}$ \\
\hline Impedimento para prosseguir viagem & & & $1,020^{* *}$ & & & & $1,010^{* *}$ & $1,120^{* *}$ & $0,995^{\star *}$ & $1,030^{\star *}$ & $1,030^{* *}$ \\
\hline Demonstração direta de hostilidade do outro condutor & & & $1,230^{* *}$ & & & & $1,250^{\star *}$ & $1,290^{* *}$ & $1,290^{* *}$ & $1,300^{* *}$ & $1,300^{* *}$ \\
\hline Imprudência de outros condutores & & & $1,960^{* *}$ & & & & $1,990^{* *}$ & $1,960^{* *}$ & $2,020^{\star \star}$ & $1,980^{\star *}$ & $1,980^{* *}$ \\
\hline Habilidades dos demais condutores & & & $-1,290^{\star *}$ & & & & $-1,290^{* *}$ & $-1,200^{* *}$ & $-1,270^{\star *}$ & $-1,200^{\star *}$ & $-1,200^{* *}$ \\
\hline Ações que prejudicam a concentração e vigilância ao conduzir & & & $1,180^{*}$ & & & & $1,180^{*}$ & $1,210^{*}$ & $1,220^{*}$ & $1,210^{*}$ & $1,210^{*}$ \\
\hline Busca de sensações & & & $1,140^{* *}$ & & & & $1,130^{* *}$ & $1,160^{* *}$ & $1,180^{* *}$ & $1,180^{* *}$ & $1,180^{* *}$ \\
\hline Portugal & & & & $-0,319^{*}$ & & & & $-0,323^{*}$ & & & \\
\hline Frota $<65610$ & & & & & $-0,493^{* *}$ & & & & & $-0,475^{* \star}$ & $-0,475^{\star \star}$ \\
\hline $65610<=$ Frota $<164554$ & & & & & $-0,457^{* *}$ & & & & & $-0,413^{* *}$ & $-0,413^{* *}$ \\
\hline $164554<=$ Frota $<319753$ & & & & & $-0,322^{*}$ & & & & & $-0,367^{\star}$ & $-0,367^{*}$ \\
\hline BR_Nordeste & & & & & & & & & 0,491 & & \\
\hline Número de parâmetros estimados & 2 & 2 & 7 & 2 & 4 & 3 & 8 & 9 & 9 & 11 & 11 \\
\hline Log de verossimilhança inicial & $-1.179,737$ & $-1.179,737$ & $-1.179,737$ & $-1.179,737$ & $-1.179,737$ & $-1.179,737$ & $-1.179,737$ & $-1.179,737$ & $-1.179,737$ & $-1.179,737$ & $-1.179,737$ \\
\hline Log de Verossimilhança Final & $-1118,781$ & $-1117,070$ & $-1050,065$ & $-1119,052$ & $-1113,015$ & $-1113,500$ & $-1044,621$ & $-1041,835$ & $-1041,476$ & $-1036,991$ & $-1036,991$ \\
\hline Teste de razão de verossimilhança do modelo inicial & 121,911 & 125,333 & 259,343 & 121,369 & 133,444 & 132,472 & 270,232 & 275,803 & 276,521 & 285,490 & 285,490 \\
\hline Rho-quadrado & 0,052 & 0,053 & 0,110 & 0,051 & 0,057 & 0,056 & 0,115 & 0,117 & 0,117 & 0,121 & 0,121 \\
\hline Rho-quadrado ajustado & 0,050 & 0,051 & 0,104 & 0,050 & 0,053 & 0,054 & 0,108 & 0,109 & 0,110 & 0,112 & 0,112 \\
\hline Critério de Informação de Akaike (AIC) & 2241,562 & 2238,140 & 2114,130 & 2242,104 & 2234,029 & 2233,001 & 2105,241 & 2101,670 & 2100,952 & 2095,983 & 2095,983 \\
\hline Critério de Informação Bayesiano (BIC) & 2252,441 & 2249,019 & 2152,207 & 2252,983 & 2255,788 & 2249,319 & 2148,758 & 2150,626 & 2149,908 & 2155,818 & 2155,818 \\
\hline
\end{tabular}

